\title{
Quadruped Trotting with Passive Knees - Design, Control, and Experiments
}

\author{
Geoff Hawker \\ Department of Mechanical Engineering \\ McGill University, Montréal, Canada
}

November 1999

A Thesis submitted to the Faculty of Graduate Studies and Research in partial fulfilment of the requirements of the degree of Master of Engineering

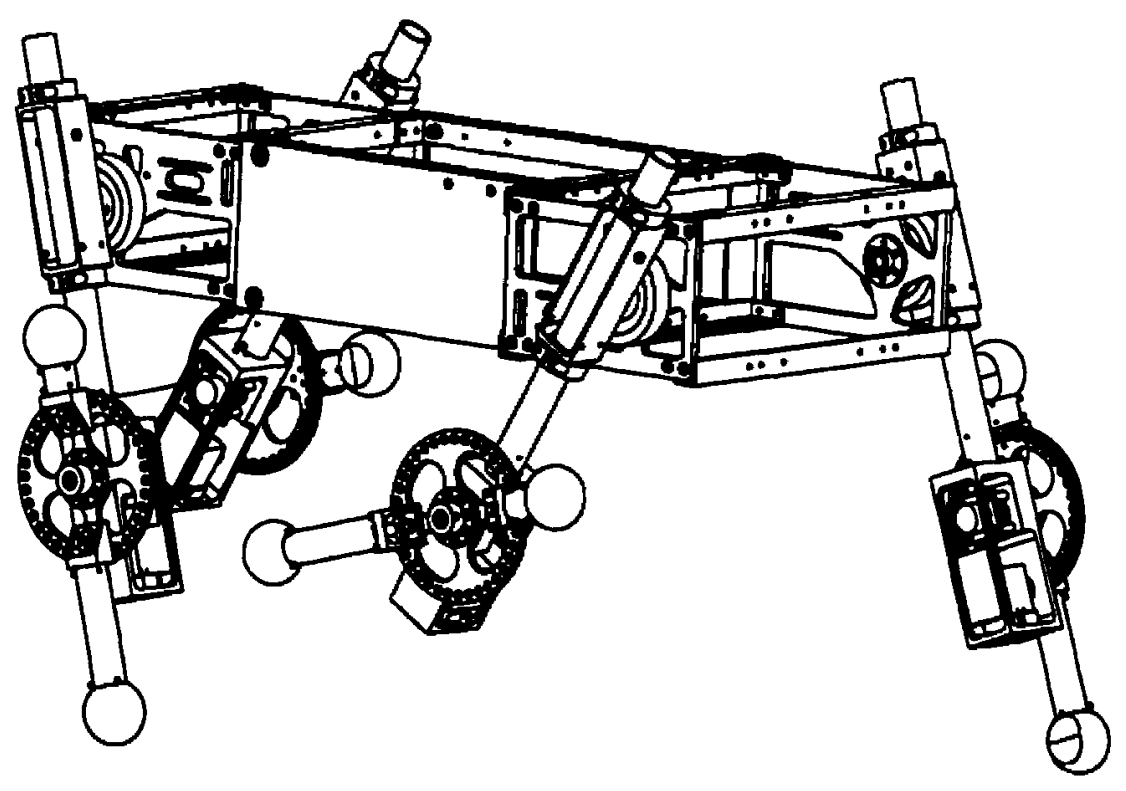

(C) Geoff Hawker, 1999 
National Library

of Canada

Acquisitions and Bibliographic Services

395 Wellington Street Otame ON KIA ONA Canada
Bibliothèque nationale du Canada

Acquisitions ef services bibliographiques

395, nue Welingtion Otrawa ON KIA ONA

Canada
The author has granted a nonexclusive licence allowing the National Library of Canada to reproduce, loan, distribute or sell copies of this thesis in microform, paper or electronic formats.
L'auteur a accordé une licence non exclusive permettant à la Bibliothèque nationale du Canada de reproduire, prêter, distribuer ou vendre des copies de cette thèse sous la forme de microfiche/film, de reproduction sur papier ou sur format électronique.

L'auteur conserve la proprièté du droit d'auteur qui protège cette thèse. copyright in this thesis. Neither the thesis nor substantial extracts from it may be printed or otherwise reproduced without the author's permission.
$\mathrm{Ni}$ la thèse ni des extraits substantiels de celle-ci ne doivent être imprimés ou autrement reproduits sans son autorisation.

\section{Canadă}


To Jen, Mom, Dad, and Whit 


\section{Abstract}

The Ambulatory Robotics Laboratory (ARL) has been pursuing an agenda of developing low cost, simple legged robots, with the hopes of increasing the usefulness of legged robots by reducing their price and increasing their reliability. Currently, ARL is developing the Scout class of robots. These are electrically powered quadruped robots with only one actuated degree of freedom per leg. Previous work with these robots developed bounding gaits, in which the front and back legs operate together as pairs. The topic of this research is to design and implement trotting gaits by using a passive knee. A passive knee has no motor, but relies on natural dynamics and the dynamic coupling with the upper leg for knee angle control. A trot is a walking gait in which the diagonal legs operate together as pairs. In this research, a new passive knee is designed and built. It is interfaced with Scout II, the larger of the two Scout robots at ARL. Models of it are developed and simulations are performed to develop and verify walking controllers. Experiments are performed and two types of trotting gaits are successfully achieved. 


\section{Résumé}

À l'ARL (Ambulatory Robotics Laboratory), notre but est le dévelopement de plateformes robotiques qui se caractérisent par un mécanisme simple et un faible coût, avec l'espoir d'augmenter leur utilité, tout en reduisant leur prix et augmentant leur fiabilité. Présentement, l'ARL est entrain de développer la série de robots Scout. Ces derniers sont des robots quadrupèdes actionnés par l'énérgie électrique, et ayant un seul degré de liberté par jambe. Des travaux antécédants ont porté sur la réalisation d'une démarche où les paires de jambes antérieures et postérieures fonctionnent ensemble. Le sujet de cette thèse porte sur la conception et la mise en æuvre d'une démarche au trot, en utilisant des genoux passifs. Un genou passif n’a pas de moteur, mais dépend du dynamisme naturel ainsi que de l'interaction avec la jambe supérieure pour le contrôle de l'orientation du genou. Un trot est une démarche durant laquelle les jambes diagonales fonctionnent paralèllement. Pour cette recherche, un nouveau genou passif est conçu, et monté sur Scout II, qui est le plus grand des deux modèles de robots Scout à l'ARL. Un modèle semblable fut dévelopé et simulé sur logiciel, afin de vêrifier les différentes stratégies de marche. Des expériences sont implementées et deux sortes de trot sont accomplies avec succès. 


\section{Acknowledgements}

I would like to thank the following people who helped me throughout the course of my research.

- First and foremost, I would like to thank my supervisor, Professor Martin Buehler, for his guidance and support. His superb knowledge of this discipline, his interest in me and my work, and his encouragement were a constant motivation. This would not have been possible without him.

- The Natural Sciences and Engineering Research Council of Canada (NSERC) for their support through a graduate scholarship.

- Everyone at ARL, past and present. I was truly blessed to have ended up working with such an accomplished, generous, and fun bunch of people. From hard days in the lab to fun evenings starting at Thomson House, you all made my experience here intellectually challenging, rewarding, and enjoyable. To those of you still in the lab, I wish you luck as you finish your research, and to those who have already left, my deepest thanks.

- Robert Battaglia for his extremely generous help in learning ProE ${ }^{\mathrm{TM}}$. Despite my near constant interruptions at times, he never refused to help, even when he was finishing his own thesis.

- Martin de Lasa, for his excellent knowledge of computers and programming (and detailed knowledge of the Windows Registry!)

- Sami Obaid, both for his great work in developing the sensory web on Scout II (on which we all depend), but also for his great understanding of the electrical systems on Scout II. He was a great asset when debugging the electronics. He is also 360 , under the table. 
- Shervin Talebinejad, for his selfless assistance. More than once during my research, he stopped all of his own work and would spend a few days working with me to solve some tricky electronics problems. Ultimately, it was always he who found the solution.

- Didier Papadopoulos, for his dedication to his work. He achieved some great results with Scout II which were a great personal motivator.

- Ken Yamazaki, for his contributions to the lab. He helped develop the SPPSPI system on which we all depend. Furthermore, Ken was always willing to answer any of my questions.

- Steve Kecani and Eddie Del Campo of the Physics machine shop. They did all the machining for this project, and taught me a lot about machining too.

- Prof. Post for his time and expertise in discussing locking mechanism design possibilities.

- Marlene Gray, Kathleen VanderNoot, and Ornella Cavaliere, the CIM administrative staff. Not only did they make everything at CLM run smoothly, they made it fun too.

- Dave McMordie, whose knowledge of electronics was vital for my work.

- Don Campbell, for having the magic touch with the treadmill.

- Jan Binder, the CIM system administrator. He does a fantastic job for the centre, which helps us all, and he helped me on many occasions in debugging our own QNX network, a responsibility of mine that I could not have managed without his help.

- I especially want to thank my partner, Jen Tung, for her love, companionship, and understanding when I would come home late so many nights in a row. Her support was unwavering, and I owe her everything. 


\section{Table of Contents}

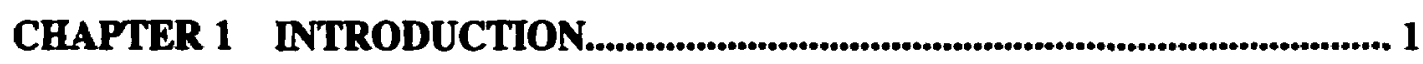

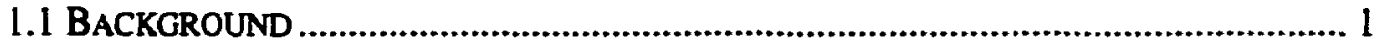

1.2 PREVIOUS WORK AT ARL ....................................................................... 2

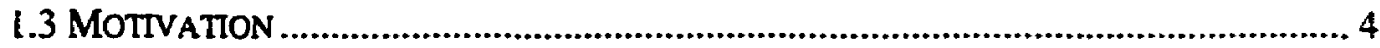

I.3.1 Biological Motivation ............................................................................ 5

1.3.2 Passive Kneed Walking ................................................................................ 6

1.3.3 Passive Dynamics ...................................................................................... 8

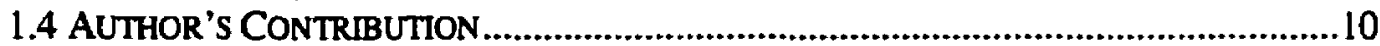

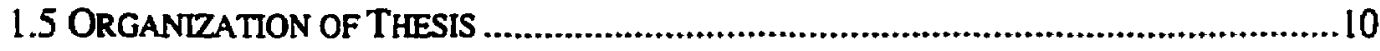

CHAPTER 2 MECHANICAL AND ELECTRICAL DESIGN..............................11

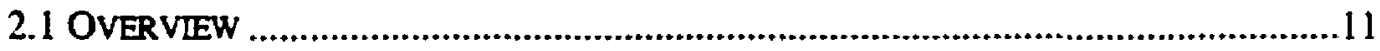

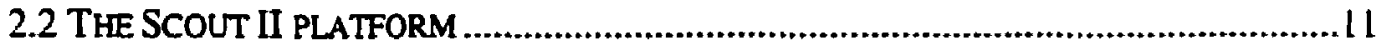

2.2.I Mechanical Specifications of Scout II Without Knees .....................................I2

2.2.2 Electrical Specifications of Scout II..............................................................12

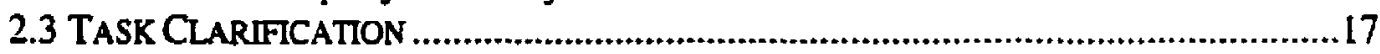

2.3.1 Basic Requirements of Knee......................................................................17

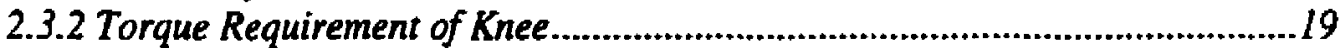

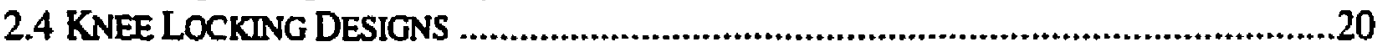

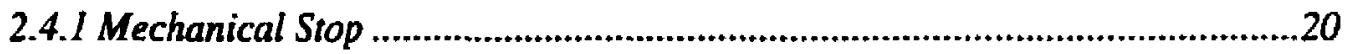

2.4.2 Electric Brakes and Clutches .................................................................21

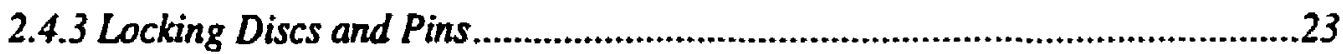

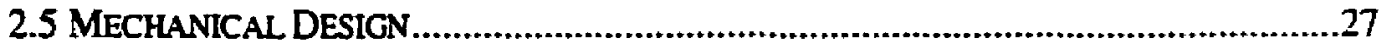

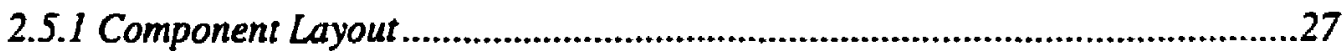

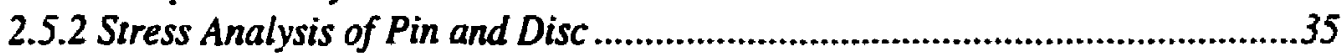

2.5.3 Mechanical Properties of Knee ................................................................39

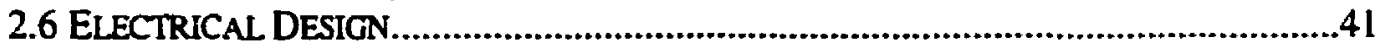

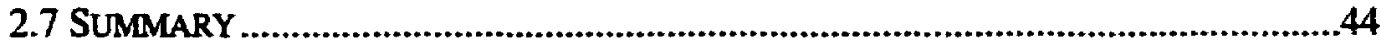

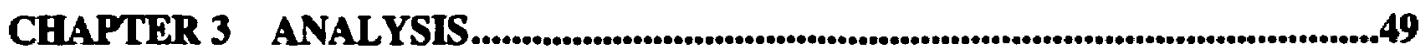

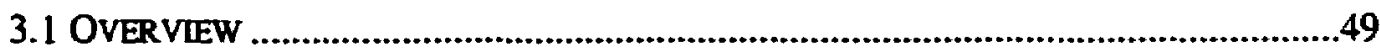

3.2 NOMENCLATURE

3.3 TROTTING ALGORITHM: SUPPORT-LEG TRAJECTORIES .......................................52

3.3.I Stepping Support-Leg Trajectory..............................................................52

3.3.2 Controlled Forward Body Velocity Support-Leg Trajectory ............................54

3.4 TROTTING ALGORITHM: SWING-LEG TRAJECTORY ............................................54

3.5 SINGLE SWING-LEG MODEL..............................................................................57

3.6 VALIDATION OF PERFECT POSITION INPUT ASSUMPTION OF SINGLE LEg MODEL....60

3.7 DEVELOPMENT OF THE EQUATIONS OF MOTION OF THE SINGLE-LEG SYSTEM..........61 
3.7.I Potential Energy .............................................................................................63

3.7.2 Kinetic Energy ........................................................................................63

3.7.3 Equations of Motion.....................................................................................64

3.8 VALIDATION OF EQUATION OF MOTION FOR SINGLE-LEG MODEL ............................64

3.9 STEP-TROT, COSINE KNEE ANGLE TRAJECTORY ANALYSIS …..................................67

3.10 STEP-TROT SIMULATION RESULTS FOR COSINE KNEE ANGLE TRAJECTORY ..........70

3.10.1 Step-Trot Working Model ${ }^{T M}$ Simulation Algorithm and Controller Gains ....70

3.10.2 Step-Trot Working Model ${ }^{T M}$ Simulation Results...........................................71

3.11 TWO-PART COSINE KNEE TRAJECTORY STEP-TROT ANALYSIS ............................75

3.12 STEP-TROT SIMULATION RESULTS FOR TWO-PART COSINE TRAJECTORY ................78

3.13 CONTROLLED FORWARD VELOCITY, COSINE KNEE ANGLE TRAJECTORY..............82

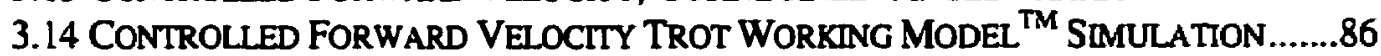

3.14.1 Working Model ${ }^{T M}$ Controlled Forward Velocity Simulation ............................86

3.14.2 Working Model ${ }^{T M}$ Controlled Forward Velocity Simulation Results ..............87

3.15 SUMMARY ................................................................................................92

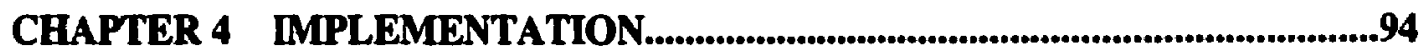

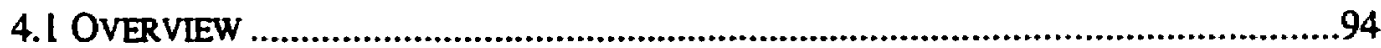

4.2 EXPERIMENTAL SETUP .................................................................................94

4.3 SINGLE LEG EXPERIMENTS..........................................................................94

4.4 STEP-TROT EXPERIMENTS.......................................................................98

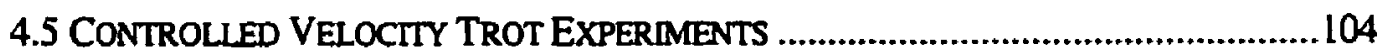

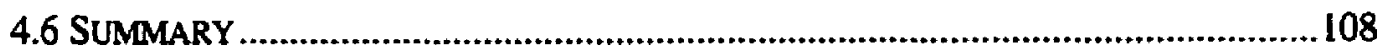

CHAPTER 5 CONCLUSION ...........................................................................11

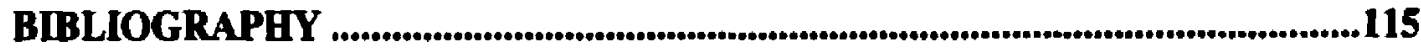

APPENDIX MECHANICAL DRAWINGS .....................................................119 


\section{List of Figures}

FIGURE 1.1 - CARL - COMPLIANT ARTICULATED ROBOT LEG [31] ................................... 2

FIGURE 1.2 - ARL MONOPOD I [4] ............................................................................. 3

FIGURE 1.3 - ARL MONOPOD II [4] ....................................................................... 3

FIGURE 1.4 - SCOUT I [44].................................................................................. 3

FIGURE 1.5 - GENERAL BOUND GATT FOR SCOUT CLASS OF ROBOTS (STIFF-LEG) ................ 4

FIGURE 1.6 - SCOUT II [27] ..................................................................................... 4

FIGURE 1.7 - GENERAL TROT GAIT ……….......................................................................... 5

FIGURE 1.8 - MCGEER'S GRAVITY POWERED WALKER (NO KNEES) [29] ............................ 6

FIGURE 1.9 - SPRING FLAMINGO [38] .................................................................... 7

FIGURE 1.10 - ARAI AND TACHI'S UNDERACTUATED MANIPULATOR [7] .........................9

FIGURE 1.11 - BERGERMAN AND XU'S UNDERACTUATED MANIPULATOR [12] ................. 9

FIGURE 2.1 - SCOUT II TOP VIEW AND ISOMETRIC VIEW ....................................................12

FIGURE 2.2 - SCOUT II DIMENSIONS IN NO KNEE CONFIGURATION (INCHES [MM]) [8] .......13

FIGURE 2.3 - EXPLODED VIEW OF SCOUT II LEG IN COMPLIANT NO KNEE MODE [8]...........15

FIGURE 2.4 - WORST CASE LOADING CONDIION OF KNEE................................................. 19

FIGURE 2.5 - MECHANICAL STOP KNEE LOCKING MECHANISM...........................................21

FIGURE 2.6 - PHYSICAL MODEL OF 2-D PASSIVE DYNAMIC BIPEDAL WALKER [18] .........2]

FIGURE 2.7 - DISCRETIZED LOCKING MECHANISM SCHEMATIC ......................................24

FIGURE 2.8 - LATCHING AND NON-LATCHING SOLENOID SCHEMATICS ..............................25

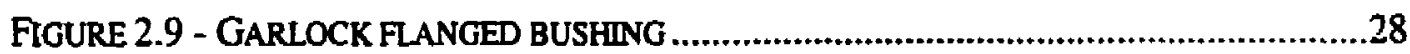

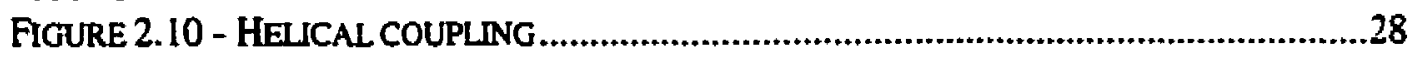

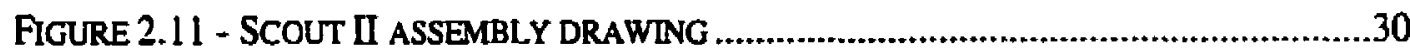

FIGURE 2.12 - KNEE ASSEMBLY IN LONG \& SHORT UPPER LEG LENGTH CONFIGURATIONS.30

FIGURE 2.13 - EXPLODED VIEW OF KNEE..........................................................

FIGURE 2.14 - KNEE ASSEMBLY ..............................................................................

FIGURE 2.15 - UPPER KNEE EXPLODED VIEW ...........................................................32

FIGURE 2.16 - UPPER KNEE ASSEMBLY

FIGURE 2.17 - DORMEYER SOLENOID ASSEMBLY …................................................32

FIGURE 2.18 - LOWER KNEE EXPLODED VIEW ...............................................................33

FIGURE 2.19 - SCOUT II WITH STRAIGHT KNEES..............................................................34

FIGURE 2.20 - SCOUT II WITH KNEES ON FLOOR .....................................................34

FIGURE 2.21 - SCOUT II WITH LOCKED KNEES ON TREADMIIL L...........................................34

FIGURE 2.22 - SCOUT II WITH LOCKED KNEES, SHORTER LEG CONFIGURATION ...................34

FIGURE 2.23 - PLANARIZER AND TREADMIIL...........................................................34

FIGURE 2.24 - SCOUT II MOUNTED TO PLANARIZER ON TREADMIIL...................................34

FIGURE 2.25 - LOCKING PIN LOADING DIAGRAM .............................................................35

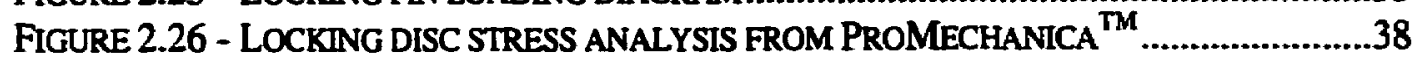

FIGURE 2.27 - MIDORO CP-2FK POTENTIOMETER ........................................................42

FIGURE 2.28 - H-BRIDGE SCHEMATIC .........................................................................43 
FIGURE 2.29 - CIRCUIT DIAGRAM OF H-BRIDGE SOLENOID CIRCUIT .............................45

FIGURE 2.30 - PIN OUT AND DIMENSIONS OF H-BRIDGE CIRCUTT (INCHES [MM])..............46

FIGURE 2.31 - H-BRDGE CIRCUIT ISOMETRIC VIEW ...............................................47

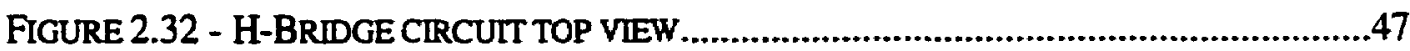

FIGURE 2.33 - H-BRIDGE CIRCUIT WTTH RCIO MODULE MOUNTED ON TOP .....................48

FIGURE 3.1 - GENERAL TROT GAIT STATES FOR SCOUT II ROBOT ....................................50

FIGURE 3.2 - PLANAR MODEI OF SCOUT II (LEGS 3 AND 4 OMITTED) ..........................53

FIGURE 3.3 - STEPPING SUPPORT LEG TRAJECTORY ..................................................5.5

FIGURE 3.4 - COSINE-TYPE SWING-LEG KNEE ANGLE TRAJECTORY ............................56

FIGURE 3.5 -MOCHON AND MCMAHON'S MODEL ...................................................56

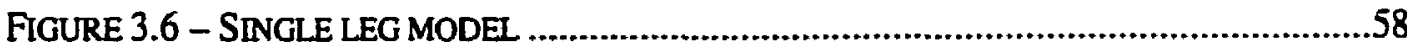

FIGURE 3.7 - PLOTS OF $\phi_{2}$ ACTUAL (-) AND DESIRED (-) VS TIME, DEGREE ERROR BETWEEN

$\phi_{2}$ ACTUAL AND DESIRED, AND TORQUE VS SPEED FOR HIP 2 WTTH THE TORQUE/SPEED MODEL LIMIT SHOWN FOR STATES 11 AND 12 OF THE STEPPDNG TROT GATT (LEGS 2 AND

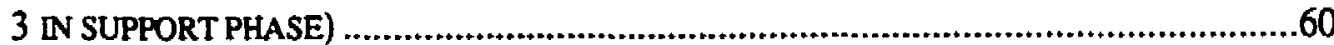

FIGURE 3.8 - WORKING MODEI ${ }^{\text {TM }}$ SIMULATION TO VERIFY PERFECT HIP AND UPPER SWING-

LEG POSIIION INPUT ASSUMPTION..............................................................6I

FIGURE 3.9 - WORKING MODEI ${ }^{\text {TM }}$ SIMULATION TO VERIFY THE EOM FOR THE SINGLE

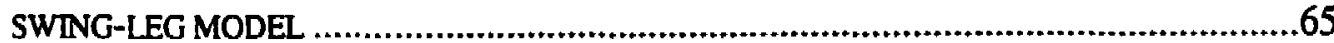

FIGURE 3.10 - VERIFICATION OF EQUATION OF MOTION, .............................................66

FIGURE $3.11-\phi_{\text {FRE }}$ AND TOE-HEIGHT OF SWING-LEG FOR ALPHA COSINE KNEE ANGLE TRAJECTORY, STEP-TROT SUPPORT-LEG TRAJECTORY, LUP OF $0.2 \mathrm{M}$, AND VARYING OTHER PARAMETERS

FIGURE 3.12 - $\phi_{\text {FREE }}$ AND TOE-HEIGHT OF SWING-LEG FOR ALPHA COSINE KNEE ANGLE

TRAJECTORY, STEP-TROT SUPPORT-LEG TRAJECTORY, LUP OF $0.1 \mathrm{M}$, AND VARYTNG OTHER PARAMETERS

FIGURE 3.13 - STEP-TROT WITH COSINE KNEE ANGLE TRAJECTORY FLOWCHART...............72

FIGURE $3.14-\phi_{1}, \alpha_{1}$ ACTUAL AND DESIRED VS TIME WITH SCALED STATE SHOWN, FOR

STEP-TROT WITH $\phi_{\text {SUP }}^{0}=10^{\circ}$ AND LUP $=0.2 \mathrm{M}$

FIGURE 3.15 - TORQUE, VS $\phi_{1}$ SPEED (DEG/S) WITH MOTOR MODEL BOUNDING BOX SHOWN, AND BODY FORWARD VELOCTTY VS TIME WITH SCALED STATE FOR STEP-TROT WITH $\phi_{\text {SUP }}^{0}=10^{\circ}$ AND LUP $=0.2 \mathrm{M}$

FIGURE 3.16 - TOE HEIGHT I AND SCALED STATE VS TIME FOR STEP-TROT WITH $\phi_{\text {SUP }}^{0}=10^{\circ}$ AND $L_{U P}=0.2 \mathrm{M}$.

FIGURE 3.17 - $\phi_{\text {FREE }}$ AND TOE-HEIGHT FOR VARIOUS PARAMEIERS, $L_{U P}=0.2 \mathrm{M}$, AND FOR $\tau_{\text {AMP, } \alpha}=0.25 * T_{L S \alpha}$ FOR SHIFTED COSINE KNEE ANGLE TRAJECTORY STEP-TROT..........76

FIGURE 3.18 - $\phi_{\text {FREE }}$ AND TOE-HEIGHT FOR VARIOUS PARAMETERS, $L_{I P}=0.2 \mathrm{M}$, AND FOR

$T_{\text {AMP. } . \alpha}=0.10^{*} T_{\text {LSa }}$ FOR SHIFTED COSINE KNEE ANGLE TRAJECTORY STEP-TROT ..........77 FIGURE $3.19-\phi_{\text {FREE, }} \alpha_{\text {DESRED }}(-$.$) AND \alpha_{\text {ACTUAL }}(-)$ VS. TIME FROM WORKING MODEL ${ }^{\text {TM }}$, AND DESIRED TORQUE-SPEED FROM WORKING MODEL ${ }^{\text {TM }}$ FOR TWO-PART COSINE KNEE

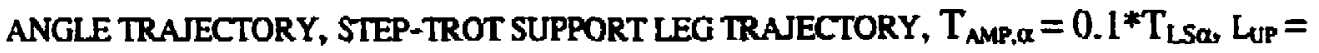
$0.2 \mathrm{M}, \phi_{\text {FRE }}^{0}=-10 \mathrm{DEGREES}$ 
FIGURE 3.20 - TOE HEIGHT AND FORWARD VELOCITY VS TIME FOR STEP-TROT WITH TWOPART COSINE TRATECTORY; $T_{\text {AMP, }, \mathrm{C}}=0.1^{*} \mathrm{~T}_{\text {LSQ, }} \phi_{\mathrm{RREE}}^{0}=-10^{\circ}$, LUP $=0.2 \mathrm{M}$.

FIGURE $3.21-\phi_{1}, \alpha_{1}$ ACTUAL AND DESIRED VS TIME WITH SCALED STATE SHOWN, FOR STEP-TROT WITH $\phi_{\text {SUP }}^{0}=10^{\circ}$ AND $L_{U P}=0.2 \mathrm{M}$, AND WTIH TWO-PART COSINE KNEE ANGLE TRAJECTORY WITH $\mathrm{T}_{\text {AMP, } \alpha}=0.25 * \mathrm{~T}_{L S}$

FIGURE 3.22 - TORQUE, VS $\phi_{1}$ SPEED (DEG/S) WTTH MOTOR MODEL BOUNDING BOX SHOWN, AND BODY FORWARD VELOCITY VS TIME WITH SCALED STATE FOR STEP TROT WTTH $\phi_{\text {SUP }}^{0}=10^{\circ}$ AND $L_{\text {IP }}=0.2 \mathrm{M}$, AND TWO-PART COSINE KNEE ANGLE TRAJECTORY WTTH $T_{\text {AMP, } \alpha}=0.25 * T_{L S \alpha}$

FIGURE 3.23 - TOE HEIGHT 1 AND SCALED STATE VS TIME FOR STEP-TROT WTTH $\phi_{\text {SUP }}^{\circ}=10^{\circ}$ AND $L_{\mathbb{T P}}=0.2 \mathrm{M}$, AND AND TWO-PART COSINE KNEE ANGLE TRAJECTORY WITH $T_{\text {AMP. } \alpha}=$ $0.25 * T_{\text {LSO }}$

FIGURE 3.24 - TOE-HEIGHT AND $\phi_{\text {FREE }}$ FOR CONTROLLED HORIZONTAL BODY VELOCITY TROT OF $0.5 \mathrm{M} / \mathrm{s}$ WITH SDMPLE COSINE KNEE ANGLE TRAJECTORY, LUP OF $0.2 \mathrm{M}$, AND OTHER VARYING PARAMETERS

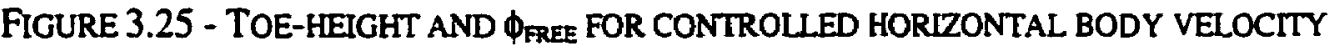
TROT OF $0.5 \mathrm{M} / \mathrm{S}$ WITH SIMPLE COSDNE KNEE ANGLE TRAJECTORY, LUP OF $0.1 \mathrm{M}$, AND OTHER VARYING PARAMETERS

FIGURE 3.26 - TOE-HETGHT VS TIME FOR MATLAB ${ }^{\text {TM }}$ AND WORKING MODEL ${ }^{\text {TM }}$ SIMULATIONS WITH UPPER LEG LENGTH OF $0.2 \mathrm{M}$, DESIRED FORWARD BODY VELOCTTY OF $0.3 \mathrm{M} / \mathrm{S}$, NITLAL $\phi_{\text {FREE }}=-20$ DEGREES, UNLOCKED KNEE SWING TIME OF 0.75 SECONDS, AND $\alpha_{\text {AMP }}$ OF -30 DEGREES .88

FIGURE 3.27 - FREE AND SUPPORT LEG ANGLES VS TIME FOR MATLAB ${ }^{\text {TM }}$ AND WORKING MODEL $^{\text {TM }}$ SIMULATIONS AND TORQUE/SPEED CURVES FROM THE WORKING MODEL ${ }^{\text {TM }}$ SIMULATION FOR A DESIRED FORWARD BODY VELOCITY OF $0.3 \mathrm{M} / \mathrm{s}$, UPPER LEG LENGTH OF $0.2 \mathrm{M}$, INTTAL $\phi_{\text {FREF }}=-20$ DEGREES, UNLOCKED KNEE SWING TIME OF 0.75 SECONDS, AND $\alpha_{\text {AMP }}$ OF -30 DEGREES

FIGURE 3.28 - SUPPPORT LEG TORQUE FOR CONTROLLED VELOCITY TROT OF $0.3 \mathrm{M} / \mathrm{S} . . . . . . .89$ FIGURE 3.29 - FORWARD BODY VELOCTTY VS TIME FOR MATLAB ${ }^{\text {TM }}$ AND WORKING MODEI ${ }^{\mathrm{TM}}$ SIMULATIONS. NOMINAL DESIRED VELOCTTY $=0.3 \mathrm{M} / \mathrm{S}, L_{\mathrm{LP}}=0.2 \mathrm{M}, \phi_{\text {FREF }}^{0}$ $=-20$ DEGREES, $\alpha_{A M P}=-30$ DEGREES, $T_{L S \alpha}=0.75 \mathrm{~s}$

FIGURE 3.30 - FORWARD BODY VELOCITY FOR RAMP UP DOWN CONSTANT VELOCITY ALGORTTHM $L_{\mathbb{P}}=0.2 \mathrm{M}$ .91

FIGURE $3.31-\mathrm{HT}_{1}$ AND $\phi_{1}$ FOR CONSTANT VELOCTTY RAMP UP DOWN $L_{C P}=0.2 \mathrm{M}$ .92

FIGURE 4.1 - $\phi$ ACTUAL AND DESIRED AND STATE VS TIME FOR SINGLE LEG EXPERIMENT ON SCOUT II AND FOR THE SAME EXPERIMENT SIMULATED IN WORKING MODEL ${ }^{\text {TM }}$. THE SECOND GRAPH IS A CLOSER VIEW OF 2 SECONDS OF THE SAME DATA.

FIGURE 4.2 - $\alpha$ ACTUAL AND DESIRED AND STATE VS TIME FOR SINGLE LEG EXPERIMENT ON SCOUT II AND FOR THE SAME EXPERIMENT SIMULATED IN WORKING MODEI ${ }^{\text {TM }}$. THE SECOND GRAPH IS A CLOSER VIEW OF 2 SECONDS OF THE SAME DATA. .......................97

FIGURE 4.3 - SINGLE IEG CYCLE FOR PASSIVE KNEE TROTTING.........................................98

FIGURE $4.4-\phi_{1}$ AND $\alpha_{1}$ (DESTRED AND ACTUAL) AND SCALED STATE VS. TIME FOR STEPTROT (EXPERIMENTAL DATA) . 
FIGURE 4.5 - TOE HEIGHT OF LEG 1 AND SCALED STATE VS. TIME FOR STEP-TROT

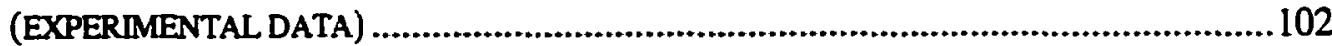

FIGURE 4.6 - SCOUT II STEP-TROTTING ON TREADMIIL. THREE STEPS TAKEN, APPROXIMATELY 9 SECONDS.

FIGURE 4.7 - FLLTERED AND UNFIL TERED VELOCITY PROFILES FOR RAMP UP AND DOWN CONTROLLED VELOCITY TROT (DESIRED AND ACTUAL SIGNALS), WTTH SCALED STATE SHOWN.

FIGURE 4.8 - $\phi_{1}$ TRAJECTORY DURING RAMP UP AND DOWN CONTROLLED VELOCITY TROT

FIGURE $4.9-\phi_{1}$ TRAJECTORY FOR 2 CYCLES OF RAMP UP AND DOWN CONTROLIED VELOCITY TROT 107

FIGURE 4.10 - TOE HEIGHT OF LEG I FOR RAMP UP AND DOWN CONTROLIED VELOCITY TROT .108

FIGURE 4.11 - TWO CYCLES OF TOE HEIGHT I FOR RAMP UP AND DOWN CONTROLLED VELOCITY TROT (EXPERIMENTAL RESULTS)

FIGURE 4.12 - TORQUE VS SPEED CURVES FOR EACH LEG DURING THE RAMP UP AND DOWN CONTROLLED VELOCITY TROT (EXPERIMENTAL RESULTS WITH THEORETICAL MOTOR MODEL SHOWN AS A BOUNDING PARALLELOGRAM) 


\section{List of Tables}

TABLE 2.1 - MECHANICAL SPECIFICATIONS OF SCOUT II WTTHOUT KNEES [8] (REFER TO

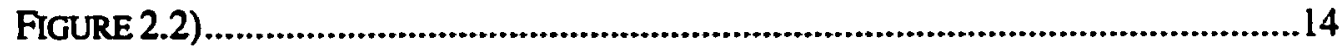

TABLE 2.2 - INPUT AND OUTPUT SIGNALS ON SCOUT II WTTHOUT KNEE [8] .......................16

TABLE 2.3 - COMMERCIALLY AVAILABLE LATCHING ELECTRIC BRAKE [16] ........................22

TABLE 2.4 - COMMERCIALLY AVAILABLE POWER ON AND OFF EIECTRIC CLUTCHES AND

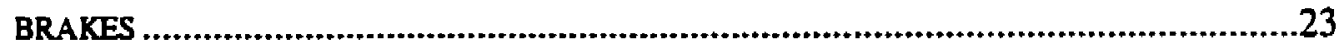

TABLE 2.5 - COMMERCIAILY AVAIIABLE LATCHING SOLENOIDS ...................................27

TABLE 2.6 - MATRIX OF MAXIMUM PRNCIPAL STRESS FOR LOADING CONDITION AND

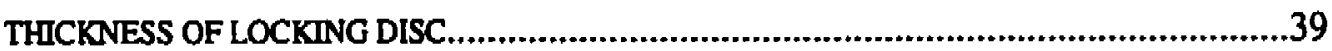

TABLE 2.7 - PART NUMBERS, QUANTITIES, AND MASSES OF KNEE ....................................40

TABLE 2.8 - LENGTHS, INERTIAS, AND CENTRES OF MASS OF UPPER LEG ASSEMBLY...........41

TABLE 2.9 - LENGTH, NERTIA, AND CENTRE OF MASS OF LOWER LEG ASSEMBLY ..............41

TABLE 3.1 - PLANAR MODEL NOMENCLATURE..............................................................53

TABLE 3.2 - SINGLE LEG MODEL NOMENCLATURE...........................................................58

TABLE 3.3 - OPTIMIZED SET OF CONDITIONS FOR STEP-IROT WITH COSINE KNEE ANGLE

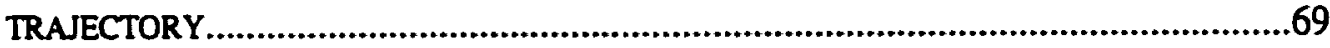

TABLE 3.4 - CONTROLLER GAINS FOR STEP-TROT WITH SIMPLE COSINE KNEE-ANGLE

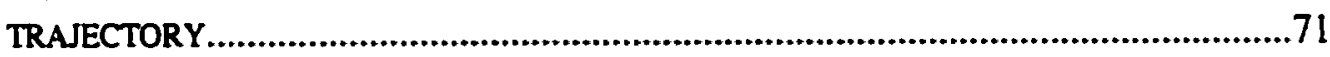

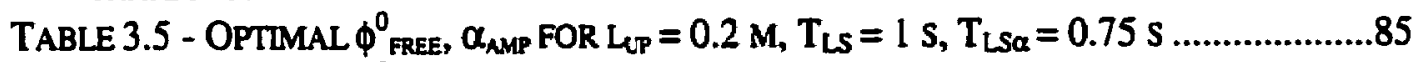

TABLE 3.6 - OPTIMAL $\phi_{\text {RREE, }}^{0} \alpha_{\text {AMP }}$ FOR $L_{U P}=0.1 \mathrm{M}, T_{L S}=1 \mathrm{~s}, \mathrm{~T}_{L S \alpha}=0.75 \mathrm{~s} \ldots \ldots \ldots \ldots \ldots \ldots . .85$

TABLE 3.7 - CONTROLLER GAINS FOR CONTROLLED VELOCTTY TROT WITH SIMPLE COSINE KNEE-ANGLE TRAJECTORY ...............................................................................87

TABLE 4.1 - TRAJECTORY PARAMETERS AND INMAL CONDITONS FOR EXPERIMENTAL

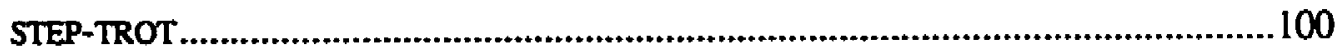

TABLE 4.2 - CONTROLLER GAINS FOR STEP-TROT EXPERIMENTAL RESULTS ......................102 


\section{Chapter 1 Introduction}

\subsection{Background}

The field of mobile robotics has reached a maturity that has resulted in an increased number of applications. Some current uses include surveillance of hazardous or dangerous environments such as volcanoes or chemical accident sites, delivery tasks in hospitals or factories, minefield clearance, or bomb disposal. The majority of these devices are wheeled or tracked. Their inherent static stability has made them an attractive first step for practical applications. However, wheels and tracks have limitations when it comes to negotiating uneven terrain or climbing stairs. Biology has shown that legs are an excellent means of traversing varied environments. Consequently, many researchers, including the members of the Ambulatory Robotics Laboratory (ARL) of McGill University, have been investigating legged robotic locomotion.

The previous work at ARL has been to develop quadrupedal robots with limited mechanical complexity to reduce their cost and their weight, to decrease their power consumption, and to increase their reliability. Thus far, two robots have successfully been built. Both of these robots have only one actuated degree of freedom (DOF) per leg, and one of them has an additional passive linear prismatic joint in each leg. The focus of the current research has been to modify the existing legs to permit the study of different gaits than were previously possible, but under the same philosophy of low cost, low mechanical complexity, and reduced power consumption.

This chapter is organized as follows. Section 1.2 reviews some of the previous work done at ARL. The motivation for the current work is discussed in Section 1.3, and the author's contributions are outlined in Section 1.4. Finally, the organization of the thesis is presented in Section 1.5. 


\subsection{Previous Work at ARL}

ARL has been studying legged locomotion for many years. Some of its initial work involved the design of a lightweight compliant robotic leg called CARL (Compliant Articulated Robot Leg) with a unique knee actuation system involving a novel lightweight transmission called LADD (Linear to Angular Displacement Device) [31][32] (Figure 1.1).

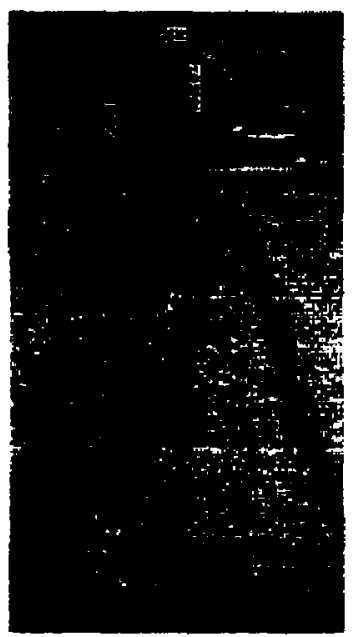

Figure 1.1 - CARL - Compliant Articulated Robot Leg [31]

Inspired by Raibert's work in hydraulically and/or pneumatically actuated, dynamically stable legged robots [39], ARL also investigated the energetics in two different single legged hopping robots, the Monopod I and Monopod II (Figure I.2 and Figure 1.3). The Monopod I was electrically actuated, and achieved running speeds up to $1.2 \mathrm{~m} / \mathrm{s}$ with an average power consumption of $125 \mathrm{~W}[2 \mathrm{l}]$, which at the time was extremely energy efficient as compared to other legged robots. The Monopod I used a spring in the leg, but had no compliance in the hip. The Monopod II added compliance in the hip joint which reduced its average power consumption to $48 \mathrm{~W}$ at a speed of $1.25 \mathrm{~m} / \mathrm{s}$ [1], which at the time held the record for the highest efficiency among all published legged robots.

The experimental part of the current research was performed on ARL's Scout class of robots. These are electrically actuated quadruped robots that were designed under a philosophy of complete autonomy and reduced mechanical complexity. The first 
prototype of this class was Scout I (Figure 1.4). This robot has only one actuated degree of freedom per leg, and the legs are rigid sticks. In addition, the robot has limited sensing, measuring only the leg angle with respect to the body, and using two touchdown sensors to detect when the front and back legs are on the ground or in the air. Despite the

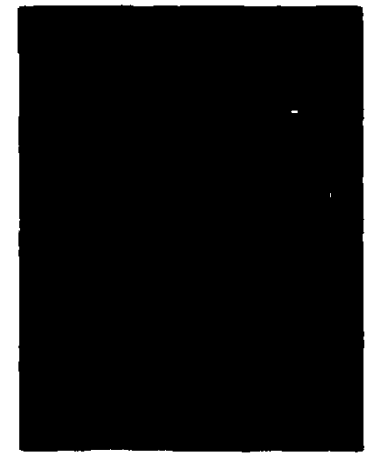

Figure 12 - ARL Monopod I [4]

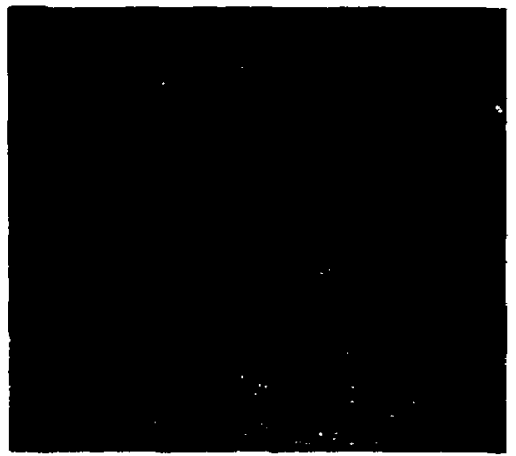

Figure 1.3 - ARL Monopod II [4]

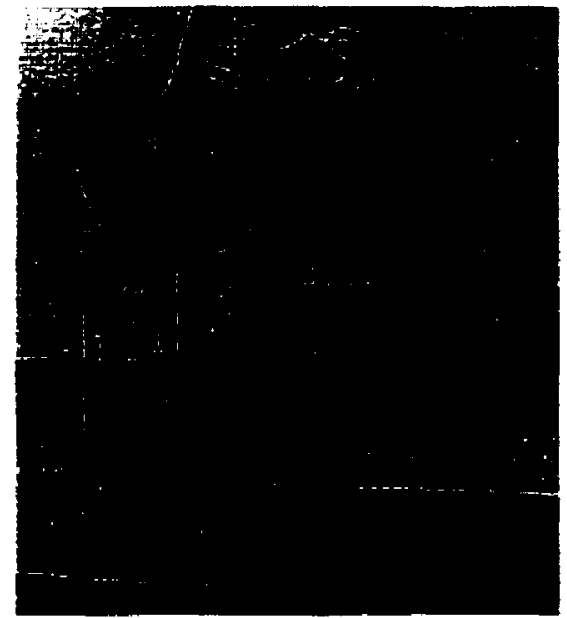

Figure 1.4 - Scont I [44]

simple sensing and limited actuation, the robot successfully walks, turns, sits down, and can climb a step with a height of $45 \%$ of its leg length [14][15][44]. The robot walks using a bound type gait. Figure 1.5 shows the bound gait for the rigid leg case. It can be seen that the front legs operate together as a pair, and the rear legs do the same. In the figure, the robot is moving from left to right, and individual frames of the motion are presented. The motion involves sweeping the legs asynchronously in such a way as to 
rock the body back and forth. As the body rocks up on the front legs, the rear legs swing forward, using the higher height of the rear of the robot to clear its rear toes. A similar effect is achieved with the front legs when the robot rocks back on the rear legs, though it is possible to achieve this type of bound motion with no front leg swinging at all.

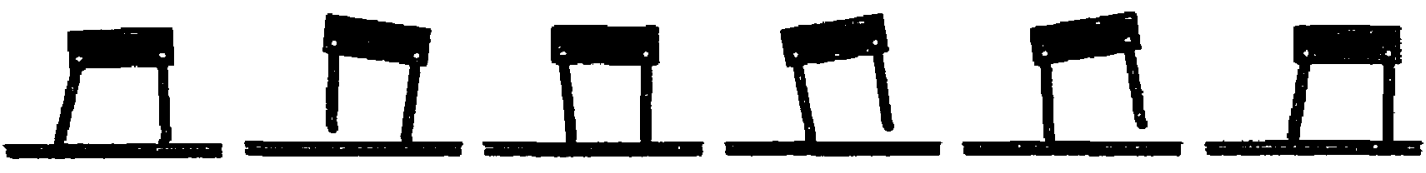

Figure 1.5 - General bound gait for Scout class of robots (stiff-leg)

Using the lessons learned with the single legged Monopod I and Monopod II, ARL made a second Scout robot, Scout II (Figure 1.6), that had an additional prismatic leg joint connected to the hips with springs [8]. This leg compliance permits an additional flight phase during bounding, which enables it to move forward more quickly - the difference is the same as that between human walking and running. Scout II can also be operated in the rigid leg mode (that of Scout I) by using simple leg clamps to lock the prismatic joint.

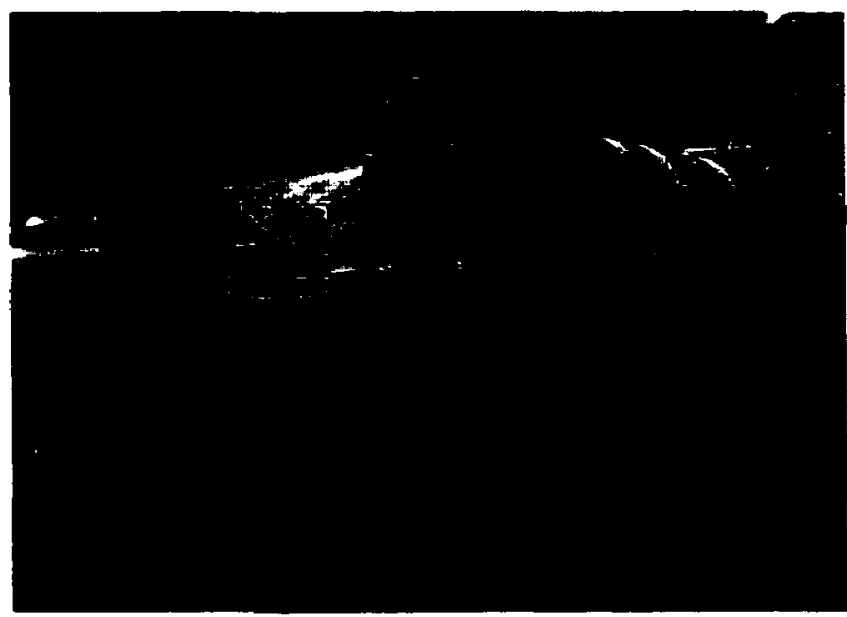

Figure 1.6 - Scout II [27]

\subsection{Motivation}

This research involved putting knees onto the Scout II robot at ARL and investigating new walking behaviours. This section will explain the motivation for putting knees on 
the robot by examining some previous work by various researchers. Prior to this, it is important to describe the new gait studied for this research, the trot. Figure 1.7 shows a gait diagram for the trot. During this gait, the diagonal legs are used in pairs. One pair operates as the support legs while the others swing forward. The motion that the legs of a biped follow is similar to the front pair or the back pair of legs of a trotting quadruped. It can be seen that the swing legs' toes would hit the ground were it not for the bending at the knee. Consequently, it can be seen that knees are critical for quadruped trotting.

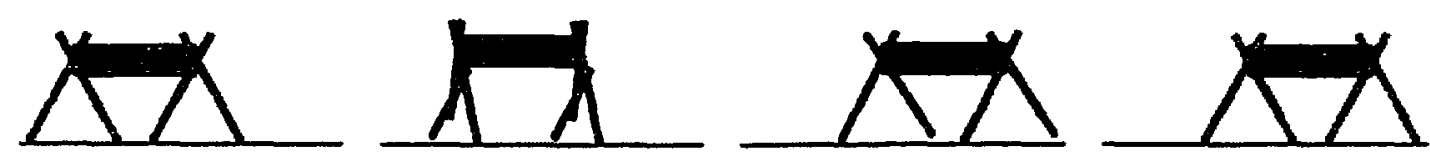

Figure 1.7 - General Trot Gait

\subsubsection{Biological Motivation}

At first glance, quadruped walking with knees appears to be a difficult task. At the very least, each leg has 2 joints to control, the hip and the knee, and these motions must both be coordinated with the other legs to produce effective and stable walking. However, Alexander reviewed several models of human movement and concluded that:

"The realization that walking may be inherently stable makes the problem of neuromuscular coordination presented by walking seem much less formidable than physiologists had supposed it to be."[2]

Furthermore, Mochon and McMahon state that by using an electromyograph, it can be shown that the muscles of the swing leg of a walking human are not used significantly during walking [34], which shows that the motion the swing legs follow is a natural one. This assertion is supported by Goswami et al. where they claim that the hypothesis that a majority of the swing state of human bipedal locomotion is passive is supported in the literature [20]. Hence, with minimal hip actuation, the swing leg can move from behind 
the person to the front of the person, while bending the knee enough to prevent toe stubbing, expending almost no muscle energy until impact. This hints at one of the major points of this research which is to design a knee that has no motor, referred to as a passive knee. The motivation for using a passive knee is discussed in more detail in Section 2.3.1, but suffice it to say that a knee without a motor is lighter in weight and simpler in complexity than a knee that does use a motor. If it can be shown that it is possible to effectively control an unactuated knee, then the savings in weight and complexity may make it a very attractive possibility for mobile, autonomous, legged robots.

\subsubsection{Passive Kneed Walking}

Several researchers have investigated robotic walking with passive knees. The seminal work in this area is McGeer's gravity powered biped [29]. In his initial work, he experimented with a rigid leg biped that had a powered foot retraction method to avoid toe stubbing (Figure 1.8). Each leg had two widely spaced ground contact points to

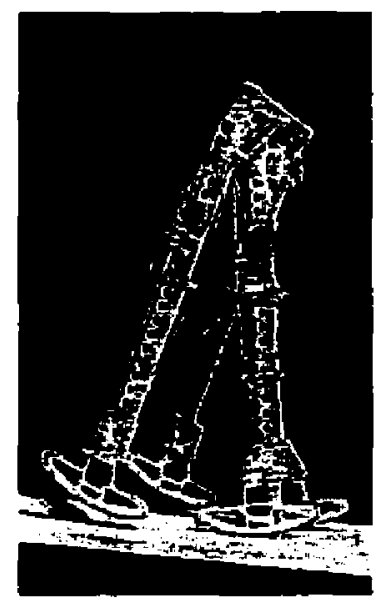

Figure 18 - MeGeer's gravity powered walker (no knees) [29]

provide lateral stability and to keep the motion only in the saggittal plane. Under the right initial conditions, this machine would reach a stable walking cycle while walking down a slight decline. He did a parametric study to determine the effects of such parameters as the foot radius, the leg inertias and locations of the centres of mass, the mass of the hip, and others. In this initial work, he also demonstrated in simulation that a similar stable 
cycle (though with a slower period) could be achieved by using passive knees instead of the actuated foot retraction device of the original biped. He followed up this work with a study that examined the passive knee problem specifically [30]. In this study, he simulated a passive kneed biped system as a system of dynamical equations, and he tested for stability and toe clearance for a variety of initial conditions. He showed that the system does indeed reach a stable cycle, and in addition, he showed that the system is somewhat robust to perturbations. His work was a key motivation for the current research: knowing that machines could walk down slopes powered only by gravity using passive knees to clear the ground, would it not be possible to attach passive knees to an existing actuated quadruped robot and control it to walk on level ground?

Jerry and Gill Pratt used a similar concept in the design and control of their Spring Flamingo biped robot [38] (Figure 1.9). In their case, all the joints were actuated, but the hip and the knee joint took advantage of the natural dynamics of a walking cycle to significantly reduce the power consumption by these actuators and to dramatically simplify the control algorithms. Their controller did not specify the forward velocity, but they found that their robot did settle into the same velocity in every experiment, the result of the natural cycle frequency of the system. In other words, the system was self stabilizing, much as McGeer had predicted.

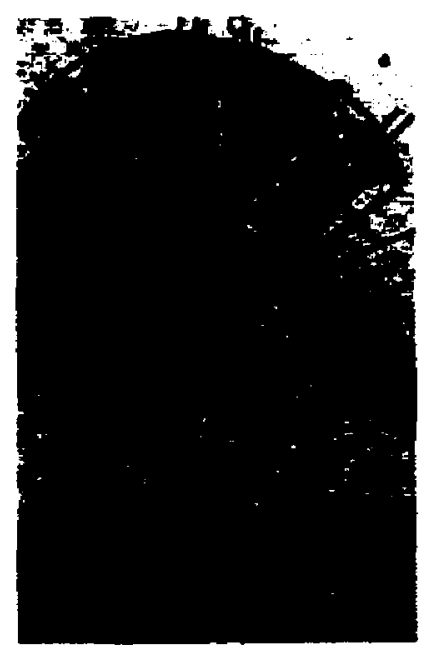

Figure 19-Spring Flamingo [38] 
Garcia, Chatterjee, and Ruina built a prototype of McGeer's passive kneed walking model and performed experiments on it [18]. They showed that at low speeds, there exist two different walking cycles, a short-step cycle and a long-step cycle, and they determined a relation between the energy loss at each step and the velocity of the robot. They confirmed many of McGeer's predictions from his passive kneed walking model.

Espiau, Guiges, and Pissard-Gibollet developed a single leg with a compliant passive knee [17]. Their knee had no actuator, but it did have a spring-damper to assist in straightening the leg during the swing phase. Although their research was intended to improve human leg orthoses ("knee-pad" devices which assist people to walk as a rehabilitation device following operations), their work does show that passive dynamical leg systems can indeed achieve stable walking cycles.

\subsubsection{Passive Dynamics}

In addition to studying legged robots with knees, there has been considerable research into the more general study of controlling underactuated systems. Arai and Tachi performed a detailed dynamical analysis of general underactuated systems with a certain number of active and passive joints [6]. They considered the situation where some of the passive joints have holding brakes. They developed the general system equations and proved that in order for the system to be controllable, the number of passive joints must be less than or equal to the number of actuated joints. For the case where all the passive joints have holding brakes, they developed a two-part controller in which they first control the desired angle of the passive joints through the dynamic coupling with the active joints, at which point these joints are locked. Then, they position all the active joints to their desired angles. They tested their controller with a two degree of freedom manipulator with one active joint and one passive joint with a holding brake in [7], and achieved repeatable, precise, point-to-point control (Figure 1.10). 


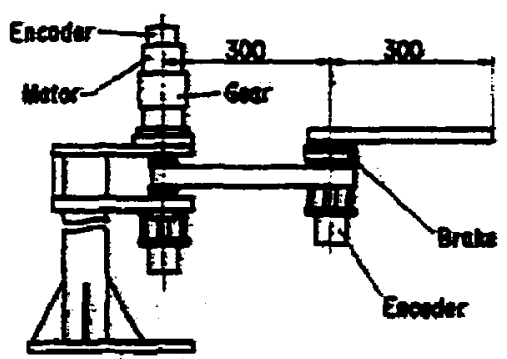

Figure 1.10 - Arai and Tachi's underactuated manipulator [7]

Bergerman, Lee, and $\mathrm{X} u$ defined a dynamic coupling index to help determine which active and passive joint configurations are controllable [9], and they proposed a way to use this index to assist in the design, analysis, and control of underactuated systems. They also used their analysis to design a robust controller which they successfully tested experimentally [10]. Finally, Bergerman and Xu used their dynamic coupling index to optimize the control sequence for underactuated systems with more than 2 joints, and they tested their controller with a three DOF manipulator with only one actuator [11]. Furthermore, they studied in detail the issue of controlling actuators with more passive joints than active joints in [12] (Figure 1.11). Please note that this is not contrary to Arai's conclusion that for controllability, the number of passive joints must be less than or equal to the number of active joints. In this case, all but one of the passive joints were locked while the remaining one was controlled to its setpoint, at which point it was locked and the sequence continued. Their control algorithm used the dynamic coupling index to determine the quickest way to bring all joints to their setpoints (ie: the order in which to control the passive joints).

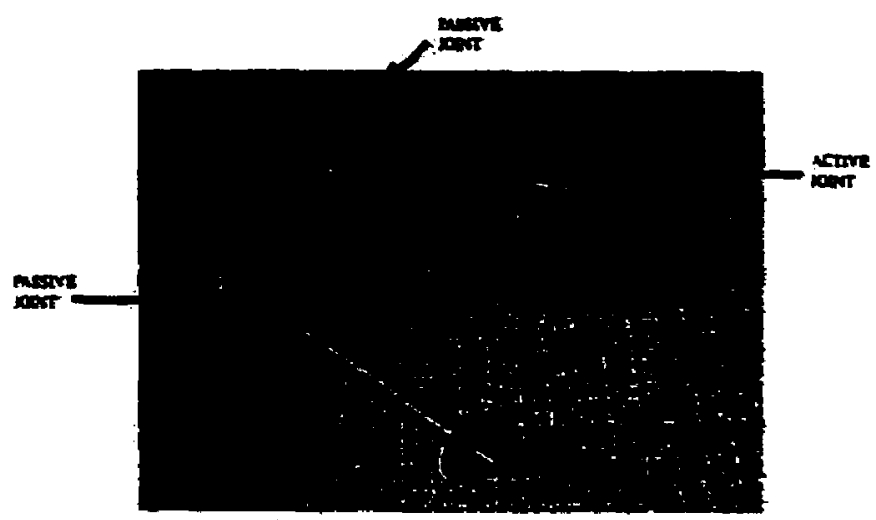

Figure L.11 - Bergerman and Xu's underactuated manipulator [12] 
Shin and Lee developed a control strategy for underactuated systems in which the passive joints do not have a braking mechanism [42]. They explained how in their system, dynamic singularities exist which must be avoided in the trajectory planning of the passive joint(s).

\subsection{Author's Contribution}

The author's contributions come from the design and control of passive kneed legs that were used on the Scout II quadruped robot to achieve various walking gaits. The explicit contributions are the following:

- Modeling and simulation of a single leg and the complete quadruped robot in Matlab $^{\mathrm{TM}}$ and Working Model ${ }^{\mathrm{TM}}$ respectively.

- Design and coordination of construction of the unactuated knees, including the locking mechanisms.

- Design and construction of locking mechanism electronics.

- Integration of knee hardware and electronics onto existing Scout II platform.

- Design and testing of control algorithms in simulation and in experiment for two walking (trotting) controllers.

- Experimental implementation of two trotting controllers.

\subsection{Organization of Thesis}

The thesis is organized as follows. Chapter 2 describes the mechanical and electrical design of the passive knee, including an overview of the mechanical and electrical systems of Scout II with which it had to interface. Chapter 3 outlines the models used to analyze and simulate the walking behaviour, and describes the controllers that were developed. In addition, the results of the trotting simulations are presented. Chapter 4 describes the experimental results of passive kneed trotting with Scout II, and Chapter 5 provides the conclusions and suggestions for future work. 


\section{Chapter 2 Mechanical and Electrical Design}

\subsection{Overview}

As described in Chapter $\mathrm{I}$, the ultimate goal of this research was to implement trotting gaits on the Scout I robot at ARL. To achieve this, a robotic knee had to be added to the Scout II platform, which involved designing it so that it interfaced with the existing mechanical, electrical, and signal input/output architectures of the robot. Furthermore, analytical, simulation, and experimental studies were done to determine how to use the entire system to achieve the trot gaits. This chapter is organized as follows: first, Section 2.2 describes the existing Scout II platform with reference to the existing mechanical. electrical, and signal input/output architectures which affected the overall design; second, in Section 2.3, the task is clarified in general terms describing the minimum specifications which the overall design had to satisfy, as well as some additional features which were added to increase the total behaviours that the knee and the robot could achieve; in Section 2.4, various potential knee locking designs are explored; Section 2.5 describes the overall mechanical design, including some stress analyses; finally, Section 2.6 introduces the electrical design.

\subsection{The Scout II platform}

Prior to this research, the Ambulatory Robotics Laboratory (ARL) bad developed the Scout II robot. This robot is a quadruped with only one actuated degree of freedom per leg. Chapter 1 describes the two modes of operation of this robot, rigid and compliant. The goal of designing the robotic knee used in this research was to involve no major changes to the existing robot. Ideally, the knee and associated lower leg could simply be mounted onto the bottom of the exisiting legs in its rigid leg mode, and the existing electrical (both power and control) systems could be used with the only changes being in 
software. This section will present these existing mechanical and electrical features. A more in depth explanation of all of these details can be found in [8].

\subsubsection{Mechanical Specifications of Scout II Without Knees}

Figure 2.1 shows the Scout II robot in its compliant leg mode without knees, Table 2.I shows its mechanical properties, and Figure 2.2 shows its dimensions. Where appropriate, these values were used in the simulations and analyses of Chapter 3 and they were used to determine the loading requirements of the knee in Section 2.5.2.

Of particular interest for interfacing the knee with the existing Scout II platform is the leg geometry, particularly at the foot. The legs of Scout II are made of $\mathrm{l}^{\text {" outer diameter }}$ stock thin walled steel tube. Figure 2.3 shows an exploded view of the Scout II leg.
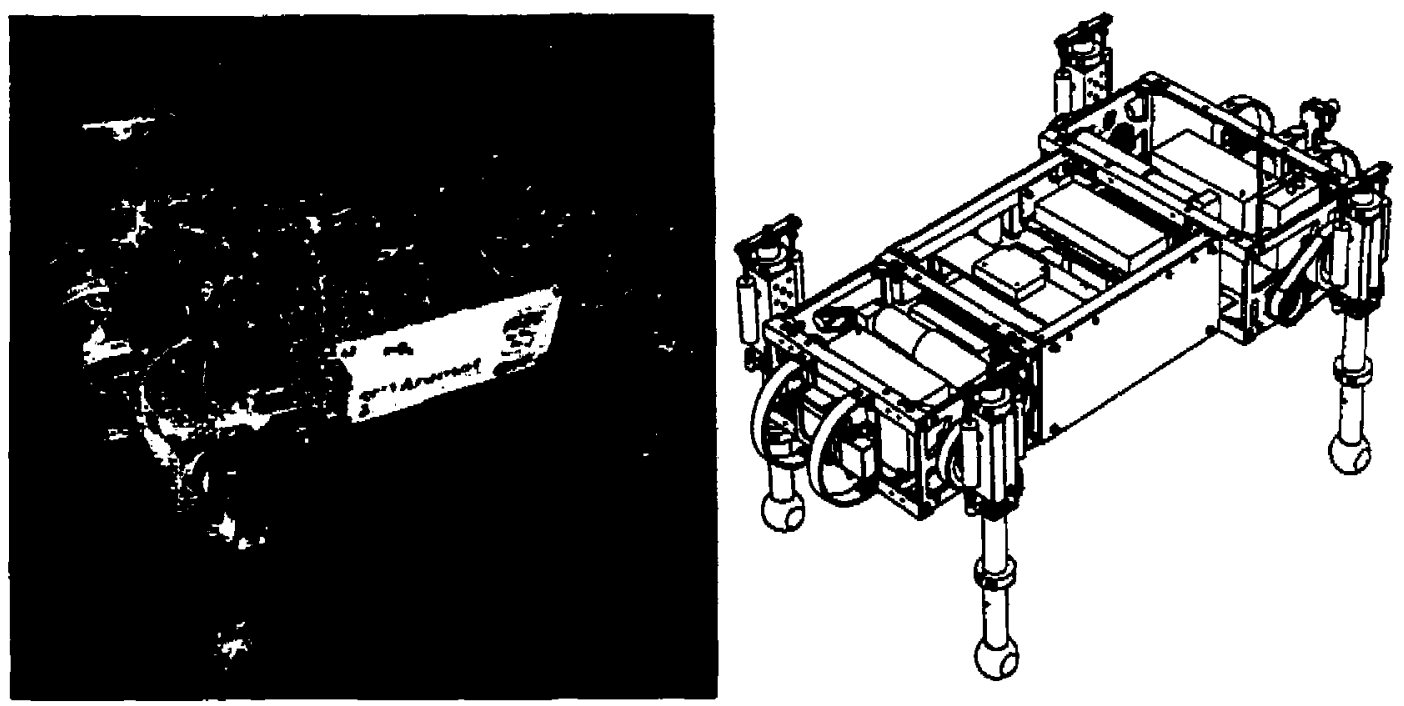

Figure 2.1 - Sccut II top view and isometric view as rendered in ProEngineer ${ }^{\mathrm{TM}}$ [8][36]

\subsubsection{Electrical Specifications of Scout II}

Scout II, in all its configurations, operates as an autonomous mobile robot. It uses electric actuators, it has an on-board computer, many sensors, and a communications system that enables the software to interpret sensor data and to apply control torques to the actuators. In addition, it has wireless network capability which enables it to communicate with user-level protocols for teleoperation. All of these systems are 


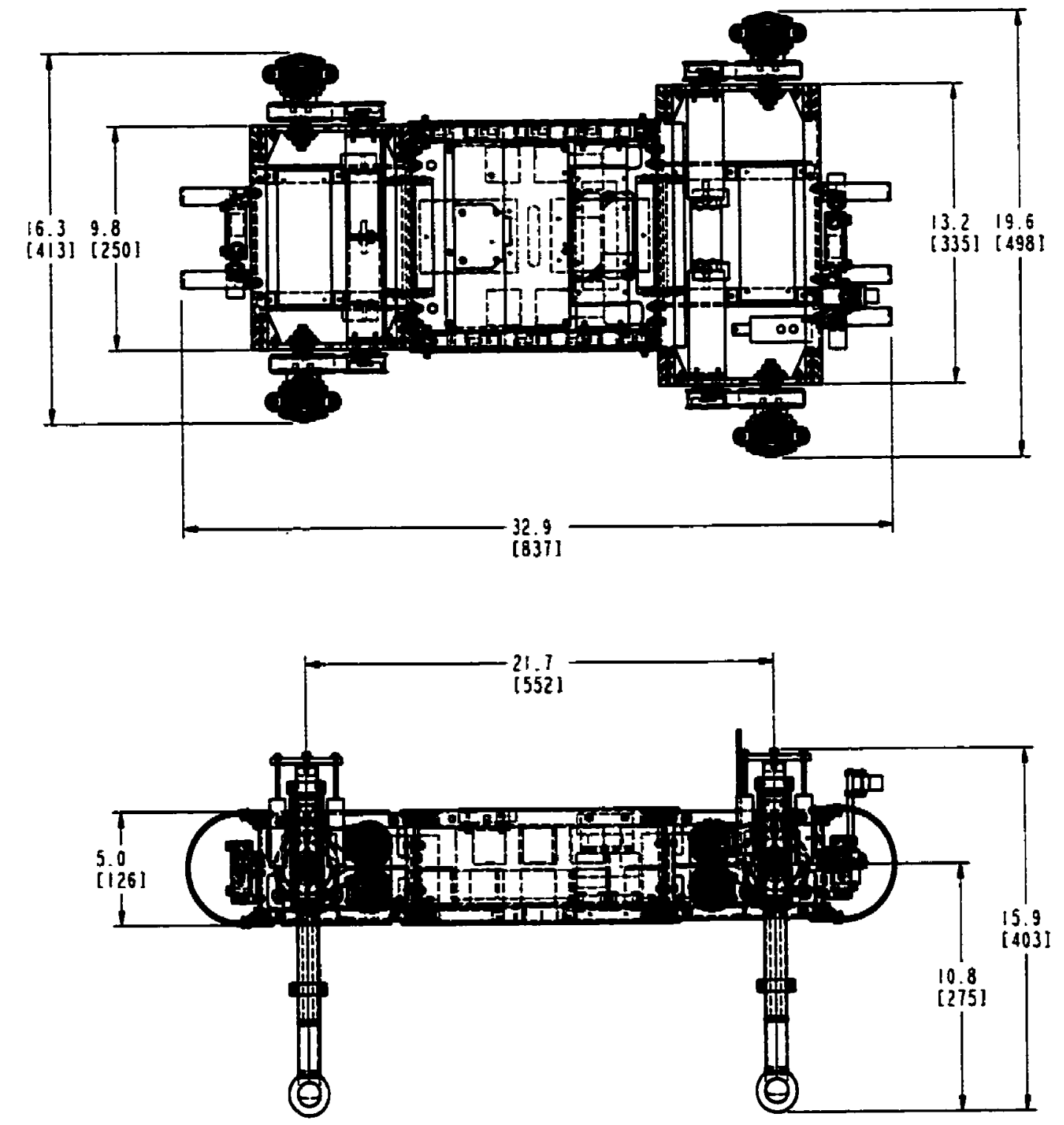

Figure 2.2 - Scout II dimensions in no knee configuration (Inches [mm]) [8] 


\begin{tabular}{|c|c|c|c|}
\hline \multicolumn{2}{|l|}{ Body length } & & $837.0 \mathrm{~mm}$ \\
\hline \multicolumn{2}{|l|}{ Body height } & & $126.0 \mathrm{~mm}$ \\
\hline \multicolumn{2}{|l|}{ Front hip width } & & $498.0 \mathrm{~mm}$ \\
\hline \multicolumn{2}{|l|}{ Rear hip width } & & $413.0 \mathrm{~mm}$ \\
\hline \multicolumn{2}{|l|}{ Hip-to-hip width } & & $552.0 \mathrm{~mm}$ \\
\hline \multicolumn{2}{|l|}{ Total mass } & & $23.77 \mathrm{~kg}$ \\
\hline \multicolumn{2}{|l|}{ Body mass } & & $20.09 \mathrm{~kg}$ \\
\hline \multirow{2}{*}{$\begin{array}{l}\text { Body inertia } \\
\text { (about body centre) }\end{array}$} & pitch axis & & $1.091 \mathrm{~kg} \cdot \mathrm{m}^{2}$ \\
\hline & Ioll axis & & $0.161 \mathrm{~kg} \cdot \mathrm{m}^{2}$ \\
\hline \multirow{3}{*}{\multicolumn{2}{|c|}{$\begin{array}{l}\text { Centre of mass location } \\
\text { (from body centre) }\end{array}$}} & \multicolumn{2}{|c|}{$14.1 \mathrm{~mm}$ (in front) } \\
\hline & & \multirow{2}{*}{\multicolumn{2}{|c|}{$\frac{2.4 \mathrm{~mm} \text { (to the right) }}{3.1 \mathrm{~mm} \text { (below) }}$}} \\
\hline & & & \\
\hline \multicolumn{2}{|l|}{ Leg length } & \multicolumn{2}{|c|}{$255.9-457.3 \mathrm{~mm}$} \\
\hline \multicolumn{2}{|l|}{ Leg mass } & \multicolumn{2}{|c|}{$0.920 \mathrm{~kg}$} \\
\hline \multirow{6}{*}{\multicolumn{2}{|c|}{ Leg inertia (about hip) }} & $\begin{array}{l}\text { Leg length } \\
\text { (mm) }\end{array}$ & $\begin{array}{c}\text { Inertia } \\
\left(\mathrm{g} \cdot \mathrm{mm}^{2}\right)\end{array}$ \\
\hline & & 255.9 & 12.94 \\
\hline & & 275.0 & 14.27 \\
\hline & & 294.1 & 16.26 \\
\hline & & 313.2 & 18.90 \\
\hline & & 332.3 & 22.19 \\
\hline
\end{tabular}

Table 2.1 - Mechanical specifications of Scout I without knees [8] (refer to Figure 2.2)

powered with on-board batteries. Important considerations in the design of the robotic knee were the available electric power, sensor input ports to the computer, and control signal output ports from the computer.

Scout II uses a variety of sensors to determine information about itself and its surroundings. Among them are optical encoders to measure the leg angles with respect to the body, laser range finders to measure the robot's height above the ground, linear potentiometers to measure the leg length and hence the spring deflection in the legs during its compliant legs mode, hall effect sensors to home the encoders, and gyroscopes to determine the robot's pitch and roll. In addition, there are four servo-amplifiers that receive control inputs from the computer to provide the current (and hence the torque) of the electric actuators. Finally, the laser range finders are mounted on small RC servo motors to keep the lasers pointed straight down (using information from the gyroscopes), or to scan the terrain in its forward path. 


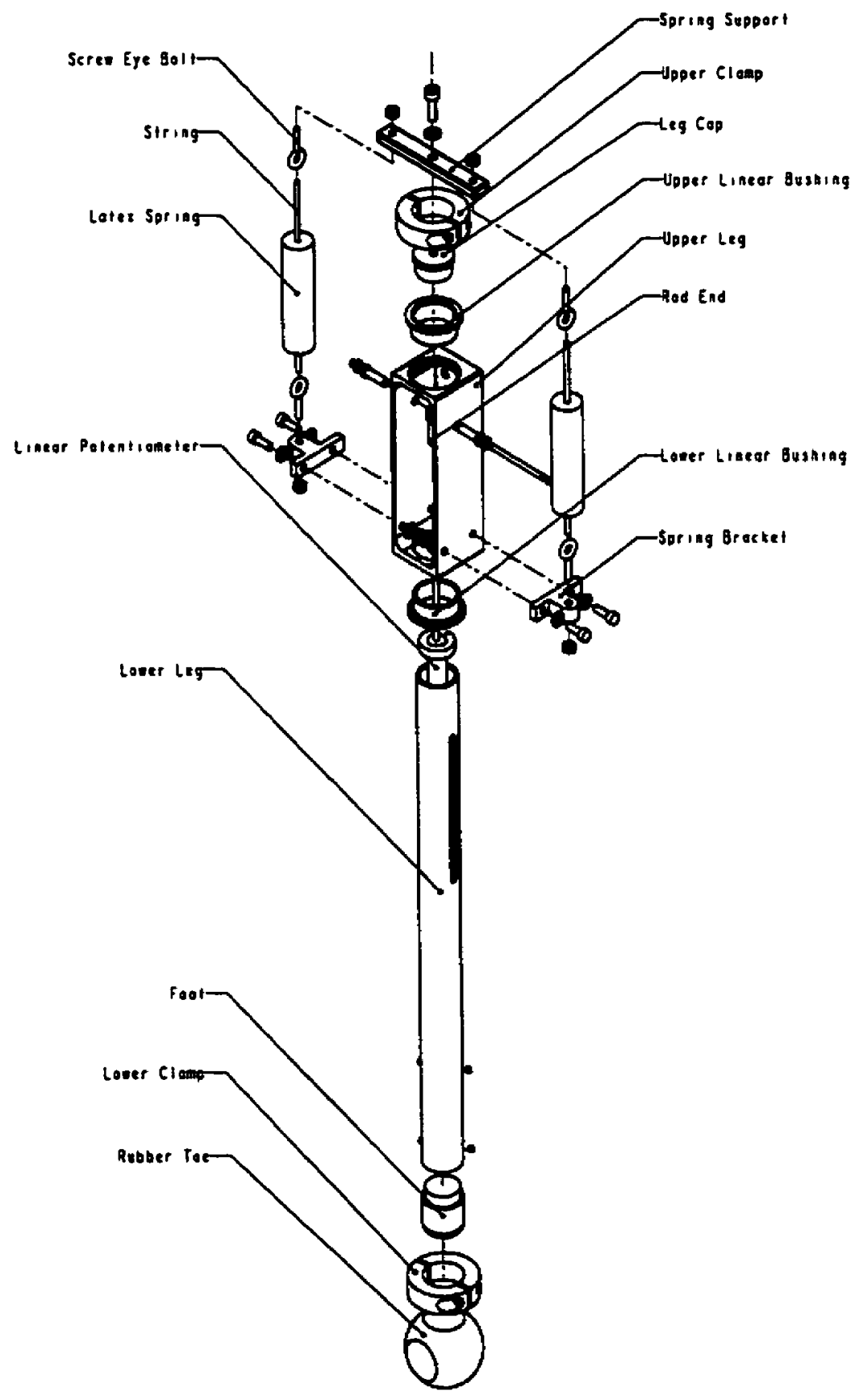

Figure 23 - Exploded view of Scout II leg in compliant no knee mode [8] 
The sensors and the motor output signals communicate with Scout II's on-board computer using the Standard Parallel Port/Serial Peripheral Interface (SPPSPI) system developed at ARL. One SPPSPI permits up to 8 inputs and 8 outputs which interface with the computer through one bi-directional parallel port. Each input and output connects to a separate module which converts the sensor or the desired output signal to the serial signal used by the SPPSPI. The following modules are used on board Scout $\Pi$ :

- ADIO: Analog to Digital Input Output - each module has 12 bits of resolution

- DAJO: Digital to Analog Input Output - used to send an analog output voltage signal to the servo amplifiers

- RCIO: R/C servo Input Output - used to drive the R/C servo motors, or as 8 digital output signals, or as a watchdog for motor enabling

- HCTL: Encoder input module for measuring leg angle with respect to the body

- DIN: Digital INput - can read up to 10 digital inputs

The on-board computer has two parallel ports, and consequently, two SPPSPI systems are used, for a total of 16 inputs and 16 outputs. Table 2.2 shows a summary of the inputs and outputs used on the two SPPSPI systems of Scout II. It shows that 13 of 16 available inputs are used, and 7 of 16 outputs are used.

\begin{tabular}{|c|c|c|c|c|c|}
\hline \multirow{4}{*}{ Inputs } & Module & Function & & & \\
\hline & ADIO & $\begin{array}{l}\text { Leg Potentiometers } \\
\text { Lasers } \\
\text { Gyroscopes }\end{array}$ & $\begin{array}{l}4 \\
2 \\
2\end{array}$ & 8 & \multirow[t]{3}{*}{13} \\
\hline & HCTL & Encoders & 4 & 4 & \\
\hline & DIN & Hall effect sensors & 1 & 1 & \\
\hline \multirow[t]{3}{*}{ Outputs } & DAIO & Servo amplifiers & 4 & 4 & \multirow{3}{*}{7} \\
\hline & $\mathrm{RClO}$ & Servo motors & 2 & 2 & \\
\hline & DOUT & Watchdog & 1 & 1 & \\
\hline
\end{tabular}

Table 2.2 - Input and Output signals on Scout II without knee [8]

Finally, it should be noted that the batteries provide 24 Volts to the system, and a power distribution board was built which has outputs of 24,12 , and 5 Volts. 


\subsection{Task Clarification}

The goal of the current research is to develop the hardware, electronics, and control software to make the Scout II robot exhibit trotting gaits, and to provide a novel legged system for which future work can explore different behaviours. To achieve this, a knee was needed. As with biological systems, the knee is used primarily for toe clearance during the swing phase of a walking cycle. In the case of a quadruped, this is especially necessary for a trot gait, in which the legs operate in diagonal pairs (Section 1.3). In this section, the basic requirements that motivated the final design of the knee are discussed, and the torque requirements of the locked knee are explained.

\subsubsection{Basic Requirements of Knee}

The primary functions of a knee are to rotate through a minimum angle as to be useful during the swing phase, but to lock in the straight or the near straight-leg configuration for the support phase of a walking cycle. Therefore, the minimum requirements of the robotic knee are that it be a revolute joint with a certain angular range, and that it lock in at least one position, the straight-leg configuration. Furthermore, it is required that if external power is required for the knee that it be electric power. The use of hydraulics or pneumatics would not interface with the existing Scout II architecture.

The fact that Scout II is a mobile and autonomous robot also imposed certain restrictions on the design of the knee. Maximizing the operational time of a single battery charge is very important. To do this, the amount of electrical current drawn by the knee must be minimized. Furthermore, the battery power required to move the entire robotic system is reduced as the overall weight of the robot is decreased. Consequently, reducing the weight of the knee was important. Table 2.1 shows that Scout II's leg mass (without knees) is $0.92 \mathrm{~kg}$. It was decided to set an upper bound on the locking mechanism's mass to $1.0 \mathrm{~kg}$, in order to keep the locking mechanism in line with the rest of the size of the robot. 
For these reasons, it was decided to investigate using a passive knee - that is, a knee with no actuator. Previous research outlined in the introduction to this thesis showed that it is possible to control two robotic joints with one actuator (Section 1.3.3). Furthermore, it was also shown that the angular trajectory cycles that the hip and the knee follow during a typical trot gait are natural motions that involve very little (if any) knee actuation. Finally, since a passive knee is both lighter and draws significantly less electrical current than a motor, it was decided to design the system with a passive knee.

Bergerman et al. [9] defined a coupling index that is a quantitative measure of the effect the dynamics of the active joints in a system with both passive and active joints have on the passive joints (Section 1.3.3). In other words, they determined a way to measure the amount of controllability of the passive joint. Furthermore, they showed that this amount can be increased or decreased in response to changes in the geometry and mass distributions of the system. Consequently, a requirement for the design was that the geometry and the mass distributions of the upper and lower legs, especially the location of the centres of mass and the relative lengths of the upper and lower legs, could be modified.

During a trot cycle, the knee must be locked when the leg is in the support phase. Since a passive knee has no motor which could be used as a brake or a lock, some sort of locking mechanism had to be implemented in the design of the knee. Preferably, the knee could be locked at any angle throughout its range of motion, to permit the most versatility in implementing various behaviours.

Finally, some additional functionality was desired to maximize the use of the money and time investment put into this robot for future research. It was felt that by enabling the knee to rotate through $360^{\circ}$ that more potential behaviours could be studied. Of particular interest would be for the leg to be able to lock in the $180^{\circ}$ position and to use its knees as feet in a rigid leg mode. By doing this, the system could dynamically be converted from kneed to non-kneed. 


\subsubsection{Torque Requirement of Knee}

In order to determine the torque requirement of the knee, the worst case loading condition(s) had to be determined. It was assumed that the worst situation was if only one of the locked legs, at some shallow angle, hit the ground while the the hip actuator was commanding the leg to be still. Effectively, this would represent a situation where the upper leg was fixed, and a large impact force was put on the toe. Figure 2.4 shows a diagram of this situation.

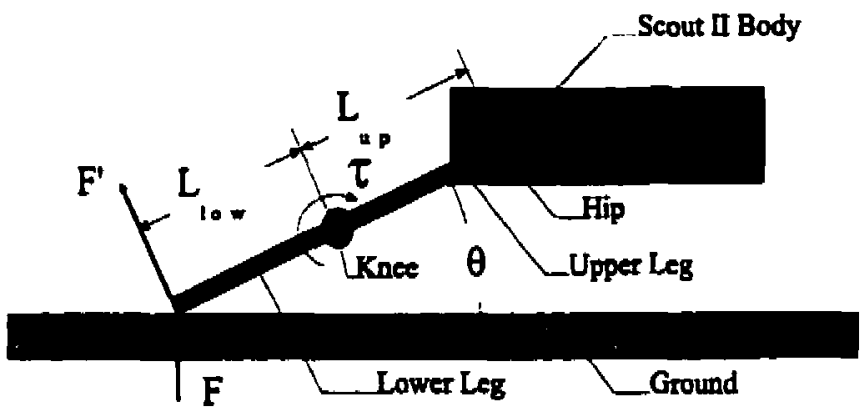

Figure 2.4 - Worst case loading condition of knee

Using the diagram as a guide, the following relation can be developed.

$$
\tau=F \cdot L_{l o w} \cos \theta
$$

To find a final value for the holding torque requirement at the knee $(\tau)$, reasonable values have to be used in (2.1). A reasonable assumption for the shallowest angle at which the leg strikes the ground $(\theta)$ is $30^{\circ}$. Please note that the torque is maximized as $\theta$ is minimized. Furthermore, based on the no-knee mode of Scout II operation, an upper limit on the total leg length is $40 \mathrm{~cm}$, which makes $20 \mathrm{~cm}$ a reasonable assumption for the longest lower leg length. Finally, the impact force, F, is taken to be 2.5 times Scout II's weight. In [8], Robert Battaglia used 20 times the weight of Scout II as the estimate for the worst case impact load experienced by the hip. The Scout II robot has been used for several months and has not suffered any plastic deformations. Consequently, it can be concluded that Battaglia's estimate was at least sufficient, if not too conservative. Under any difficult loading situation at the knee, the belt and the transmission of the motor will have a certain flexibility which will significantly reduce the effect of any impact load. 
Furthermore, Battaglia did not account for the rubber toes, which also offer some protection. His reasoning was sound since his goal for the hip design was not only to protect against impact loads at the toe, but to protect the whole robot in the case of a catastrophic fall from a certain height, such as falling down a flight of stairs. In the case of the knee design, this was not an issue. As a result of these factors, and to reduce the overall weight of the knee, this estimate was dropped to 2.5 times the weight of the robot.

The mass of the Scout II robot is $23.77 \mathrm{~kg}$ (see Table 2.1), but to account for any additional mass due to the addition of the knees and the control electronics, it is taken as $30 \mathrm{~kg}$ for the torque requirement calculations.

$$
\begin{aligned}
& F=2.5 \mathrm{mg}=2.5 \cdot 30 \mathrm{~kg} \cdot 9.8 \mathrm{~ms}^{-2}=735 \mathrm{~N} \\
& \tau=(735 \mathrm{~N})(0.2 \mathrm{~m}) \cos \left(30^{\circ}\right)=127.4 \mathrm{Nm}
\end{aligned}
$$

To conclude, the torque requirement of the knee is $127.4 \mathrm{Nm}$.

\subsection{Knee Locking Designs}

As described in the previous section, it was critical that the knee be able to lock in at least the straight or the near-straight leg position, and it was desired that the knee be able to lock in all or many positions throughout its range of motion. This section presents several alternative knee locking scenarios.

\subsubsection{Mechanical Stop}

In biological locomotion, the knee can only lock in the straight leg configuration. McGeer showed that it is possible to build a passive bipedal system with knees that can walk down a shallow slope powered only by gravity [29][30]. In his model, the knee did not have an active locking mechanism, but had a mechanical stop, as in the biological case. He showed that a simple stop could work as long as the contact point of the foot was placed in front of the knee, thereby inducing a positive moment throughout the 
support phase of a leg holding the lower leg against the stop. Figure 2.5 shows a schematic of the mechanical stop knee locking mechanism. Furthermore, Garcia et al. [18] did a stability and efficiency study of McGeer's passive kneed-walker model, and they built an experimental prototype (Figure 2.6 ) which successfully walked down shallow slopes using the mechanical stop locking mechanism approach.

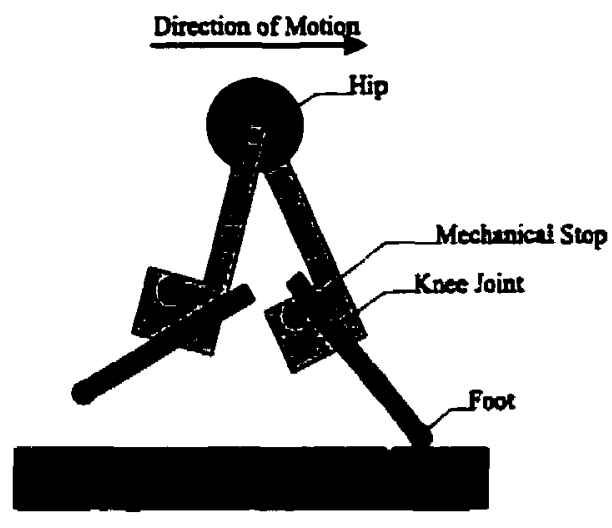

Figure 2.5 - Mechanical stop knee locking mechanism

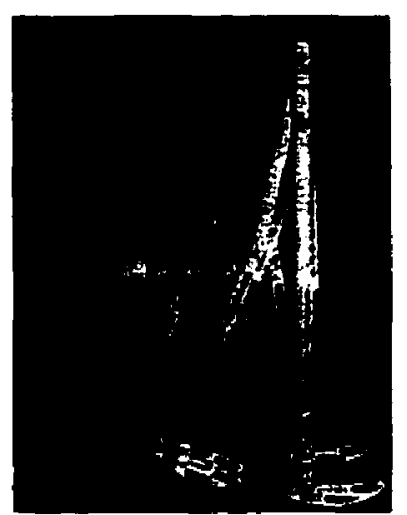

Figure 2.6 - Physical Model of 2-D Passive Dynamic Bipedal Walker [18]

This approach has good success for studying walking behaviours, but is somewhat limited for practical applications with quadrupedal robots. First of all, the direction of motion is fixed because the locking mechanism is directional. Secondly, the robot cannot provide a stable platform without leaning backwards on all of its legs. Many scenarios in which it is desired for the robot to walk backwards or to lean forwards or backwards can be imagined. Furthermore, this design does not satisfy the basic design wishes of this project to permit the study of a variety of gaits, for the knee to lock in any position, and for the knee to rotate through $360^{\circ}$. For these reasons, this design possibility was ruled out.

\subsubsection{Electric Brakes and Clutches}

An obvious starting point for a locking mechanism was to use electric brakes or clutches. Generally, brakes and clutches are very similar devices, the primary distinction being that brakes lock when energized (referred to as "Power On" devices), and clutches unlock 
when energized (referred to as "Power Off" devices). There also exists a class of electromechanical brakes and clutches that are referred to as "latching" - that is, they require only short pulses of current to lock or to unlock them, and they remain locked or unlocked with no additional energy input. A market survey was performed to determine the availability of appropriate commercial brakes and clutches. This section will discuss the market searches for both the latching brakes and clutches, and the traditional, nonlatching kind, and it will also explain why ultimately they were not considered for this application.

\section{LATCHING BRAKES AND CLUTCHES}

Latching clutches and brakes are very attractive for mobile robotics applications. First and foremost is that they require only short pulses of current to either lock or unlock them, and then no power to hold them in either of their extreme positions. An extensive market survey was done using online resources such as the Thomas Register [43], and by searching through catalogues and contacting distributors. Only one latching brake was found: part BSB-35 manufactured by the Electroid company [16]. Table 2.3 lists the relevant specifications of this latching brake. Unfortunately, it was both too heavy and not strong enough to be of use in this application.

\begin{tabular}{|l|l|c|c|}
\hline Company & \multicolumn{1}{|c|}{ Model } & $\begin{array}{c}\text { Mass } \\
(\mathrm{kg})\end{array}$ & $\begin{array}{c}\text { Rated Torque } \\
(\mathrm{Nm})\end{array}$ \\
\hline Electroid & BSB-35 & $1.9 \mathrm{lbs}$ & 4.0 \\
\hline
\end{tabular}

Table 23 - Commercially available latching electric brake [16]

\section{POWER ON/OFF BRAKES AND CLUTCHES}

A market search was done to try to find electric brakes that would satisfy the requirements of Section 2.3, and is presented in Table 2.4. In all cases, it was found that the rated torque was never strong enough (refer to Section 2.3.2) and the masses were too large (see Section 2.3). Consequently, power on and off brakes and clutches were discarded as design possibilities. 


\begin{tabular}{|l|l|c|c|c|}
\hline \multicolumn{1}{|c|}{ Company } & \multicolumn{1}{|c|}{ Model } & $\begin{array}{c}\text { Power } \\
\text { On/Off }\end{array}$ & $\begin{array}{c}\text { Mass } \\
(\mathrm{kg})\end{array}$ & $\begin{array}{c}\text { Rated Torque } \\
(\mathrm{Nm})\end{array}$ \\
\hline Electroid [16] & EC-56B & On & 1.3 & 67.9 \\
\hline API DeItran [5] & SB-50 & Off & 3.0 & 39.6 \\
\hline $\begin{array}{l}\text { Rockwell } \\
\text { Automation [40] }\end{array}$ & FB42 & On & 1.7 & 28.3 \\
\hline Lenze [25] & 14.105 .16 .1 .3 & Off & 5.49 & 120.0 \\
\hline
\end{tabular}

Table 2.4 - Commercially available power on and off electric ciutches and brakes

\subsubsection{Locking Discs and Pins}

After discovering that there were no commercially available electric brakes or clutches that would fit this application, it became clear that some sort of discretized locking mechanism would need to be used. A discretized locking mechanism is one in which the knee angle can be locked in several different positions, but unlike a brake or a clutch, the knee angular velocity cannot be smoothly slowed. The most obvious example is a pin being pushed in and out of holes on a disc: when the pin is pushed into the hole, the knee is locked, and when the pin is retracted, the knee-joint is free to turn. Figure 2.7 shows a schematic of the locking pin and disc discretized locking mechanism. In this figure, the locking disc is rigidly attached to the lower leg, and the shaft is rigidly attached to the upper leg. Since the distance between the locking hole and the knee-joint axis can be made quite large, very large holding torques for the knee can be achieved with relatively small sized pins. Although other possibilities of discretized locking mechanisms exist, it was feit that a device with one or more locking pins and a mating disc offered the most design simplicity (and therefore the most reliability) while still meeting all of the design requirements and wishes.

For the disc-pin locking mechanism to work, an actuator is needed to push and pull the locking pin into place. It was felt that a small servo-motor with some sort of rack and pinion gearing for the linear motion would be too heavy, complicated, and slow. 
Consequently, direct linear actuators were considered. In addition, solenoids (both nonlatching and latching) were investigated.
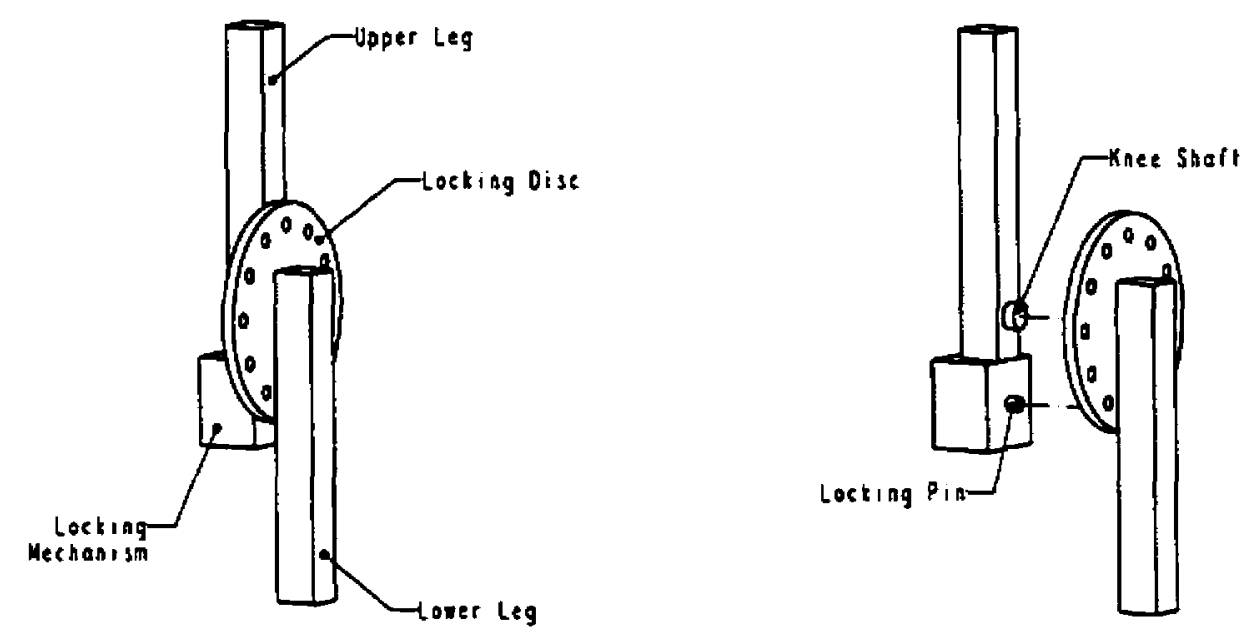

Figure 2.7 - Discretized locking mechanism schematic

\section{LINEAR ACTUATORS}

Two types of linear actuator were examined: ball screws and lead screws. Ball screws often require the addition of a motor, though some come with prepackaged motors and position sensing. In general, it was found that ball screws were quite expensive options, and would require some sort of position sensing to correctly position the pin in the extended or retracted position. Lead screws attached to stepper motors provided a simpler alternative to the ball screws as the length of extension of the locking pin could be inferred from the number of steps that were sent to the stepper motor. Nevertheless, this possibility also seemed to be complicated compared to using a simple solenoid. For both the case of the ball screw and the lead screw, the locking pin would be attached directly to the actuator, which would require the careful design of support bushings or bearings for the locking pin to prevent the actuator from being damaged by transmitted loads. In the case of a solenoid, the pin is not rigidly attached to the coil housing, which helps to protect the solenoid body from any transmitted loads. Furthermore, since 
solenoids are much less expensive than the linear actuators, it was decided to use these in the design.

\section{NON-LATCHING LINEAR SOLENOIDS}

The traditional type of solenoid is non-latching. It is composed of an inductive coil which when energized pulls a ferro-magnetic plunger into itself. When the coil is not energized, a return spring pushes the plunger out. They can also be found in the reverse directions where energizing the coil pushes the plunger out. The former are referred to as "pull-type solenoids", and the latter "push-type". Figure 2.8 shows schematics of a pulltype non-latching solenoid with a return spring (left figure), and a latching solenoid (right figure), which is described below.

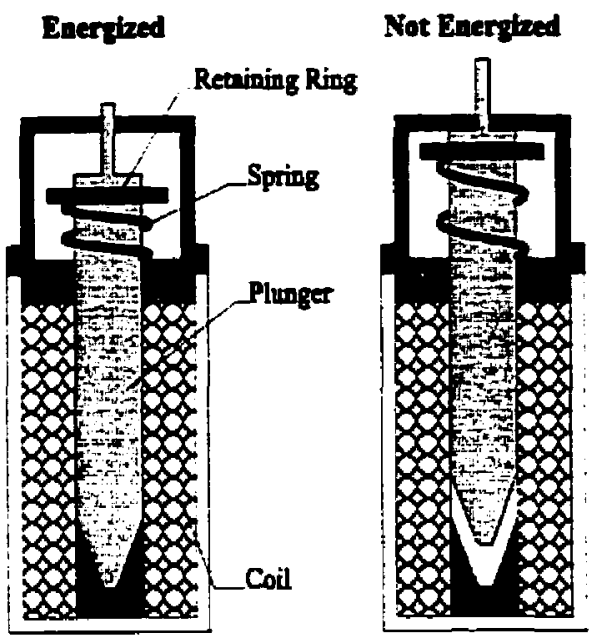

Non-Latching

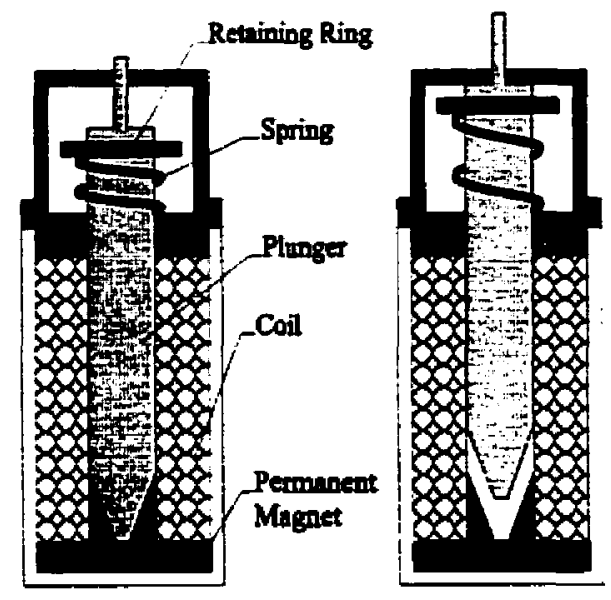

Latehing

Figure 2.8 - Latching and non-latching solenoid schematics

Although many non-latching solenoids could have satisfied the requirements of this design, they did have the drawback that in order to keep the plunger in its energized state, electric current has to be continuously supplied to the solenoid. The size of solenoid that would be needed for this application would draw on the order of 0.5 to 1.0 amperes of current, which would be a significant draw on the on-board batteries of the Scout II robot. It was ultimately decided to use latching solenoids for this application since they 
also satisfied the design requirements, but had a significantly reduced power consumption than the non-latching solenoids.

\section{LATCHING LINEAR SOLENOIDS}

Latching solenoids behave in the same manner as the non-latching kind, with the addition of a permanent magnet to hold the plunger in one of the extreme positions, while the return spring holds it in the other extreme position. In the case of the more common pulltype solenoid, a current pulse of one polarity is applied to retract the plunger, and the permanent magnet holds it in place once the current is no longer applied. A reverse polarity current pulse is applied to counter the effect of the permanent magnet and the spring extends the plunger until it hits its stop. The permanent magnet's force drops very quickly in a non-linear manner as a function of the extension distance, so at its extreme extension the spring force can prevent the magnet from pulling the plunger back in. In this manner, only short current pulses are needed to both extend and retract the solenoid. Figure 2.8 shows a schematic of the latching solenoid (right figure).

Table 2.5 shows the results of a market survey for latching solenoids. The mass for the Bicron solenoid was not available from the literature, but it is a very small solenoid which was not suitable for this application. Both the Guardian and the Dormeyer solenoids are of the right size. Ultimately the Dormeyer solenoid was chosen because of its lower holding force: in order to speed up the locking or unlocking time of the knee, it was desired to minimize the total stroke of the plunger. The larger magnet in the Guardian solenoid (hence the larger holding force) means that the force exerted on the plunger by the magnet is stronger when the plunger is in its extended position. This could cause accidental retractions of the plunger when a leg hits the ground.

In experiments, it was found that the Dormeyer solenoid requires 0.5 Amperes of current to lock or to unlock it. It was also found that it takes 150 to $200 \mathrm{~ms}$ to change the solenoid's state when it is used to lock or unlock the knee. 


\begin{tabular}{|c|c|c|c|c|c|}
\hline Company & Model & $\begin{array}{c}\text { Mass } \\
(\mathrm{kg})\end{array}$ & $\begin{array}{c}\text { Stroke } \\
(\mathrm{mm})\end{array}$ & $\begin{array}{c}\text { Holding } \\
\text { Force (N) }\end{array}$ & $\begin{array}{c}\text { Force at Stroke } \\
\text { Distance (N) }\end{array}$ \\
\hline Bicron [13] & SCL1330 & - & 0.8 & 9.5 & 3.9 \\
\hline Guardian [22] & IIL-C-24 & 0.152 & 6.35 & 44.5 & 9.7 \\
\hline Dormeyer [26] & C34-2036 & 0.207 & 6.35 & 18.4 & 7.8 \\
\hline
\end{tabular}

Table 2.5 - Commercially available latching solenoids

\subsection{Mechanical Design}

This section describes the final mechanical design of the passive knee system. First, the overall component layout is explained; second, the stress analyses of the locking pin and disc are presented.

\subsubsection{Component Layout}

Figure 2.11 shows an assembly drawing of the complete Scout II robot with the passive knee system, Figure 2.12 shows assembly drawings of the knee in two different configurations, Figure 2.13 shows an exploded view of the knee, and Figure 2.14 shows a photograph of one of the knee assemblies. All of the mechanical design was done using the ProEngineer ${ }^{\mathrm{TM}} \mathrm{CAD}$ software [36]. Figure 2.13 shows that the knee is divided into three main parts: the upper knee assembly, the lower knee assembly, and the existing upper leg and upper knee box of the Scout II robot in the no knee configuration. The knee shaft is rigidly attached to the lower leg assembly, and it rotates through teflon coated bushings in the upper knee block (Figure 2.9). It is held in place axially with a step in the shaft on the upper knee assembly side, and a machine screw and large washer on the lower knee assembly side. The bushings are press fit into the upper knee block. They are made by Garlock Bearing Inc., part number 08FDU04 (Figure 2.9) [19]. In addition, a teflon coated thrust washer was used between the teflon coated flange and the locking disc to reduce friction. The thrust washer was also made by Garlock, part number G06DU. A smaller teflon coated bearing, also made by Garlock (part number 04TH04) was used to support the solenoid plunger/pin through the upper knee block. 
In addition, the knee shaft has a small cylindrical protrusion at the upper knee assembly end which is connected to a precision potentiometer through a flexible helical coupling for knee angle sensing. The coupling serves to protect the potentiometer from any misalignments of the upper and lower knees. It is made by Helical, part number ACR050-4-4 (Figure 2.10) [23].

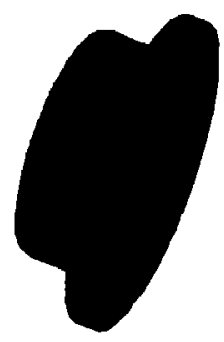

Figure 2.9 - Garlock tlanged bushing

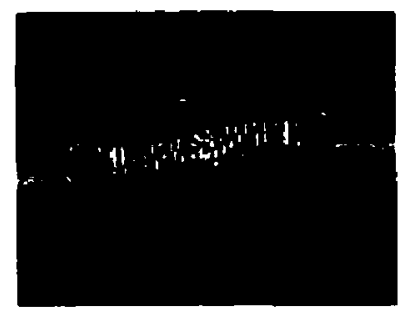

Figure 2.10 - Helical coupling

In reference to Figure 2.1 and Figure 2.11 , it can be seen that the passive knee system simply mounts onto the lower legs of the Scout II robot in its no-knee configuration. Figure 2.13 shows the manner in which the upper leg of the passive kneed Scout II (which is the lower leg of the no-knee configuration) is mounted to the knee assembly using the leg mount cylinder (Figure 2.15). This cylinder is made with a locational interference fit with respect to the inner diameter of the leg shaft [35], and it is held in place with set screws. The tight fit and length of the cylinder that extends inside the leg shaft are sufficient to prevent any bending moments from being applied to the set screws, and the bottom of the leg shaft rests on top of the upper knee block (Figure 2.15) to prevent any shear stresses from affecting the set screws when the toe is on the ground. In this manner, the set screws are only responsible for preventing rotations of the knee with respect to the upper leg, and for connecting the knee to the upper leg when it is in the air. Both of these conditions transmit only minor shear stresses to the set screws. Indeed, this technique of attaching the leg components to the knee was so simple and effective that it was used throughout this design. 
Figure 2.12 and Figure 2.13 shows how the upper leg was attached to the existing upper leg block of the robot using two leg clamps. This was a very simple manner of attaching the upper leg to the robot, and also to adjust the height of the upper leg. Adjusting the height of the upper leg was important to equalize the leg heights, and to permit the adjustment of the leg's geometry, mass distributions, and relative leg lengths. The latter is a requirement of the design as specified in Section 2.3.1.

Figure 2.15 shows an exploded view of the upper knee assembly. It can be seen how the flanged bushings are press-fit into the upper knee block, and how the shaft is passed through them. Furthermore, the manner in which the potentiometer is mounted to the upper knee block, and coupled to the shaft is also shown. Figure 2.16 and Figure 2.17 show the upper knee block assembly and a schematic of the Dormeyer latching solenoid. Finally, Figure 2.18 shows an exploded view of the lower knee assembly.

Figure 2.19 shows a photograph of the entire Scout II robot with the knees installed. Figure 2.20 is similar, but it shows the hip articulation. Figure 2.22 shows Scout II with the lower legs rotated $180^{\circ}$ and locked, demonstrating the manner in which Scout II with the passive knees can be operated as if it had shorter, rigid legs - a design requirement specified in Section 2.3.1.

Most of the analysis of Chapter 3 is done assuming planar operation in the direction of motion. It was necessary to mount the robot to ARL's treadmill using the planarizer, a device of linear and rotational bearings which restricts motion to the sagittal plane. A mounting bracket was designed and built for this purpose. Figure 2.23 shows a photograph of the treadmill, the planarizer, and the mounting bracket, and Figure 2.24 shows Scout II attached to the planarizer with the bracket. Finally, Figure 2.21 shows a different view of the robot mounted on the treadmill. 


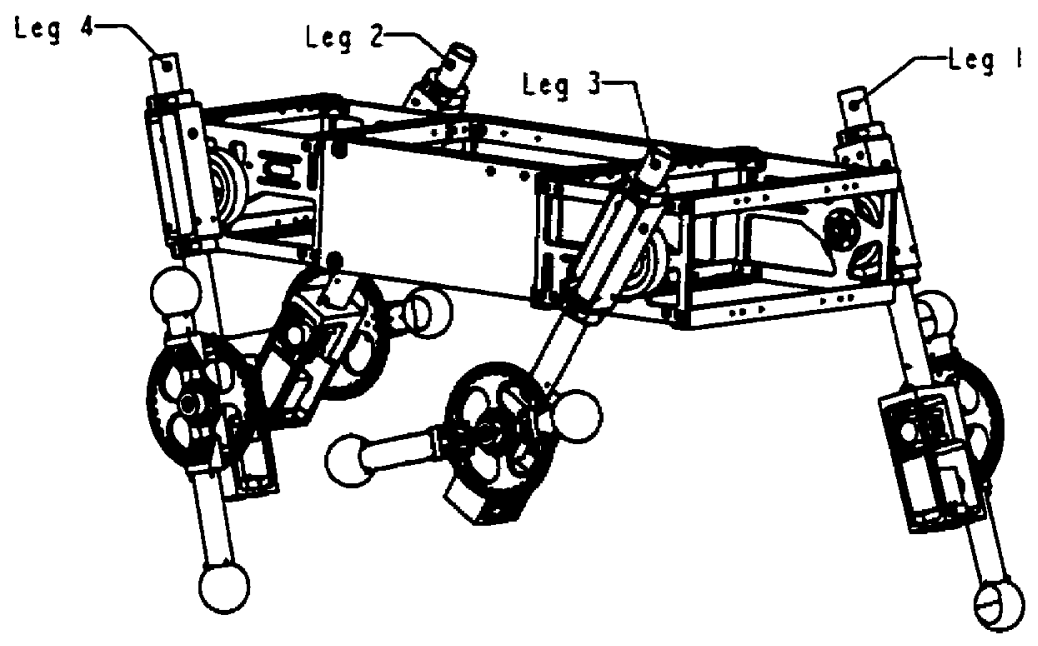

Fgure 2.11 - Scout II assembly drawing
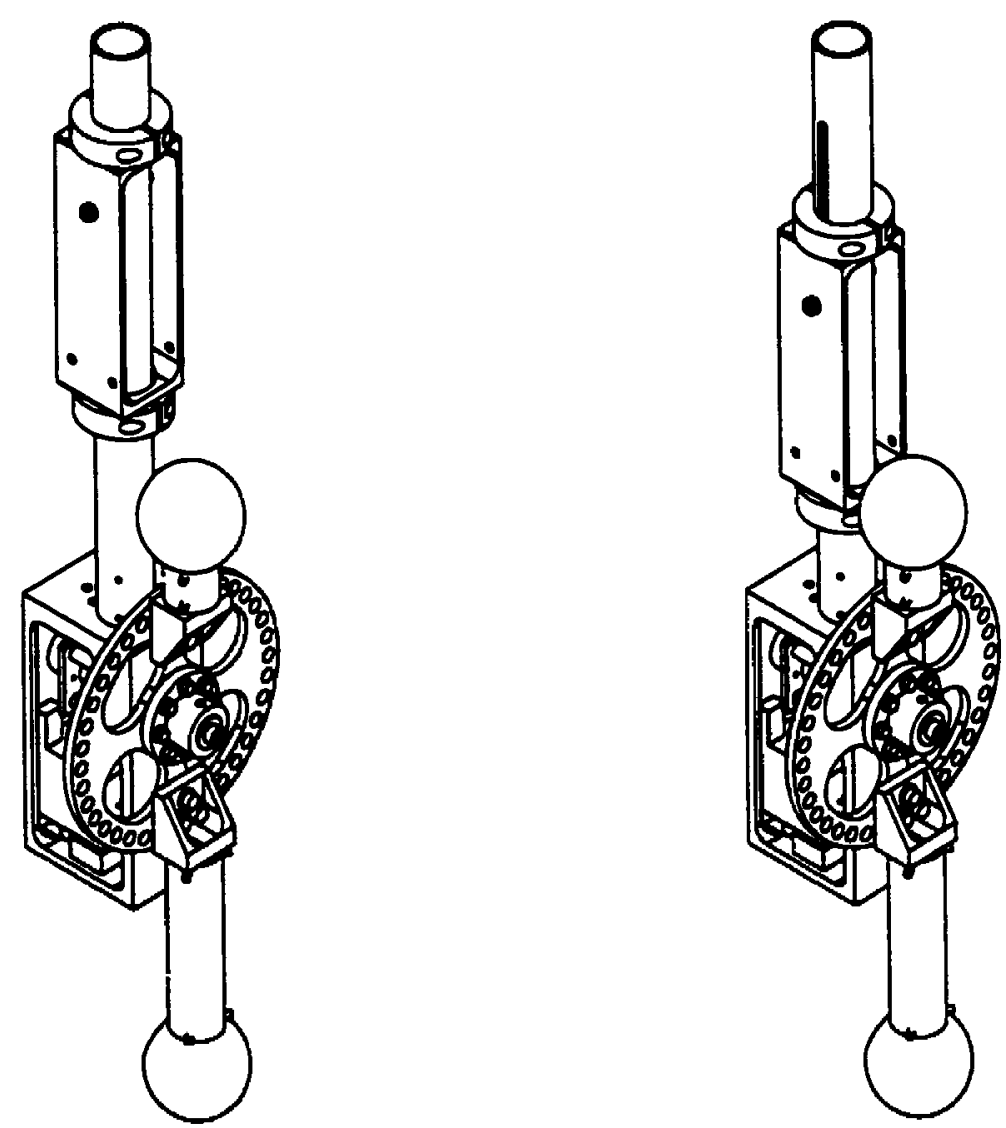

Figure 2.12 - Knee assembly in long and short upper leg length configurations 


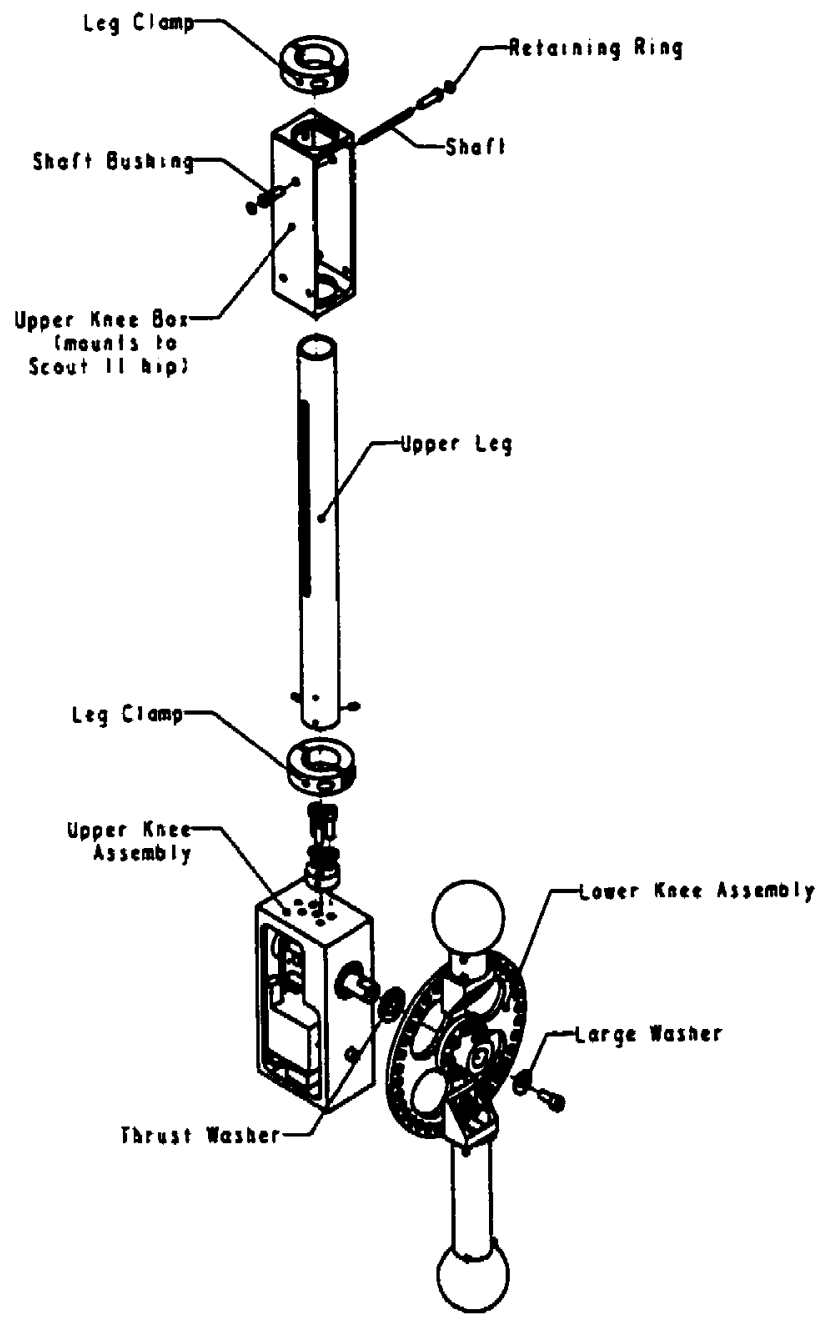

Figure 2.13 - Exploded view of knee

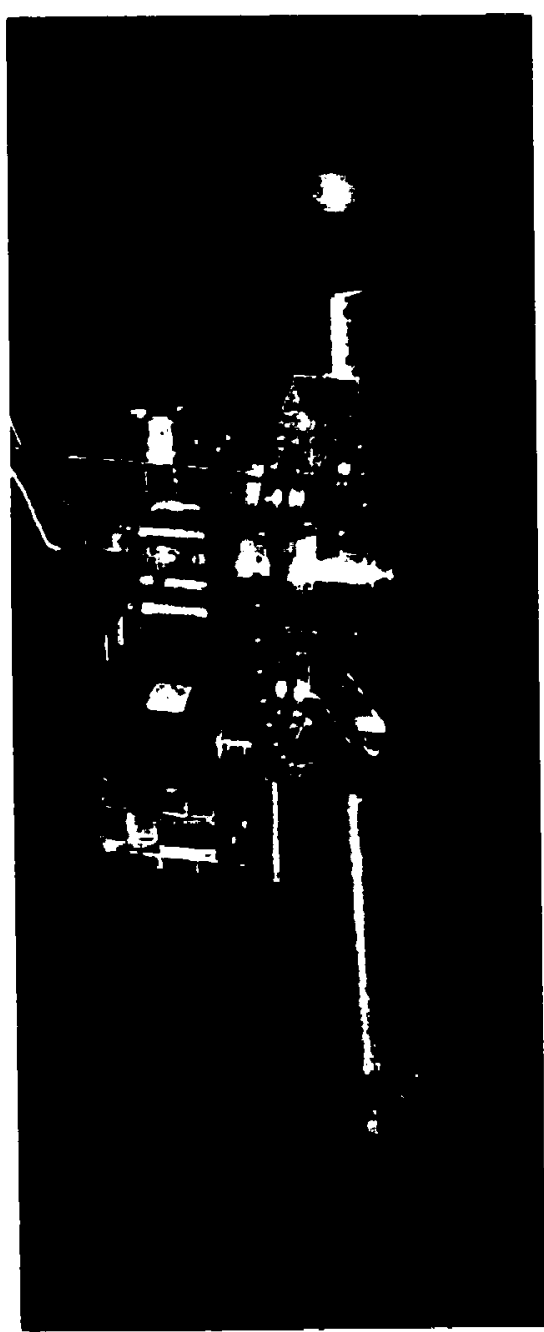

Digure 2.14 - Knee assembly 


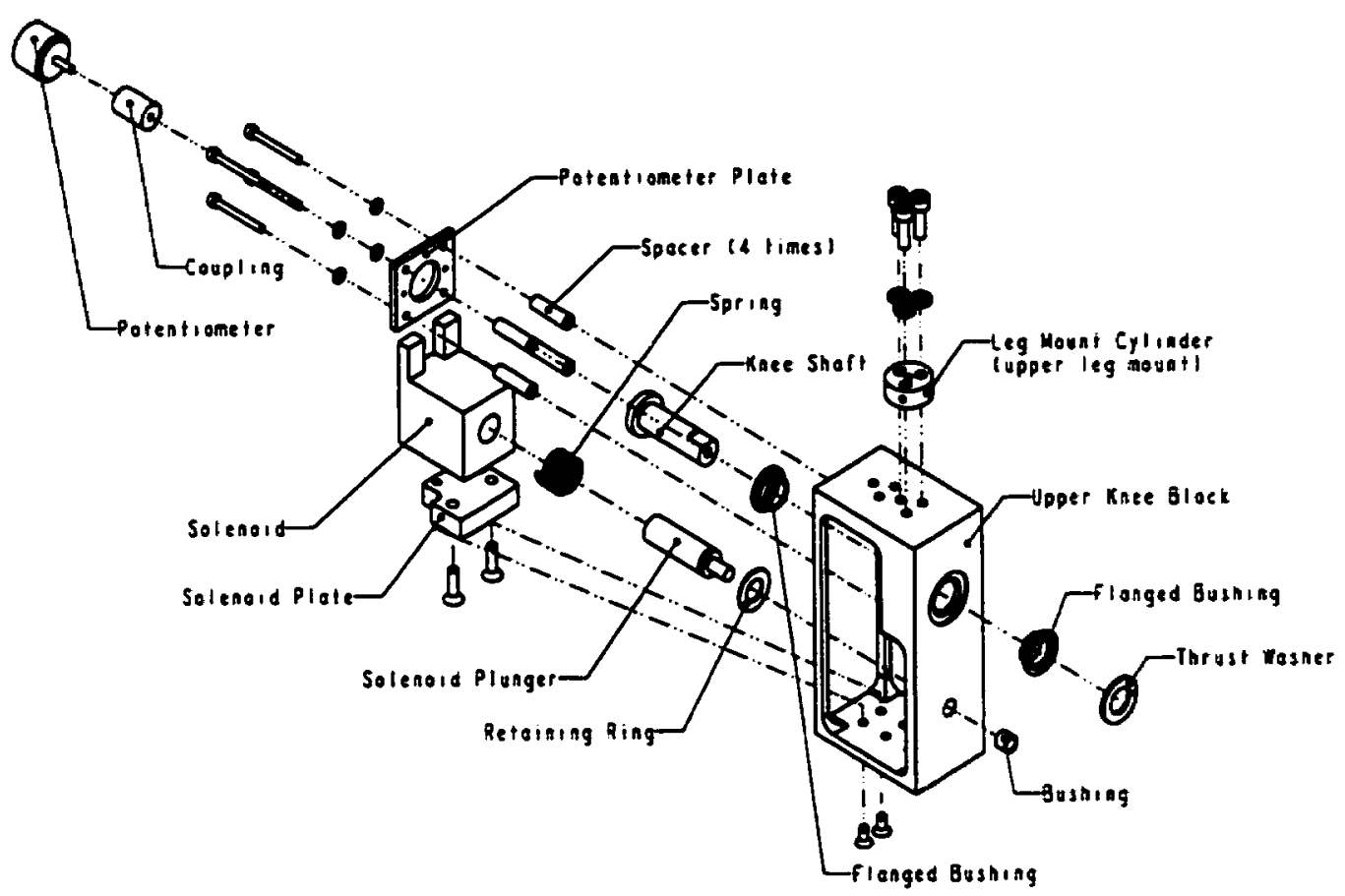

Figure 2.15 - Upper knee exploded view

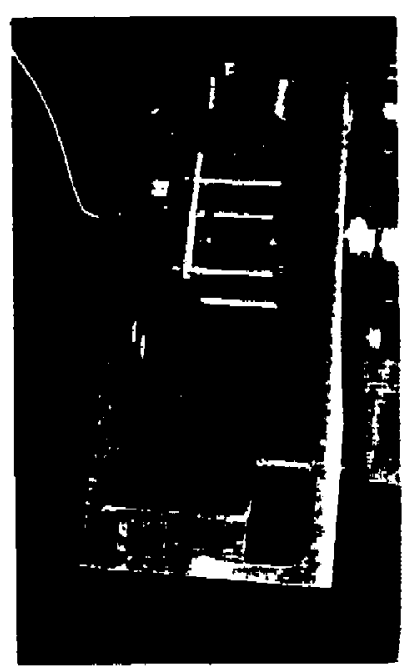

Figure 2.16 - Upper knee assembly

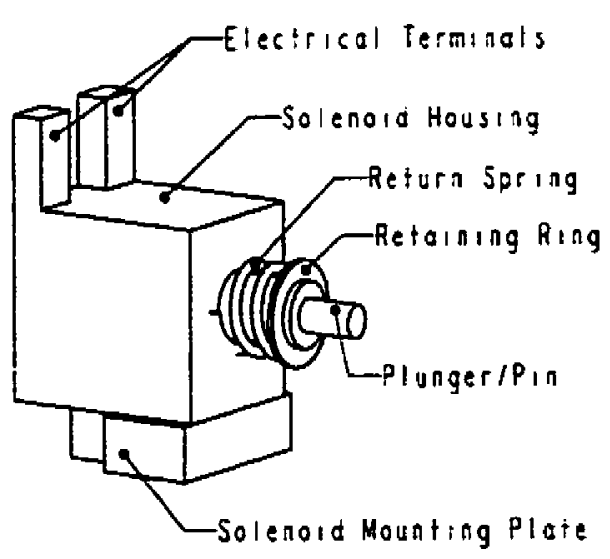

Figure 2.17 - Dormeyer solenoid assembly 


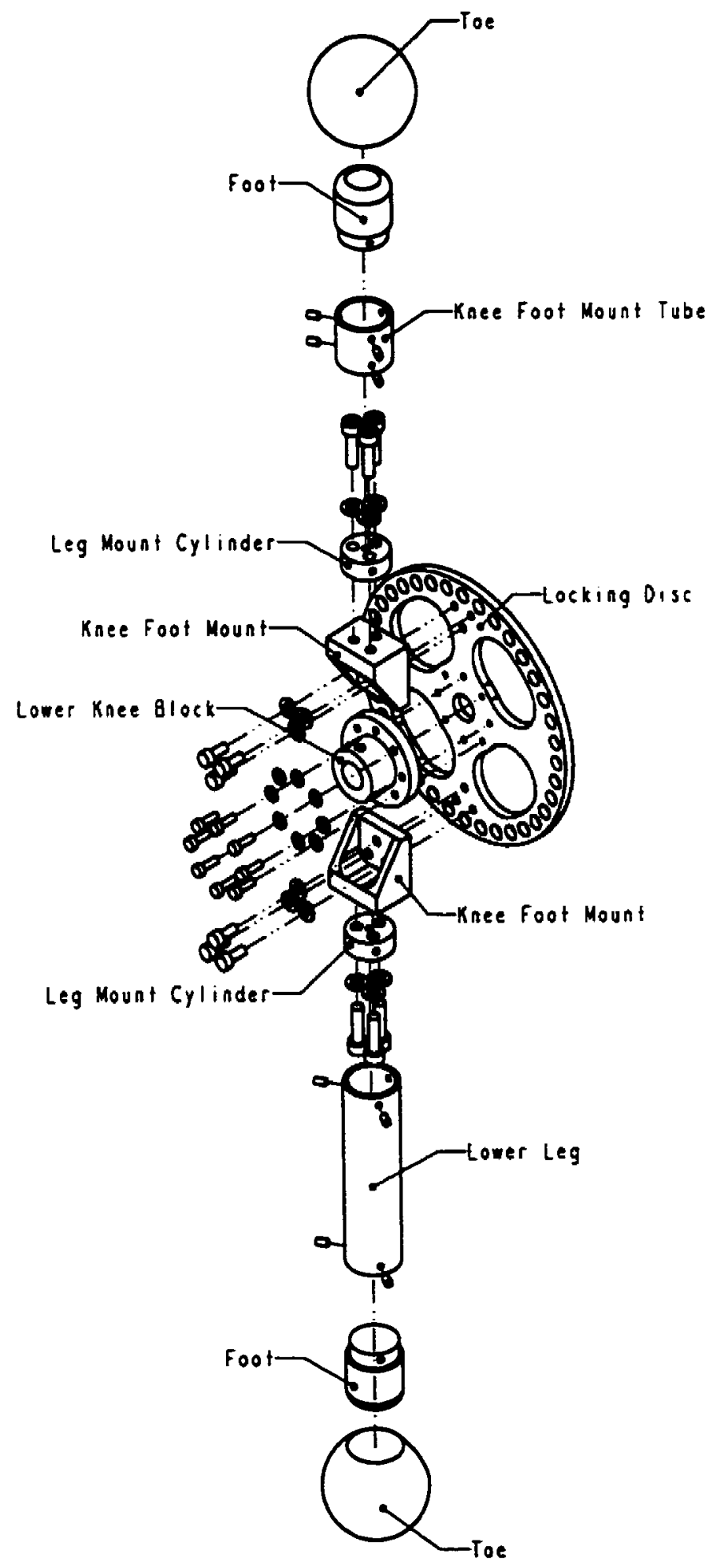

Figure 2.18 - Lower knee exploded view 


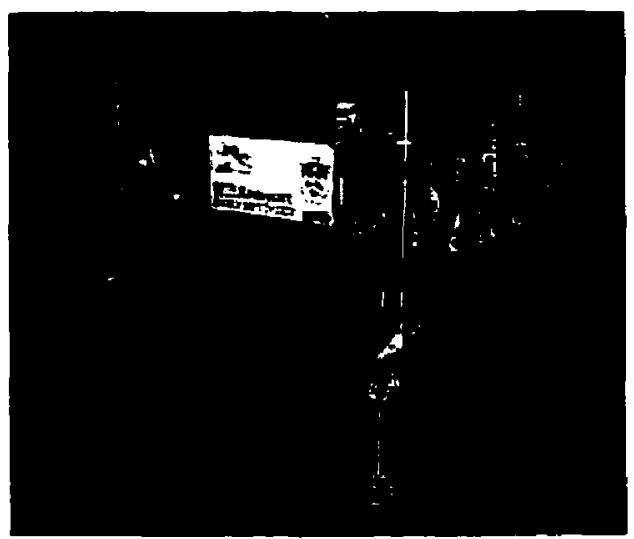

Figure 2.19 - Scout II with straight knees

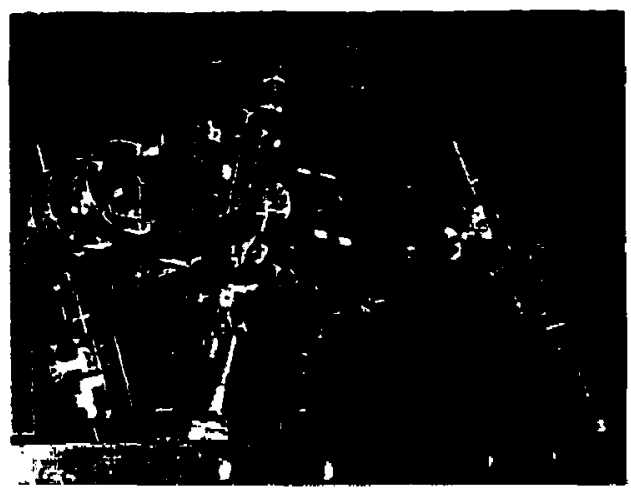

Figure 2.21 - Scout II with locked knees, longer leg confíguration, on treadmill

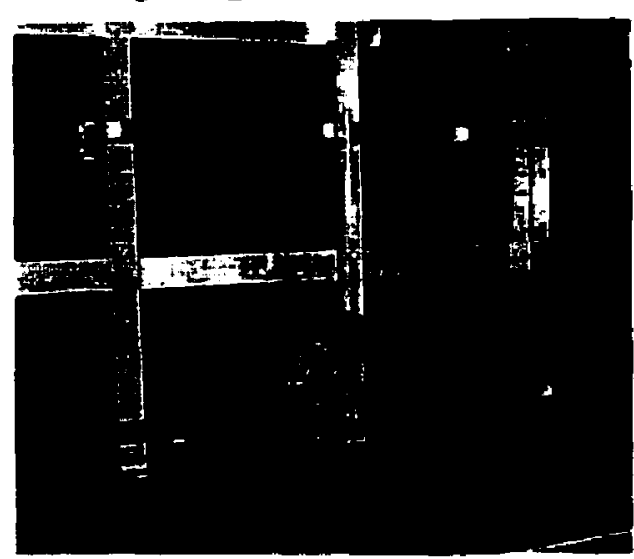

Figure 2.23 - Planarizer and treadmill

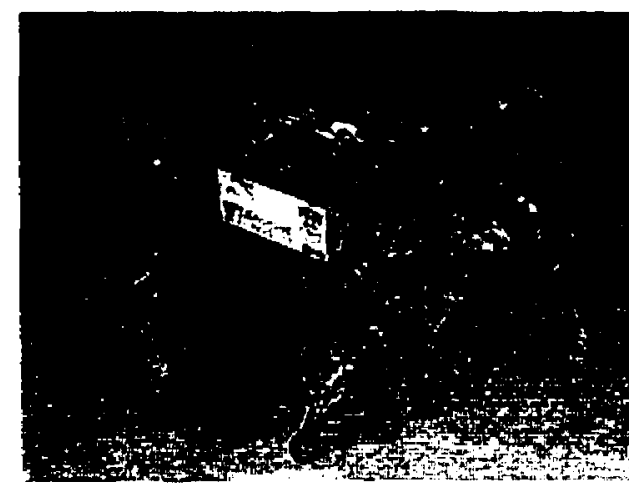

Figure 2.20 - Scout II with knees on floor

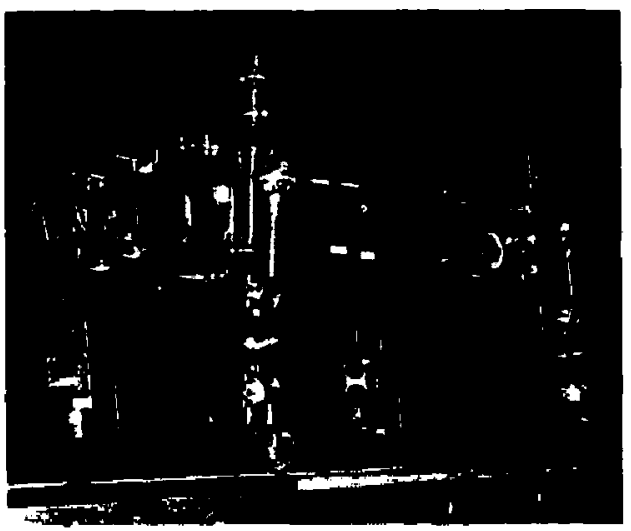

Figure 2.22 - Scout II with locked knees, shorter leg configuration

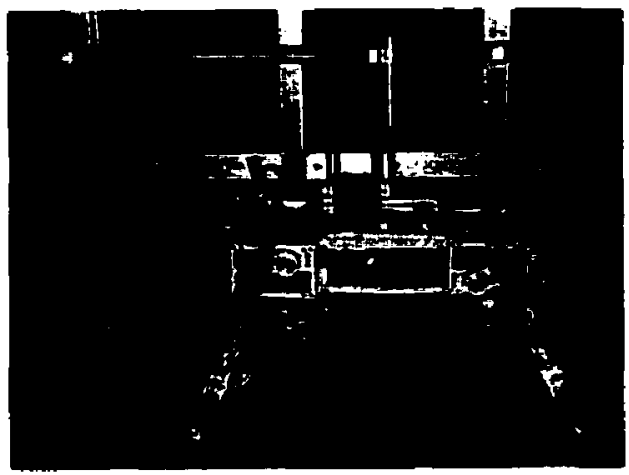

Figure 2.24 - Scout II mounted to planarizer on treadmill 


\subsubsection{Stress Analysis of Pin and Disc}

Stress analyses were done for the locking pin and the locking disc to minimize their weight (especially in the case of the locking disc) while ensuring that they would not plastically deform or fail under impact loads. This section will first explain the stress calculations done on the pin, and then the stress analysis on the locking disc.

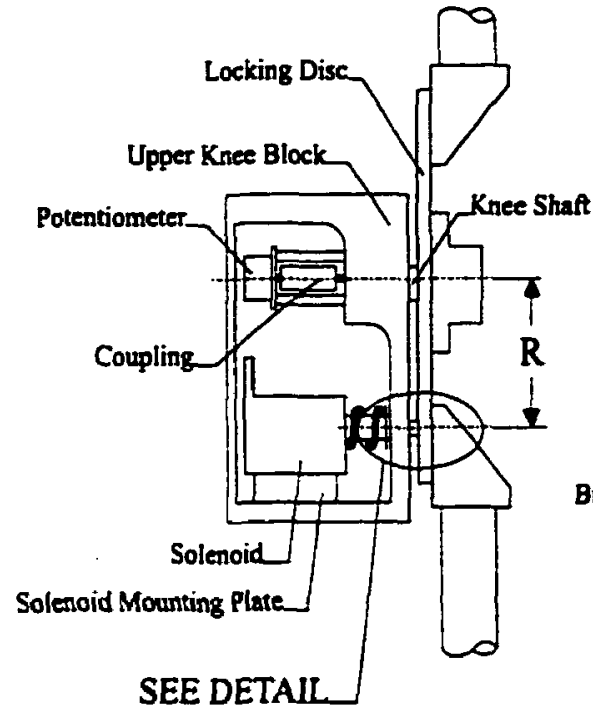

SEE DETAIL.

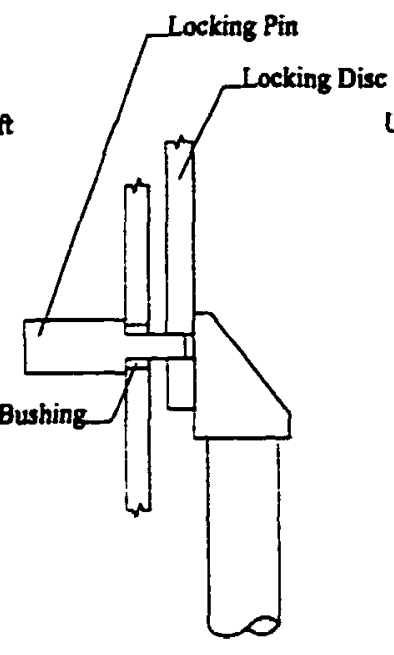

DETAII

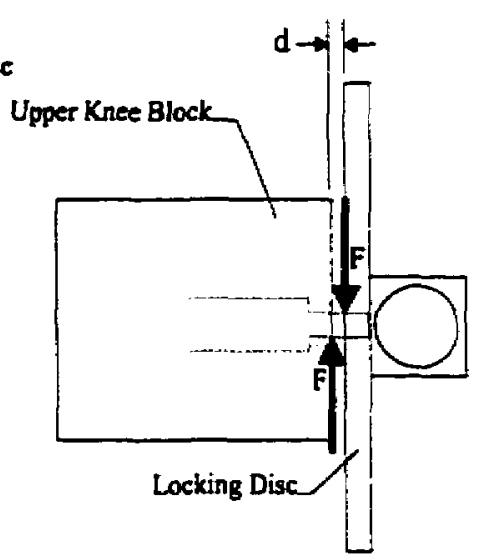

BOTTOM VIEW

(Solenoid and Solenoid Mounting Plate omitted)

Figure 2.25 - Locking pin loading diagram

Figure 2.25 shows the loading scenario of the locking pin. The pin is supported by the bushing and extends into one of the holes of the locking disc. Any force put on the foot will result in a torque at the knee which must be countered by the locking pin and disc. A gap of distance $d$ is located between the upper knee block and the locking disc to prevent the disc from rubbing against the upper knee block when it rotates. This distance is minimized to reduce the bending moment in the pin during loading, but must be sufficiently large to prevent rubbing. By using a teflon coated thrust washer between the disc and the upper knee block around the knee shaft, a clearance of $d=0.59 \mathrm{~mm}$ is obtained and disc rubbing is prevented. 
The distance between the knee shaft and the locking disc holes (and hence the locking pin) is taken as $R=59.0 \mathrm{~mm}$. This distance should be maximized to reduce the loading on the pin, but minimized to decrease the overall weight of the disc. It was decided to select the size of the disc based on reasonable proportions with respect to the rest of the robot and to design the size of the pin based on this selection.

The force on the pin during the worst case loading scenario can be calculated using the simple torque equation. The worst case scenario is a torque, $\tau$, of $127.4 \mathrm{Nm}$ (Section 2.3.2). Therefore, the force on the pin, $F$, can be calculated as follows (see Figure 2.25):

$$
F=\frac{\tau}{R}=\frac{127.4 \mathrm{Nm}}{0.059 \mathrm{~m}}=2160 \mathrm{~N}
$$

From Figure 2.25, it can be seen that the part of the locking pin that extends into the locking disc experiences both a shear stress and a bending moment due to the force $F$. The locking pin is made of steel. A lower bound for the tensile strength of steel is 300 MPa [41]. Furthermore, a common standard for the yield strength in shear is 0.6 times the tensile strength [41]. Using this relation, a lower bound for the yield strength in shear for steel can be calculated as:

Shear yield strength $=0.6 \cdot$ tensile strength $=0.6 \cdot 300 \mathrm{MPa}=180 \mathrm{MPa}$

Furthermore, in bending, the largest stresses of a shaft are tensile and compressive stresses experienced at the largest radius away from the centre. Since steel is much stronger in compression than in tension, the yield limit in bending for the pin is the tensile strength, $300 \mathrm{MPa}$.

To minimize the angular distance between successive holes on the locking disc, the diameter of the locking pin must be minimized. It was initially desired to permit the knee to lock every $5^{\circ}$, which corresponds to a pin diameter of $3.175 \mathrm{~mm}(\mathrm{l} / 8$ "). Please note that this dimension had to be chosen so that a corresponding bushing could be purchased. The bushings can be bought in standard imperial increments of 1/8", 1/4", 1/2", etc.... 
The cross-sectional area for a pin with a diameter of $3.175 \mathrm{~mm}$ is $7.9 \times 10^{-6} \mathrm{~m}^{2}$. The shear stress, $\sigma_{\text {shear }}$ is calculated as:

$$
\sigma_{\text {shear }}=\frac{F}{A}=\frac{2160 \mathrm{~N}}{7.9 \times 10^{-6} \mathrm{~m}^{2}}=273.4 \mathrm{MPa}
$$

This is above the $180 \mathrm{MPa}$ limit of equation (2.5), and so this diameter is too small. The next diameter chosen was $6.35 \mathrm{~mm}(1 / 4 ")$, which corresponds to the knee locking every $10^{\circ}$. Its area is $3.17 \times 10^{-5} \mathrm{~m}^{2}$. The shear stress is calculated again as:

$$
\sigma_{\text {shear }}=\frac{F}{A}=\frac{2160 \mathrm{~N}}{3.17 \times 10^{-5} \mathrm{~m}^{2}}=68.1 \mathrm{MPa}
$$

This is well below the $180 \mathrm{MPa}$ shear stress limit. The tensile stress due to bending is now checked. The moment, $M$, in the pin can be calculated as:

$$
M=F \cdot d=(2160 \mathrm{~N})(0.00059 \mathrm{~m})=1.27 \mathrm{Nm}
$$

The bending tension stress, $\sigma_{\text {bending, }}$ is calculated as:

$$
\sigma_{\text {bending }}=\frac{M \cdot \text { pin radius }}{I}
$$

where I is the cross-section inertia of the pin. For a cylinder, the inertia is calculated as:

$$
I=\frac{\pi(\text { pin diameter })^{4}}{64}=\frac{\pi\left(6.35 \times 10^{-3} \mathrm{~m}\right)^{4}}{64}=8.0 \times 10^{-11} \mathrm{~m}^{4}
$$

Finally, the moment, radius, and inertia are substituted into (2.9) to determine the tensile stress due to bending:

$$
\sigma_{\text {bending }}=\frac{1.27 \mathrm{Nm} \cdot 3.175 \times 10^{-3} \mathrm{~m}}{8.0 \times 10^{-11} \mathrm{~m}^{4}}=50.4 \mathrm{MPa}
$$

The bending stress is below the tensile strength of steel of $300 \mathrm{MPa}$, and consequently, a pin diameter of $6.35 \mathrm{~mm}$ is sufficient to prevent plastic deformation. 
The stress on the locking disc was analyzed using the ProMechanica ${ }^{\mathrm{TM}}$ program of the ProEngineer ${ }^{\mathrm{TM}} \mathrm{CAD}$ package [37]. Of particular interest was minimizing the thickness of the disc to minimize its mass. Figure 2.26 show the results of four of the analyses performed. Two loading scenarios were considered, and two thicknesses were compared. Thicknesses of 1/8" and 3/16" were examined. These thicknesses were chosen because the stainless steel sheet that was used to fabricate the locking discs can be purchased in these sizes. Loads were separately considered at the top hole and a side hole. A force of $2160 \mathrm{~N}$ was used as the force input, as described in equation (2.4). The disc was held in place by placing no translation and no rotation constraints on the 8 mounting holes that surround the central hole. The results initially showed stress concentrations on the corners of the spokes closest to the centre of the disc. To reduce these, the radius at these corners was increased.

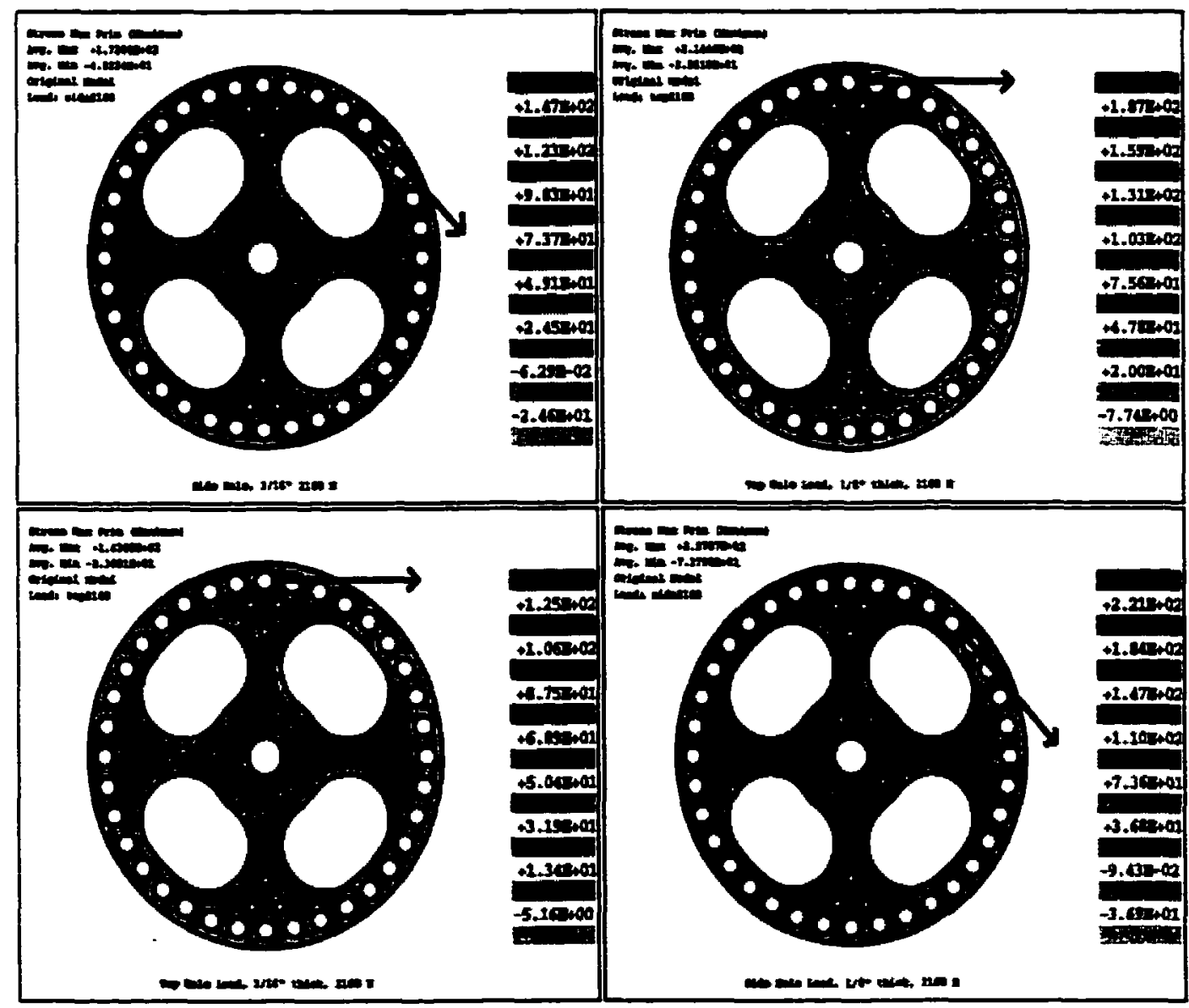

Figure 2.26 - Locking disc stress analysis from ProMechanica ${ }^{\text {TM }}$ 
The results from Figure 2.26 show that the largest maximum principal stresses occur in the side hole loading condition (see Table 2.6). Since the maximum stress for the $1 / 8$ " thick disc is quite close to the limit of $300 \mathrm{MPa}$, a thickness of $3 / 16$ " was used in the final design.

\begin{tabular}{|c|c|c|}
\hline & $1 / 8$ " Thickness & $3 / 16 "$ Thickness \\
\hline Side Hole Load of $2160 \mathrm{~N}$ & $258 \mathrm{MPa}$ & $172 \mathrm{MPa}$ \\
\hline Top Hole Load of $2160 \mathrm{~N}$ & $214 \mathrm{MPa}$ & $143 \mathrm{MPa}$ \\
\hline
\end{tabular}

Table 2.6 - Matrix of maximum principal stress for loading condition and thickness of locking disc

\subsubsection{Mechanical Properties of Knee}

This section will provide a summary of the mechanical properties of the knee, including the parts used, their masses, and the upper and lower leg inertias. Table 2.7 shows a list of all the parts used in the knee, the manufacturer or designer, the fasteners used, and all the masses. Please note that the mechanical drawings are provided in the Appendix. The total mass of one knee without the upper and lower legs is $1.3 \mathrm{~kg}$, somewhat above the $1.0 \mathrm{~kg}$ limit set in section 2.3.1. The added weight can be attributed to increasing the thickness of the locking disc as a result of the stress analysis in Section 2.5.2 and to an initial underestimate of the weight of the upper knee block. Nevertheless, simulations in Chapter 3 show that the hip actuators can handle the additional weight, and so the design was not modified any further to reduce more weight.

Using the modeling features of ProEngineer ${ }^{\mathrm{TM}}$, the inertias and locations of the centres of mass of the upper and lower leg assemblies were determined. These values are needed for the analytical and simulation studies of Chapter 3. Please recall that the length of the upper leg can change (Figure 2.12), which in turn changes the inertia and the location of the centre of mass. Three configurations were analyzed, corresponding to leg lengths of $0.1,0.15$, and 0.2 metres. Table 2.8 and Table 2.9 show these results. 


\begin{tabular}{|c|c|c|c|c|c|c|c|c|c|}
\hline Part & Manufacturet & Part * & Mat. & Mass & QTY & $\begin{array}{l}\text { Fasteners for } \\
\text { mounting surfaces }\end{array}$ & $\begin{array}{l}\text { Mass } \\
\text { I fsinr }\end{array}$ & $\begin{array}{c}\text { QTY } \\
\text { fstarknee }\end{array}$ & $\begin{array}{l}\text { Mass (g) Unit } \\
\text { system (one knee) }\end{array}$ \\
\hline $\begin{array}{l}\text { Leg Mount } \\
\text { Cylinder }\end{array}$ & GH & PK04 & $\mathbf{A}$ & 7.98 & 12 & & & & 23.94 \\
\hline \multirow[t]{4}{*}{$\begin{array}{l}\text { Upper Knee } \\
\text { Block }\end{array}$} & GH & PK09 & $\mathbf{A}$ & 289.6 & 4 & MB $\times 30 \mathrm{~mm} \mathrm{Hex} \mathrm{CS}$ & 2219 & 4 & 313.028904 \\
\hline & & & & & & M3 washer & 0.119 & 4 & \\
\hline & & & & & & MS $x 16 \mathrm{~mm} \mathrm{Hex} \mathrm{CS}$ & 4.250 & 3 & \\
\hline & & & & & & MS wasther & 0.442 & 3 & \\
\hline \multirow[t]{2}{*}{ Knee Shaft } & GH & PK02 & S-less: & 48.8 & 4 & MS x I 2 mm Hex CS & 3.6 & I) & 52.842 \\
\hline & & & & & & MS large washer & 0.442 & 1 & \\
\hline \multirow[t]{3}{*}{$\begin{array}{l}\text { Locking } \\
\text { Disc }\end{array}$} & GH & PK08 & S-less: & 212.7 & 4 & M3 x $10 \mathrm{~mm} \mathrm{Hex} \mathrm{CS}$ & 1.1 & 8 & 236.5 \\
\hline & & & & & & M4 x $10 \mathrm{~mm}$ Hex CS & 2.2 & 6 & \\
\hline & & & & & & M4 Washer & 0.3 & 6) & \\
\hline \begin{tabular}{|l|} 
Lower \\
Knee Block
\end{tabular} & GH & PKDI & Al & 35.1 & 4 & MS $\times 6 \operatorname{mm} 5 S$ & 0.9 & 1 & 36 \\
\hline \begin{tabular}{|l|} 
Dormeyer \\
Plunger
\end{tabular} & GH & PKO3 & \begin{tabular}{|l|} 
Zinc \\
Pl. \\
Steel
\end{tabular} & 41.1 & 4 & & & & \\
\hline $\begin{array}{l}\text { Dormeyer } \\
\text { Sol. Mitg. } \\
\text { Plare }\end{array}$ & GH & PK06 & Al & 16 & & $\begin{array}{l}\text { M4 } \times 8 \mathrm{~mm} \text { Hex } \\
\text { CSUNK }\end{array}$ & 1) & 2 & 18 \\
\hline \multirow[t]{2}{*}{$\begin{array}{l}\text { Knee Foor } \\
\text { Mount } \\
\end{array}$} & GH & PKOS & AI & 29.2 & 8 & MS $\times 16 \mathrm{~mm}$ Hex CS & 4.250 & 3 & 86.552 \\
\hline & & & & & & M5 washer & 0.442 & 3 & \\
\hline $\begin{array}{l}\text { Knee Foot } \\
\text { Mount } \\
\text { Tube }\end{array}$ & GH & PKIO & Steel & 21.8 & 4 & $\mathrm{M} 3 \times 6 \mathrm{mmSS}$ & 0.3 & 4 & 23 \\
\hline \multirow[t]{2}{*}{$\begin{array}{l}\text { Knee Po } \\
\text { Plate }\end{array}$} & GH & PK07 & $\mathbf{A}$ & 8.7 & 4 & M2.5 $\times 5 \mathrm{~mm} \mathrm{Hex} \mathrm{CS}$ & 0.5 & 2 & 9.7 \\
\hline & & & & & & MD.S washer & 0.1 & 2 & 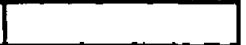 \\
\hline Lower Leg & GH & PK12 & Stexl & 89.8 & 4 & M3 x 6 mn SS & 0.3 & 4 & 107.76 \\
\hline Upper Leg & $\overline{G H}$ & PKII & Steel & 265 & 4 & $\mathrm{M} 3 \times 6 \mathrm{~mm}$ SS & 0.3 & 2 & 265.6 \\
\hline Foot & $\mathbf{R B}$ & SCII-017-A & $\mathbf{A}$ & 37.7 & 8 & & & & 301.6 \\
\hline $\begin{array}{l}\text { Dormeyer } \\
\text { Solenoid }\end{array}$ & Donneyer & C34-2036 & & 163 & & $\begin{array}{l}10-32 \times 3 / 8 \text { inch } \\
\text { CSUNK }\end{array}$ & 1.6 & 2 & 166.2 \\
\hline $\begin{array}{l}\text { Pin } \\
\text { Bushing }\end{array}$ & Garlock & 02DU03 & & 0.4 & 4 & & & & 0.4 \\
\hline $\begin{array}{l}\text { Shaft } \\
\text { Bushing }\end{array}$ & Garlock & 08FDU04 & & 3.8 & 8 & & & & 7.6 \\
\hline $\begin{array}{l}\text { Shaft } \\
\text { Thrust } \\
\text { Washer }\end{array}$ & Garlock & G06DU & & 3 & 4 & & & & 3 \\
\hline $\begin{array}{l}\text { Potentio- } \\
\text { meter }\end{array}$ & Midori & CP-2FK & & 12 & 4 & & & & 12 \\
\hline $\begin{array}{l}\text { Pot-Shaft } \\
\text { coupling }\end{array}$ & Helical & $\begin{array}{l}\text { ACR 050-4- } \\
4\end{array}$ & & 5 & 4. & & & 1) & 5 \\
\hline $\begin{array}{l}\text { Pot Plate } \\
\text { Spacer }\end{array}$ & MSC - Unicorp & 67710905 & $\begin{array}{l}\text { Zine } \\
\text { PR. } \\
\text { Steel } \\
\end{array}$ & 43 & 16 & & & 4 & 17.2 \\
\hline Toe & Pet Store & & & 23 & 8 & & & & 46 \\
\hline \multicolumn{2}{|c|}{ Mass I lunee with lew (0): } & 1731.92 & & & & & & & \\
\hline \multicolumn{2}{|c|}{ Maes 1 bnee no leos (o): } & 1316.42 & & & & & & & \\
\hline
\end{tabular}

Table 2.7 - Part numbers, quantities, and masses of knee 


\begin{tabular}{|l|c|c|}
\hline \multicolumn{3}{|l|}{$\begin{array}{l}\text { Upper Leg Assembly: } \\
\text { upper leg, upper knee assembly, upper knee box - see Figure 2.13 }\end{array}$} \\
\hline & $\begin{array}{c}\text { Inertia about } \\
\text { Centre of Mass } \\
\left(\mathrm{kg} \cdot \mathrm{m}^{2}\right)\end{array}$ & $\begin{array}{c}\text { Centre of Mass Offset } \\
\text { (down from hip joint) } \\
(\mathrm{m})\end{array}$ \\
\hline Length $=0.1 \mathrm{~m}$ & 0.0124 & 0.0585 \\
\hline Length $=0.15 \mathrm{~m}$ & 0.0135 & 0.103 \\
\hline Length $=0.2 \mathrm{~m}$ & 0.0151 & 0.148 \\
\hline Mass $(\mathrm{kg})$ & & 1.03 \\
\hline
\end{tabular}

Table 2.8 - Lengths, inertias, and centres of mass of upper leg assembly

Lower Leg Assembly: lower leg, lower knee assembly- see Figure 2.18

\begin{tabular}{|c|c|c|c|}
\hline Mass (kg) & Length (m) & $\begin{array}{c}\text { Inertia about Centre of Mass } \\
\left(\mathrm{kg} \cdot \mathrm{m}^{2}\right)\end{array}$ & $\begin{array}{c}\text { Centre of Mass Offset } \\
\text { (down from knee joint) } \\
(\mathrm{m})\end{array}$ \\
\hline 0.782 & 0.2 & 0.006 & 0.0204 \\
\hline
\end{tabular}

Table 2.9 - Length, inertia, and centre of mass of lower leg assembly

\subsection{Electrical Design}

The two new electrical components of the knee design are the rotary potentiometers used to measure the knee angle, and the solenoids used to actuate the locking pins. This section will first discuss the use of the potentiometers, and then the electronics used to control and power the solenoids will be explained.

The decision to use precision potentiometers instead of encoders was two-fold. First of all, encoders are not precise enough when measuring the rotational output directly - they are usually mounted onto a motor shaft which is then geared, providing increased resolution in the angle sensing. In this case, it was simpler to attach the potentiometer directly to the knee shaft. Secondly, as described in Table 2.2, 13 of 16 inputs to the SPPSPI system are taken by other sensing needs, which leaves only three available inputs. This is not enough to provide the four encoder inputs needed for the four knees. However, four of the 13 used inputs are for the linear potentiometers for measuring the 
leg length in the compliant leg mode of Scout II. Since the upper legs are not compliant in the passive knee mode, the inputs for these potentiometers could be used. Since the linear potentiometers of the leg use exactly the same three connections as the rotary potentiometers ( 5 Volt power, signal, ground), it was a simple matter to use these inputs for the knee angle sensing. The potentiometers used are made by the Midori Company, part number CP-2FK (Figure 2.27) [33].

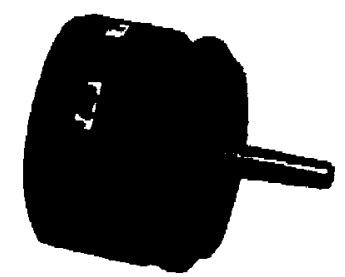

Figure $2.27 \cdot$ Midoro CP-2FK potentiometer

As discussed in Section 2.4.3, the solenoids used are magnetically latching. They require short bi-directional current pulses to lock and to unlock them. Furthermore, control signals must be sent to indicate the enabling time, and the current direction. H-Bridge circuits are well suited for this task. They are composed of four transitors set up in a bridge. By turning on and off opposite pairs of the transistors, bi-directional current flow can be achieved. Often, diodes are placed in parallel with each transistor to protect against inductive loads.

Figure 2.28 shows a schematic of an $\mathrm{H}$-Bridge circuit. If transistors $\mathrm{A}$ and $\mathrm{D}$ are turned on, and $B$ and $C$ are turned off, the current will travel through the solenoid from left to right, along Path $A D$. Similarly, if transistors $B$ and $C$ are turned on, and $A$ and $D$ are turned off, current will flow through the solenoid from right to left. By controlling the switching on and off of the transistors, current can flow in either direction through the solenoid.

Many H-Bridge circuits can be bought as small chips. A search was done to find an appropriate H-Bridge chip that met the following characteristics. First of all, the maximum voltage available on the robot is 24 Volts. Since the linear force in the 
solenoid is maximized with increasing current (and hence increasing voltage), the chip had to be rated to at least 24 Volts. Second, it had to have digital control inputs for both the direction of the current flow, and for turning the current on and off. The latter is required because the goal of using the latching solenoids is to turn the current off when the solenoid is in either of its extreme positions, thereby reducing the power consumption of the knee.

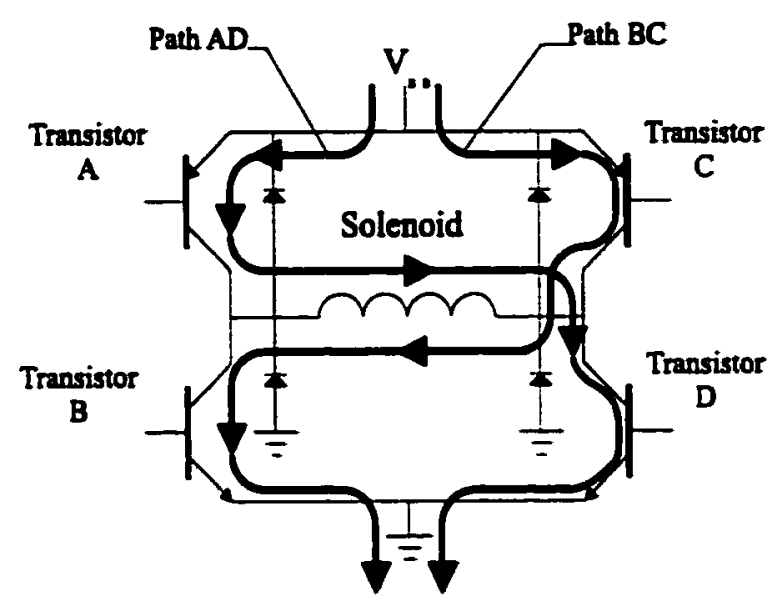

Figure 2.28 - H-Bridge schematic

The Allegro 2917 dual full bridge PWM motor driver fit all of the required specifications [3]. It houses two H-Bridge circuits in one chip, and has enable (current on) and phase (direction) inputs. It also has PWM inputs for motor speed control, but in this case, the PWM input was simply tied to a logic high for a maximum current output. The chip itself fits into a PLCC socket which makes it very convenient to replace the chips should they become damaged.

Since each chip has two H-Bridge circuits, and since there are four solenoids that need to be controlled, a circuit was designed and built around two of the chips. A schematic of the circuit is provided with Figure 2.29. The whole circuit is powered by one 24 Volt input, which is taken directly from the on-board batteries of the robot. Two 7805 voltage regulators provide the 5 Volt references need for each chip. The phase and enable signals 
are provided from an RCIO Module operating in the digital output mode, which in turn is connected to the SPPSPI (Section 2.2.2). Please recall that each RCIO module can provide 10 digital output signals: each knee requires one phase and one enable signal for a total of 8 digital output signals, hence only one RCIO module is needed.

The RCIO module is protected with an optical isolator. Consequently, the output side of the module requires a 5 Volt source for it to operate. Pull-up resistors were added between the output of the 7805 regulator and the outputs to solve this problem.

Figure 2.30 shows the pin out map of the actual circuit board, and an isometric view rendered in ProEngineer $^{\mathrm{TM}}$. It is a relatively small circuit board $(94.0 \mathrm{~mm}$ long, $71.0 \mathrm{~mm}$ wide, and $30.0 \mathrm{~mm}$ deep) and the only connections it has with the existing electronics of the robot are the 24 Volt power and the connections to the RCIO module. It was positioned inside the protective frame of the robot to protect it in case the robot fell during operation. Figure 2.31 and Figure 2.32 show isometric and top views of the $\mathrm{H}$ Bridge circuit, and Figure 2.31 shows the H-Bridge circuit with the RCIO module mounted on top.

\subsection{Summary}

The mechanical and electrical systems of the Scout II quadruped were discussed, and were used as motivation for the design of a passive knee for the robot. The requirements and the design of the knee were presented, and a stress analysis was performed. The electrical systems used for its control were also explained. Ultimately, the mechanical and electrical designs were buitt and used to implement various walking controllers on the Scout II quadruped at ARL. The design was a success - successful walking was achieved with no mechanical or electrical failures. Furthermore, all of the design objectives were met, which opens the door for further experimentation and research into a variety of related topics. 


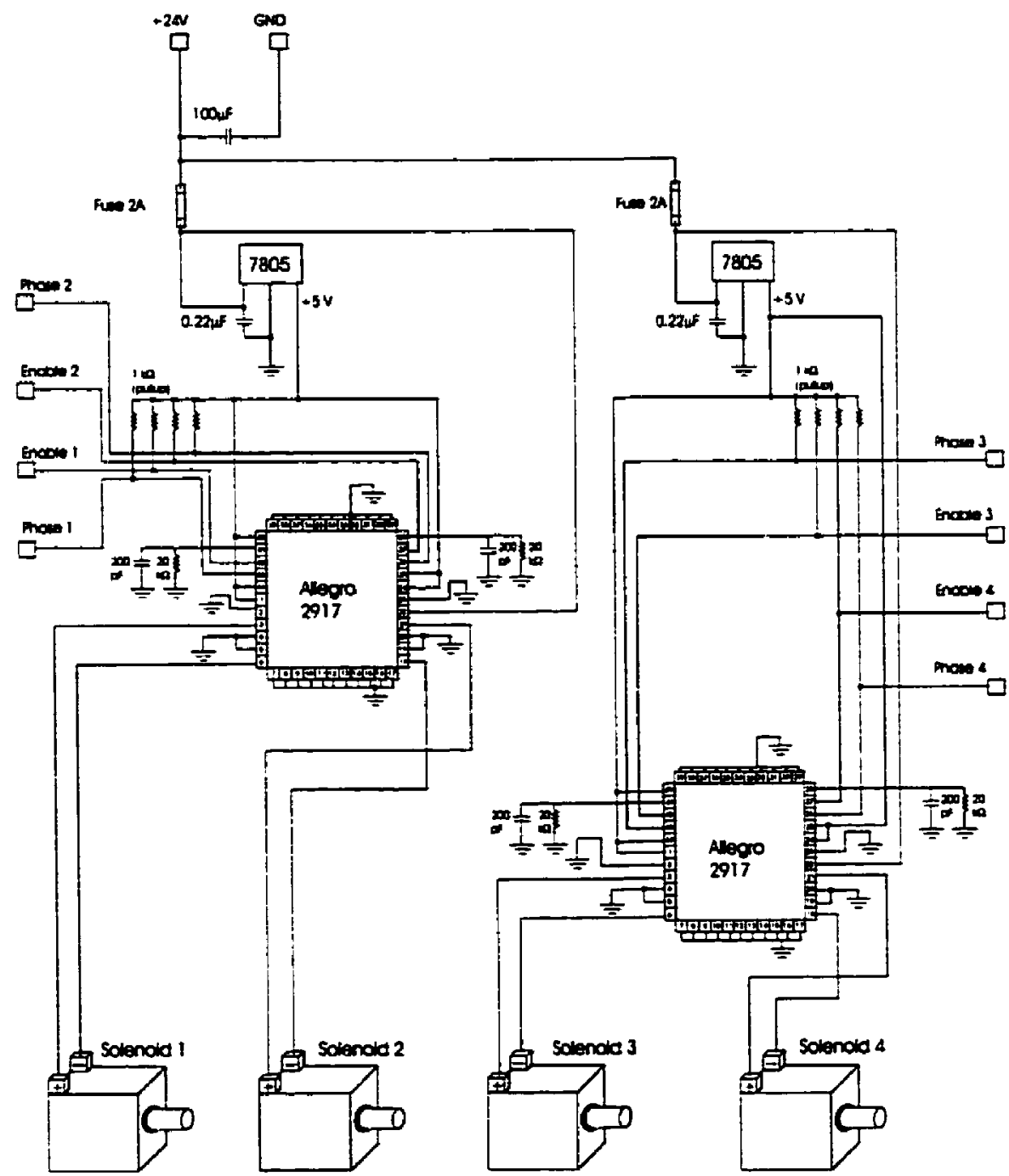

Figure 229 - Circuit diagram of H-Bridge solenoid circuit 

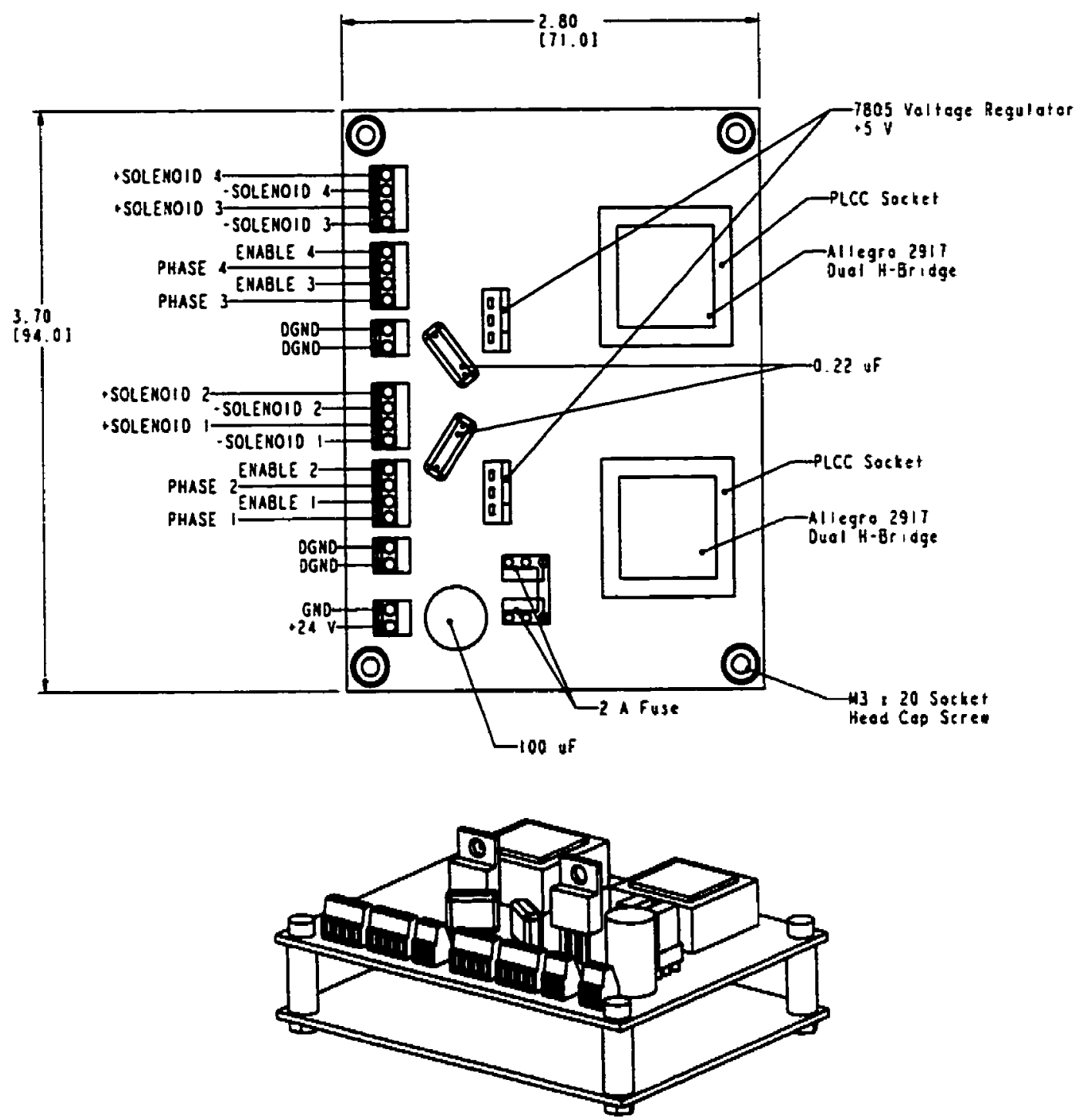

Figure 2.30 - Pin out and dimensions of H-Bridge solenoid circuit (Inches [mm]) 


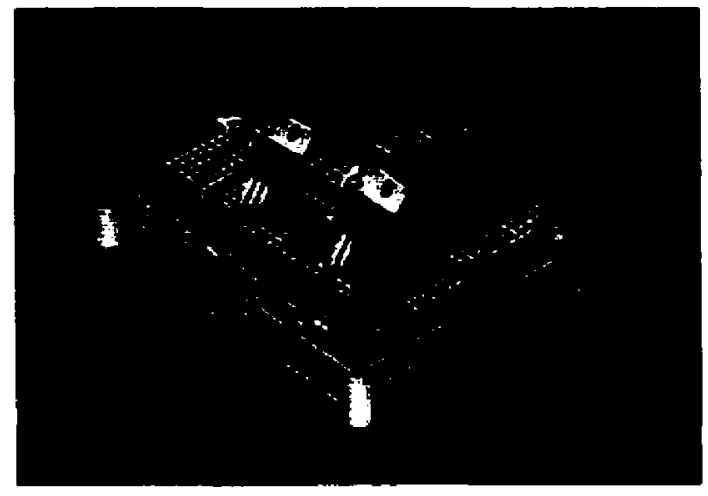

Figure 2.31 - H-Bridge circuit isometric view

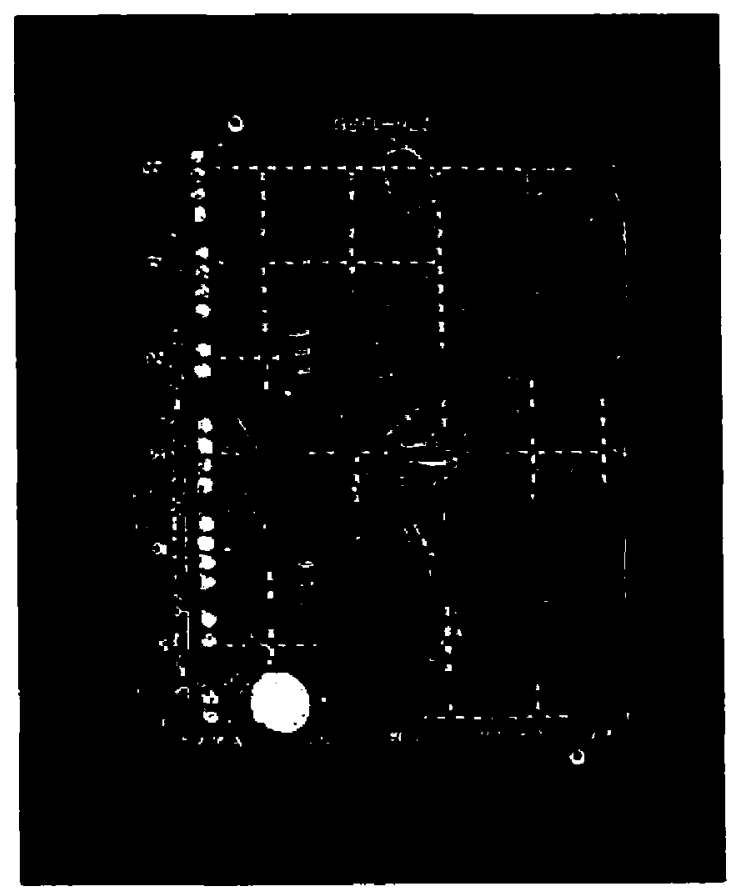

Figure 2.32 - H-Bridge circuit top view 


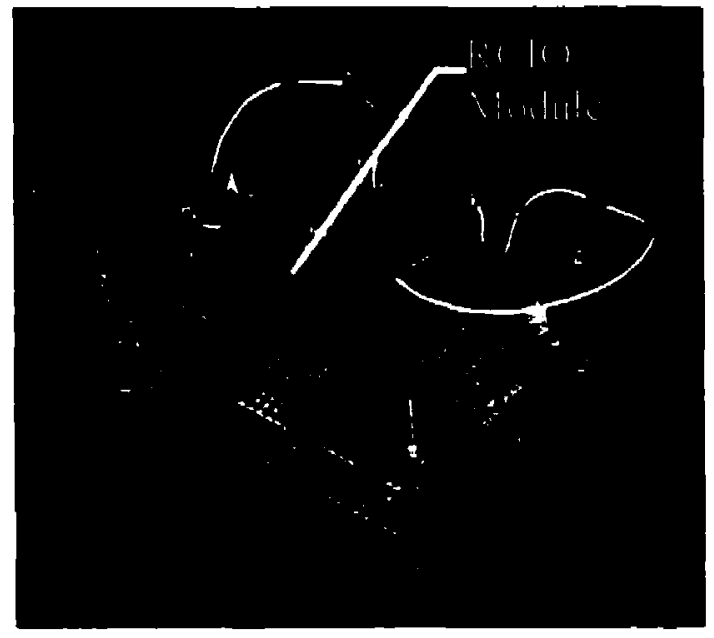

Figure 2.33 -H-Bridge circuit with RClO module mounted on top 


\section{Chapter 3 Analysis}

\subsection{Overview}

As described in the introduction, the goal of adding passive knees to the Scout II robot is to enable new walking behaviours which could not be achieved with the previous leg configurations.

Prior to the current research, the Scout II robot operated without knees. Its legs were operated in one of two modes. The first is the rigid mode, in which the legs are a fixed length. The second is the compliant mode, in which the legs have an additional unactuated, spring-loaded linear joint. In both cases, the bound is the primary gait which has successfully been achieved. Please refer to Chapter I for a more detailed discussion of the bound gait of the Scout class of robots, and to Chapter 2 for a detailed discussion of the mechanical characteristics of the Scout II robot.

Characteristic of both the rigid and the compliant bound is that there is significant pitching of the robot and there are somewhat severe impacts with the ground at each step (Figure 1.5). For these reasons, and to explore new behaviours, unactuated knees are added for this research.

In this research, the trotting gait is examined. Figure 3.1 shows a gait diagram of the trot. The trot is defined as the gait in which the front-right and the rear-left legs are in ground contact while the others swing forward, and vice versa. When a leg pair is in ground contact (front-right/rear-left or front-left/rear-right), it is said to be in the support state. When a leg pair is in the air, it is said to be in the swing phase or state. During a trot, the knees are used to shorten the overall leg length of the swing-legs so that their toes do not 
hit the ground (stub) while they swing forward. In addition, the swing legs must have the appropriate final positive angle with respect to the vertical immediately prior to touchdown to permit the legs to switch states - in the case of the swing legs, from the swing stare to the support state. During the leg swing, the support-leg knees are locked in the
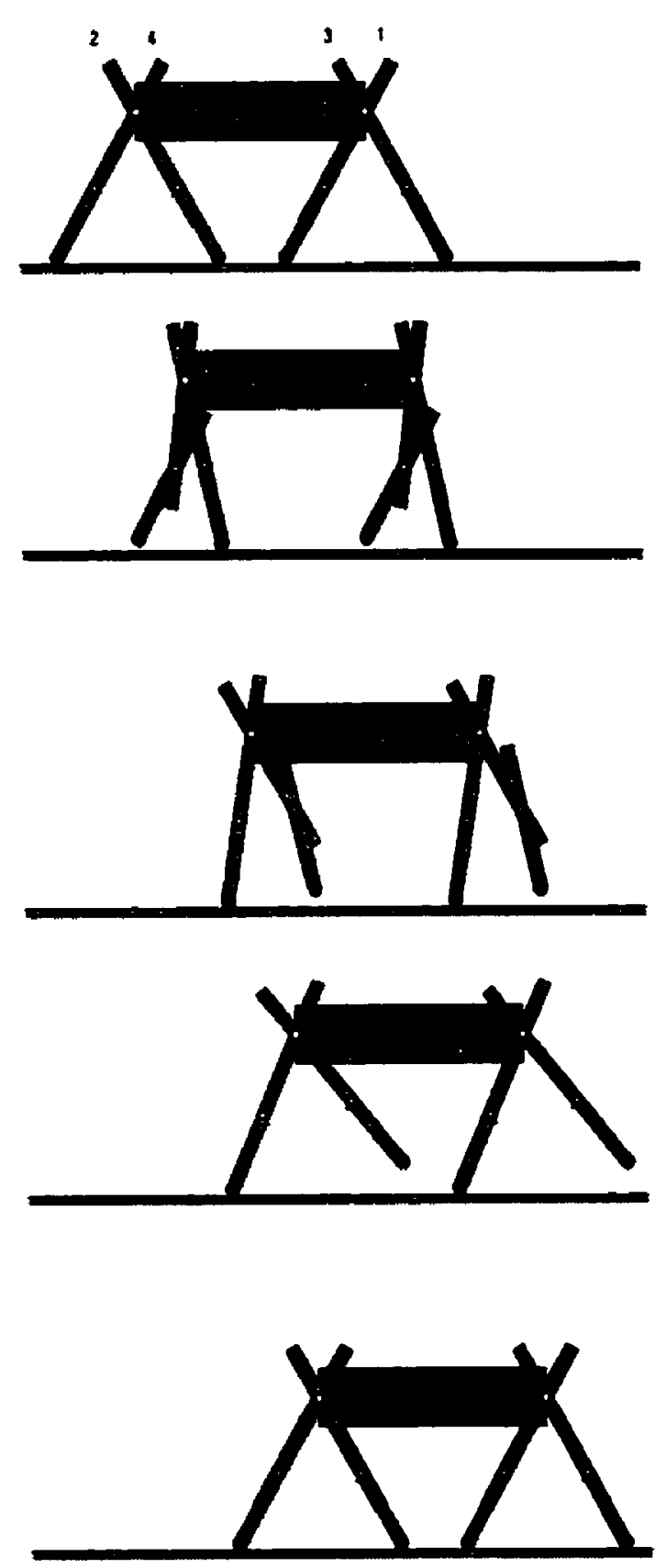

\section{State 11 \\ - Legs 2 and 3 are support legs \\ - Knees 1 and 4 are unlocked}

- Legs 2 and 3 sweep towards rear of robot propelling it forward

- Upper legs 1 and 4 sweep towards front of robot

- Knees 3 and 4 deflect lower legs 3 and 4 back to raise toe above ground

- Legs 2 and 3 continue to sweep toward rear of robot

- Once the ground has been cleared by legs 1 and 4, knees 1 and 4 straighten legs

\section{State 12}

- Legs 2 and 3 continue to sweep toward rear of robot

- Once lower legs 1 and 4 are in line with their upper legs, knees 1 and 4 lock, and legs 1 and 4 sweep to desired touchdown angle

State 21

- Once legs 1 and 4 touch down, knees 2 and 3 unlock, and the cycle repeats with exchanged roles for leg pairs 1-4 and 2-3

- State 22 is the equivalent of state 12 with switched leg pairs

Figure 3.1 - General trot gait states for Scout II robot - robot moves from left to right 
zero angle position with respect to the upper legs, and the support-legs sweep from some positive angle with respect to the vertical to a negative angle, thereby moving the body forward. After swing-leg touchdown, the legs change state and the cycle continues.

By comparing the bound and the trot gaits of Figure 1.5 and Figure 3.1 respectively, it can be seen that knees are required for trotting. In the case of the current research, the knees are unactuated. The knee angle is affected only by natural dynamics, resulting from gravity, inertia, body motion, and upper leg motion. Unactuated knees are investigated because of the reduction in weight and mechanical complexity that the elimination of an actuator provides. Furthermore, by reducing the weight and by not having an actuator, the battery life of the robot is increased. Please refer to Chapter 2 for a detailed discussion of the motivation of using passive knees, and of the passive knee design used in this research.

The goal of this analysis is to develop an algorithm that adequately controls the swing-leg from some negative angle to an appropriate positive angle during the cycle time, while achieving toe clearance. In Section 3.2, the nomenclature of the models studied is discussed, and Sections 3.3 and 3.4 present the leg trajectories for the trotting gait. A model of a single leg-knee system is developed in Section 3.5, and certain model assumptions are verified in Section 3.6. The equations of motion of this model are developed in Section 3.7, and they are verified in Section 3.8. This model is used to search through trajectory and geometric variables to determine optimal configurations for passive-knee trotting for a step-trot in Sections 3.9 and 3.11, and these configurations are simulated in Sections 3.10 and 3.12. A controlled velocity trot is studied in Section 3.13 and simulated in Section 3.14.

\subsection{Nomenclature}

Figure 2.11 shows the drawing of the complete Scout II robot, as rendered in the ProEngineer ${ }^{\mathrm{TM}}$ CAD package, with the leg numbers defined. In the simulation and the 
analysis, the robot was treated as being planar in the direction of motion. Figure 3.2 shows the planar model and Table 3.1 describes the nomenclature used throughout the simulation, the implementation, and the analysis. In Figure 3.2, legs 3 and 4 are omitted for clarity.

\subsection{Trotting Algorithm: Support-Leg Trajectories}

It is the motion of the support-legs that move the body. To propel the body forward, the support-legs must sweep from a positive $\phi$ angle to a negative one, but the trajectories that they follow can vary. In reference to Figure 3.1, the support legs are legs 2 and 3 during states 11 and 12 , and legs $I$ and 4 during states 21 and 22. Two different supportleg trajectories are examined for the trot gait of the passive knee quadruped system: stepping and controlled forward velocity.

\subsubsection{Stepping Support-Leg Trajectory}

In this trajectory, the support legs follow a cosine type trajectory with zero initial and final angular velocity. The leg starts at a positive angle, $\phi_{0}$, and ends at a negative angle, $\phi_{f}$, after some time $t_{f}$. This is referred to as stepping because the body comes to rest at the beginning and end of each cycle. Consequently, it could be used to move forward one step at a time. Figure 3.3 shows this type of trajectory. It is defined by the following equations:

$$
\begin{gathered}
\phi_{\text {sup }}(t)=\frac{\left(\phi_{0}+\phi_{f}\right)}{2}+\frac{\left(\phi_{0}-\phi_{f}\right)}{2} \cos \left(\frac{\pi}{t_{f}} t\right) \\
\dot{\phi}_{\text {spp }}(t)=-\left(\frac{\pi}{t_{f}}\right) \frac{\left(\phi_{0}-\phi_{f}\right)}{2} \sin \left(\frac{\pi}{t_{f}} t\right)
\end{gathered}
$$

where $t$ is the time from the start of the trajectory. 


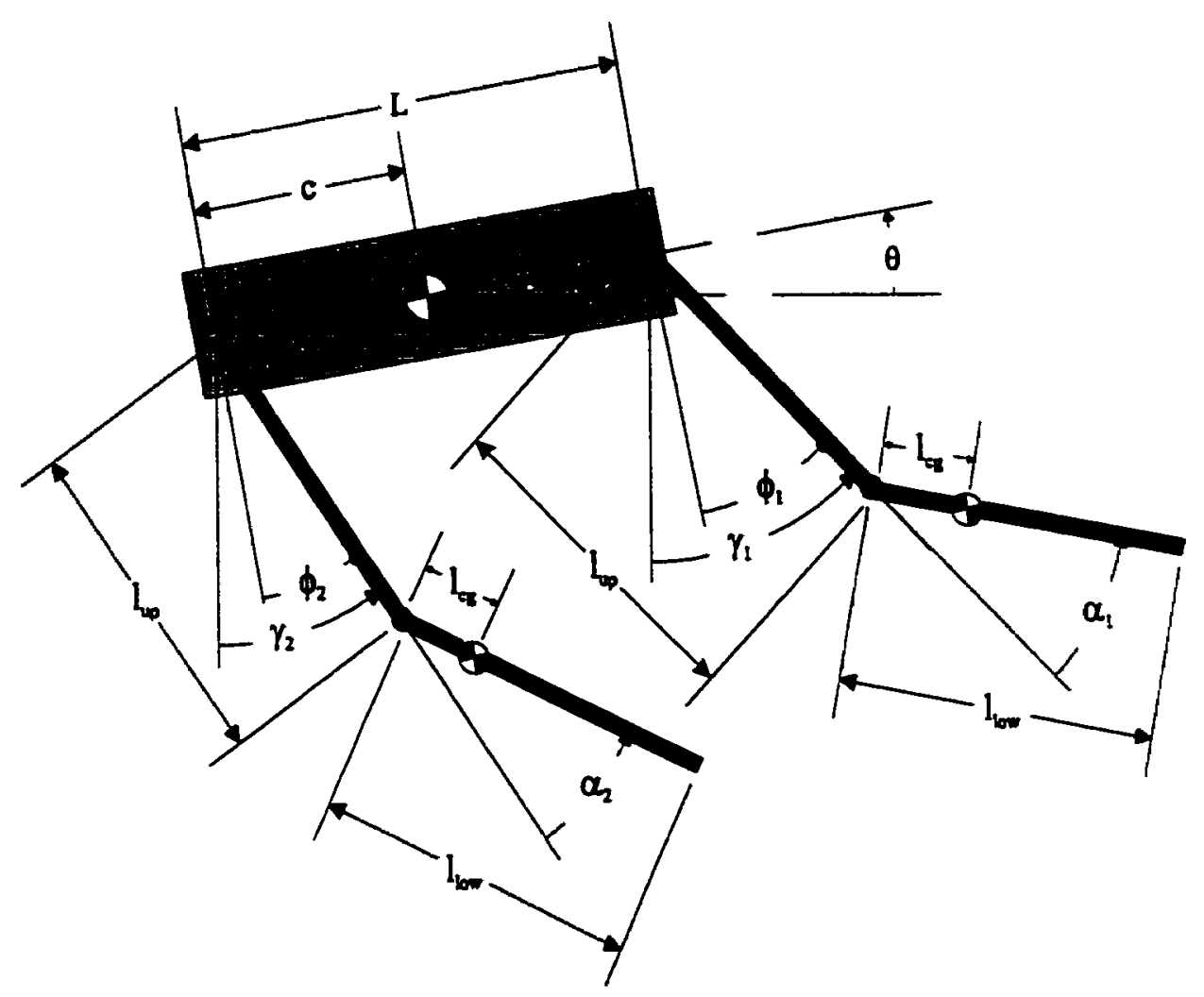

Figure 3.2 - Planar model of Scout II (legs 3 and 4 omitted)

\begin{tabular}{|c|c|}
\hline L: & Total body length \\
\hline c: & Distance of centre of mass from rear of robot \\
\hline lup: & Length of upper leg \\
\hline low: & Length of lower leg \\
\hline$I_{\text {eg: }}$ & $\begin{array}{l}\text { Distance of centre of mass of lower leg from the } \\
\text { knee }\end{array}$ \\
\hline$\theta:$ & Body pitch \\
\hline$\phi_{1,2,3,4:}$ & Upper leg angle with respect to the body \\
\hline$\gamma_{1,2,3,4:}$ & Upper leg angle with respect to the vertical \\
\hline$\alpha_{1,2,4:}$ & $\begin{array}{l}\text { Knee angle - angle of lower leg with respect to } \\
\text { upper leg }\end{array}$ \\
\hline
\end{tabular}

Table 3.1 - Pianar model nomenclature 


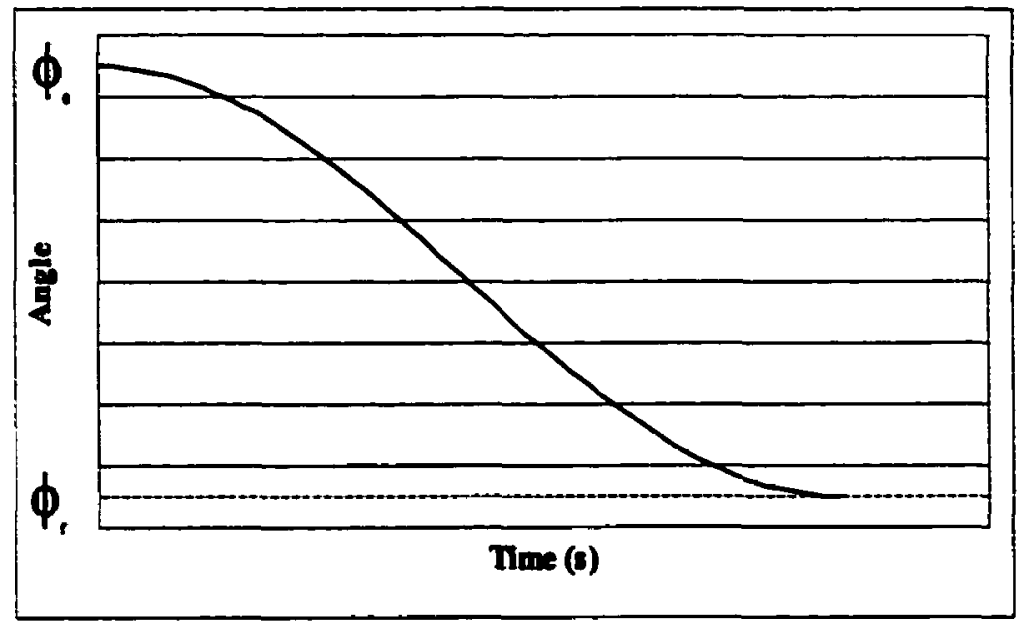

Figure 3.3 - Stepping support leg trajectory

\subsubsection{Controlled Forward Body Velocity Support-Leg Trajectory}

The problem with the stepping support leg trajectory of Section 3.3.1 is that the forward body velocity is not constant. In order to control the forward body velocity, the following trajectory was derived:

$$
\begin{gathered}
\phi_{\text {sup }}(t)=\sin ^{-1}\left\{\sin \phi_{0}-\left(\frac{v}{l_{\text {up }}+l_{\text {low }}}\right) t\right\} \\
\dot{\phi}_{\text {spp }}(t)=-\left[\frac{v}{\left(l_{\text {low }}+l_{\text {up }}\right)}\right] \frac{1}{\cos \phi_{\text {sup }}(t)}
\end{gathered}
$$

\subsection{Trotting Algorithm: Swing-Leg Trajectory}

The mechanical design of the knee permits it to be locked every ten degrees (including the zero degree, straight position), or to rotate freely under the influence of gravity and other dynamical effects. The leg will be in the zero angle position at the start and the end 
of each swing cycle. At the start of the swing cycle, the knee will be unlocked and the leg will be free swinging. Arai and Tachi [6] [7] studied this type of system, but in the absence of gravity, and developed a control approach which involved locking the knee at some angle, swinging the upper limb to provide both limbs with some angular velocity (momentum), and then releasing the brake to get the lower limb to swing into position. Although Arai had good success with this approach, it was difficult to mimic in this situation because the knee has to start at zero degrees.

A simpler approach is used in this research. The upper leg angle is controlled using feedback on the knee angle, with the desired knee angle ( $\left.\alpha_{\text {desired }}\right)$ being a cosine-type curve with initial and final angular velocities of zero, and a maximum negative value $\left(\alpha_{a m p}\right)$ at some point $\left(T_{\text {amp, }}\right)$ through its cycle, and with a cycle time of $T_{L S a}$. The knee angular velocity is set to zero at the start and end of each knee sweep trajectory to facilitate locking and unlocking. Chapter 2 describes the mechanical design of the passive knee locking mechanism. Since the locking mechanism is a solenoid plunger being pushed into holes on a locking disc, locking will be ensured if the knee angular velocity is zero or near-zero at the time of knee-lock. This trajectory is shown in Figure 3.4 , and is defined by the following equations:

$$
\begin{gathered}
\alpha(t)=\frac{\alpha_{a m p}}{2}-\frac{\alpha_{a m p}}{2} \cos \left(\frac{\pi}{T_{a m p, \alpha}} t\right) \quad 0<t<T_{a m p, \alpha} \\
\alpha(t)=\frac{\alpha_{\text {ump }}}{2}+\frac{\alpha_{\text {ump }}}{2} \cos \left(\frac{\pi}{\left(T_{L S \alpha}-T_{\text {amp. } \alpha}\right.}\left(t-T_{\text {amp, } \alpha}\right)\right) \quad T_{\text {amp, } \alpha}<t<T_{L S \alpha}
\end{gathered}
$$

When $T_{\text {amp, } \alpha}$ is one half of $T_{L S \alpha}$, this trajectory reduces to a simple cosine trajectory and is referred to as the alpha cosine trajectory. It can be described by the simpler equation:

$$
\alpha_{\text {desired }}(t)=\frac{\alpha_{\text {amp }}}{2}\left[1-\cos \left(\frac{2 \pi}{T_{L S \alpha}} t\right)\right]
$$

When the trajectory is taken as shown, with $T_{\text {amp.a }}$ not equal to one half of $T_{L S \alpha}$, it is referred to as the two-part cosine trajectory. 


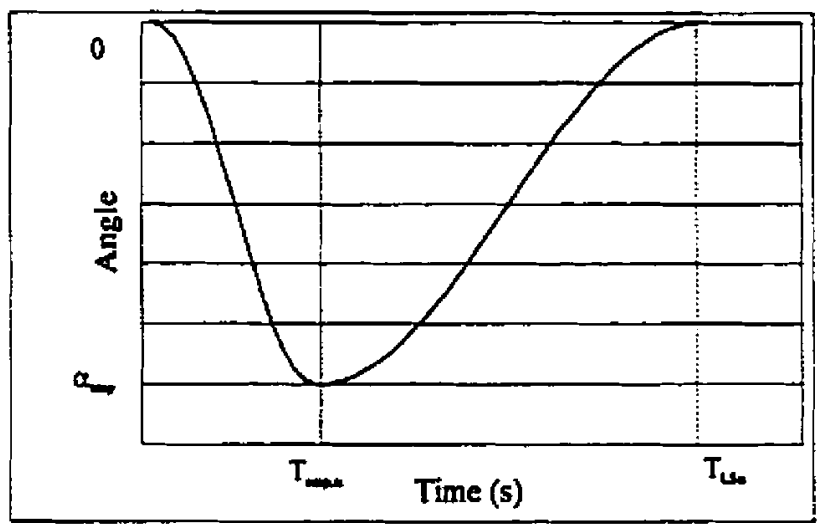

Figure 3.4 - Cosine-type swing-leg knee angle trajectory

This type of trajectory is similar to the trajectory that a human knee follows during the swing phase of a walking cycle. The knee bas a maximum negative value roughly halfway through its cycle ( $\left.\alpha_{a m p}\right)$, around the time that the support leg is perpendicular to the ground. Mochon and McMahon developed a model of human walking using anthropometric data which shows these types of trajectories [34]. Figure 3.5 shows some of their resuits. It can be seen that the knee $(K)$ reaches a maximum angle (their knee angle is the negative of the current definition), when the support-leg $(\theta)$ is near perpendicular, and that this is at roughly the midpoint of the cycle. An important difference between the cosine-type knee angle trajectory defined in (3.5), (3.6), and (3.7) is that in Mochon's model, the knee has a non-zero angle at toe-off.

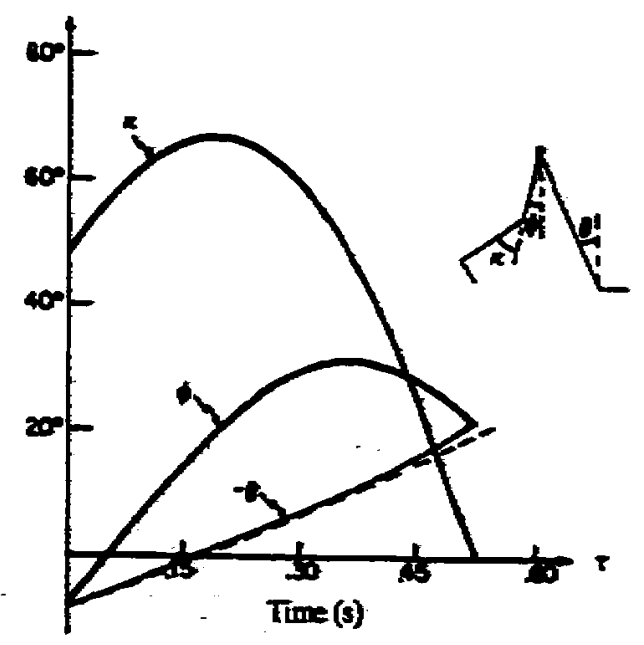

Figure 35 - Knee and thigh angles for a walking cycle of Mochon and McMahon's model [34] 
Since the distance from hip to toe is shortest at maximum knee angle, toe clearance is ensured as long as the upper swing-leg trajectory follows a roughly forward sweeping motion. Although it is impossible to actively control both the knee and the upper swingleg trajectories simultaneously, a theoretical analysis of the system in the following sections shows that with the appropriate selection of various geometric and trajectory parameters, the desired cosine-type knee angle trajectory can be achieved while having a forward sweeping upper swing-leg trajectory.

Since the upper swing-leg trajectory is not controllable during the unlocked knee phase, the knee trajectory cycle time is chosen to be only the first $75 \%$ of the support cycle time, thereby providing $25 \%$ of the cycle time to position the now locked swing-leg to the desired touchdown angle. In other words, the cycle time for the knee cosine trajectory, $T_{L S \alpha}$, is taken to be $75 \%$ of the total swing-leg cycle-time, $T_{L S}$.

\subsection{Single Swing-Leg Model}

As discussed in the introduction to this chapter, the primary problem with achieving trotting gaits is sweeping the swing-leg forward during the swing state without stubbing the toe. For this purpose, passive knees were added to the existing Scout II robot. To better understand the dynamics of the toe clearance problem, a simplified system of a single swing-leg is developed.

Figure 3.6 shows the single leg model, and Table 3.2 shows the nomenclature used. The goal of this model is to determine the swing leg toe height $\left(\mathrm{h}_{\mathrm{t}}\right)$ and the upper swing-leg angle trajectory ( $\left.\phi_{\text {free }}\right)$ for a given support-leg trajectory $\left(\phi_{\text {sup }}\right)$ and swing-leg knee angle trajectory $(\alpha)$ during a trot cycle. $\phi_{\text {sup }}$ is in turn defined by the type of trot being studied: either a step-trot or a controlled forward body velocity trot (refer to Section 3.3). $\phi_{\text {sup }}$ is 
also defined by the cycle time ( $T_{L S}$ - Time for $\mathrm{Leg}$ Swing) and the initial support-leg angle ( $\left.\phi^{\circ}{ }_{\text {sup }}\right)$. The following assumptions and simplifications were made:

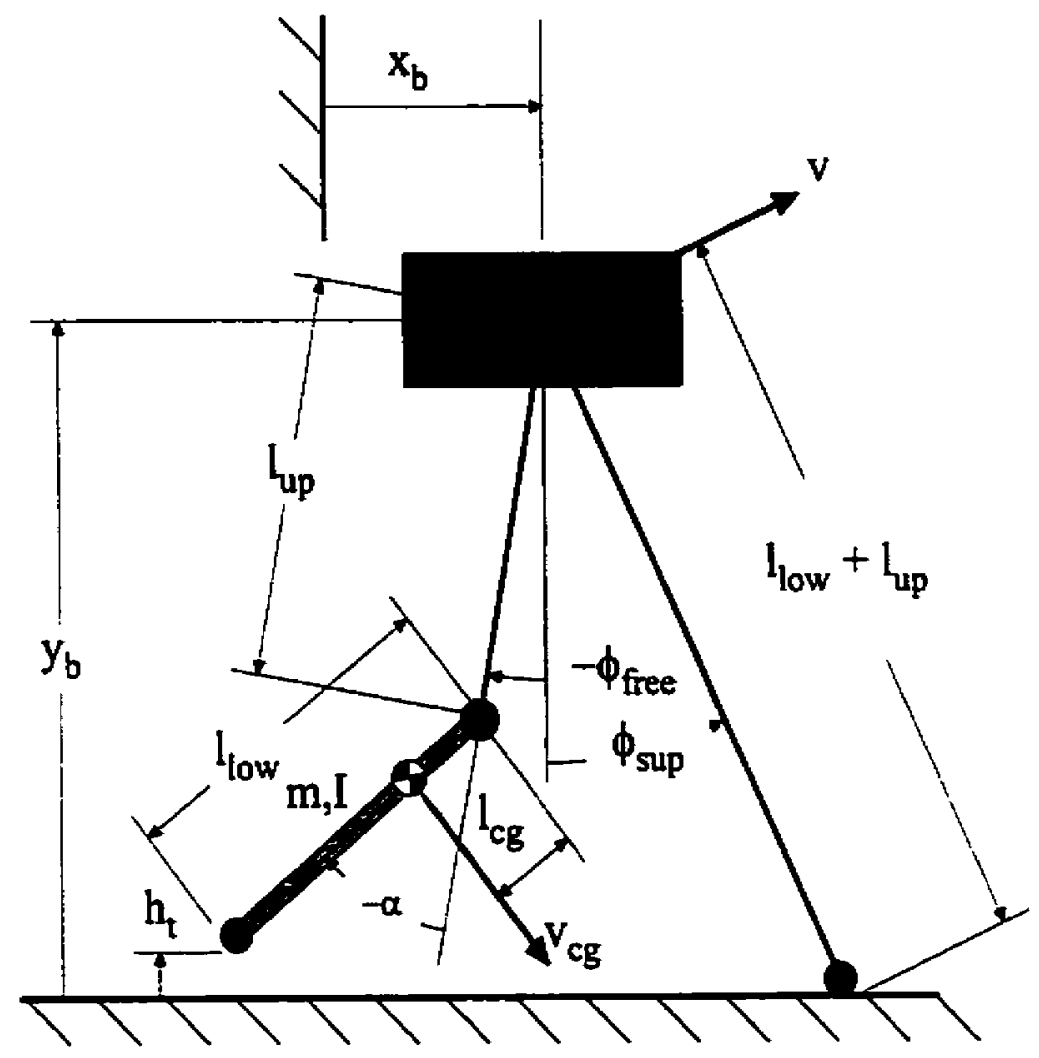

Figure 3.6 - Single leg model

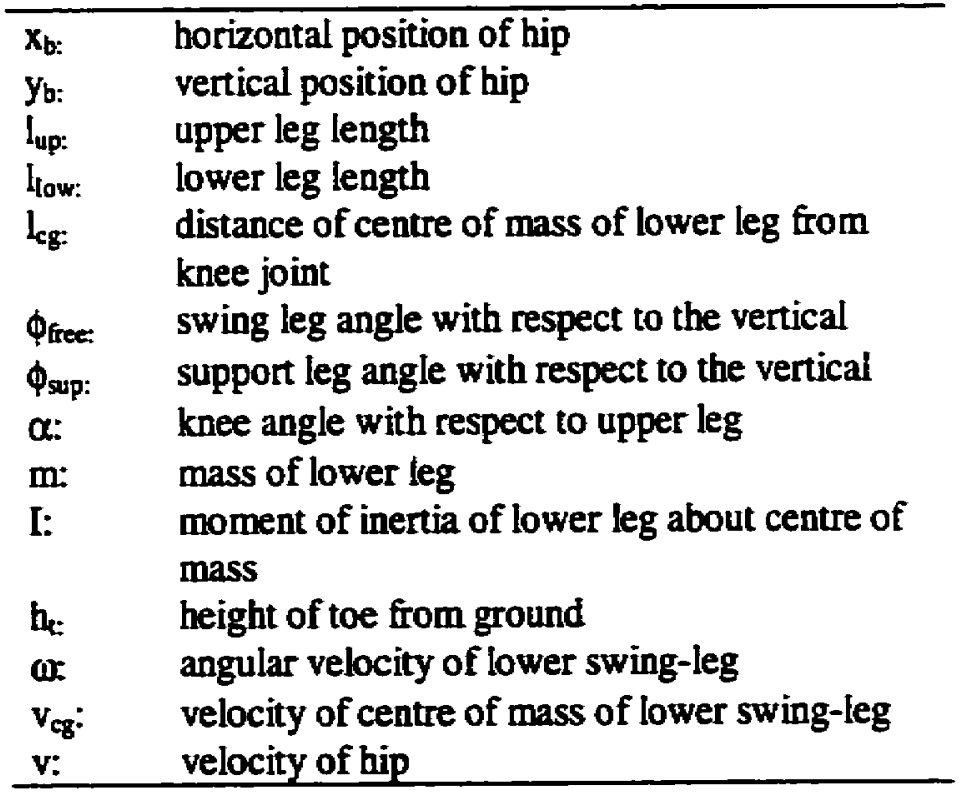

Table 32 - Single leg model nomenclature 
- The cartesian coordinates of the hip ( $x_{b}$ and $y_{b}$ ), and the swing-leg hip angle are assumed to be perfect inputs to the system. Through previous work at ARL, it was found that with a well-tuned PD torque controller, both support and swing-leg angles are very accurately controlled. In other words, it is assumed that the legs can track the desired reference trajectories during the support phase. The cartesian coordinates of the hip are defined as functions of the support-leg sweep trajectories $\left(\phi_{s p p}\right)$. By including these terms, the effect of the dynamics of the body motion on the lower leg can be accurately represented, and trot gaits with different support-leg trajectories can be examined.

- The upper swing-leg is rigid and massless. Again, because it is known that the hip motors can provide very accurate tracking, it is assumed that the upper swing-leg trajectory can be commanded at will.

- The friction in the knee joint is neglected.

- In the complete model system, there is a distinction made between the leg angle with respect to the vertical $\left(\gamma_{12,3,4}\right)$ and the leg angles perpendicular to the body $\left(\phi_{1,2,3,4}\right)$. From Figure 3.2, the following relation between the pitch $(\theta), \phi$, and $\gamma$ can be seen:

$$
y=\phi+\theta
$$

In the case of the trot, it is assumed that front and rear support-legs follow the same hip trajectories, which results in a constant pitch of zero degrees. Therefore, $\gamma$ will equal $\phi$. Since it is the hip angle, $\phi$, which is actuated on the robot, it was decided to use this parameter in the single-leg analysis and simulation to most closely mimic the real system, despite the fact that in the presence of a non-zero pitch, it is $\gamma$ which should be used to evaluate the potential energy term of the Lagrangian. 


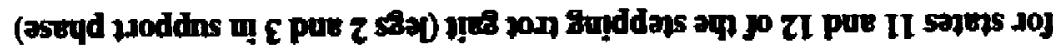

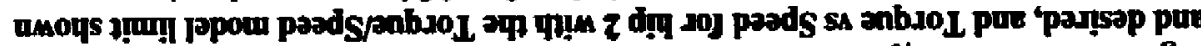

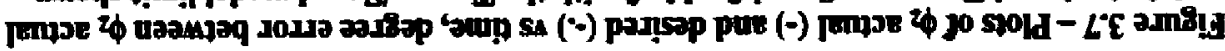

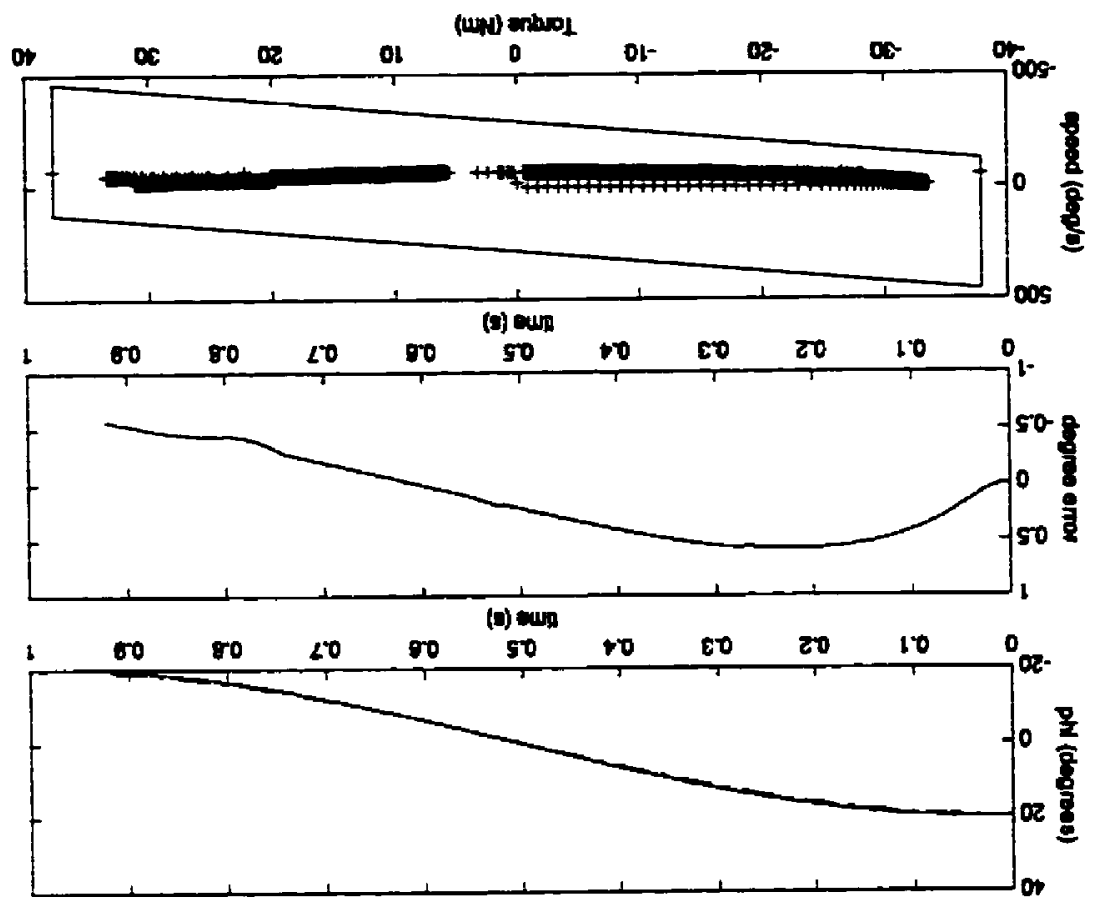

-uo!̣ejnun!s

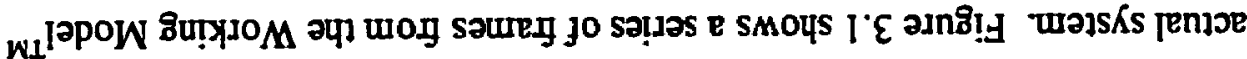

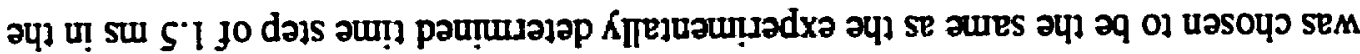

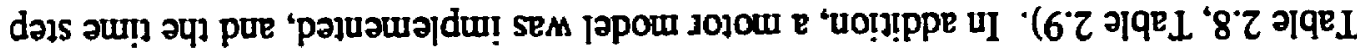

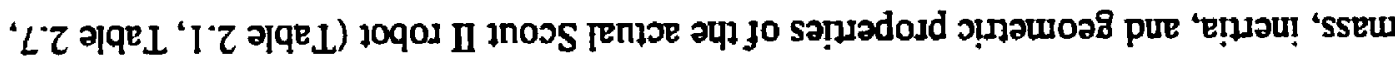

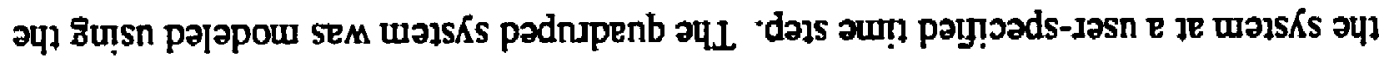

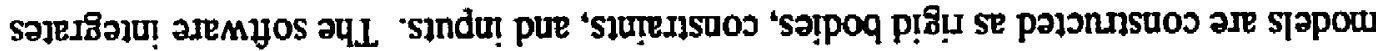

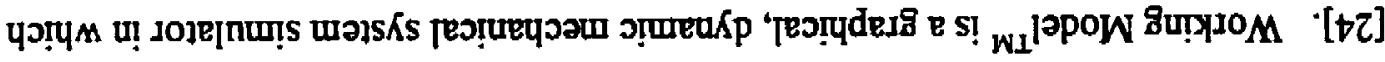

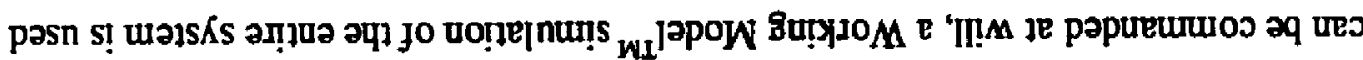

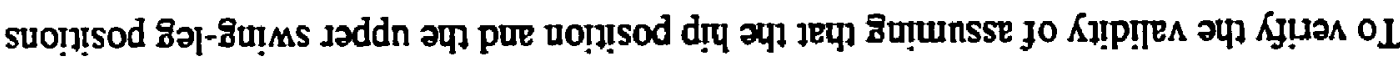

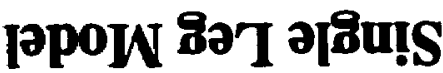

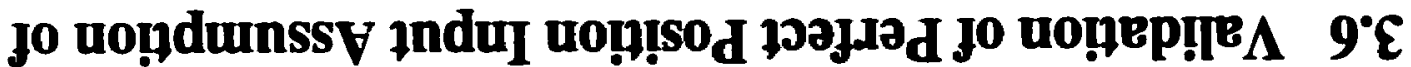




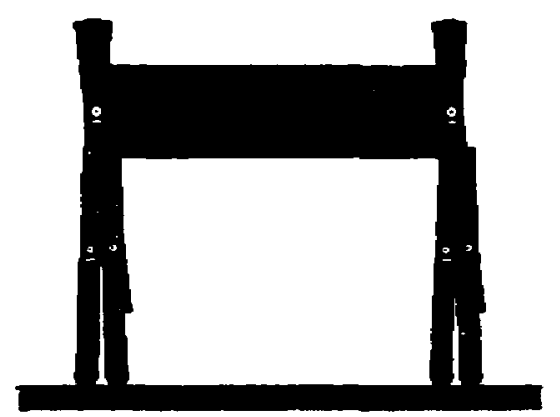

Figure 3.8 - Working Model ${ }^{\mathrm{TM}}$ simulation to verify perfect hip and upper swing-leg position input assumption

The first plot of Figure 3.7 shows the actual vs the desired $\phi_{2}$ trajectory during the support sweep of a stepping cycle and the second plot shows that the degree error between them is always less than 1 degree. Further, a motor model is implemented in the simulation which limits the torque applied at any joint to remain within the limits provided by the manufacturer. This motor model was developed by Didier Papadopoulos and Martin de Lasa at ARL, and was verified experimentally by Robert Battaglia. The third plot shows the torque/speed curve from the Working Model ${ }^{\mathrm{TM}}$ simulation, with the model's torque speed limit shown as a bounding parallelogram. Figure 3.8 shows the Working Model ${ }^{\mathrm{TM}}$ simulation from which the data was obtained. The plots show that while maintaining realistic torque and speed curves, the desired support-leg trajectory can be achieved with less than I degree error, thereby verifying the perfect input assumption. Furthermore, since the support trajectory is a much tougher loading condition than the upper swing-leg trajectory, these plots also verify the assumption that the upper swingleg trajectory can be commanded at will.

\subsection{Development of the Equations of Motion of the Single-Leg System}

The equations of motion of the single-leg system are developed using the Lagrangian approach. From the accurate motor tracking assumption of Section 3.5, the hip position 
$\left(x_{b}, y_{b}\right)$ and the upper swing-leg angle ( $\left.\phi_{\text {ree }}\right)$ can be considered as perfect inputs to the system. The relation between the support leg angle and the hip position is as follows, were $\phi_{\text {sap }}^{0}$ is the initial support-leg angle (at which point $x_{b}=0$ - Figure 3.6).

$$
\begin{gathered}
x_{b}(t)=\left(l_{\text {low }}+l_{\text {up }}\right) \sin \phi_{\mathrm{spp}}^{0}-\left(l_{\text {low }}+l_{\text {up }}\right) \sin \phi_{\text {sup }}(t) \\
\dot{x}_{b}(t)=-\dot{\phi}_{\text {sup }}(t)\left(l_{\text {low }}+l_{\text {up }}\right) \cos \phi_{\text {sup }}(t) \\
\ddot{x}_{b}(t)=-\ddot{\phi}_{\text {sup }}(t)\left(l_{\text {low }}+l_{\text {up }}\right) \cos \phi_{\text {sup }}(t)+\phi_{\text {sup }}^{2}(t)\left(l_{\text {low }}+l_{\text {up }}\right) \sin \phi_{\text {sup }}(t) \\
y_{b}(t)=\left(l_{\text {low }}+l_{\text {up }}\right) \cos \phi_{\text {sup }}(t) \\
\dot{y}_{b}(t)=-\dot{\phi}_{\text {sup }}(t)\left(l_{\text {low }}+l_{u p p}\right) \sin \phi_{\text {sup }}(t) \\
\ddot{y}_{b}(t)=-\ddot{\phi}_{\text {supp }}(t)\left(l_{\text {low }}+l_{\text {up }}\right) \sin \phi_{\text {spp }}(t)-\phi_{\text {sup }}^{2}(t)\left(l_{\text {low }}+l_{u p}\right) \cos \phi_{\text {sup }}(t)
\end{gathered}
$$

By examining Figure 3.6, it can be seen that the only degree of freedom is the knee angle, $\alpha$. For this system, the Lagrangian equation can be written as:

$$
\frac{d}{d t}\left\{\frac{\partial L}{\partial \dot{\alpha}}\right\}-\frac{\partial L}{\partial \alpha}=0
$$

where the Lagrangian, $\mathrm{L}$, is:

$$
\mathrm{L}=\mathrm{T}-\mathrm{U}
$$

$$
\begin{aligned}
& T=\text { Kinetic energy of the system } \\
& U=\text { Potential energy of the system }
\end{aligned}
$$

Since the support-leg and upper swing-leg trajectories are considered to be perfect position inputs, they can be included in the potential and kinetic energy terms on the left hand side of the Lagrangian term instead of as a force input term on the right hand side. The potential and kinetic energy terms are developed separately, and then the entire system is differentiated as in (3.15). 


\subsubsection{Potential Energy}

The only potential energy term comes from gravitational potential energy of the lower swing-leg. It is written as:

$$
U=m g\left(y_{b}-l_{u p} \cos \phi_{f r e c}-l_{c z} \cos \left(\phi_{\text {free }}+\alpha\right)\right)
$$

\subsubsection{Kinetic Energy}

The kinetic energy is determined with the velocity and angular velocity terms of the lower swing-leg as follows:

$$
T=\frac{1}{2} m\left\|v_{c x}\right\|^{2}+\frac{1}{2} I \omega^{2}
$$

The squared velocity term of (3.18) can be written as:

$$
\left\|\vec{v}_{c s}\right\|^{2}=v_{c s, x}^{2}+v_{c a y}^{2}
$$

The horizontal velocity of the centre of mass of the lower swing-leg is:

$$
v_{c z, x}=\dot{x}_{b}+l_{u p} \dot{\phi}_{\text {fret }} \cos \phi_{\text {free }}+l_{c s}\left(\dot{\phi}_{\text {free }}+\dot{\alpha}\right) \cos \left(\phi_{\text {free }}+\alpha\right)
$$

The vertical velocity of the centre of mass of the lower swing-leg is:

$$
v_{c g y}=\dot{y}_{b}+l_{\text {up }} \dot{\phi}_{\text {frex }} \sin \phi_{\text {fret }}+l_{c k}\left(\dot{\phi}_{\text {free }}+\dot{\alpha}\right) \sin \left(\phi_{\text {free }}+\dot{\alpha}\right)
$$

The angular velocity of the lower swing-leg is:

$$
\omega=\dot{\phi}_{\text {frue }}+\dot{\alpha}
$$

Substituting equations (3.19), (3.20), (3.21), and (3.22) into (3.18) gives the following complete expression for the kinetic energy:

$$
\begin{aligned}
& T=\frac{1}{2} m\left\{\begin{array}{c}
{\left[\dot{x}_{b}+l_{\text {up }} \dot{\phi}_{\text {free }} \cos \left(\phi_{\text {fret }}\right)+l_{c \text { cos }}\left(\dot{\phi}_{\text {fret }}+\dot{\alpha}\right) \cos \left(\phi_{\text {fret }}+\alpha\right)\right]^{2}} \\
+\left[\dot{y}_{b}+l_{\text {su }} \dot{\phi}_{\text {fret }} \sin \left(\phi_{\text {free }}\right)+l_{\text {sz }}\left(\dot{\phi}_{\text {free }}+\dot{\alpha}\right) \cos \left(\phi_{\text {free }}+\alpha\right)\right]^{2}
\end{array}\right\} \\
& +\frac{1}{2} l\left(\dot{\phi}_{\text {fret }}+\dot{\alpha}\right)^{2}
\end{aligned}
$$




\subsubsection{Equations of Motion}

The kinetic energy term of equation (3.23) and the potential energy term of (3.17) are substituted into (3.16) to form the Lagrangian. Finally, the equation of motion is determined by substituting the Lagrangian into (3.15) and performing the differentiations. The result is as follows:

$$
\begin{gathered}
\ddot{x}_{b} \cos \left(\phi_{\text {free }}+\alpha\right)+\ddot{y}_{b} \sin \left(\phi_{\text {free }}+\alpha\right)+l_{\text {up }} \ddot{\phi}_{\text {free }} \cos \alpha-l_{\text {up }} \dot{\phi}_{\text {free }} \dot{\alpha} \sin \alpha \\
+l_{c z}\left(\ddot{\phi}_{\text {free }}+\ddot{\alpha}\right)+\frac{l}{m l_{c z}}\left(\ddot{\phi}_{\text {free }}+\ddot{\alpha}\right)+l_{u p} \dot{\phi}_{\text {free }}\left(\dot{\phi}_{\text {free }}+\dot{\alpha}\right) \sin \alpha \\
+g \sin \left(\phi_{\text {free }}+\alpha\right) \quad=0
\end{gathered}
$$

To obtain this system equation in state space form, the following transformation is used:

$$
\begin{aligned}
& x_{1}=\phi_{\text {free }} \\
& x_{2}=\dot{\phi}_{\text {free }}
\end{aligned}
$$

The state space form of the system is then written as:

$$
\begin{aligned}
& \dot{x}_{1}=x_{2} \\
& \dot{x}_{2}=\frac{\left\{\begin{array}{c}
-\ddot{x}_{b} \cos \left(x_{1}+\alpha\right)-\ddot{y}_{b} \sin \left(x_{1}+\alpha\right)-\left(l_{c g}+\frac{l}{m l_{c g}}\right) \ddot{\alpha} \\
-l_{u p} x_{2}^{2} \sin \alpha-g \sin \left(x_{1}+\alpha\right)
\end{array}\right\}}{l_{u p} \cos \alpha+l_{c g}+\frac{I}{m l_{c g}}}
\end{aligned}
$$

\subsection{Validation of Equation of Motion for Single-Leg Model}

To verify the equation of motion, the system is simulated in Working Model ${ }^{\mathrm{TM}}$, and the results are compared to those from integrating the equation of motion in $\mathrm{Matlab}^{\mathrm{TM}}$ [28]. In the Matlab ${ }^{\mathrm{TM}}$ simulation, a desired $\alpha$ trajectory as in Section 3.4 is input as a function 
of time into the state space form of the equation of motion, as in equations (3.26). The system is integrated using the ode45 function to solve for the upper swing-leg trajectory needed to achieve the desired $\alpha$ trajectory. In the Working Model ${ }^{\mathrm{TM}}$ simulation, the desired $\alpha$ trajectory is used as the feedback for the following PID hip torque controller:

$$
\tau=-K_{P_{1}}\left(\alpha_{d}-\alpha\right)-K_{D_{a}}\left(\dot{\alpha}_{d}-\dot{\alpha}\right)-K_{l_{a}} \int_{t=-}^{t}\left(\alpha_{d}-\alpha\right) d t
$$

where $t_{\text {start }}$ is the start time for a particular state.

The dynamic coupling between the upper leg and the lower leg (the hip and the knee) is such that a positive torque in the hip actuator will cause a negative torque in the knee. Consequently, (3.27) is simply the negative of the standard PID controller where the actuator is directly coupled to the joint. Furthermore, the integral term is reset to zero at the start of each swing cycle (states 11 and 21 ).

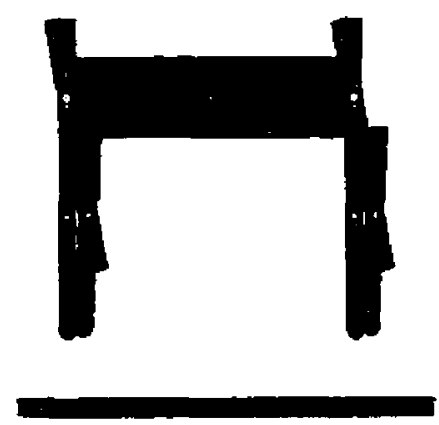

Figure 3.9 - Working Model ${ }^{\mathrm{TM}}$ simulation to verify the EOM for the single swing-leg model

The two simulations are set up with the same initial conditions and physical parameters. The physical parameters such as mass, inertia, leg lengths, and location of the centre of mass are the ones of the actual Scout II robot (Section 2.5.3). To simplify the situation for the purpose of verifying the equation of motion, the body trajectory is taken to be zero velocity. To achieve this in the Working Model $^{\mathrm{TM}}$ simulation, the body is anchored in the air far enough above the ground to avoid toe stubbing. Figure 3.9 shows a frame from the Working Model ${ }^{\mathrm{TM}}$ simulation, and Figure 3.10 shows the plots of the data. The top two plots show $\phi_{\text {tree }}$ from both the Working Model ${ }^{\mathrm{TM}}$ simulation and from integrating the equation of motion in $\mathrm{Matlab}^{\mathrm{TM}}$, and the error in degrees between the two. It can be 
seen that the error is always less than 0.002 degrees. The bottom two plots show the $\alpha$ trajectories from the Working Model ${ }^{\mathrm{TM}}$ and the $\mathrm{Matlab}^{\mathrm{TM}}$ simulations, and the degree error between them. Again, the error is always less than 0.002 degrees. The conclusion is that the $\alpha$ trajectories input into the equation of motion in Matlab ${ }^{\mathrm{TM}}$, and the $\alpha$ trajectory obtained by torque control of the hip motor in Working Model ${ }^{\mathrm{TM}}$ agree very closely, as do the resultant hip angle trajectories, and therefore, the equation of motion is verified and validated.
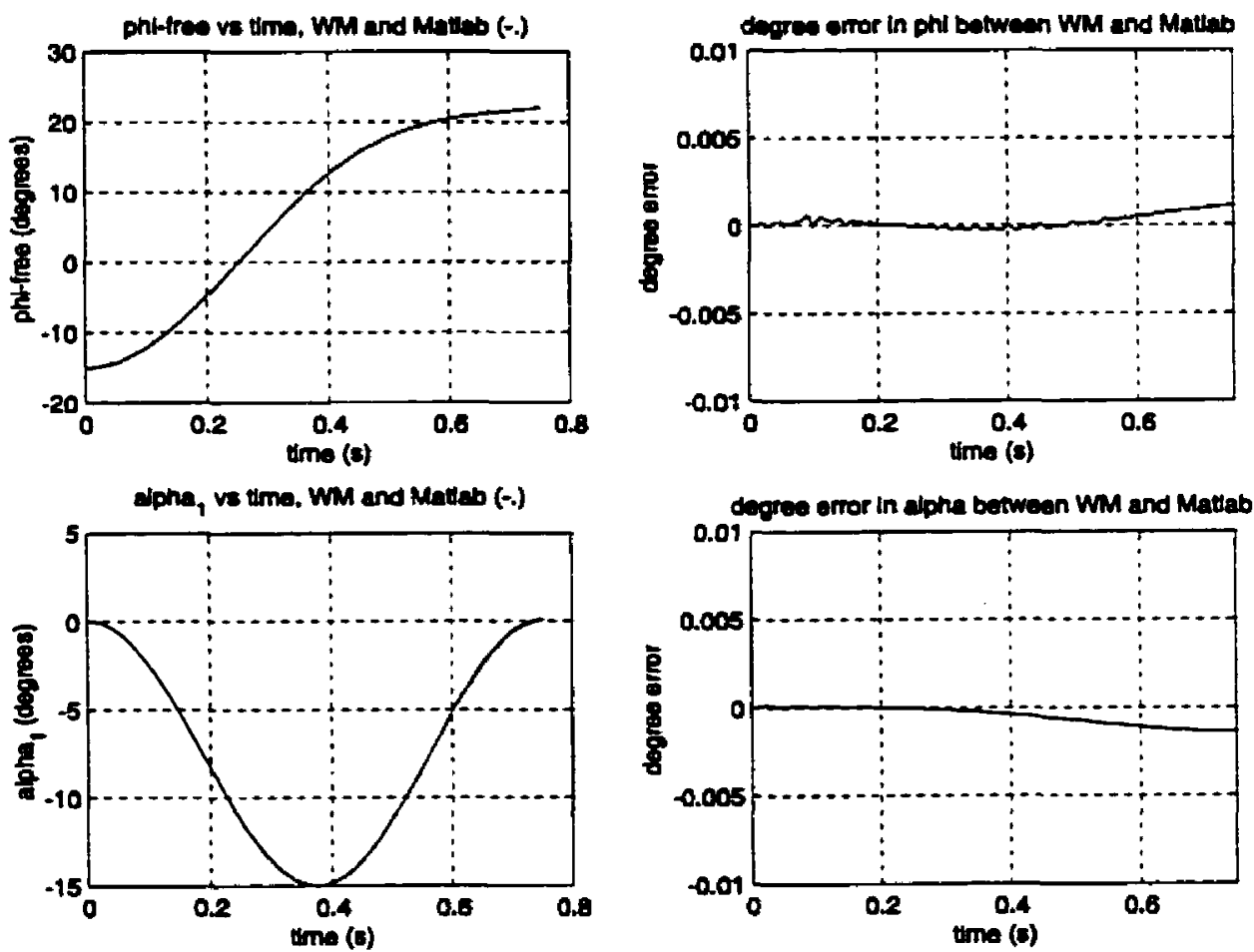

Figure 3.10 - Verification of equation of motion. The first plot shows three vs time for the Working Model $^{\mathrm{MM}}$ simulation and for the integrntion of the equation of motion in Matlab ${ }^{\mathrm{TM}}$. The second plok shows the degree error between pre $_{\text {for the Working Model }}{ }^{\mathrm{TM}}$ and Matlab ${ }^{\mathrm{TM}}$ simulations. The third plot shows the $\alpha$ angle that was achieved through PD torque control in $\phi_{\text {tre }}$ in the Working Model ${ }^{\mathrm{M}}$ simulation, and the $\alpha$ angle that was input into the Matiab ${ }^{\mathrm{TM}}$ simulation to determine what the upper swing-leg trajectory (中rre) needed to be to achieve this desired $\alpha$ trajectory. The fourth plot shows the degree error between the two $\alpha$ trajectories. 


\subsection{Step-Trot, Cosine Knee Angle Trajectory Analysis}

The single leg model equation of motion is used to analyze the behaviour of the singleleg system for different trajectory and geometric parameters. In this section, the singleleg model is integrated for a simple cosine knee angle trajectory with a step-trot motion for the body, $x_{b}$ and $y_{b}$. In other words, the support-legs are assumed to move in a cosine-type trajectory as described in Section 3.3.1, and the hip (ie: body) motions, $x_{b}$ and $y_{b}$ are calculated from equations (3.9) through (3.14) and are input into the equation of motion. In the next section, the complete system is modeled in Working Mode! ${ }^{\mathrm{TM}}$ and this step-trot is repeated step-to-step by switching the free and the support-legs as described in Section 3.1.

The system is integrated using the following inputs and parameter ranges:

- Cosine knee angle trajectory as described by equation (3.7)

- Cosine support-leg trajectory as described in equations (3.1) and (3.2)

- $\mathrm{I}_{\text {up }}=0.2,0.1 \mathrm{~m}$

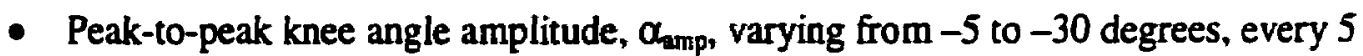
degrees

- Initial $\phi_{\text {free }}$ varying from -10 to -40 degrees, every 10 degrees

- Support cycle time $\left(T_{L S}\right)=1$ second

- $\alpha$ cycle time $\left(T_{L S \alpha}\right)=0.75$ seconds

Figure 3.11 and Figure 3.12 show the upper swing-leg trajectories $\left(\phi_{\text {fres }}\right)$ and the toe height for the parameters listed above. It is clear that the final upper swing-leg angle is always positive, independent of the parameter choice. It can also be seen that the toe heights are higher for the longer upper leg configuration. Unfortunately, it can be seen that there is significant toe-drag for all of these cases. Toe-drag is defined as the total time during the cycle at which the toe-height is equal to or less than zero. Although it is possible to step-trot with toe-drag during the first portion of the swing cycle, it is undesireable because of the increased wear on the foot, and because it reduces the ease 
with which the legs can clear obstacles. Consequently, it is important to minimize or to eliminate toe-drag where possible. By examining these figures, it can be seen that with
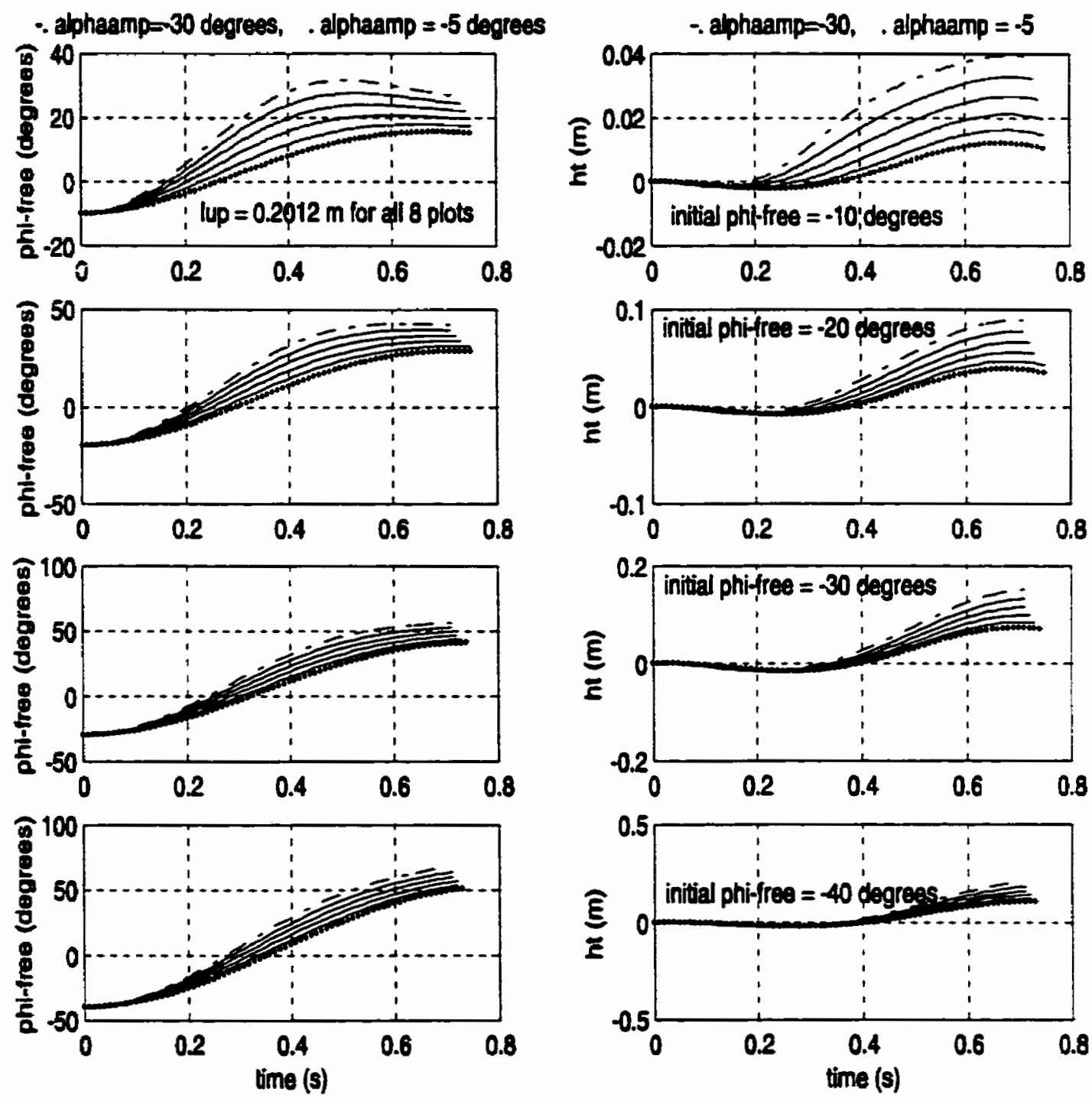

Figure 3.11 - the and toe-height of swing-leg for alpha cosine knee angle trajectory, steptrot support-leg trajectory, $\mathrm{l}_{\mathrm{q}}$ of $0.2 \mathrm{~m}$, and varying other parameters

these free and support leg trajectories, toe-drag cannot be eliminated, but it is reduced by decreasing the initial support-leg angle, $\phi_{\text {sup. }}^{0}$ Furthermore, it can be seen that the overall 

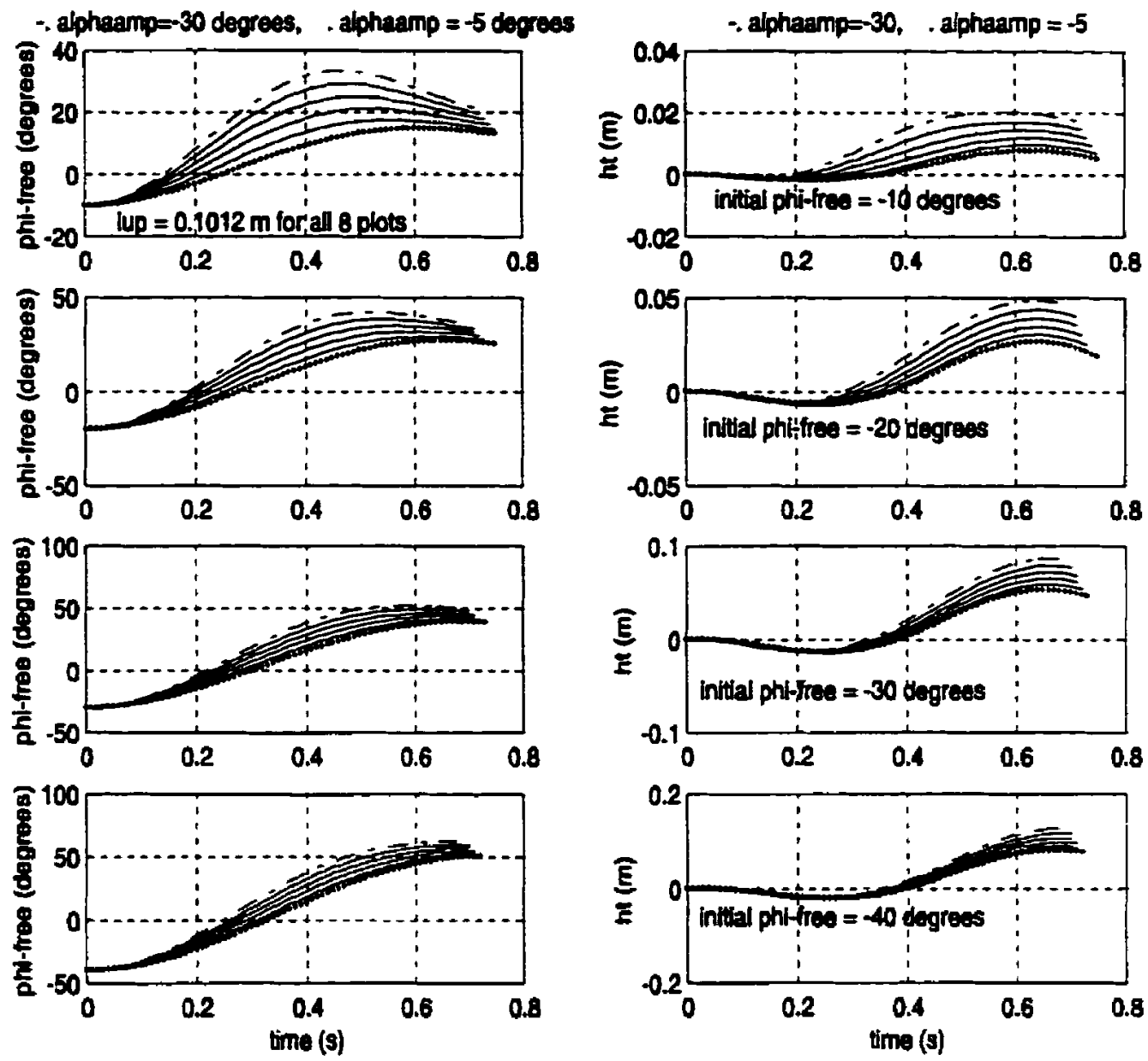

Figure 3.12 - hree and toe-height of swing-leg for alpha cosine knee angle trajectory, step-trot support-leg trajectory, $I_{\text {op }}$ of $0.1 \mathrm{~m}$, and varying other parameters

toe-heights are higher for the longer leg configuration. Therefore, it is concluded that an optimized set of conditions for the step-trot with the cosine-type knee angle trajectory are the following:

\begin{tabular}{ll}
\hline$\alpha_{\text {amp: }}:$ & $-30^{\circ}$ \\
lug: $:$ & $0.2 \mathrm{~m}$ \\
$\phi_{\text {free }}:$ & $-10^{\circ}$ \\
$\phi_{\text {sup: }}^{0}$ & $10^{\circ}$ \\
$\mathrm{T}_{\text {LS: }}$ & 1 second \\
$T_{L S \alpha:}$ & 0.75 seconds \\
\hline
\end{tabular}

Table 3.3 - Optimized set of conditions for step-trot with cosine knee angle trajectory 
The following section shows the results of using these conditions in the Working Model $^{\mathrm{TM}}$ simulation.

\subsection{Step-Trot Simulation Results for Cosine Knee Angle Trajectory}

The system is simulated in Working Model ${ }^{\mathrm{TM}}$ for the step-trot with the cosine knee angle trajectory as defined by equation (3.7) and with the optimized set of conditions as found in Section 3.9. This section will first discuss the overall step-trot algorithm as implemented in Working Model ${ }^{\mathrm{TM}}$, including the selection of the controller gains, and then the results of the simulation will be presented.

\subsubsection{Step-Trot Working Model ${ }^{\mathrm{TM}}$ Simulation Algorithm and Controller Gains}

The system is modeled in Working Model ${ }^{\mathrm{TM}}$ using all of the physical properties as described in Section 2.5.3, (Table 2.7, Table 2.8, and Table 2.9), and with the longer upper leg length configuration of $0.2 \mathrm{~m}$. The step-trot algorithm used is described in detail in the flow-chart of Figure 3.13; it is a specific form of the general trot as described in Section 3.1, and in Figure 3.1. The flow-chart describes states 11 and 12 of the trot, and it shows the transition to state 21 . States 21 and 22 behave in exactly the same manner as states 11 and 12 respectively, but the support and the free leg-pairs are swapped. In states 11 and 12 , legs 1 and 4 are free, and legs 2 and 3 are the support-legs that propel the body forward.

In the simulation, the hip motors are modeled as torque motors, and a motor model is used that limits the torque/speed characteristics of the simulated model to those of the motors on the real Scout II robot. Consequently, position control is achieved in the simulation using the same PD or PID control schemes as are used on the real system, and the model only implements torque/speed values that are achievable on the real system. In 
this simulation, the controller gains are determined by iteration and are chosen so as to obtain a fast response, with very close tracking, and low overshoot. The support-leg position control is done with a simple PD controller, the unlocked swing-leg control is done with a PID controller (states 11 and 21), and the locked free leg position control (states 12 and 22) is done with a simple PD controller. Each of these cases used different gain values and they are listed below.

\begin{tabular}{|l|l|l|l|l|l|}
\hline Support-legs & \multicolumn{2}{|l|}{ Unlocked free legs } & \multicolumn{2}{|l|}{ Locked free legs } \\
\hline $\mathrm{KP}_{\text {suppor: }}$ & 2500 & $\mathrm{KP}_{\mathrm{a}:}:$ & 500 & $\mathrm{KP}_{\text {free }}:$ & 1000 \\
\hline $\mathrm{KD}_{\text {suppor: }}$ & 250 & $\mathrm{KD}_{\mathrm{a}}:$ & 3 & $\mathrm{KD}_{\text {free }}:$ & 50 \\
\hline & & $\mathrm{KI}_{\mathrm{a}}:$ & 10000 & & \\
\hline
\end{tabular}

Table 3.4 - Controller gains for step-trot with simple cosine knee angle trajectory Near perfect tracking of the simple cosine knee angle trajectory could be achieved with a $\mathrm{PD}$ controller with gains $\mathrm{KP}_{\alpha}=5000$ and $\mathrm{KD}_{\alpha}=3$. However, a tracking error and significant overshoot is observed in the two-part cosine trajectory (Section 3.11), so the PID controller is used. The integral term in the PID controller reduces the tracking error while permitting a reduction in $\mathrm{KP}_{\alpha}$, which reduces the overshoot.

The communications hardward on the actual Scout II robot operates at a bandwidth of $667 \mathrm{kHz}$, which is equivalent to a time-step of 1.5 miliseconds. Therefore, the time-step used in the Working Model ${ }^{\mathrm{TM}}$ simulation is set to 1.5 miliseconds.

\subsubsection{Step-Trot Working Model ${ }^{\mathrm{TM}}$ Simulation Results}

Figure 3.14, Figure 3.15 and Figure 3.16 show the results of the step-trot simulation with the parameters and the controller gains developed in Sections 3.9 and 3.10.1. The first plot of Figure 3.14 shows the upper leg angle for leg $l\left(\phi_{1}\right)$ as a function of time for a 10 second step-trot, and the second plot shows the data between 3.5 and 5.5 seconds. In both these plots, the state value is scaled to fit within the data, and the states $11,12,21$, and 22 can clearly be made out as the horizontal lines. The first plot shows that this motion is repetitive, and therefore stable. The second plot shows one complete cycle through all four states for leg 1 . During state 11 , the knee is unlocked for leg 1 and the 
upper leg trajectory does not follow a $\phi_{1}$ desired trajectory, but is rather controlled to achieve the cosine knee angle trajectory. At the transition to state 12 , the upper leg is smoothly controlled to the desired touchdown angle of 10 degrees. During states 21 and 22 , leg 1 is a support-leg, and it follows a cosine trajectory from 10 to -10 degrees.

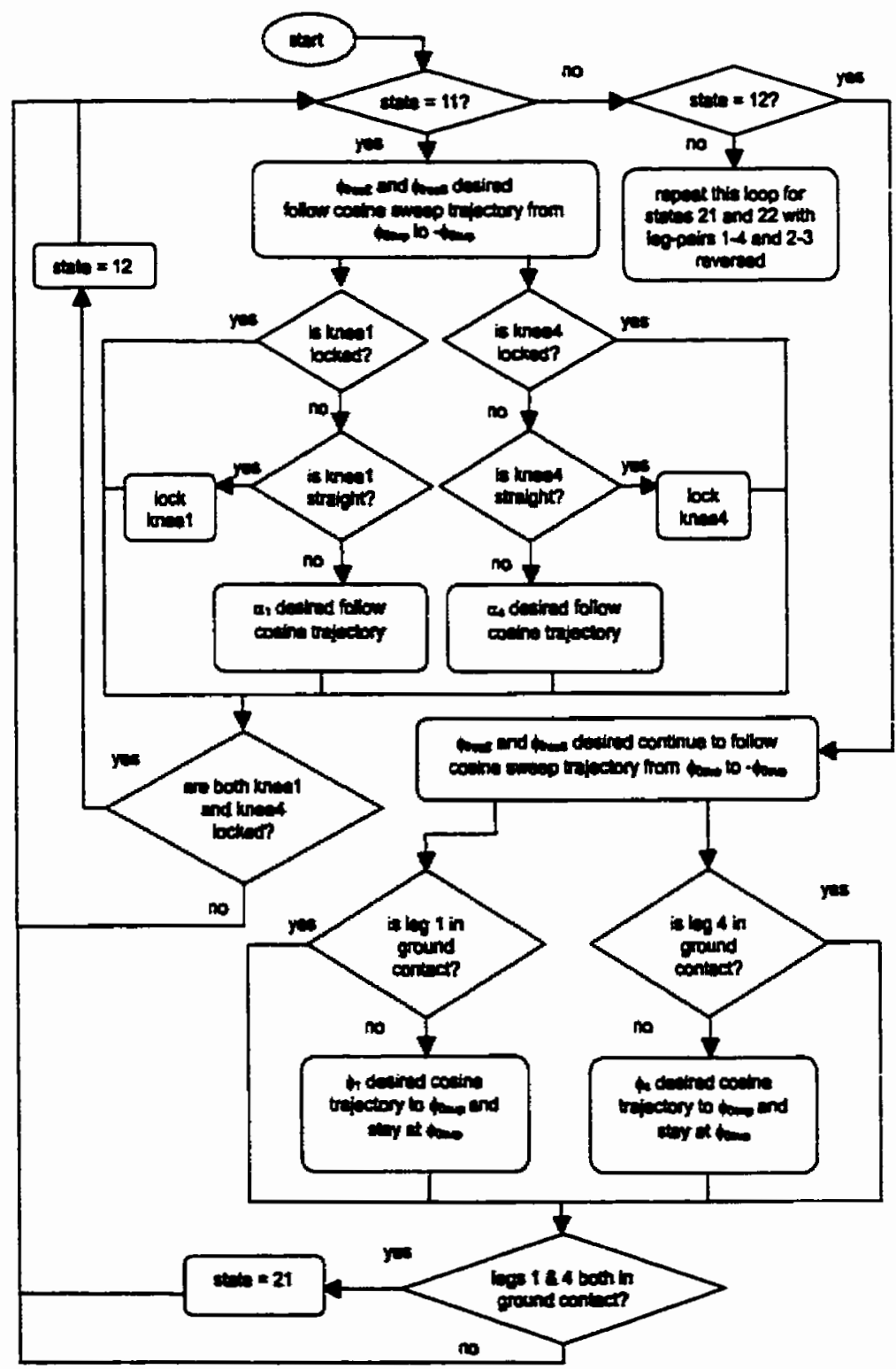

Figure 3.13 - Step-trot with cosine knee angle trajectory flowchart 
The third and fourth plots of Figure 3.14 show the $\alpha$ trajectory for leg 1 for the step-trot cycle. The third plot is for the full 10 seconds, and the fourth plot is a closer view of the knee angle trajectory between 1.75 and 2.6 seconds. On both plots, the state is scaled
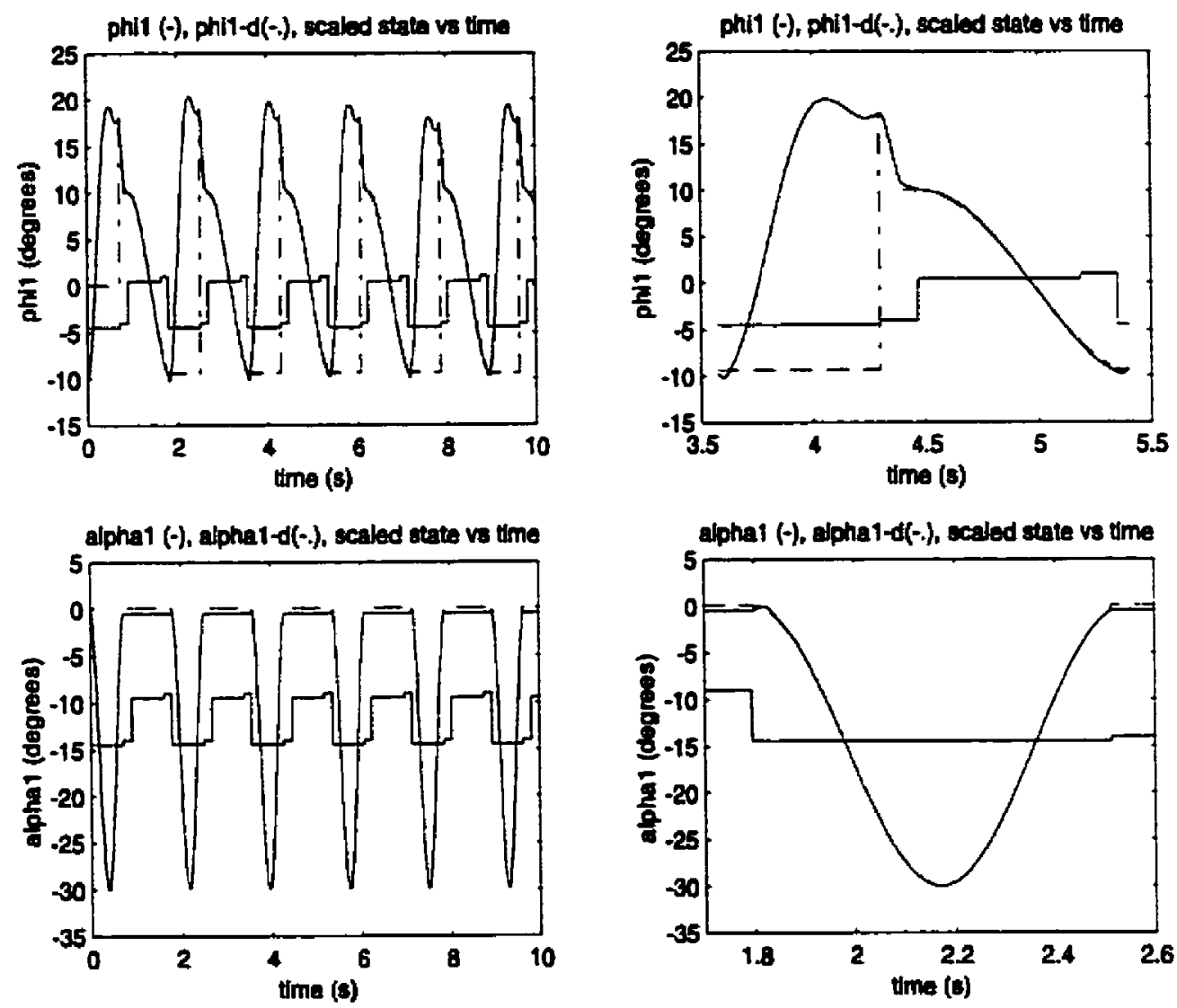

Figure $3.14-\phi_{1}, \alpha_{1}$ actual and desired vs time with scaled state shown, for step-trot with $\phi^{0}{ }_{s 00}=10^{\circ}$ and $\mathrm{I}_{\text {sp }}=0.2 \mathrm{~m}$

to fit within the data. It can be seen that the knee angle trajectory tracks the desired trajectory with the same type of accuracy as shown in Figure 3.10. The step-trot algorithm locks the knee when the knee is within one half degree of the zero degree desired locking position, which accounts for the 0.5 degree error at the start and at the end of the cycle. 


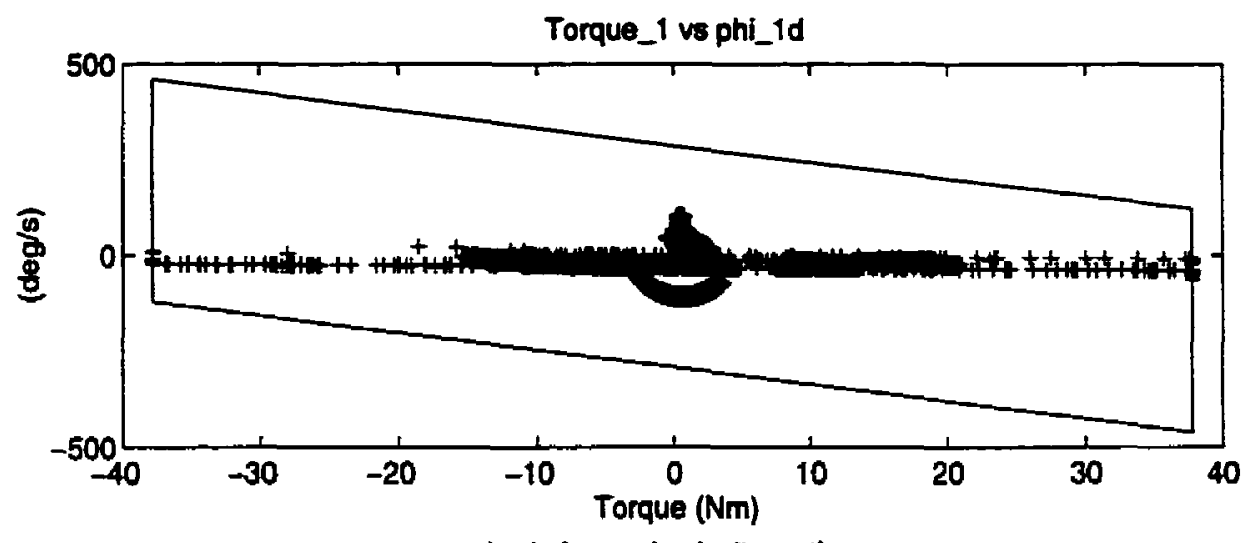

body forward velocity us time

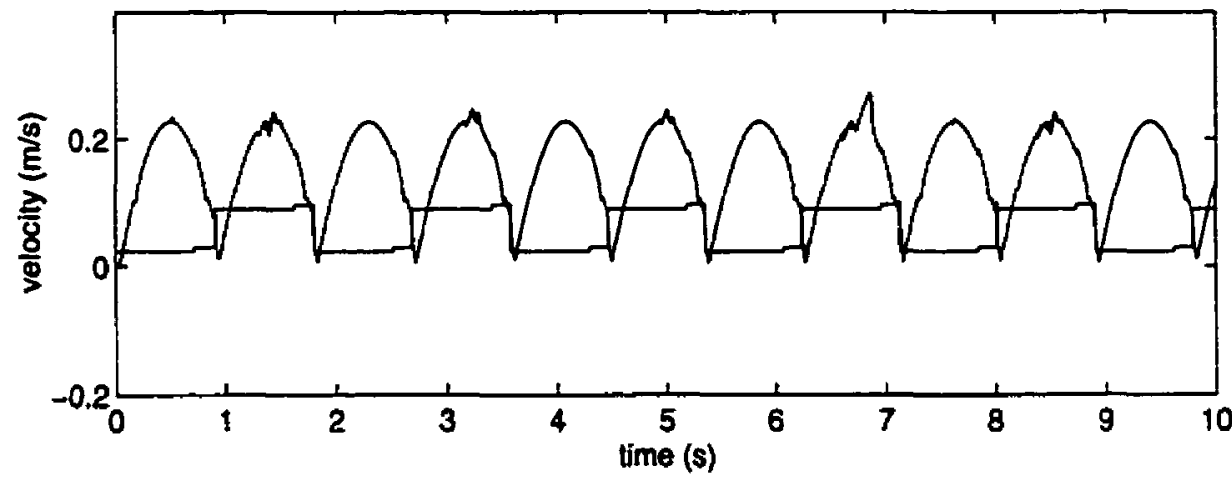

Figure 3.15 - Torque, is $\phi_{1}$ speed (deg/s) with motor model bounding box shown, and body forward velocity vs time with sciled state for step-trot with $\phi_{\mathrm{mp}}^{0}=10^{\circ}$ and $\mathrm{I}_{\mathrm{up}}=0.2 \mathrm{~m}$

Figure 3.15 shows the torque/speed curve with the motor model shown, and the forward body velocity of the robot, with the state scaled to fit within the data. The torque/speed curve shows that there is not excessive motor saturation in achieving this step-trot. The velocity curve shows a cosine type velocity profile with the velocity dropping to zero at the beginning and end of each cycle, as desired for the step-trot.

Figure 3.16 shows the toe-height of leg $\mathrm{L}$ as a function of time for the 10 second step-trot simulation, and it also shows the data for the first 1.0 second. The state is also shown, but is scaled to fit within the data. The first plot shows that the toe-height behaviour is repetitive, and that in general, toe ciearances reaching between 1.0 and 1.6 centimetres are achieved during the middle of the step cycle. Furthermore, the second plot shows that for the first 0.1 second, the toe height remains at $0.0 \mathrm{~m}$, which indicates that there is toe-drag at the start of the cycle, as predicted in section 3.9 . 

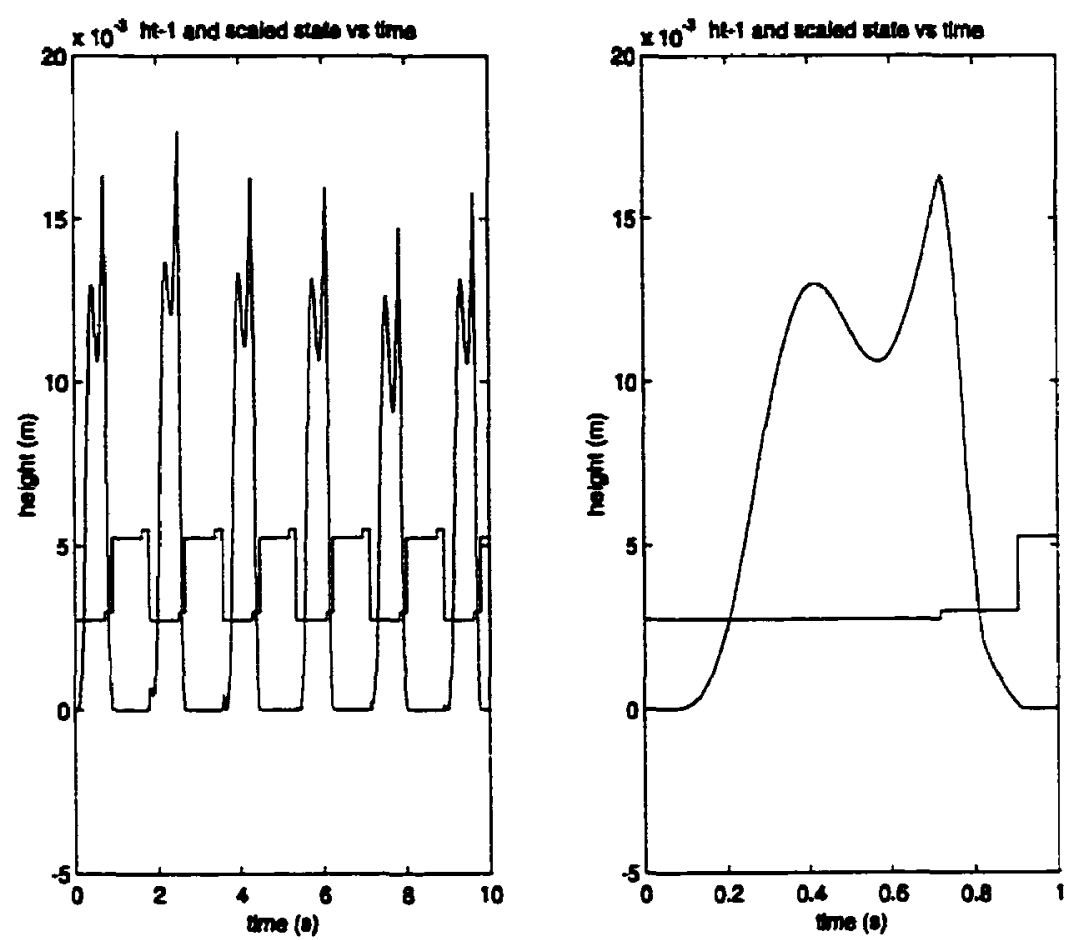

Figure 3.16 - Toe height 1 and scaled state vs time for step-trot with $\phi_{\text {sup }}^{0}=10^{\circ}$ and $\mathrm{I}_{\mathrm{up}}=0.2 \mathrm{~m}$

\subsection{Two-Part Cosine Knee Trajectory Step-Trot Analysis}

To reduce toe-drag during a step-trot, the knee trajectory has to achieve its maximum amplitude sooner than halfway through its swing cycle. The two-part cosine knee angle trajectory of Section 3.4 is input as the desired knee angle trajectory into the Matlab $^{\text {TM }}$

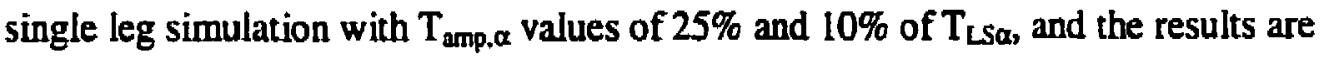
shown in Figure 3.17 and Figure 3.18. Please note that only the longer upper leg length condition is used since it was found in Section 3.9 that the longer leg length provides a larger ground clearance.

It can be seen that toe-drag is reduced for increasing $\alpha_{\text {ampy }}$ for decreasing initial $\phi_{\text {free, }}$ and for decreasing $T_{\text {amp.c. }}$. Nevertheless, there is always some toe-drag at the start of the 
cycle. The following section shows the results of simulating this system in Working Model $^{\text {TM }}$.
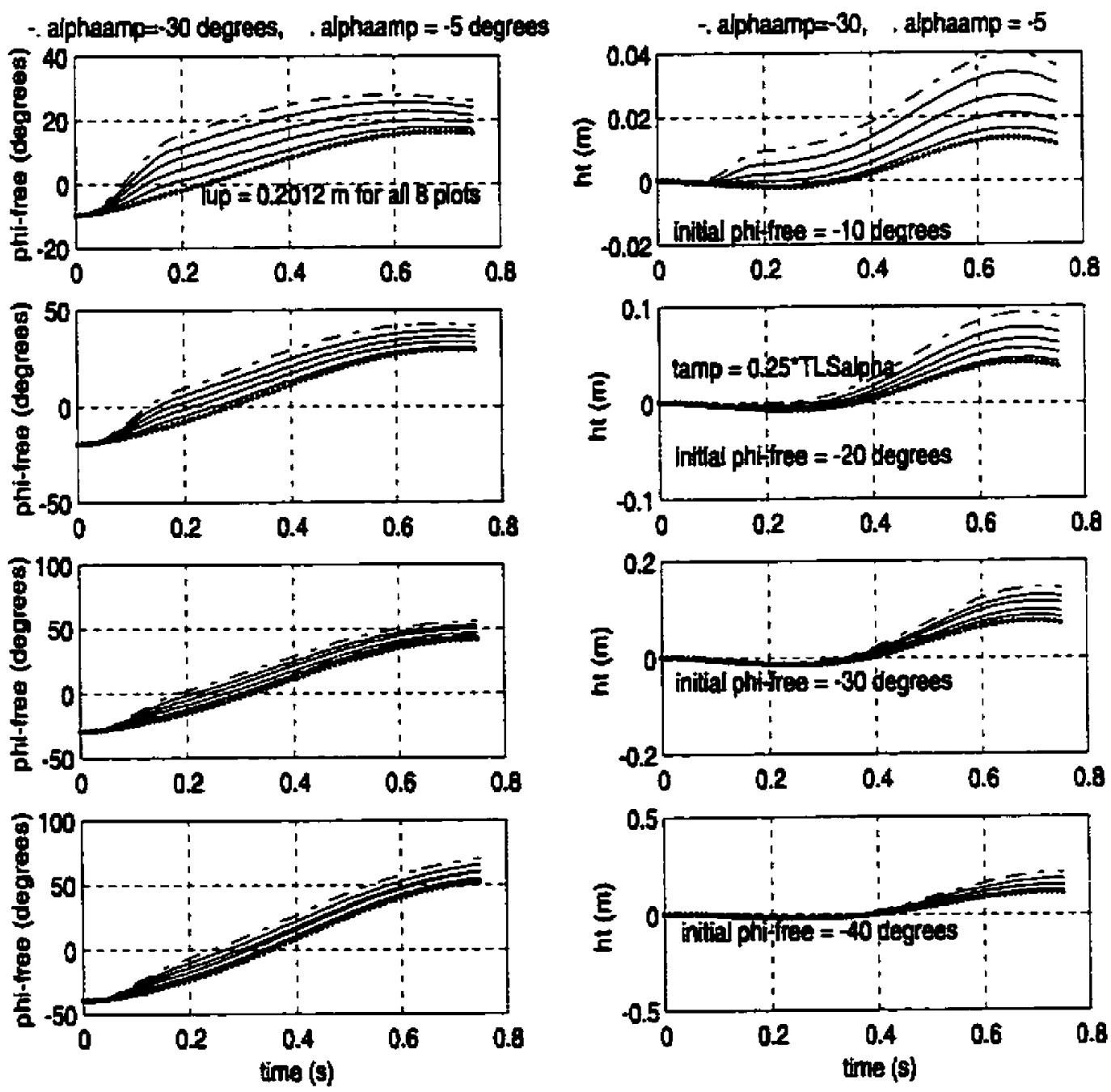

Figure 3.17 - the and toe-height for various parameters, $I_{w p}=0.2 \mathrm{~m}$, and for $T_{\text {ampa }}=0.25 * T_{\text {LSa }}$ for shilied cosine knee angle trajectory step-trot 

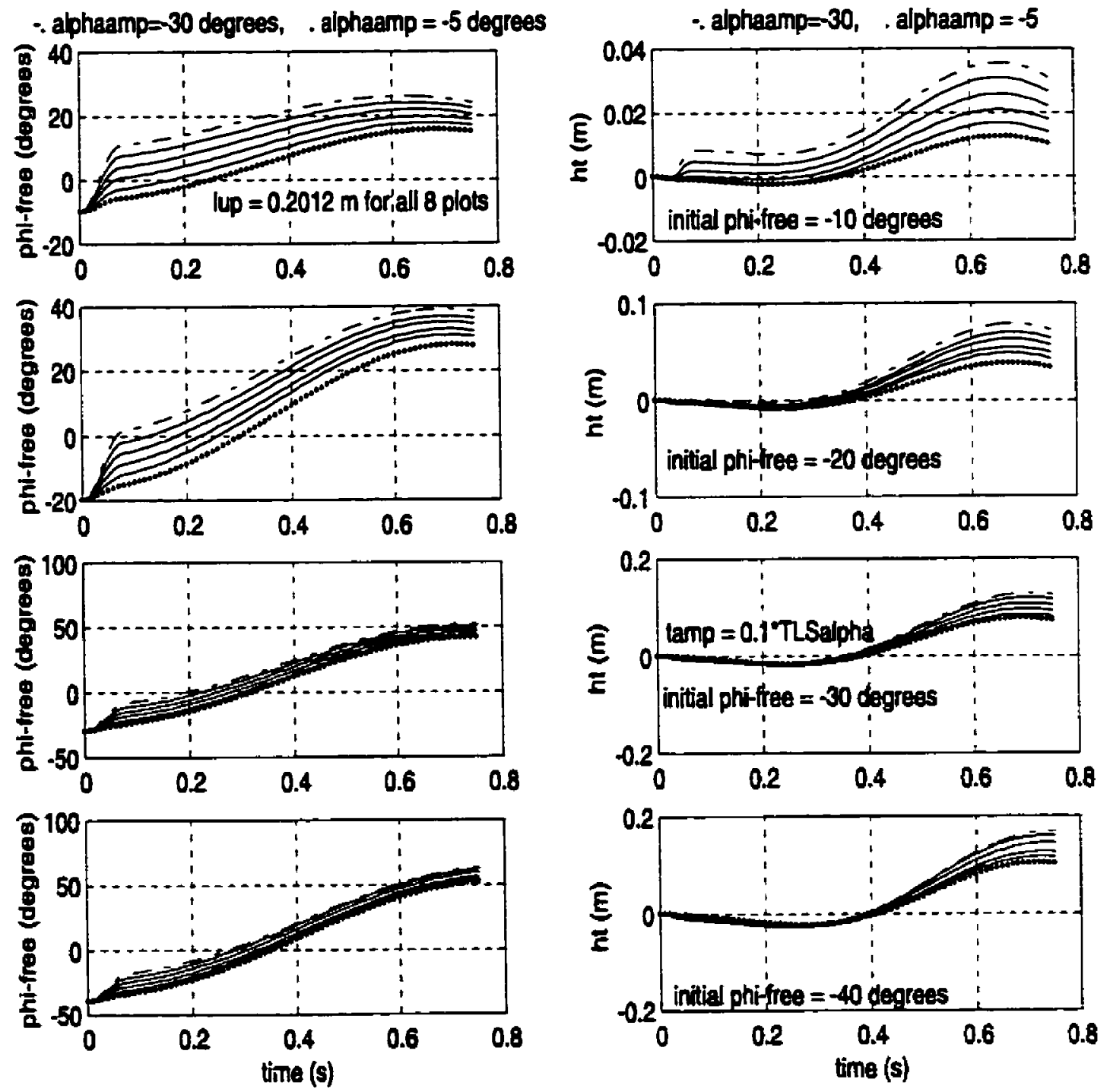

Figure 3.18 - hree and toe-height for various parameters, $I_{u p}=0.2 \mathrm{~m}$, and for $T_{m p x}=0.10 * T_{L S \alpha}$ for shifted cosine knee angle trajectory step-trot 


\subsection{Step-Trot Simulation Results for Two-Part Cosine Knee Angle Trajectory}

The system is simulated in Working Model in exactly the same fashion as in Section 3.10 , with the same controller gains. The only difference is that the desired knee angle trajectory of states 11 and 21 is not a simple cosine, but is the two-part cosine with $T_{\text {amp, }}$ values of $10 \%$ and $25 \%$ of $\mathrm{T}_{\mathrm{LS \alpha}}$.
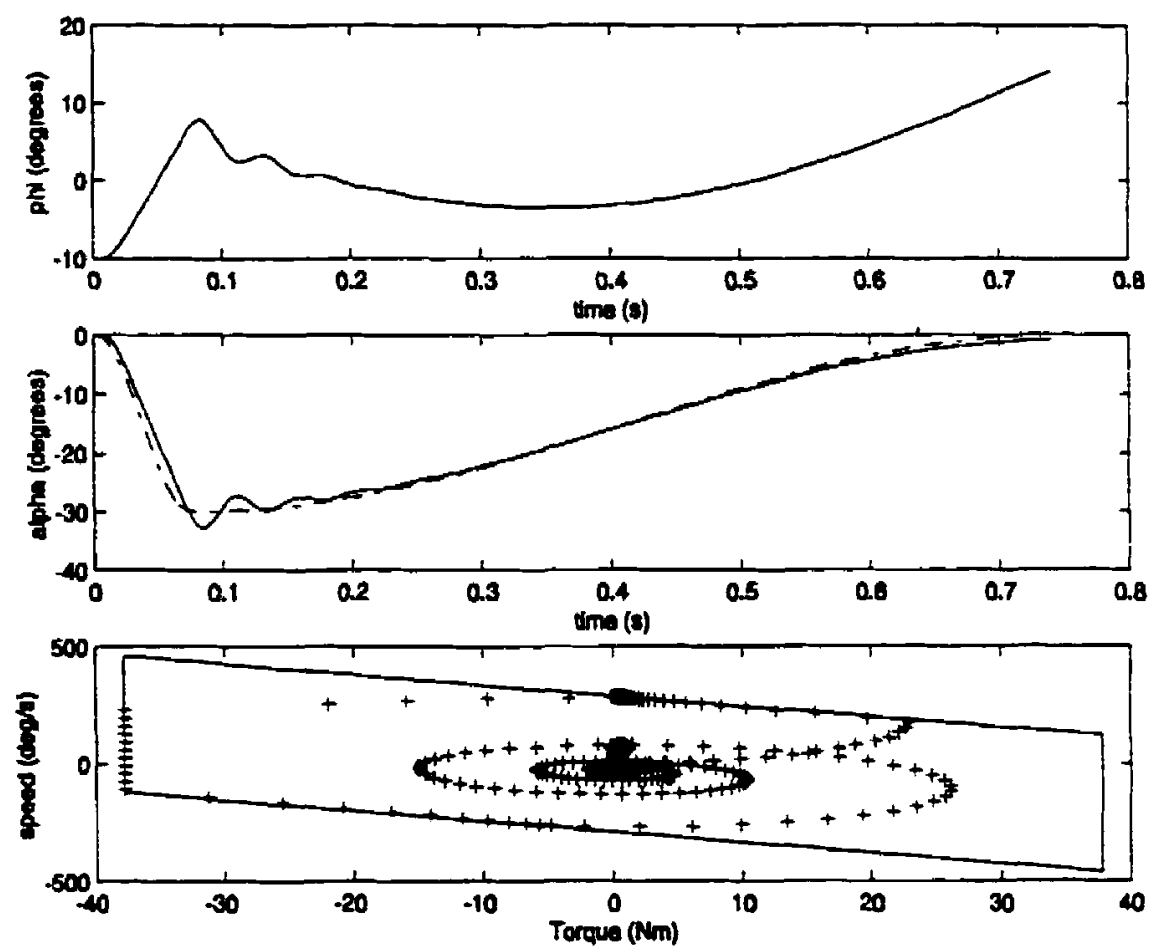

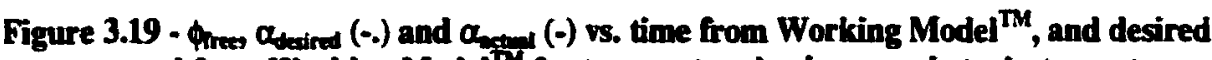
torque-speed from Working Model ${ }^{\text {tM }}$ for two-part cosine knee angle trajectory, steptrot support leg trajectory, $T_{\text {apax }}=0.1 * T_{L S \infty} I_{m p}=0.2 \mathrm{~m}, \varphi_{\text {tre }}^{\circ}=-10$ degrees

Figure 3.19 and Figure 3.20 show the results of the simulation for the case where $T_{\text {amp.o }}$ is $10 \%$ of $T_{L S \alpha}$. The first plot of Figure 3.19 shows the $\phi_{\text {frec }}$ trajectory that was commanded using feedback on the desired $\alpha$ two-part cosine trajectory, and the second plot shows the desired and the achieved $\alpha$ trajectory. It can be seen that $\phi_{\text {free }}$ is not as smooth as it is in the cases of the Matlab ${ }^{\mathrm{TM}}$ simulation (Figure 3.18) where no motor 
model is implemented. Furthermore, in the second plot, it can be seen that the torques are limited by the motor model causing poor $\alpha$ tracking, especially around the time of $\mathrm{T}_{\text {amp, }, \mathrm{c}}(0.075$ seconds), where the actuators are saturated. Finally, the third plot shows the desired torque-speed requirements, and the bounding box shows how they were limited. Clearly, the actuators are saturated a significant amount of the time, which accounts for the poor $\alpha$ tracking.
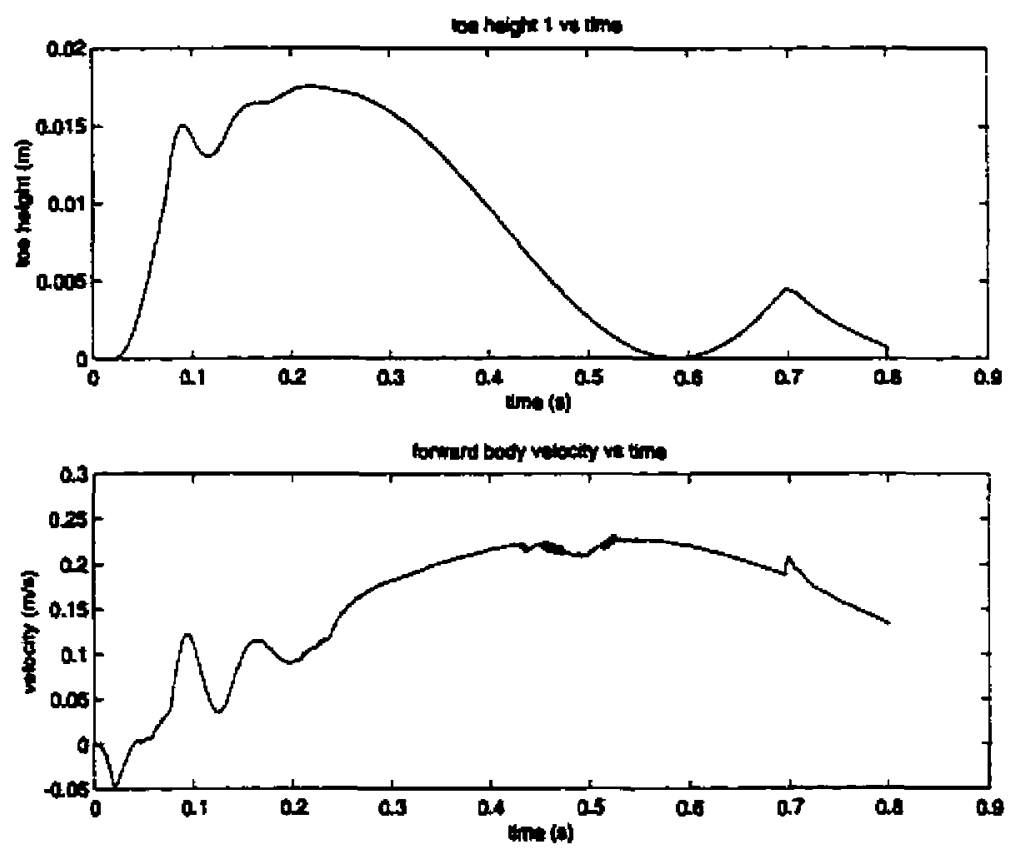

Figure 3.20 - Toe height and forward velocity vs time for step-trot with twopart cosine trajectory; $T_{\text {mpax }}=0.1^{*} T_{\text {Lso }} \phi^{*} \mathrm{mw}=-10^{\circ}$, lup $=0.2 \mathrm{~m}$

Figure 3.20 shows the toe-height and the forward body velocity for the $T_{\text {amp. } \alpha}=$ $0 . \mathrm{I}^{*} \mathrm{~T}_{\mathrm{La}}$ case. It can be seen that the velocity is not as smooth as in the case of the simple cosine knee trajectory step-trot of Sections 3.9 and 3.10, especially just after the time the knee reaches its maximum amplitude. At this time, the free legs accelerate very quickly to achieve the desired knee angle trajectory, which gives the system a disturbance significant enough that the support leg controller has a difficult time completely rejecting it. Furthermore, near 0.6 seconds, the free leg toe nearly hits the ground. In fact, it was found that if this simulation was run for a longer period of time, small disturbances are enough to cause the robot to stub its toe and to fall. 

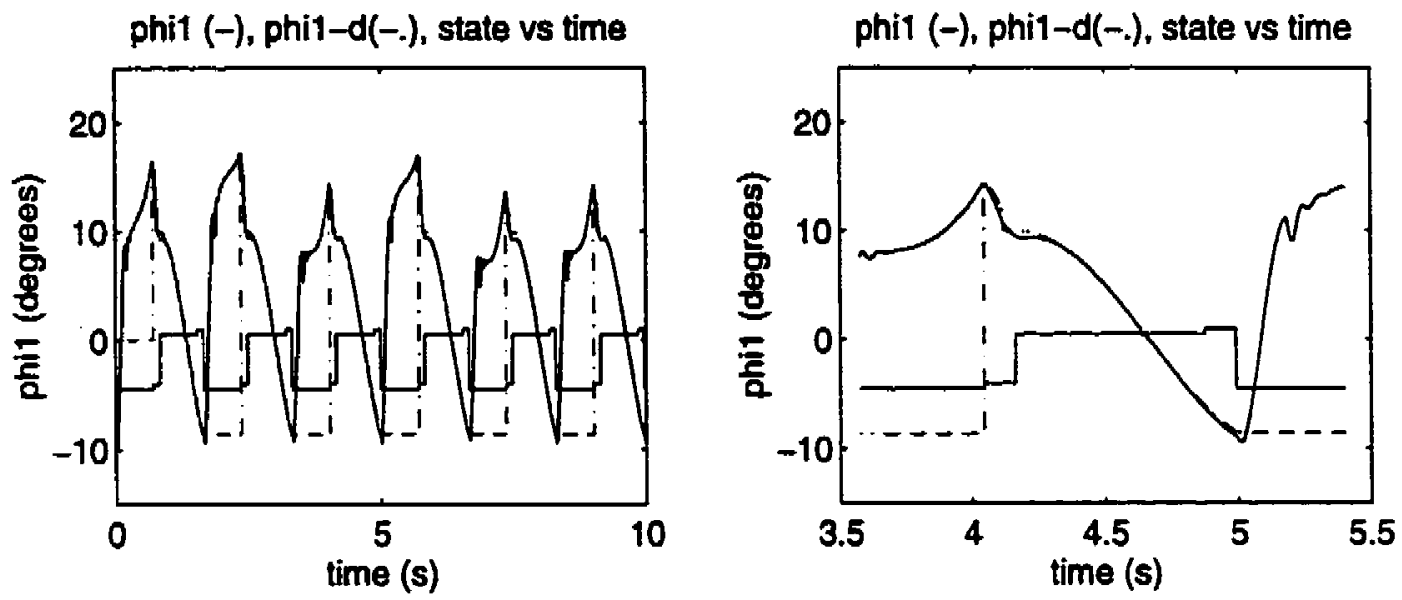

alpha1 (-), alpha1-d(-.), scaled state vs time
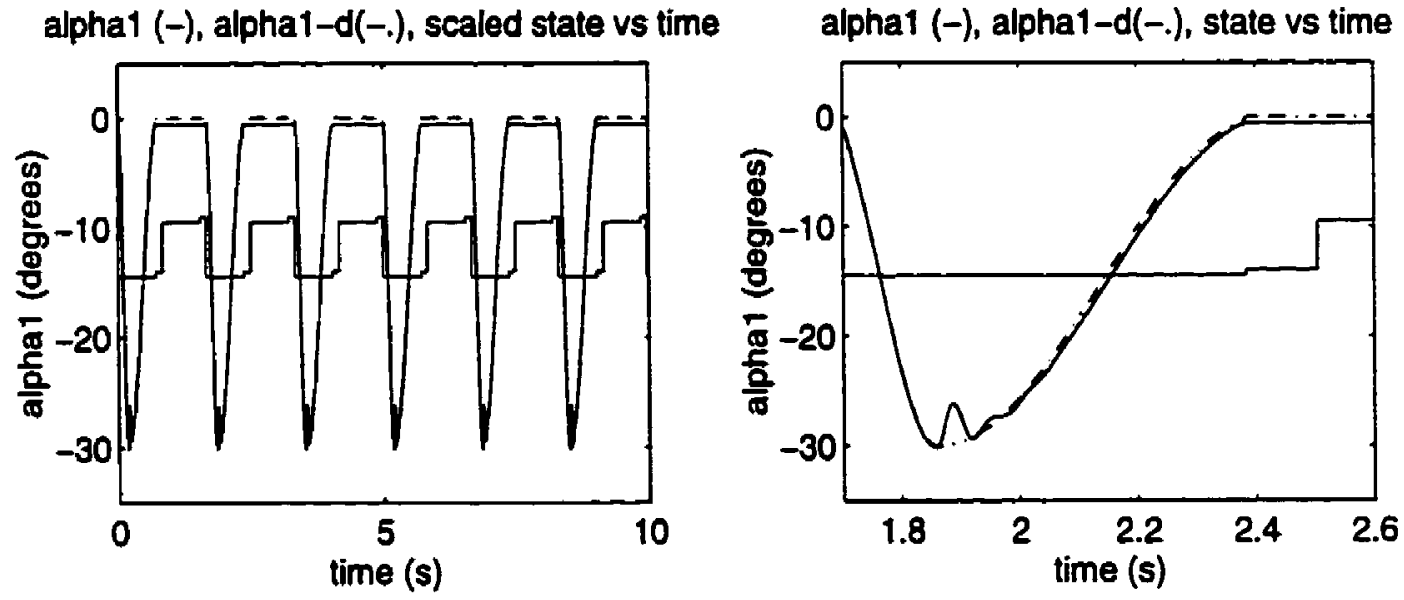

Figure $3.21-\phi_{1}, \alpha_{1}$ actual and desired vs time with scaled state shown, for step-trot with $\phi_{\text {sup }}^{0}=10^{\circ}$ and $\mathrm{l}_{\mathrm{sp}}=0.2 \mathrm{~m}$, and with two-part cosine knee angle trajectory with $T_{\text {umpec }}=0.25^{*} \mathrm{~T}_{L s}$

Due to the problems with motor saturation and toe-stubbing, it is concluded that the twopart cosine trajectory with $T_{\text {amp, } \alpha}=0.1^{*} T_{L S \alpha}$ is not an appropriate set of parameters for a step-trot. The case of setting $T_{\text {amp, },}$ to $0.25 * T_{L S \alpha}$ is investigated to see if this less abrupt $\alpha$ trajectory has less toe-drag than the simple cosine a trajectory case, yet with better toeheight and reduced system disturbances than in the $T_{\text {amp, } \alpha}=0.1 * T_{L S \alpha}$ case.

Figure 3.21 shows the $\phi_{\text {free }}$ and $\alpha$ trajectories for the $T_{\text {amp, } \alpha}=0.25 * T_{L S}$ two part cosine case. It can be seen that the $\alpha$ tracking is much better than the $T_{\text {amp, } \alpha}=0.1^{*} T_{L S \alpha}$ case, with the exception of the same type of disturbance at maximum knee angle amplitude. Furthermore, Figure 3.22 shows that the actuators are not overly saturated, as in the 
previous case. By comparing Figure 3.16, Figure 3.20, and Figure 3.23, it can be seen that toe-drag is decreased by decreasing $T_{a m p, \alpha}$ However, this reduction in toe-drag comes at the expense of worsening $\alpha$ tracking, and a reduction in maximum toe-height. Since toe drag cannot be completely eliminated, and since the worst case toe drag of the simple cosine $\alpha$ trajectory is relatively small (albeit larger than the $T_{a m p, \alpha}=0.1^{*} T_{L S \alpha}$ or $\mathrm{T}_{\text {amp, } \alpha}=0.25^{*} \mathrm{~T}_{\mathrm{LS \alpha}}$ cases), it is felt that the simple cosine $\alpha$ trajectory is better due to its higher maximum toe-height, which minimizes the risk of toe-stubbing due to disturbances.

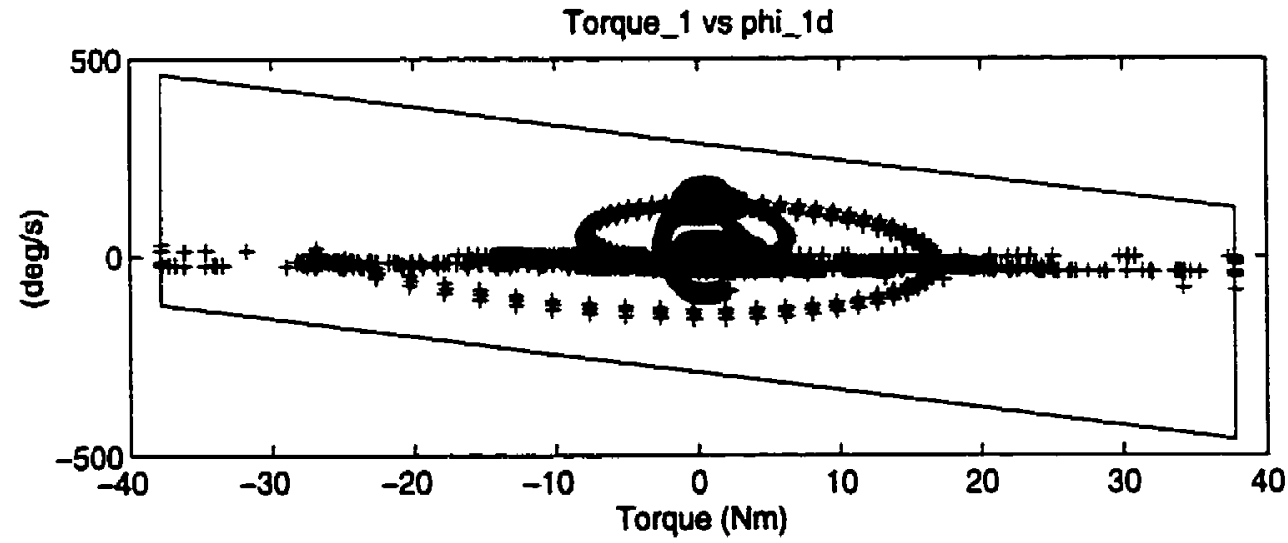

body forward velocity vs time

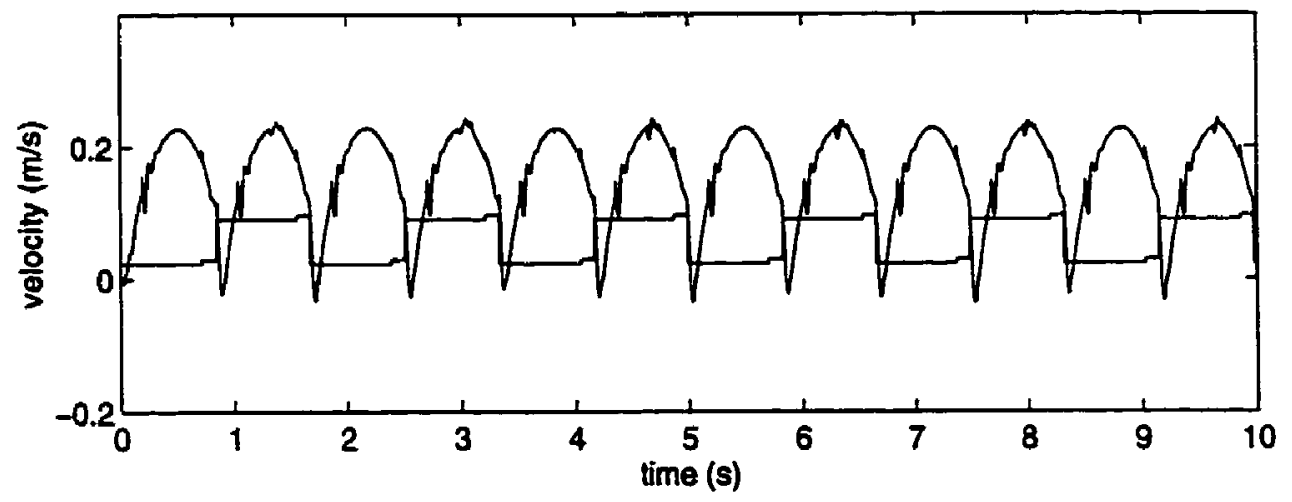

Figure 3.22 - Torque 1 vs $\phi_{1}$ speed (deq/s) with motor model bounding box shown, and body forward velocity vs time with scaled state for step trot with $\phi_{\text {sup }}^{0}=10^{\circ}$ and $I_{u p}=0.2 \mathrm{~m}$, and two-part cosine knee angle trajectory with $T_{\text {ano } \alpha}=0.25 * T_{L S \alpha}$ 


\subsection{Controlled Forward Body Velocity, Cosine Knee Angle Trajectory}

It has been shown that for step-trotting, toe-drag cannot be eliminated for simple cosinetype knee angle trajectories. However, step-trotting is only one class of trot. During steady-state walking, it is more likely that a controlled or a constant forward body velocity will be desired. Step-trots involve coming completely to rest at the start and the end of each step cycle, and consequently, significant energy must be expended to accelerate and decelerate the robot. Clearly, the step-trot is very useful for situations where single steps must be taken, such as when approaching a target or an obstacle. However, to cover larger distances it is more efficient to maintain a constant forward body velocity.
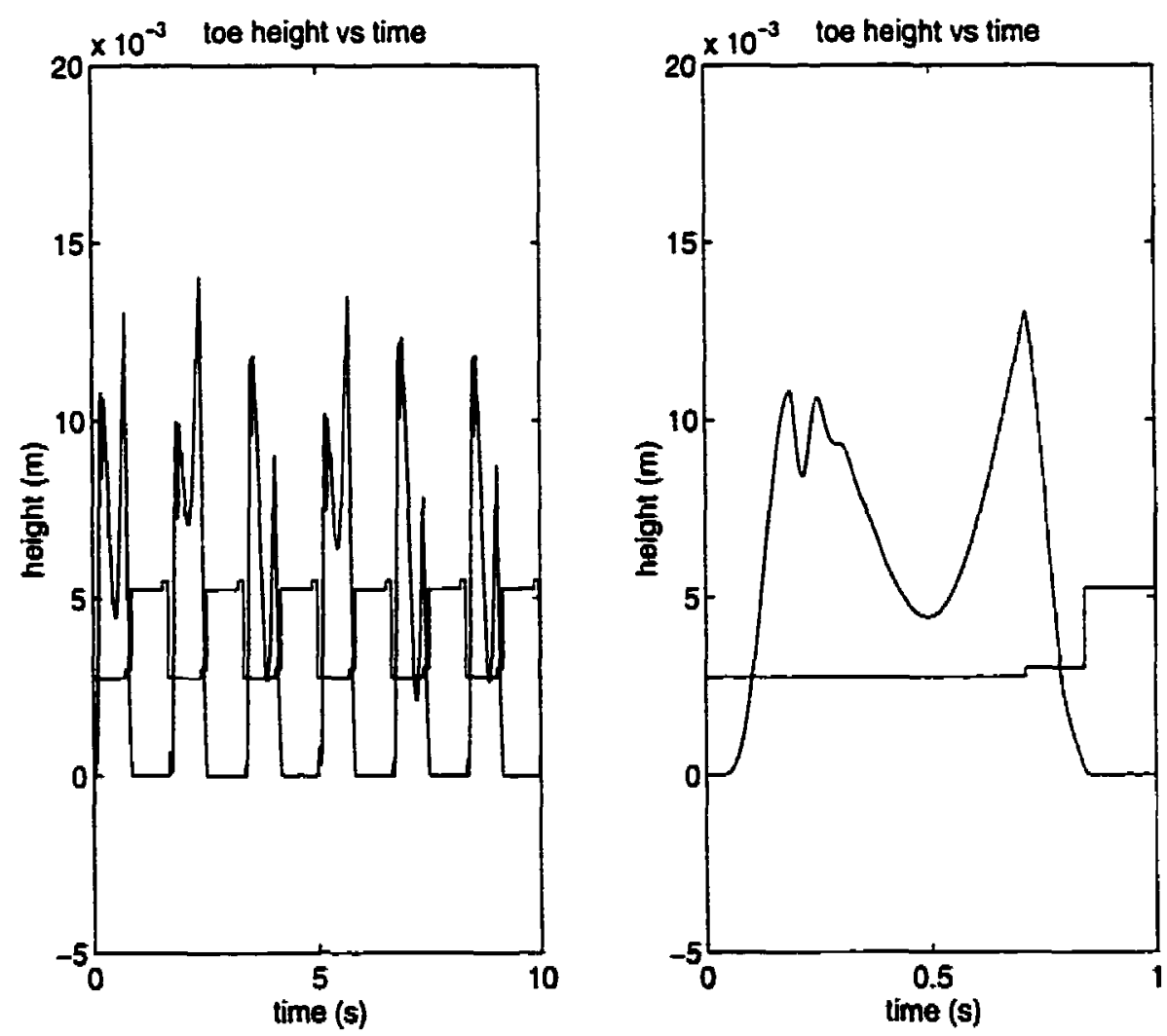

Figure 3.23 - Toe beight 1 and scaled state vs time for step-trot with $\phi_{\text {spp }}^{0}=10^{\circ}$ and $I_{m p}=$ $0.2 \mathrm{~m}$, and and two-part cosine knee angle trajectory with $T_{\text {max }}=0.25^{*} T_{L S x}$ 
The system is simulated in Matlab ${ }^{\mathrm{TM}}$ and Working Model ${ }^{\mathrm{TM}}$ using the support-leg trajectory for a controlled forward body velocity trot as described in Section 3.3.2, with the desired velocity being $0.5 \mathrm{~m} / \mathrm{s}$. Figure 3.24 and Figure 3.25 show the results of these simulations for upper leg lengths of 0.2 and $0.1 \mathrm{~m}$ respectively.

For the case of an upper leg length of $0.2 \mathrm{~m}$, it can be seen (Figure 3.24) that there is no toe-stubbing or toe-drag for the case where the initial $\phi_{\text {free }}$ is more negative than -30 degrees, and the maximum knee angle deflection is more negative than - 10 degrees. Furthermore, the ground clearance is maximized with an initial $\phi_{\text {free }}$ of -30 degrees and a $\alpha_{\text {emp }}$ of -30 degrees. In addition, the final $\phi_{\text {frec }}$ is only 15 degrees larger than the desired touchdown angle of 30 degrees, which can easily be corrected in the remaining $25 \%$ of the total leg swing cycle time after knee lock.
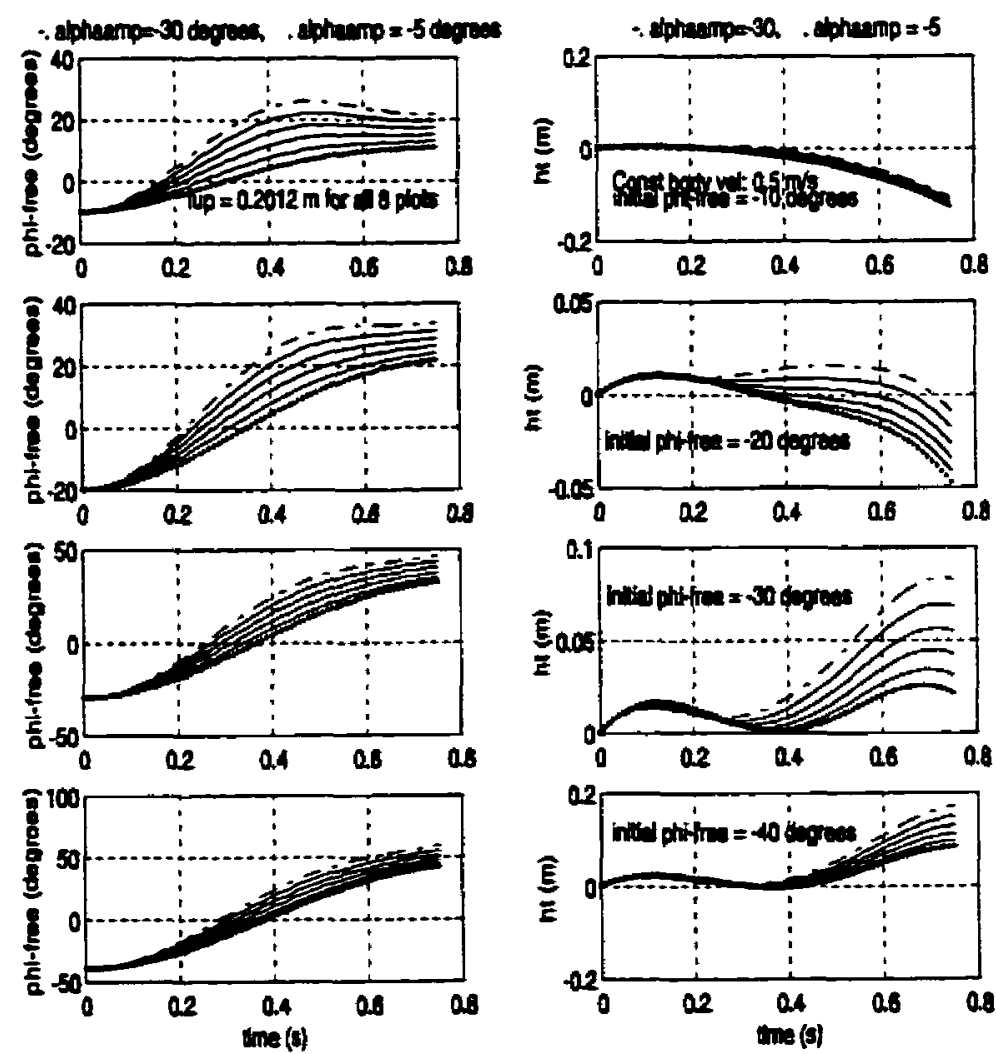

Figure 3.24 - Toe-height and the for controlled borizontal body velocity trot of $0.5 \mathrm{~m} / \mathrm{s}$ with simple cosine knee angle trajectory, $I_{m}$ of $0.2 \mathrm{~m}$, and other varying parameters 
- alphamp $=30$ degrees, . alphaamp $=.5$ degrees
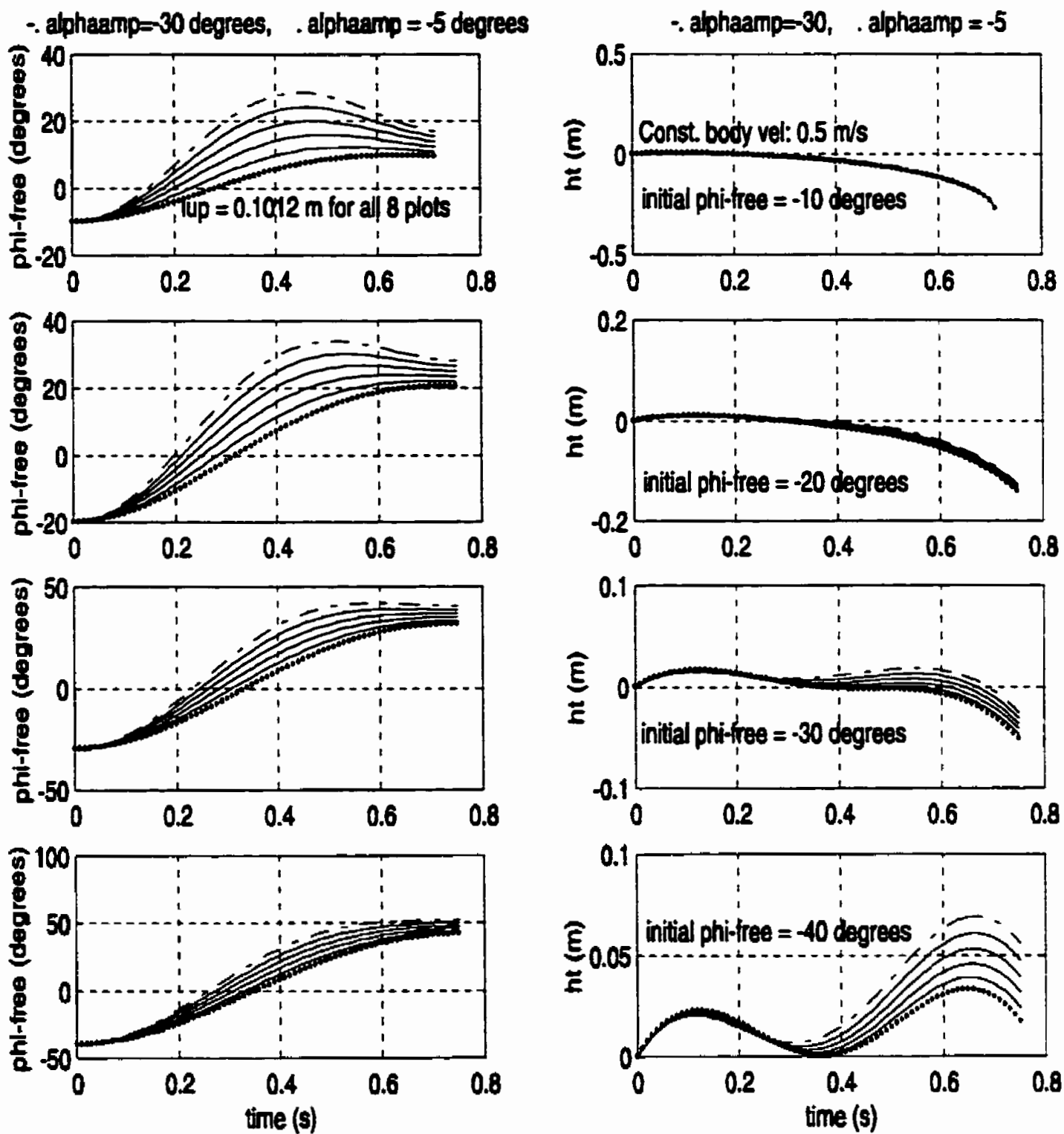

Figure 3.25 - Toe-height and hre for controlled hortzontal body velocity trot of $0.5 \mathrm{~m} / \mathrm{s}$ with simple cosine knee angle trajectory, $I_{\mathrm{mp}}$ of $0.1 \mathrm{~m}$, and other varying parameters

Figure 3.25 shows the same simulations but for the shorter $l_{u p}$ of $0.1 \mathrm{~m}$. In this case, it can be seen that the optimal characteristics are an initial $\phi_{\text {free }}$ of -40 degrees and a $\alpha_{\text {amp }}$ of -30 degrees. In this case, the final $\phi_{\text {free }}$ is 20 degrees higher than the desired final $\phi_{\text {free }}$ touchdown angle of 30 degrees, which can also be corrected in the remaining $25 \%$ of cycle time. 
The Matlab ${ }^{\mathrm{TM}}$ simulation is used to determine the appropriate $\phi_{\text {free }}^{0}$ and $\alpha_{\text {amp }}$ parameters for different velocities and different upper leg lengths. To reduce the search space, the total cycle time ( $\left.T_{L S}\right)$ is kept at 1.0 seconds with the corresponding unlocked knee swing time ( $\mathrm{T}_{\mathrm{LS \alpha}}$ ) of 0.75 seconds. The individual results as in Figure 3.24 are not shown, but the optimal parameters found through that type of analysis are compiled in Table 3.5 and Table 3.6 for the longer and the shorter tup values respectively.

\begin{tabular}{ccc}
\hline velocity $(\mathrm{m} / \mathrm{s})$ & $\phi_{\text {free }}^{0}$ (degrees) & $\alpha_{\text {amp }}$ (degrees) \\
\hline 0.1 & -10 & -30 \\
0.2 & -10 & -30 \\
0.3 & -20 & -30 \\
0.4 & -20 & -30 \\
0.5 & -30 & -30 \\
0.6 & -30 & -30 \\
0.7 & -40 & -30 \\
0.8 & - & - \\
\hline
\end{tabular}

Table 3.5 - Optimal $\phi_{\text {trese }}^{0} \alpha_{\text {ump }}$ for $I_{q p}=0.2 \mathrm{~m}, T_{L s}=1 \mathrm{~s}, T_{L S \alpha}=0.75 \mathrm{~s}$

\begin{tabular}{ccc}
\hline velocity $(\mathrm{m} / \mathrm{s})$ & $\phi_{\text {free }}^{0}$ (degrees) & $\alpha_{\text {amp }}$ (degrees) \\
\hline 0.1 & -10 & -30 \\
0.2 & -20 & -30 \\
0.3 & -20 & -30 \\
0.4 & -30 & -30 \\
0.5 & -40 & -30 \\
0.6 & - & - \\
0.7 & - & - \\
0.8 & - & - \\
\hline
\end{tabular}

Table 3.6 - Optimal $\phi_{\text {tree }}^{0} \alpha_{\text {map }}$ for $I_{\text {up }}=0.1 \mathrm{~m}, \mathrm{~T}_{\mathrm{LS}}=1 \mathrm{~s}, \mathrm{~T}_{\mathrm{LSa}}=0.75 \mathrm{~s}$

It can be seen that the longer upper leg length configuration has a larger range of velocities that it can cover. Furthermore, it can also be seen that the optimal $\alpha_{a m p}$ is always -30 degrees, which implies that the larger the magnitude of the backwards knee deflection, the higher the ground clearance. However, this also results in a larger difference between the $\phi$ angle at the end of the unlocked knee swing phase and the desired touchdown angle, and so a value of - 30 degrees for $\alpha_{\mathrm{amp}}$ is felt to be the best compromise. 


\subsection{Controlled Forward Body Velocity Trot Working Model $^{\mathrm{TM}}$ Simulation}

The system is simulated in Working Model ${ }^{\mathrm{TM}}$ for the controlled forward body velocity case. In this section, the controlled velocity trot algorithm and controller gain selection is discussed, the results from the simulation are shown, and they are compared to the results from the Matlab ${ }^{\mathrm{TM}}$ single leg simulation.

\subsubsection{Working Model ${ }^{\mathrm{TM}}$ Controlled Forward Body Velocity Simulation Algorithm and Controller Gains}

The controlled velocity trot is similar to the step-trot with a few exceptions. First of all, the support leg trajectory is that of Section 3.3.2 (equation (3.3) and (3.4)), and not the trajectory for the step-trot. Second, the goal of this trajectory is to move the hip angle in such a way that the desired velocity of the robot is achieved. Unlike the step-trot, there is no set liftoff angle, since the support legs must continue to move until the free legs both touchdown. At this time, the legs exchange roles, and the state changes from 22 to 11 or from 12 to 21 . An additional change is that when the knees lock, their $\phi$ angles are equalized prior to touchdown. This is done so that the locked free legs touchdown at the same angle, reducing the pitch and the roll throughout the subsequent cycle. Despite these differences, the overall algorithm is quite similar to the step-trot. As in the steptrot, the free leg knees are unlocked and knee angle control is performed during state II or 21 . Once the free legs are straightened at the end of the knee angle control, the knees are locked and the locked free legs are brought into ground contact, where the support and the free legs exchange states.

This algorithm is implemented in Working Model ${ }^{\mathrm{TM}}$ and the controller gains are determined experimentally. They are summarized in Table 3.7. Since the support-leg trajectories are different for the controlled velocity trot than the step-trot, it is not surprising that the controller gains are different. What is observed is that in order to 
maintain good position control, the Proportional and the Derivative gains $\left(\mathrm{KP}_{\text {support }}\right.$ and $\mathrm{KD}_{\text {support }}$ have to be reduced compared to those of the step-trot to prevent overshoot and instabilities. However, this tends to reduce the overall accuracy of the controller, and so a large Integral gain ( $\left.\mathrm{KI}_{\text {suppon }}\right)$ has to be implemented. It should be noted that since the controlled velocity trot is meant to achieve higher velocities than the step-trot, that it is a tougher loading condition. It was also observed that the performance did not change over a large range of controller gains: the sensitivity of the system to variations of gains was small. Although not tested, it is likely that the controlled velocity gains would have worked for the step-tot. This was the case for the experimental results of Chapter 4.

\begin{tabular}{|l|l|l|l|l|l|}
\hline \multicolumn{2}{|l|}{ Support-legs } & \multicolumn{2}{|l|}{ Unlocked free legs } & \multicolumn{2}{|l|}{ Locked free legs } \\
\hline $\mathrm{KP}_{\text {suppon: }}$ & 150 & $\mathrm{KP}_{\alpha:}:$ & 800 & $\mathrm{KP}_{\text {free: }}$ & 1000 \\
\hline $\mathrm{KD}_{\text {suppor: }}: 75$ & $\mathrm{KD}_{\alpha:}:$ & 2.5 & $\mathrm{KD}_{\text {free }}$ & 50 \\
\hline $\mathrm{KI}_{\text {suppor: }}$ & 9000 & & & & \\
\hline
\end{tabular}

Table 3.7 - Controller gains for controlled velocity trot with simple cosine knee-angle trajectory

\subsubsection{Working Model ${ }^{\mathrm{TM}}$ Controlled Forward Body Velocity}

\section{Simulation Results}

The system is simulated in Working Model ${ }^{\mathrm{TM}}$ for the longer upper leg case with the optimal conditions of $\phi_{\text {fiee }}^{0}=-20$ degrees, $\alpha_{\text {amp }}=-30$ degrees, $T_{L S a}=0.75$ seconds, and a constant desired velocity of $0.3 \mathrm{~m} / \mathrm{s}$ for the first unlocked knees state (state 11). Figure 3.26, Figure 3.27, and Figure 3.29 show the results of this simulation compared against the Matlab ${ }^{\mathrm{TM}}$ simulation.

Figure 3.27 shows the upper leg angle trajectories for both the support and the free legs, and the torque/speed curves as determined in Working Model ${ }^{\mathrm{TM}}$, with the bounding parallelogram of the motor model shown. It is clear that there are differences between the upper free leg trajectories from the two simulations. These differences can be attributed to the fact that in the Working Model ${ }^{\mathrm{IM}}$ simulation, the forward body velocity was not constant at $0.3 \mathrm{~m} / \mathrm{s}$ as it was in the Matlab ${ }^{\mathrm{TM}}$ simulation as can be seen in Figure 
3.29. The reason that the velocity could not be kept as constant in the Working Model ${ }^{\mathrm{TM}}$ simulation is because the torques needed to do this exceeded the motor model and were consequently clipped, as can be seen in the bottom right plot of Figure 3.27. Figure 3.28 shows the support leg torque vs time and it can be seen that there is an initial saturation of the torque (Torque $=-38 \mathrm{Nm}$ ) at touchdown $(t=0.0 \mathrm{~s})$. It is these effects that explain the apparent large differences in the toe heights between the two simulations as seen in Figure 3.26. Since the upper swing leg trajectory needed to achieve the $\alpha$, cosine trajectory in the free leg is very dependent on the dynamics of the entire system, it is not surprising that these small changes in velocity would cause such a discrepancy. What is more important to note, however, is that by selecting the parameters from the Matlab ${ }^{\mathrm{TM}}$ simulation so as to maximize toe-height, the system is robust enough to handle these types of disturbances. Figure 3.26 does show a large difference between the toe-heights as determined in the Matlab ${ }^{\mathrm{TM}}$ and the Working Model ${ }^{\mathrm{TM}}$ simulations, but it also shows that the toe-height from the Working Model ${ }^{\mathrm{TM}}$ simulation is still positive and with a substantial clearance, despite the disturbance in velocity.

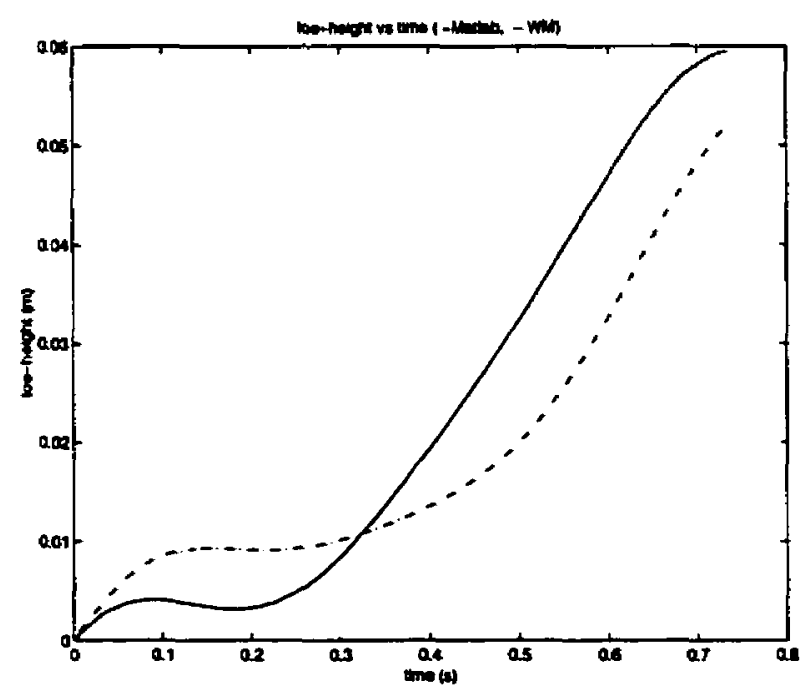

Figure 3.26 - Toe-height vs time for Matiab ${ }^{\mathrm{TM}}$ and Working Model ${ }^{\mathrm{TM}}$ simulations with upper leg length of $0.2 \mathrm{~m}$, desired forward body velocity of $0.3 \mathrm{~m} / \mathrm{s}$, initial thre $=-20$ degrees, unlocked knee swing time of 0.75 seconds, and cum of - 30 degrees 

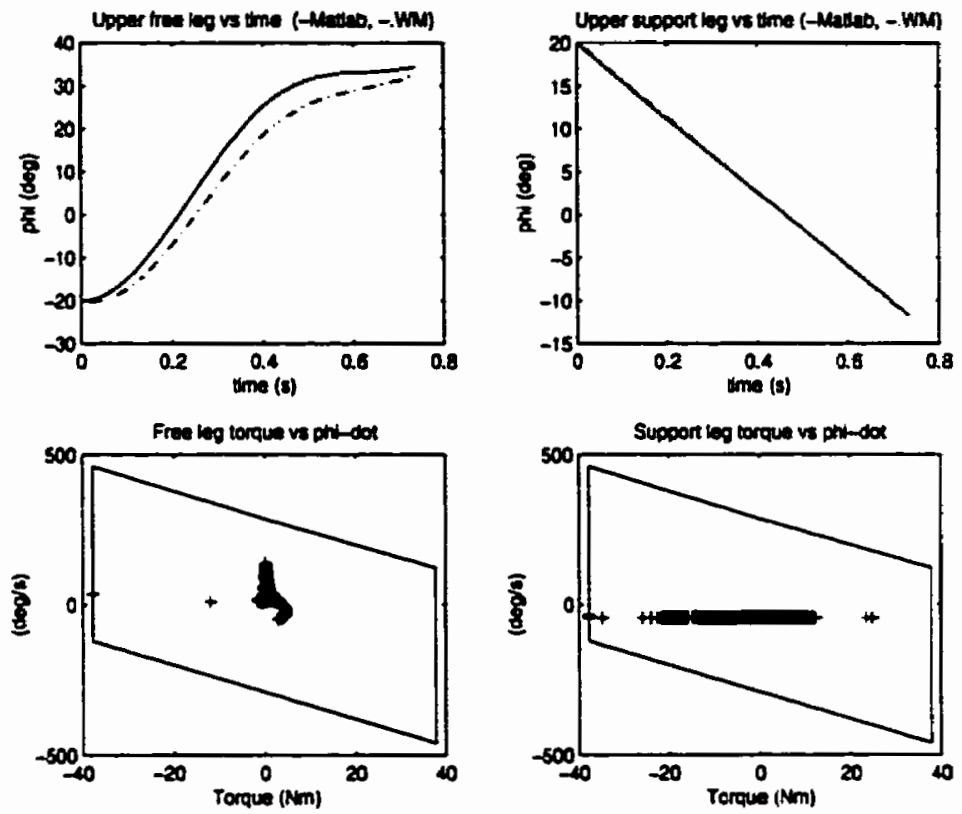

Figure 3.27 - Free and support leg angles vs time for Matlab ${ }^{\mathrm{TM}}$ and Working Model ${ }^{\mathrm{TM}}$ simulations and torque/speed curves from the Working Model ${ }^{\mathrm{TM}}$ simulation for a desired forward body velocity of 0.3 $\mathrm{m} / \mathrm{s}$, upper leg length of $0.2 \mathrm{~m}$, initial hree $=-20$ degrees, unlocked knee swing time of 0.75 seconds, and $\alpha_{\text {mpp }}$ of .30 degrees

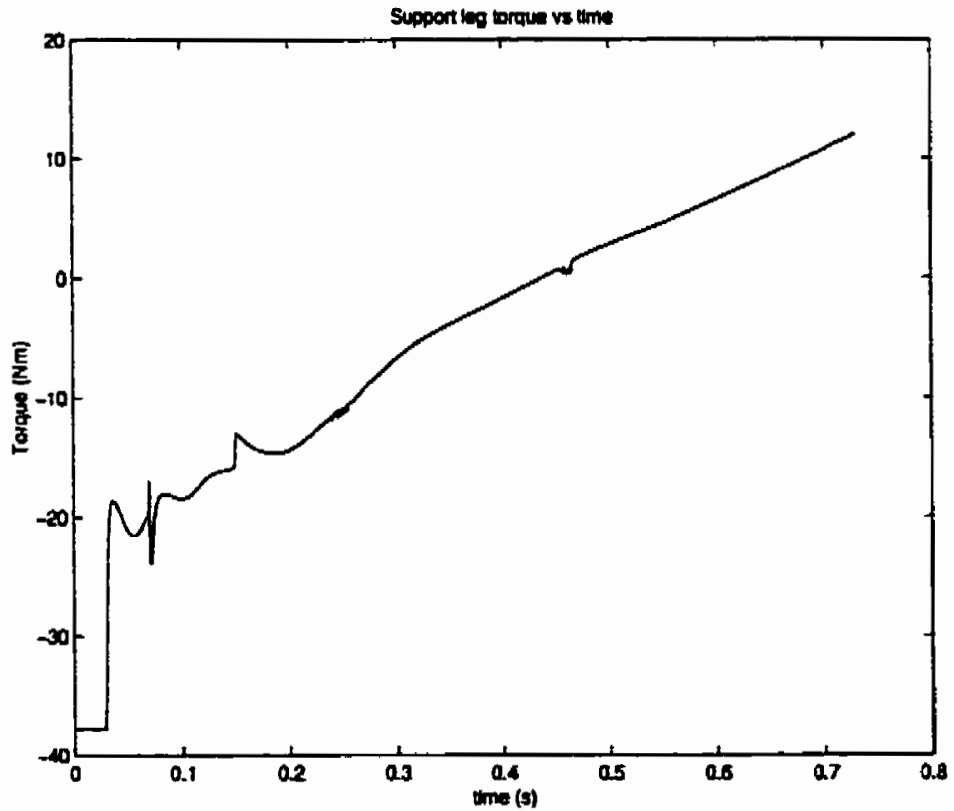

Figure 3.28 -Suppport leg torque for controlled velocity trot of $0.3 \mathrm{~m} / \mathrm{s}$ 


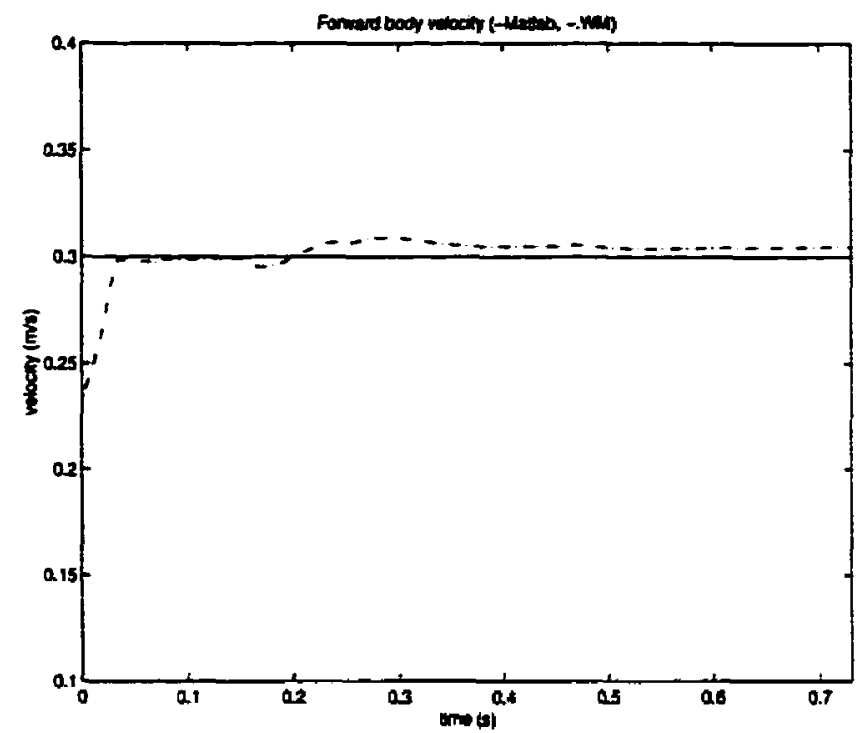

Figure 3.29 - Forward body velocity vs time for Matlab ${ }^{\mathrm{TM}}$ and Working Model ${ }^{\mathrm{TM}}$ simulations. Nominal desired velocity $=0.3 \mathrm{~m} / \mathrm{s}, \mathrm{I}_{\mathrm{up}}$ $=0.2 \mathrm{~m}, \phi_{\mathrm{nux}}^{0}=-20$ degrees, $\alpha_{\mathrm{m}, q}=-30$ degrees, $\mathrm{T}_{L S \alpha}=0.75 \mathrm{~s}$

The system is simulated in Working Model ${ }^{\mathrm{TM}}$ for a longer duration following a nonconstant velocity profile. Figure 3.30 and Figure 3.31 show the results of this Working Model $^{\mathrm{TM}}$ simulation. Figure 3.30 shows the velocity profile, where the dashed line represents the desired velocity, and the solid line represents the actual velocity. The desired velocity profile can be seen to be a linear increase from 0.05 to $0.4 \mathrm{~m} / \mathrm{s}$ in the first 5 seconds, then a constant velocity of $0.4 \mathrm{~m} / \mathrm{s}$ for 5 seconds, and then a return to $0.05 \mathrm{~m} / \mathrm{s}$ over the last 5 seconds. The optimal $\phi_{\text {tree }}^{0}$ and $\alpha_{\text {amp }}$ values as functions of desired velocity as determined in Section 3.13 are used in this simulation.

It can be seen that the overall velocity tracking is quite good, but that there are significant losses in velocity at each touchdown. These losses become worse as the desired velocity increases. Figure 3.31 shows the toe height and $\phi$ angle of leg 1 . The plot of $\phi_{l}$ shows that as the velocity increases, the overall stride of the legs increase. This is a manifestation of the optimal $\phi_{\text {free }}^{0}$ values of Table 3.5. As the touchdown angle 
increases, the torque required to lift the body increases. Furthermore, as the velocity increases, the angular velocity required of the legs increases. Both of these effects increase the torque required of the actuators to the point of saturation, which causes the increasing drops in velocity at leg touchdown as the desired velocity increases.

Despite these losses, it can be seen that the overall velocity tracking is quite good. In addition, the fact that this simulation lasted for 15 seconds indicates that the controller is stable. The plot of toe height $I$ in Figure 3.3I shows that there is no toe-drag using this algorithm, as predicted in Section 3.13.

The Working Mode ${ }^{\mathrm{TM}}$ simulations show that an upper bound for the velocity is $0.4 \mathrm{~m} / \mathrm{s}$. Beyond this value, the losses in velocity become too severe to provide adequate velocity control.

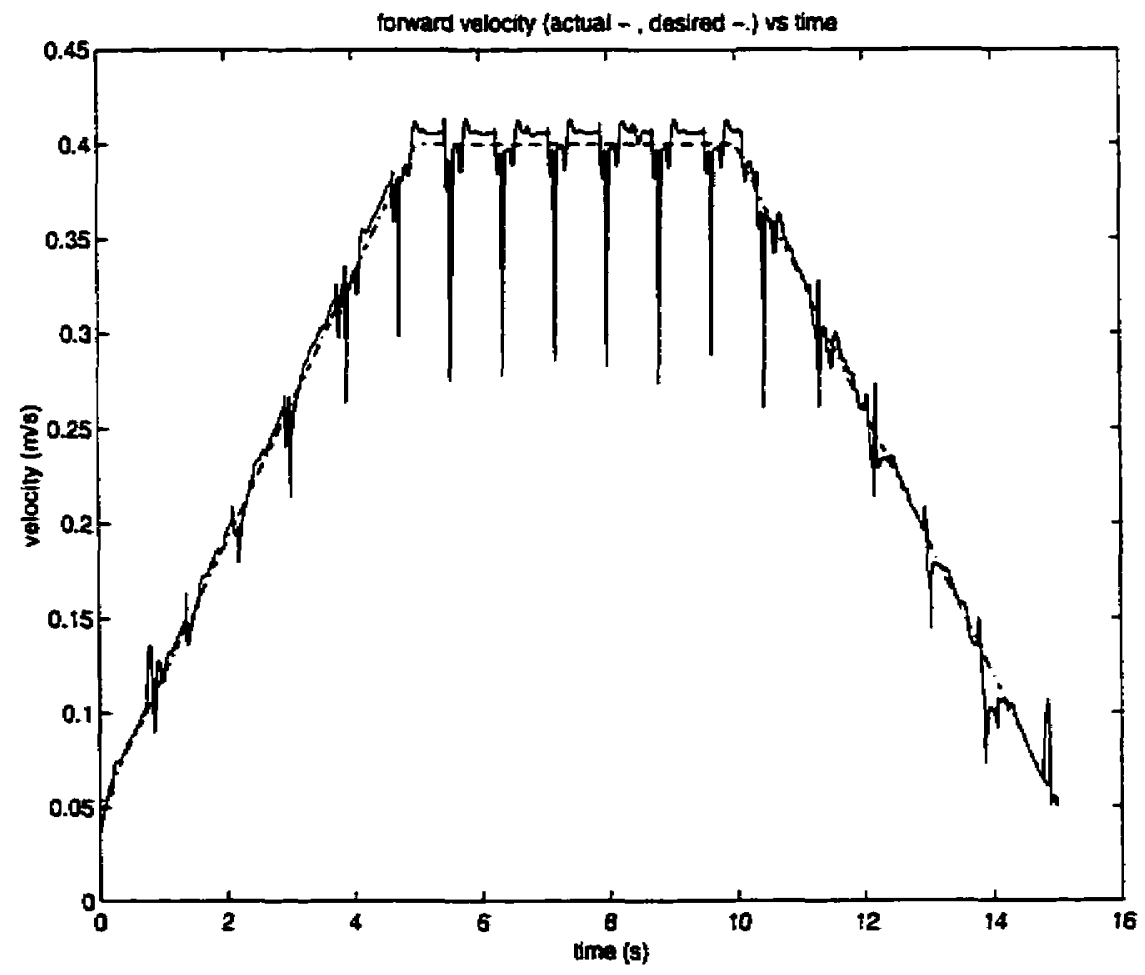

Figure 3.30 - Forward body velocity for ramp up down constant velocity algarithm $I_{\square}=0.2 \mathrm{~m}$ 

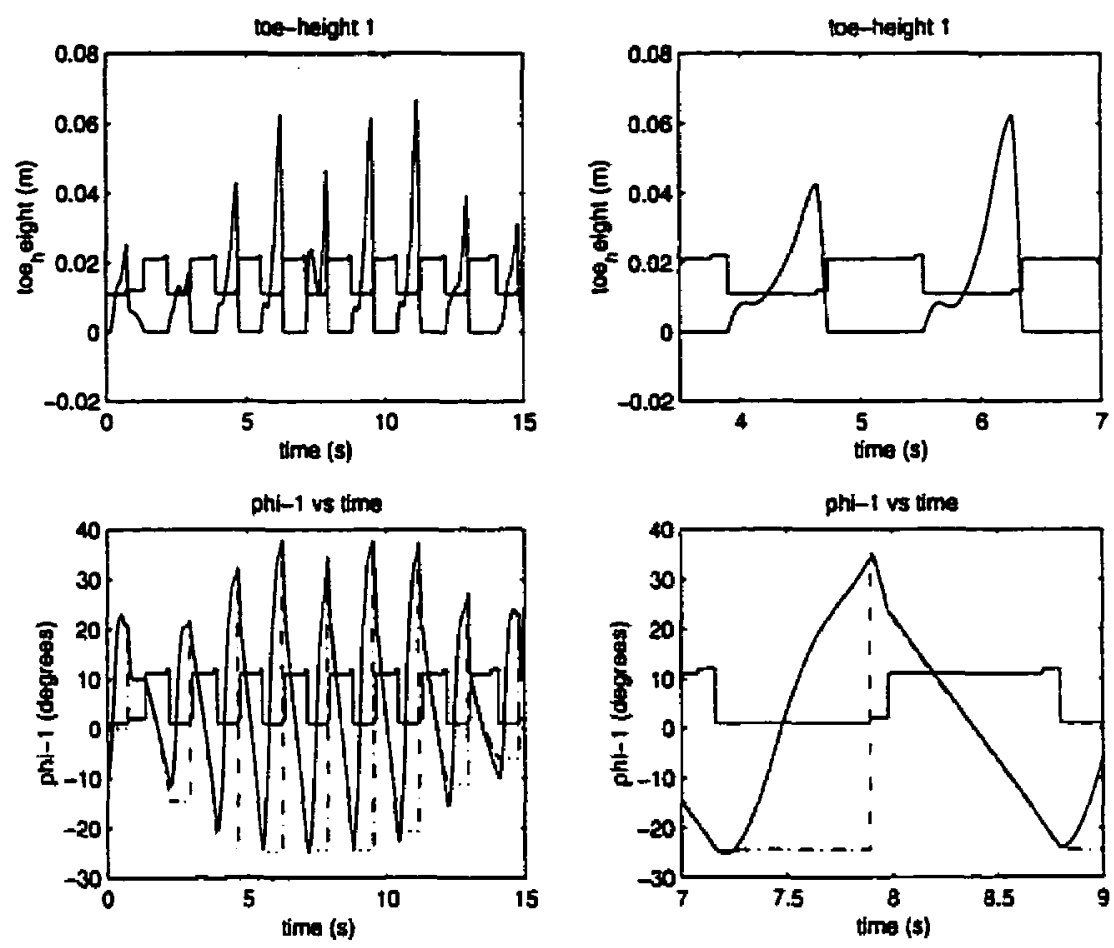

Figure $3.31 \cdot h t_{1}$ and $\phi_{1}$ for constant velocity ramp up down $I_{u p}=0.2 \mathrm{~m}$

\subsection{Summary}

This chapter introduced a model of a passive kneed quadruped system. The model was used to determine optimal parameter values for two different trotting controllers. A single leg system was modeled and simulated, and the results were used to simulate the entire system in the Working Model ${ }^{\mathrm{TM}}$ simulation package. Step and controlled velocity trots were successfully simulated.

The limits of the current robot were determined by implementing a motor model into the simulations. This model limits the applied torques to values that can actually be achieved by the actuators on board the real robot. It was found that an upper limit for the forward velocity of the robot (in simulation) is $0.4 \mathrm{~m} / \mathrm{s}$. This limit stems from the fact that in order to increase the speed, the stride of the robot must be increased, causing shallower hip angles at touchdown. Losses of velocity at each touchdown are increased as the 
touchdown angle becomes shallower, and at the higher speeds, the motors become saturated and cannot track the required trajectories. Nevertheless, step-trotting and controlled velocity trotting were achieved in simulation. 


\section{Chapter 4 Implementation}

\subsection{Overview}

This chapter describes the experimental results achieved for passive kneed trotting of the Scout II quadruped robot. The knee design of Chapter 2 was built and was mounted onto Scout II at ARL. Experiments were performed to achieve trotting gaits, using the algorithms developed in Chapter 3. Section 4.2 describes the setup used to perform the experiments. Section 4.3 shows the results of experiments performed on a single leg of the robot. The results of implementing the step-trot controller of Chapter 3, Section 3.9 are presented in Section 4.4. Finally, the controlled velocity trot (Chapter 3, Section 3.13) experimental results are presented in Section 4.5.

\subsection{Experimental Setup}

The knee was installed on Scout II and the robot was mounted onto the treadmill through the planarizer, a device of linear and rotational bearings which restricts the robot's motion to the saggittal plane (Section 2.5.1). This was done because the robot has no active way to prevent roll rotations, and the analysis was done assuming planar motion. The existing SPPSPI system was used to gather the robot data and it was stored in the onboard computer's memory. At the end of each experiment, the data was transferred as a data file to the ARL computer network, where it could be accessed, analyzed, and graphically displayed using Matlab ${ }^{\mathrm{TM}}$. The planarizer has a total travel of 1.0 metres. Consequently, for longer experiments where the robot travelled more than $1.0 \mathrm{~m}$, the treadmill was manually controlled to match the robot's speed.

\subsection{Single Leg Experiments}

As a first step in implementing the trotting controllers, a single passive kneed leg was attached to the robot and was controlled to follow a cycle that is representative of a trot. 
The robot was not mounted onto the treadmill, but was rested on a stand so that the leg did not hit the ground. By doing this, the mechanical, electrical, software, and data logging components of the system were tested and debugged. Figure 4.3 shows a series of still images from a video of a single leg experiment. Frames I through 4 represent state 11 , frame 5 is state 12, and frames 6 through 9 are states 21 and 22 (recall that the transition from state 21 to 22 is dependent on the legs that are of the different cycle - the algorithm for the locked support leg is the same for both of these states).

Figure 4.I shows a plot of the upper leg angle of the single leg as it is cycled through four cycles of states $11,12,21$, and 22 of the step-trot, using the optimal parameters determined in Chapter 3, Section 3.9. In addition, the results of the simulated system are plotted on the same graph. The bottom plot shows a closer view of one cycle of the same experiment and simulation. The legend shows which curves are from the Working Model $^{\mathrm{TM}}$ simulation (WMphi_1, WMphi_1_d, WMstate), and which are from the experiment. WMphi_1_d and phi_1_d represent the desired upper leg angles of the simulation and the experiment respectively, which are input into the PID controllers. WMphi_I and phi_l represent the achieved upper leg $\phi$ trajectories. The horizontal lines are the state values, which are scaled to fit within the data at 1:1 (ie: 11 degrees on the axis represents state 11 ). It can be seen that during the $\phi$ control states (states $12,21,22$ ), the actual and the desired signals of both the simulation and the experiments agree almost perfectly. During state 11, when the knee angle control torques are applied to the hip actuator, the simulation and the experimental values differ slightly. In this situation, the controller moves the $\phi$ angle in whatever path is necessary to achieve the cosine type knee angle trajectory, $\alpha$. Figure 4.2 shows the $\alpha$ trajectories (achieved and desired) from the simulation and the experiment. It can be seen that the $\alpha$ tracking for both the simulation and the experiment agree quite closely. The bottom plot of this figure shows the delay in the $\alpha$ tracking at the start of state 11 due to the time it takes for the solenoid locking device to unlock the knee. Furthermore, the slight jitter at the end of state 11 shows the time it takes to lock the knee. 
The differences between the upper leg angle ( $\phi)$ curves (simulation and experiment) of Figure 4.1 during state 11 (the unlocked knee phase) are due to unmodeled factors. The dynamic coupling is larger in the simulation because friction is neglected. In the actual robot, despite having teflon coated bearings for the knee joint, some friction still remained which forced the hip motion to be a bit more dramatic to achieve the same knee angle trajectory. Please note that during state 11 , the $\phi$ angle is not controiled to follow a desired $\phi$ trajectory, which is why the desired trajectory curves are flat. The model limitations are discussed in more length in Section 4.4.
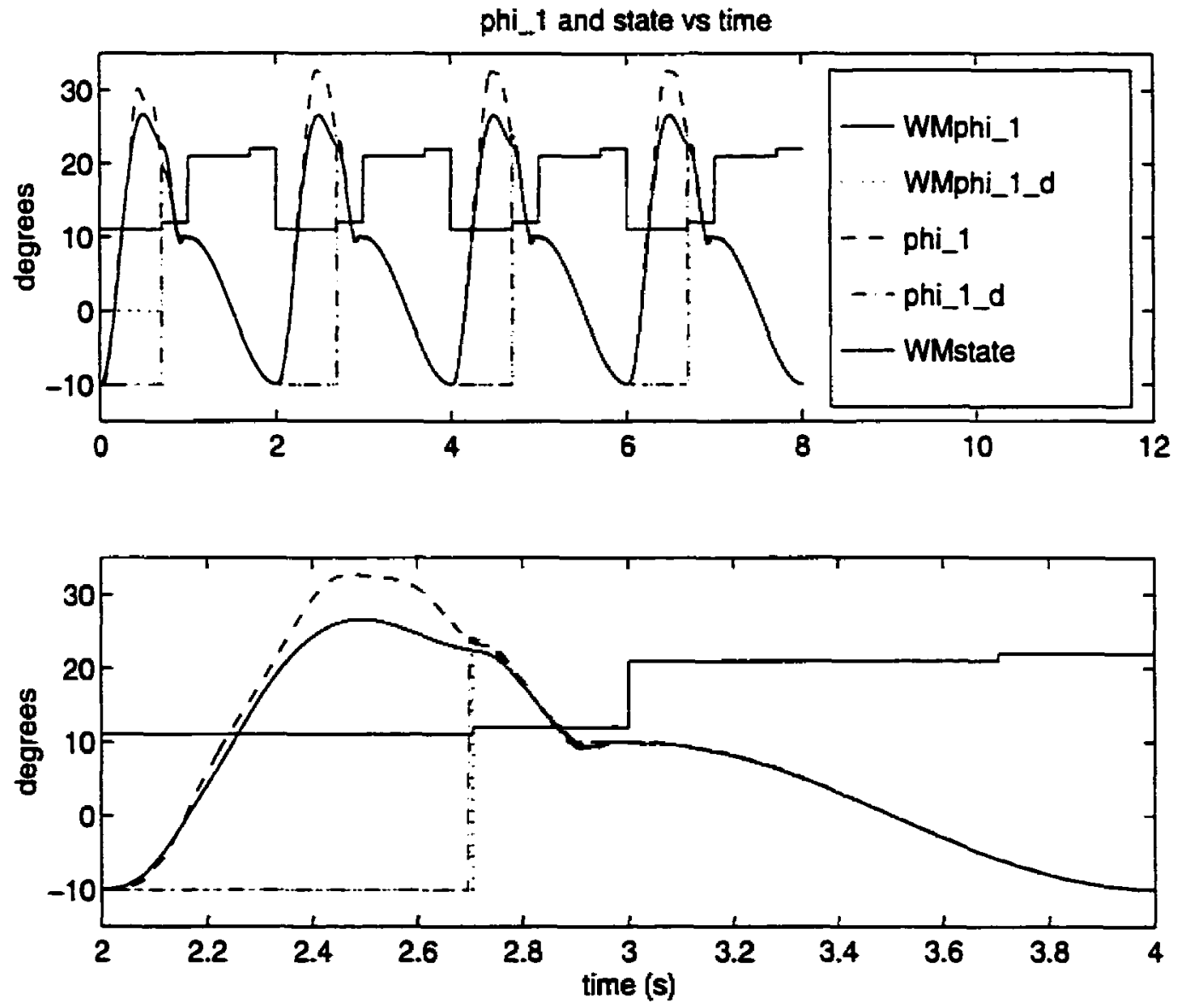

Figure 4.1 - $\phi$ actual and desired and state vs time for single leg experiment on Scout II and for the same experiment simulated in Working Model ${ }^{\mathrm{TM}}$. The second graph is a closer view of 2 seconds of the same data. 

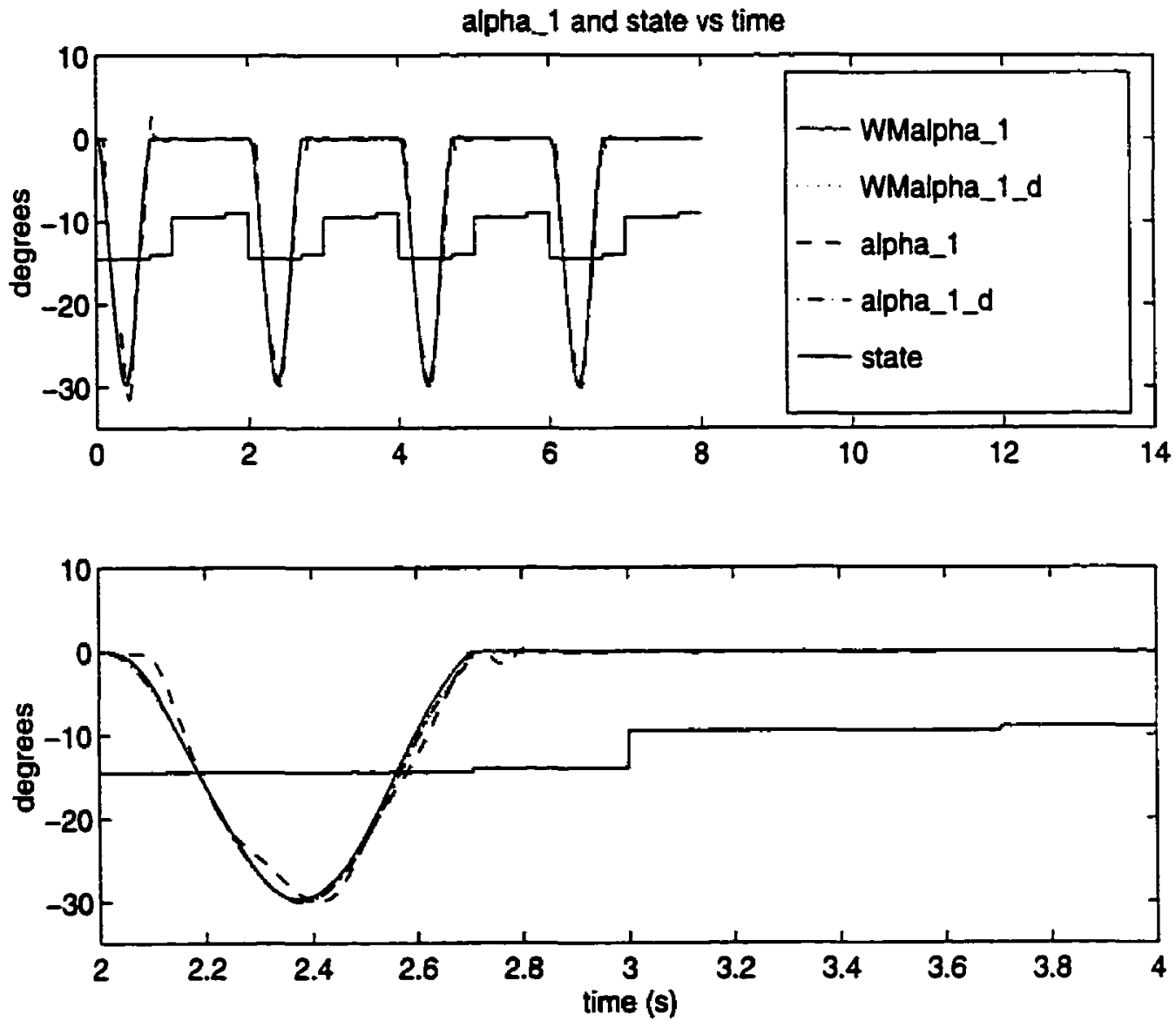

Figure $4.2-\alpha$ actual and desired and state vs time for single leg experiment on Scout II and for the same experiment simulated in Working Model ${ }^{T M}$. The second graph is a closer view of 2 seconds of the same data. 
1

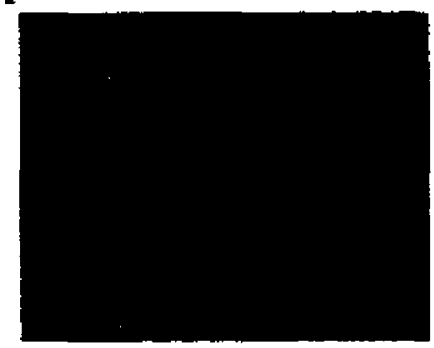

4

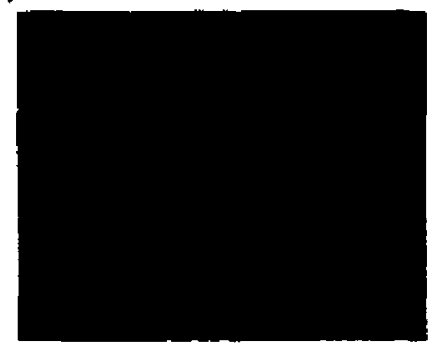

7

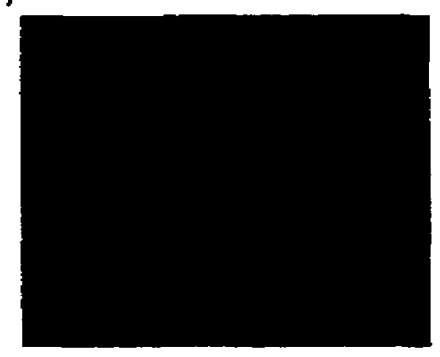

2

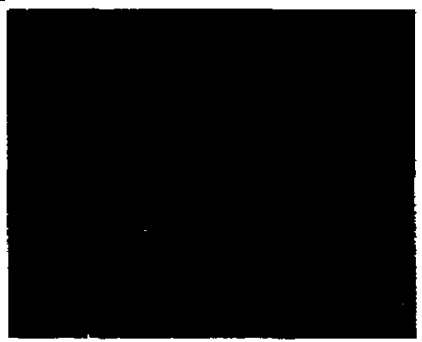

5

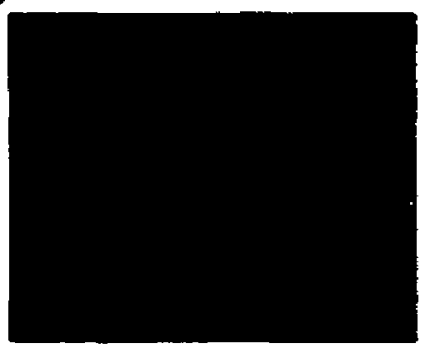

8

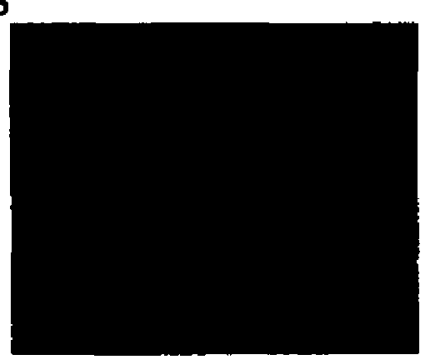

3

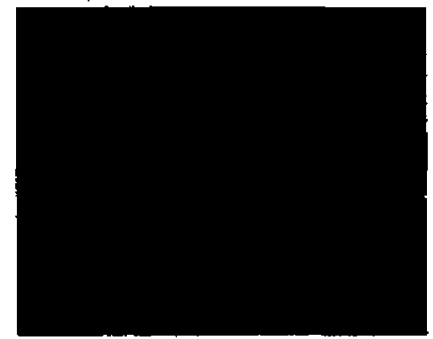

6

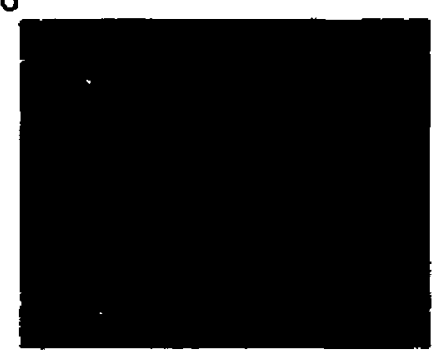

9

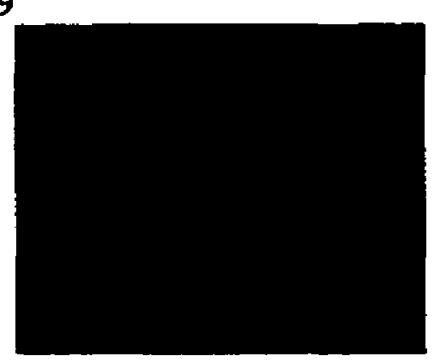

Figure 4.3 - Single leg cycle for passive knee trotting

\subsection{Step-Trot Experiments}

The robot was mounted on the treadmill using the planarizer, and step-trot experiments were performed, using the algorithm developed in Section 3.10.1. Only the longer leg length configuration was tested because Section 3.9 determined that this offered the most toe-height, and consequently the most robustness to toe-stubbing. Figure 4.6 shows a series of still images from a video of a step-trot. Three steps are taken, with the following frames correponding to the following states: frames 1 through 4 show state 11 , 
frames 5 through 7 show state 12 , frames 8 and 9 show state 21 , frames 10 and 11 show state 22, frames 11 and 13 show state 11 , and frames 14 and 15 show state 12.

Figure 4.4 shows the upper leg $\phi_{l}$ and knee angle $\alpha_{l}$ trajectories for a $35 s$ step-trot. The experiment was stopped by the researcher, and not because the robot stumbled. It can be seen that the shape of the $\phi$ trajectory during knee control (state 11 ) is similar to the simulated results (Figure 3.14), and that the support $\phi$ trajectories (states $2 l$ and 22) track the desired values quite well.

Figure 4.5 shows the toe height of leg 1 for the same step-trot. The second plot shows the toe height for states 11 and 12 of the first cycle. It can be seen that the toe height is positive for all of state 11 and that it touches the ground during state 12 at the desired touchdown value.

Although a successful step-trot was achieved, the experimental parameters and initial conditions that were used to obtain a stable step-trot on the treadmill (Table 4.1) are significantly different from the simulation values (Table 3.3). However, it is important to note that the general trajectory shapes are the same, and that the resulting trot is stable. The discrepancies are due to unmodeled factors. For example, the solenoids selected were not strong enough to unlock the knee when the leg was bearing any weight. It was assumed that during all four leg ground contact, a minor decrease in the support legs angles would raise the swing leg high enough that the solenoid could unlock the knee. Unfortunately, the backlash in the motor, the gearhead, and the belt transmission was of the order of several degrees, which made it impossible to rely on solely a small angular difference between the support and the free legs. To accomodate this, the initial free leg angle was selected to be greater in magnitude (though opposite in sign) of the touchdown angle (initial support angle). Consequently, the toe was in the air at the time of unlocking, and the symmetry of the initial free leg and support leg angles was lost. The 
second plot of Figure 4.5 shows that at the start of the cycle (state 11), the toe height was not zero, but close to $4.0 \mathrm{~cm}$.
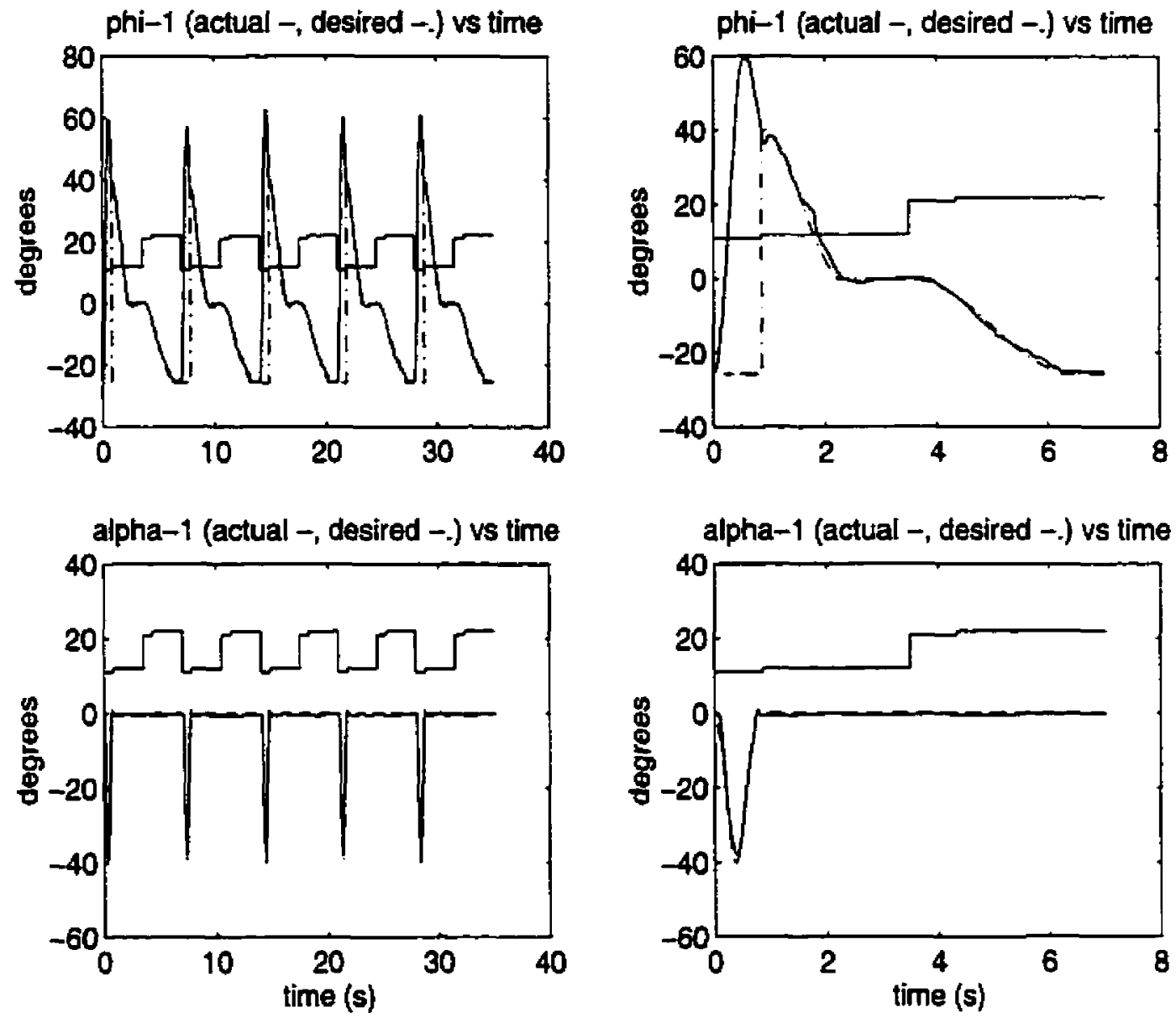

Figure 4.4 - $\phi_{1}$ and $\alpha_{1}$ (desired and actual) and scaled state vs. time for step-trot (experimental data)

\begin{tabular}{|l|l|}
\hline$\alpha_{\text {mmp }}$ & $-40^{\circ}$ \\
\hline$L_{\text {Lp }}$ & $0.20 \mathrm{~m}$ \\
\hline Initial $\phi_{\text {free }}$ & $-22^{\circ}$ \\
\hline Initial $\phi_{\text {sup }}$ & $0^{\circ}$ \\
\hline$T_{L S}$ & $3 \mathrm{~S}$ \\
\hline$T_{L S \alpha}$ & $0.75 \mathrm{~s}$ \\
\hline
\end{tabular}

Table 4.1 - Trajectory parameters and initial conditions for experimental step-trot 
The backlash of the belt transmission provided an additional discrepancy: the encoder that measures the hip angle $(\phi)$ is mounted on the motor shaft. Consequently, any backlash in the belt will not be picked up by the angle sensor. This resulted in an uncertainty in the support leg angle of roughly one degree. To compensate for this, the initial support leg angle had to be reduced from $10^{\circ}$ to $0^{\circ}$, the total cycle time $\left(T_{L S}\right)$ had to be increased from $1.0 \mathrm{~s}$ to $3.0 \mathrm{~s}$, and the initial free leg angle had to be changed from $-10^{\circ}$ to $-22^{\circ}$ to give the free legs time to clear the ground. Furthermore, the amplitude of the knee trajectory had to be increased from $30^{\circ}$ to $40^{\circ}$ to ensure ground clearance.

A final source of error is that the moment of inertia of the lower leg used in the simulation was taken from the CAD package (ProEngineer ${ }^{\mathrm{TM}}$ ) and not determined experimentally. Differences in the masses and mass distributions of the components that formed the lower leg could account for some differences between the simulation and the experiment.

Table 4.2 shows the controller gains for the trotting experiments. Please note that these remained constant for both step trotting and for the controlled velocity trot of Section 4.5. The discrepancies described above partially account for the large differences between these and those used in the simulations (Table 3.4 and Table 3.7). Perhaps a more significant difference is due to the derivative gain. The $\dot{\phi}$ and $\dot{\alpha}$ terms used in the PID controllers are obtained by differentiating their angular values in real time. Electrical noise and the effect that differentiation has of amplifying errors create large errors in these signals. Consequently, they are filtered with a digital low pass filter prior to use. The effect of the filter is to create a slight delay in the derivative signal, and in addition, the filtering does not remove all of the noise. The consequence of this is that the derivative signal is not completely reliable, and therefore, the derivative gain terms (KD) must be kept quite low. As in any dynamical system, changing the gain values of one of the controller terms has a cascade effect on the remaining gain values. In other words, the poor sensing of angular velocity necessitated the reduction in the KD gain values, 
which in turn forced changes in the proportional (KP) and integral (KI) gain values. Despite all this, it was possible to experimentally tune the controller gains to achieve good tracking, as can be seen in Figure 4.4.

\begin{tabular}{|l|l|l|l|l|l|}
\hline \multicolumn{2}{|l|}{ Support-legs } & \multicolumn{2}{|l|}{ Unlocked free legs } & \multicolumn{2}{l|}{ Locked free legs } \\
\hline $\mathrm{KP}_{\text {suppor: }}$ & 1000 & $\mathrm{KP}_{\alpha:}$ & 65 & $\mathrm{KP}_{\text {free: }}$ & 100 \\
\hline $\mathrm{KD}_{\text {suppon: }}$ & 3 & $\mathrm{KD}_{\alpha:}$ & 1 & $\mathrm{KD}_{\text {free }}:$ & 1 \\
\hline $\mathrm{KI}_{\text {suppor: }}$ & 700 & $\mathrm{KI}_{\alpha:}$ & 50 & $\mathrm{KI}_{\text {free: }}$ & 5 \\
\hline
\end{tabular}

Table 4.2 - Controller gains for step-trot experimental results
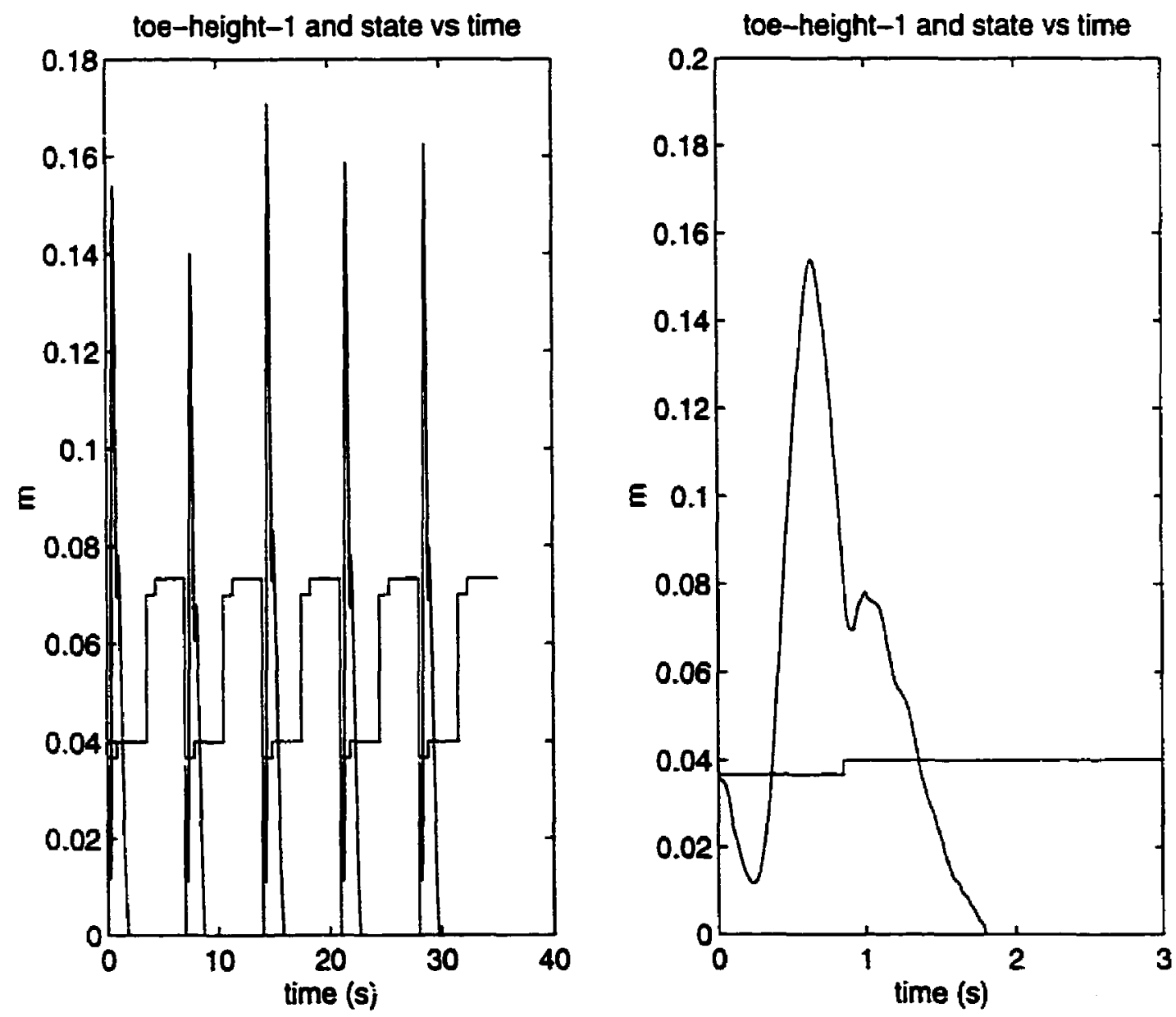

Figure 4.5 - Toe height of leg 1 and scaled state vs. time for step-trot (experimental data) 

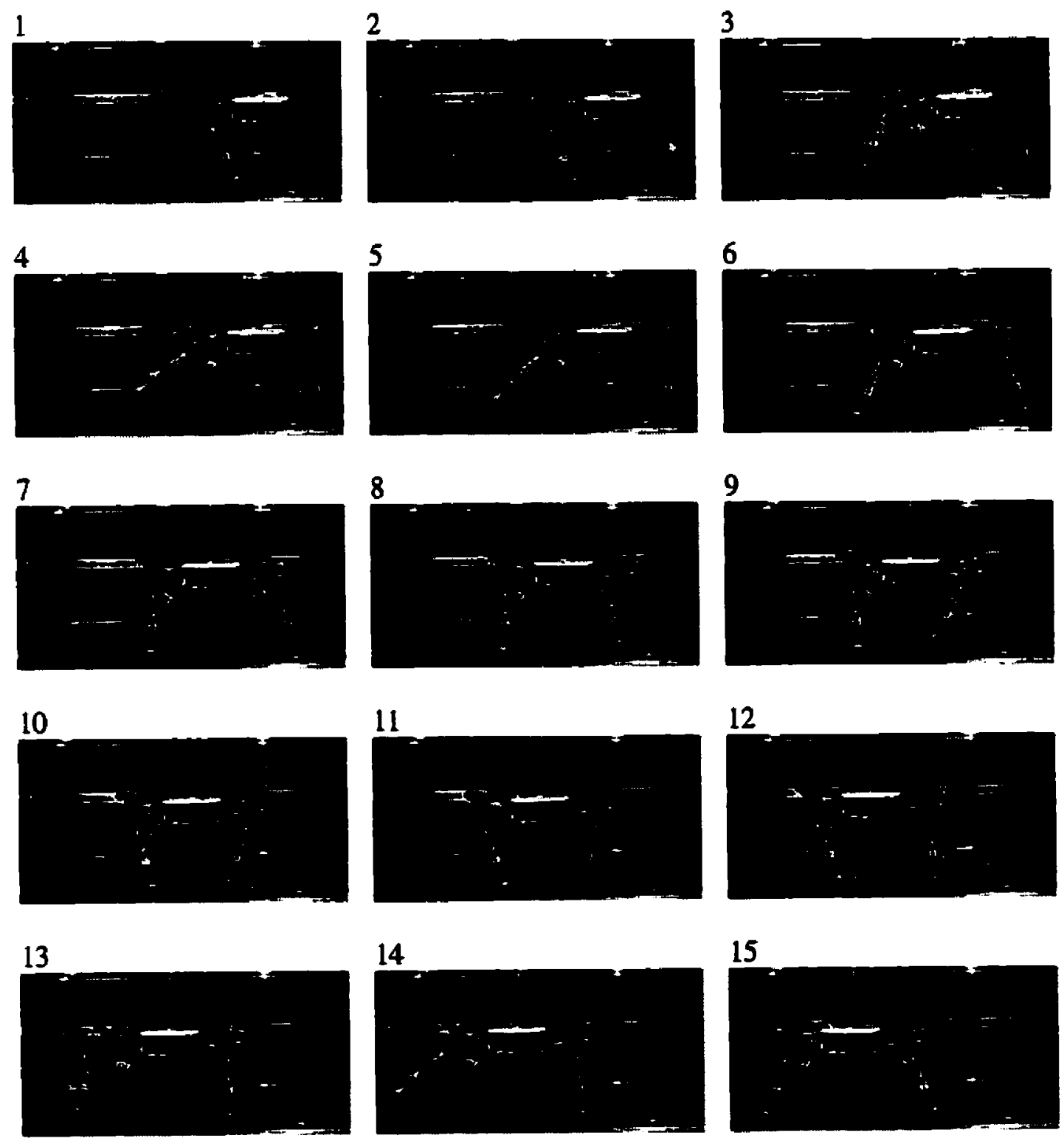

Figure 4.6 - Scout II step-trotting on treadmill. Three steps taken, approximately 9 seconds. 


\subsection{Controlled Velocity Trot Experiments}

The controlled velocity trot algorithm was implemented on Scout II. Figure 4.7 shows the velocity data obtained from one experiment where the robot tracked a non-constant desired velocity signal for over 90 seconds. The desired velocity signal is the dashed line of the second plot of the figure. It can be seen to stay constant at $0.05 \mathrm{~m} / \mathrm{s}$ for the first 10 seconds, then it follows a linear trajectory to $0.1 \mathrm{~m} / \mathrm{s}$ for roughly 15 seconds, where it stays for 15 seconds. Finally, it ramps back down to $0.05 \mathrm{~m} / \mathrm{s}$ where it stays for the remainder of the experiment. It should be noted that the robot started initially from rest, and that it can easily come to a complete stop from a speed of $0.05 \mathrm{~m} / \mathrm{s}$ by locking all four knees and by applying a zero angular velocity control signal to the hip angles.
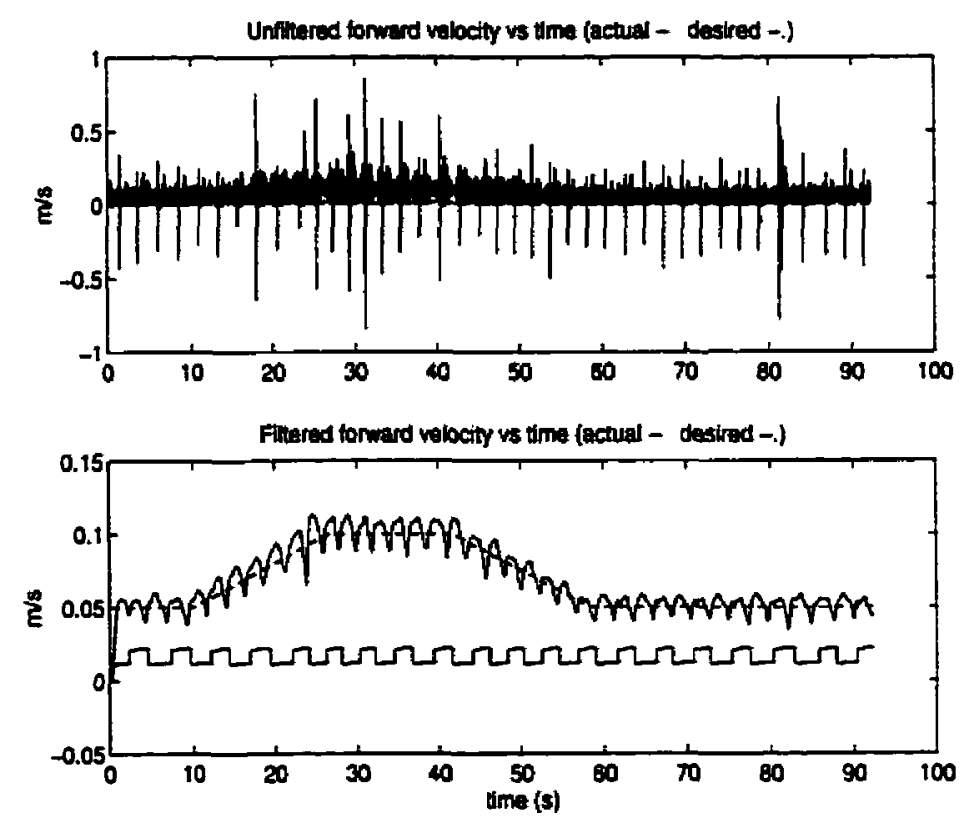

Figure 4.7 - Filtered and unfiltered velocity profiles for ramp up and down controlled velocity trot (desired and actual signals), with scaled state shown

Figure 4.7 shows both the filtered and the unfiltered velocity signal. The robot velocity is calculated as a function of the support leg angles and angular velocities. In reference to Chapter 3, Section 3.3.2, equation (3.4), the robot's forward velocity can be calculated as: 


$$
v=-\left(l_{\text {low }}+l_{\text {up }}\right) \dot{\phi}_{\text {sup }}(t) \cos \phi_{\text {sup }}(t)
$$

The hip angular velocities were determined experimentally by differentiating the hip angle signal. It was found that the $\dot{\phi}$ signals thus obtained were extremely noisy, and required filtering. It is the dependence of the velocity on the hip angular velocity (as seen in (4.1)) that resulted in such a noisy velocity signal Nevertheless, once the signal was properly filtered, it can be seen that the velocity of the robot does track the desired velocity quite well. Furthermore, the velocity drops once per step - this can be seen by comparing the period of fluctuation of the velocity with the state signal. This drop in velocity was observed during the simulations (Figure 3.30 of Chapter 3), and is caused by losses due to leg touchdowns. This is described in detail in Chapter 3.

Section 4.4 describes the discrepancies between the simulation studies and the actual experiments. These discrepancies necessitated some changes to the controller algorithm to achieve a successful step-trot. The same is true for the controlled velocity trot. Again, as a result of backlash in the motor, gearing, and belt transmission, and because the solenoid was not strong enough to unlock the knee when it was bearing any weight, the toe had to be raised to roughly $4.0 \mathrm{~cm}$ prior to unlocking it. This necessitated setting the initial support leg angle to $0^{\circ}$ to ensure that the swing toe did not hit the ground. In simulation, this value was not set because the free leg converts to a support leg as soon as it touches the ground after knee lock, and the free leg unlocks its knee at the same instant. In simulation, the exchange of support was perfect, so the consideration of the strength of the solenoid was neglected. Consequently, to ensure that the solenoid was not trying to unlock while bearing any weight in the actual experiments, the toe had to be raised to roughly $4.0 \mathrm{~cm}$, as described above. 


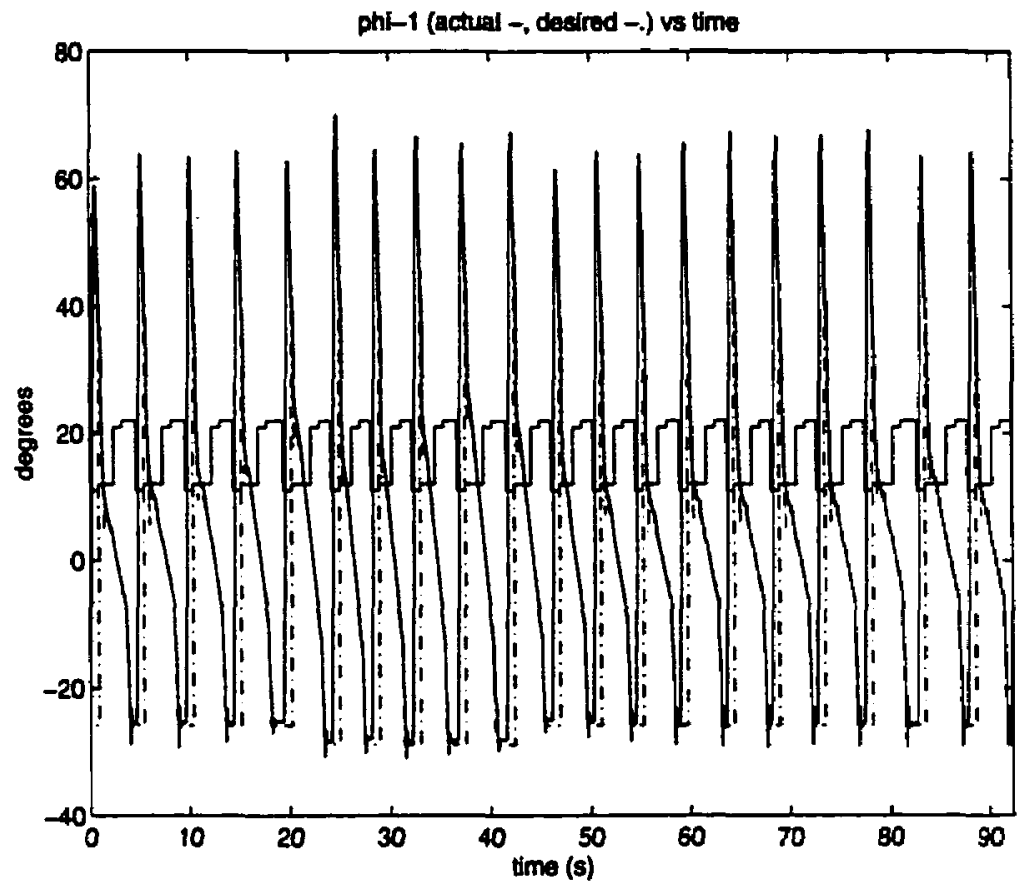

Figure 4.8 - $\phi_{1}$ trajectory during ramp up and down controlled velocity trot

Figure 4.8 shows a plot of the hip angle of leg 1 during this experiment, and the state value. Figure 4.9 shows a closer view of two of the steps of this cycle. Although the data for the remaining three legs is not provided, they are all very similar. The first plot of Figure 4.9 corresponds to a desired velocity of $0.05 \mathrm{~m} / \mathrm{s}$ and the second plot corresponds to $0.1 \mathrm{~m} / \mathrm{s}$. A few more modifications to the simulation algorithm can be observed in these plots. A problem encountered during the implementation was that because the knees were not unlocked until the support legs reached $0^{\circ}$ (to raise the free leg toes high enough to permit the knee to unlock), the subsequent touchdown angle was much larger than in the simulation. To help reduce this effect, the locked free legs were swept at a much faster rate towards the ground than the controlled velocity sweep trajectory of Section 3.3.2, as was done in the simulation. This is observed as the steeper negative slope trajectories during the first part of state 12 in both plots of Figure 4.9. The point at which this slope becomes less steep is when the leg touches the ground and it begins to follow the controlled velocity support leg trajectory. What can be observed is that as the body's forward velocity increases, the touchdown angle becomes larger. As 
this angle becomes larger, the torques required of the actuators increase, ultimately to the point of saturation and stall. Figure 4.12 shows the torque speed curves of this experiment for each leg, with the theoretical motor model bounding box of Chapter 3 shown. Clearly it can be seen that the motors are saturated a fair amount of the time. It was found that if speeds in excess of $0.1 \mathrm{~m} / \mathrm{s}$ were attempted, that the legs would hit the ground at a steep enough angle that the motors could not provide enough torque to continue the stride, and the robot would come to a stand still. This explains why the top speed the robot achieved in experiment is smaller than that achieved in simulation.

Furthermore, please note that although the data for the knee angle $(\alpha)$ trajectories is not provided, the response is very similar to that achieved during the step trotting experiments (Figure 4.4).

Figure 4.10 shows the height above the ground of toe 1 for the experiment, and Figure 4.11 shows a closer view of two of the cycles (the left plot corresponds to a velocity of $0.05 \mathrm{~m} / \mathrm{s}$, and the right plot corresponds to a velocity of $0.1 \mathrm{~m} / \mathrm{s}$ ). It can be seen that at the start and the end of each cycle that the toe is raised to roughly $4.0 \mathrm{~cm}$, as described earlier in this section.
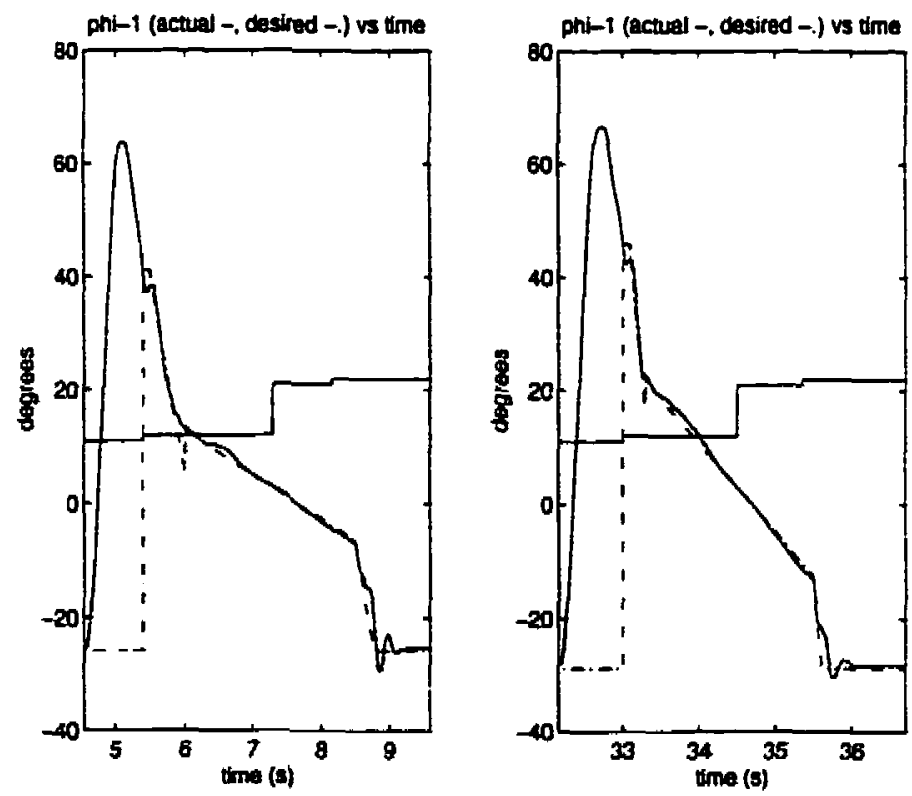

Figure 49 - $\phi_{1}$ trajectory for 2 cycles of ramp up and down controlled velocity trot 
To conclude, the controlled velocity trot was successfully implemented on the Scout II robot for speeds ranging from 0.05 to $0.1 \mathrm{~m} / \mathrm{s}$. Certain unmodeled factors necessitated some modifications to the controller algorithm, which in turn reduced the maximum achievable speed as compared to the simulations. Nevertheless, stable, controlled velocity trotting with passive knees was successfully implemented.

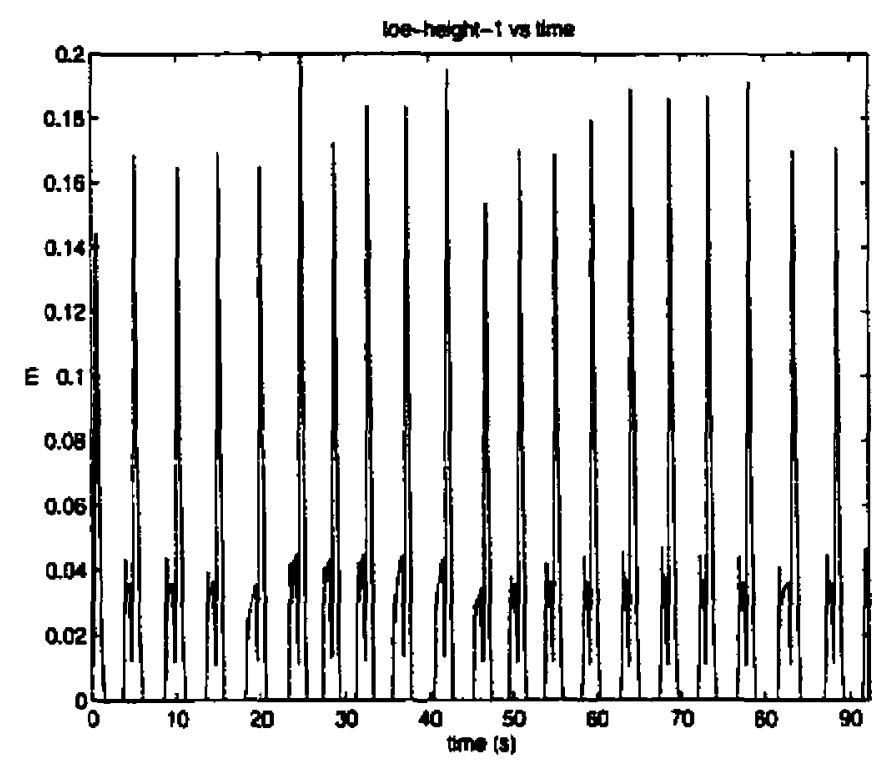

Figure 4.10 - Toe height of leg 1 for ramp up and down controlled velocity trot

\subsection{Summary}

Step trotting and controlled velocity trotting were successfully implemented. Although some modifications to the theoretical algorithms had to be made, both simulated gaits were achieved in experiment.

The causes of some deviations in the algorithms and results from the simulations are explained, and the data from the experiments are graphically presented. It was found that certain unmodeled mechanical factors such as friction and backlash forced some 
modifications to the setpoints determined in the analysis and simulation of Chapter 3. The friction in the knee joint caused a slightly different upper leg feedback response to the knee angle trajectory, and the backlash caused enough uncertainty in some of the sensed robot parameters that the algorithm trajectories had to be modified. Nevertheless, much of the information and many of the ideas learned in simulation were used in the implementation. Ultimately it was found that the upper velocity limit of the robot was $0.1 \mathrm{~m} / \mathrm{s}$. Beyond this, the touchdown angles were steep enough to cause motor stall. In addition, up to $0.1 \mathrm{~m} / \mathrm{s}$, the velocity could track a linear ramp signal quite well.
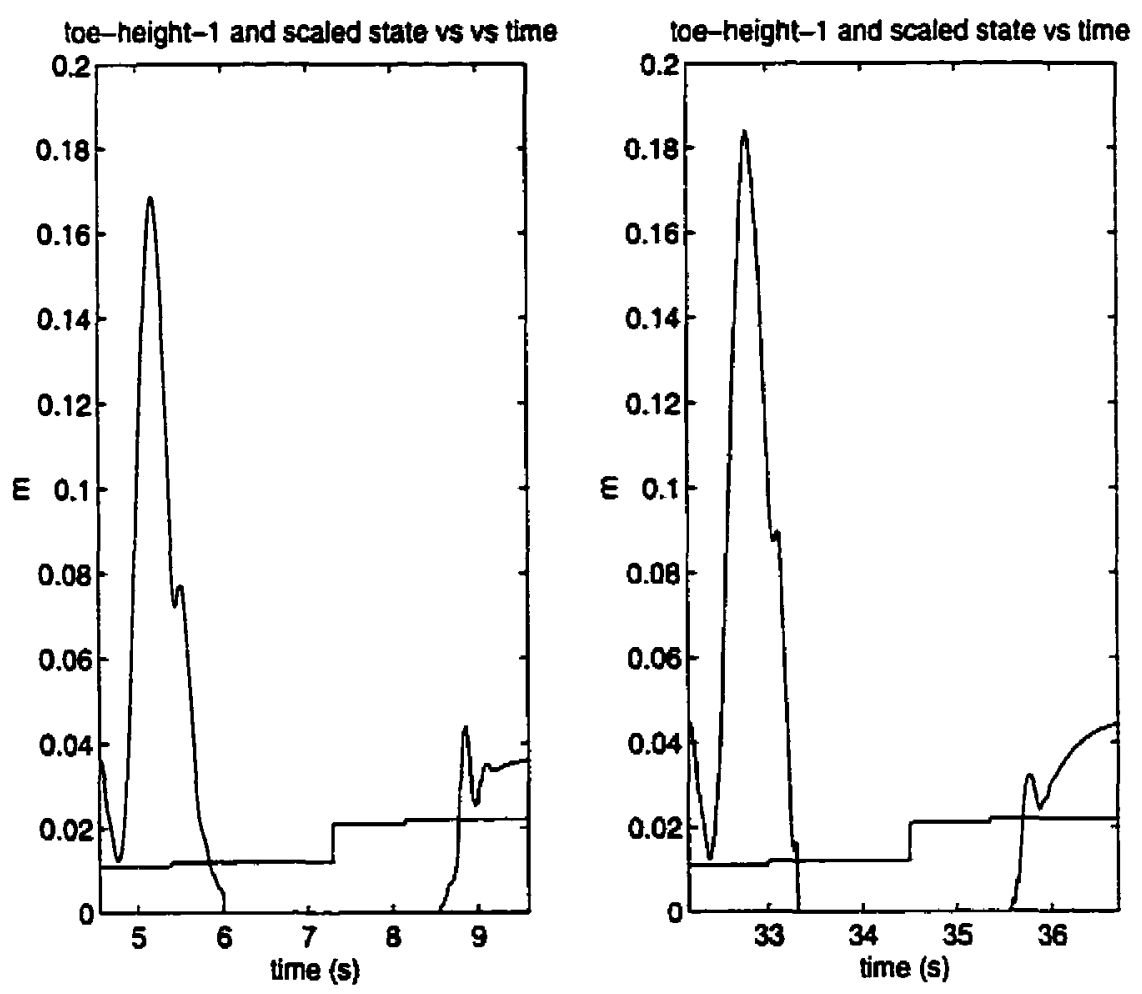

Figure 4.11 - Two cycles of toe height 1 for ramp up and down controlled velocity trot (experimental results) 

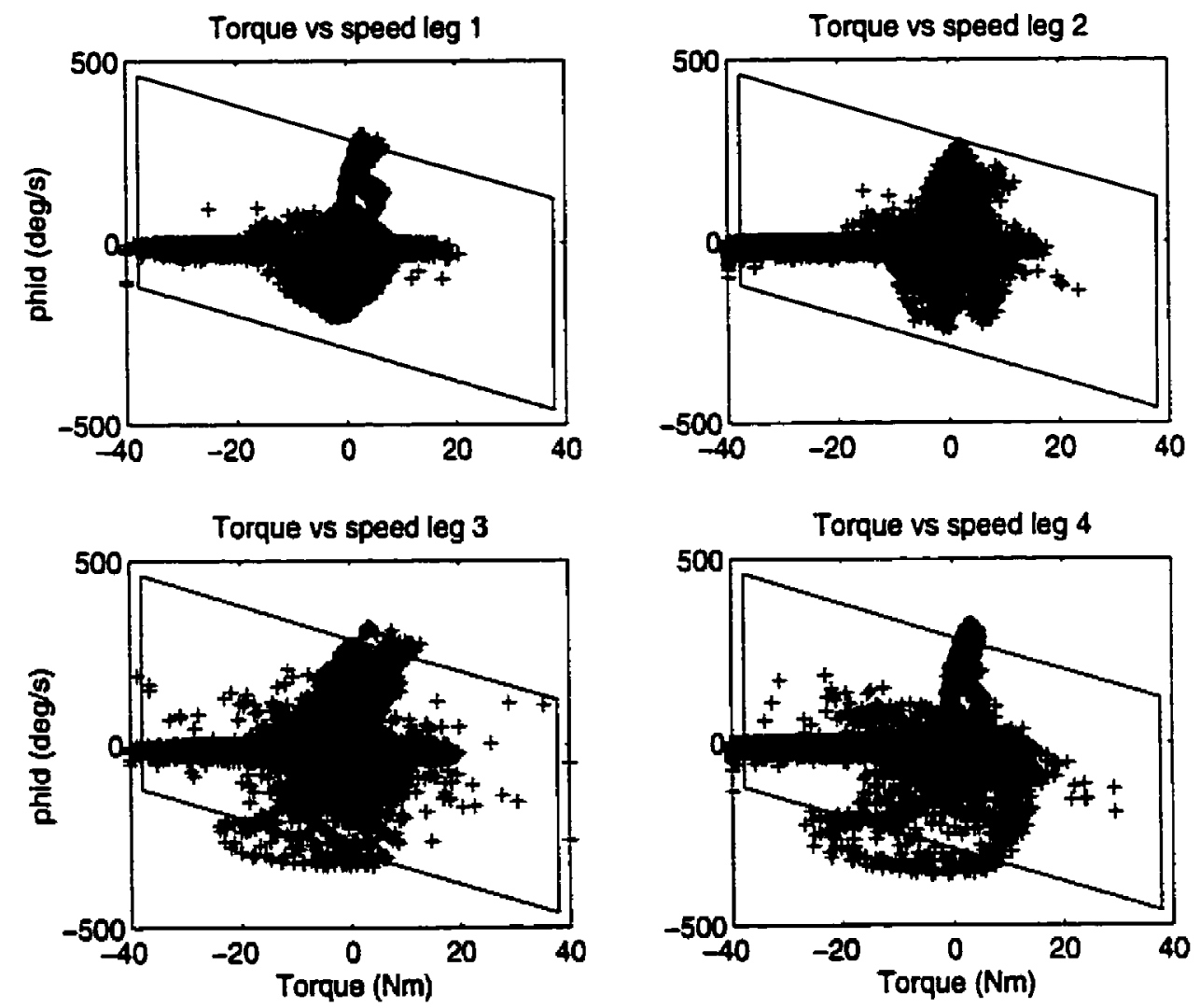

Figure 4.12 - Torque vs speed curves for each leg during the ramp up and down controlled velocity trot (experimental results with theoretical motor model shown as a bounding parallelogram) 


\section{Chapter 5 Conclusion}

Passive kneed trotting with the Scout II quadruped was successful. This research project began with a quadruped robot that did not have knees, and through a series of steps including mechanical and electrical design, theoretical analysis, and experimental implementation, a majority of the initial goals were achieved. Among the contributions of this work are the development and integration of a new passive knee system with an energy efficient locking mechanism, an electronic circuit for power and computer control of the lock, and the software to control the lock as part of various walking algorithms. Furthermore, the dynamics of the knee were modeled and analyzed as an individual leg system, and as part of the complete passive kneed quadruped system. These models were used to develop and simulate two different walking controllers. The information obtained from these simulations was used to assist in the successful implementation of trotting gaits using the passive knee in conjunction with Scout II.

The thesis began by reviewing past work at the Ambulatory Robotics Laboratory (ARL), and of passive dynamical systems, particularly as they relate to legged robotics. Subsequently, the mechanical and electrical details of Scout II were outlined. The design of the passive knee was explained, including a description of the specifications the knee had to satisfy. Stress analyses of two components of the locking mechanism were performed verifying that the knee would withstand the loads exerted on it when walking. A discussion of the various commercial components used in the knee was provided. In Chapter 3, a detailed dynamical analysis was performed by developing the equation of motion of a simplified single leg system. This model was verified independently in a separate commercial simulation software package. It was used to determine a set of optimal trajectory and geometric parameters for various types of trotting. The entire quadruped system was simulated in the software package, using the information obtained from the single leg model anaiysis. Finally, the walking controllers that had been 
simulated were implemented on Scout II, and the results were presented in Chapter 4. A good correlation was observed between the experimental and simulated single leg system. Successful trotting was achieved, but certain unmodeled factors in the simulation forced certain changes in the implemented algorithms (as compared to the simulated algorithms), which made comparing them difficult. Despite these differences, the experimental results showed that it is possible to achieve robotic walking with 2 degree of freedom legs, in which there is only active control of the hip joint. It is hoped that this work will inspire others to investigate using natural dynamics and passive systems to achieve energy efficient, reliable robotic walking.

Despite the successes achieved, there are certain limitations of the current work that need to be addressed. First and foremost is that the robot cannot use the current trotting algorithms if it is not mounted to the planarizer to stabilize the roll rotations. In the previous operations of Scout I and II, the gait used is the bound, in which the front or the back legs are always on the ground, or one set of them will hit the ground together at the next touchdown. If touchdown occurs earlier than anticipated, automatic stabilization occurs since the unstable body rotation is the pitch, which can be stabilized by ground contact with a front or a rear leg pair. In the case of the trot, the unstable roll rotation is along the axis formed by the diagonal between the touchdown legs. In this case, if the rotation along this diagonal causes a premature leg touchdown, the result is toe stubbing. With no active way for the knee to recover from a toe stub, this will most likely result in a fall. Consequently, some form of roll stabilization must be developed and implemented to get the robot off of the treadmill and planarizer. This could be done by adding a lateral actuated hip rotation degree of freedom, or by installing platform type feet that are large and wide enough to stabilize this rotation when the robot is standing on only one of the diagonal pairs.

An additional problem is that the individual solenoids were not strong enough to unlock their corresponding knee when the leg was bearing any weight. This problem was compounded by the large amount of backlash in the motor, the gearhead, and the belt 
transmission, which gave a large uncertainty to the hip angle. Perhaps a better approach is not to use a fully passive knee, but to use a very smail actuator in the knee which could hold the knee against a mechanical stop for locking purposes, but could automatically become a pin joint by controlling for zero torque in the knee. Unfortunately, this would lose the added functionality of complete $360^{\circ}$ rotation of the knee. A different alternative is to design a better locking mechanism, but this could come at the expense of a heavier knee.

Other future work would involve developing turning and other behaviours. Once active roll stabilization is achieved, the project will not be a complete success until the robot can navigate through a building or a series of obstacles. This would involve being able to turn, to survive any falls, and to be able to stand up again after a fall. All of these behaviours could be studied.

Furthermore, in this work, the passive knee trajectory was explicitly controlled. Another approach would be to determine the natural walking cycle and to take advantage of it. Rather than control the knee angle throughout the unlocked knee state, the knee could simply be unlocked and the hip angle commanded to follow a simple forward sweeping trajectory. Ultimately, this could be tuned through simulation and experiment to achieve the desired angular trajectories as a natural cycle, perhaps necessitating only small control corrections near the end of the cycle.

A final area of study could be to develop sensing and recovery techniques for toe stubbing. Currently, the research is aimed at avoiding premature toe-ground contact altogether. In a rougher environment however, it is certain that the toe will sometimes hit the ground earlier than anticipated. Determining when this occurs, through direct means such as force or proximity sensors on the foot, or through indirect methods by analyzing either the hip or the knee angular trajectories, would be of vital importance. Furthermore, developing control schemes to correct for these disturbances would be a real challenge with an underactuated system such as this one. 
To conclude, passive dynamics offer a significant reduction in weight and power consumption, but come at the expense of making control significantly more complicated. For appiications where reducing the weight and power are critical, this tradeoff may provide new design alternatives that could offer substantial improvements to performance. The use of passive knees on the Scout II quadruped permitted the development of new walking behaviours, which ultimately could increase the usefulness of the robot. The understanding and application of passive dynamics in conjuction with legged robots is still in its infancy. This project demonstrated certain possibilities, and points in new directions for exploration. 


\section{Bibliography}

[1] M. Ahmadi and M. Buehler. The ARL Monopod II Running Robot: Control and Energetics. In Proc. IEEE Int. Conf. Robotics and Automation, pages 1689-1694, Detroit, Michigan, May 1999.

[2] R. Alexander. Simple Models of Human Movement. Applied Mechanics Review. 48:461-469, August 1995.

[3] Allegro Microsystems, Inc. http://www.allegromicro.com

[4] Ambulatory Robotics Laboratory (ARL), Centre for Intelligent Machines, McGill University. 3480 University St., McConnell Engineering Building room 411, Montréal, QC, Canada, H3A 2A7. http://www.cim.mcgill.ca/ arlweb

[5] API Deltran, API Motion Inc. htop://www.apideltran.com

[6] H. Arai, S. Tachi. Position Control of a Manipulator with Passive Joints Using Dynamic Coupling. In IEEE Transactions on Robotics and Automation, pages 528534, August 1991.

[7] H. Arai, S. Tachi. Position Control System of a Two Degree of Freedom Manipulator with a Passive Joint. In IEEE Transactions on Industrial Electronics. pages 15-20, February 1991.

[8] R. Battaglia. Design of the SCOUT II Quadruped with Preliminary Stair-Climbing. Master's Thesis, McGill University, Montréal, QC, Canada. May 1999.

[9] M. Bergerman, C. Lee, Y. Xu. Dynamic Coupling of Underactuated Manipulators. In Proc. IEEE Conference on Control Application, pages 500-505, Piscataway, New Jersey, 1995.

[10] M. Bergerman, C. Lee, Y. Xu. Experimental Study of an Underactuated Manipulator. In Proc. IEEE Int. Conf. on Intelligent Robots and Systems, pages 317-322, Piscataway, NJ, 1995.

[11] M. Bergerman, Y. Xu. Optimal Control Sequence for Underactuated Manipulators. In Proc. IEEE Int. Conf. Robotics and Automation, pages 3714-3719, Minneapolis, Minnesota, April 1996. 
[12] M. Bergerman, Y. Xu. Optimal Control of Manipulators with Any Number of Passive Joints. Joumal of Robotic Systems 15(3), pages 115-129, 1998.

[13] Bicron Electronics Company. http://www.bcrm.com

[14] M. Buehler, R. Battaglia, A. Cocosco, G. Hawker, J. Sarkis, K. Yamazaki. Scout: A Simple quadruped that walks, climbs and runs. In Proc. IEEE Int. Conf. Robotics and Automation, pages 1707-1712, Leuven, Belgium, May 1998.

[15] M. Buehler, A. Cocosco, K. Yamazaki, R. Battaglia. Stable Open Loop Walking in Quadruped Robots with Stick Legs. In Proc. IEEE Int. Conf. Robotics and Automation, pages 2348-2353, Detroit, Michigan, May 1999.

[16] Electroid Company. Electroid Clutches and Brakes, Catalog \#2000E, 45 Fadem Road, Springfield, NJ, USA 07081, phone (201) 467-8100. http://www.electroid.com

[17] B. Espiau, I. Guigues, R. Pissard-Gibollet. Can an Underactuated Leg with a Passive Spring at the Knee Achieve a Ballistic Step? INRIA Research Report no $3544,1998$.

[18] M. Garcia, A. Chatterjee, A. Ruina. Speed, Efficiency, and Stability of Small-Slope 2-D Passive Dynamic Bipedal Walking. In Proc. IEEE Int. Conf. Robotics and Automation, pages 235I-2356, Leuven, Belgium, May 1998.

[19] Garlock Bearings Inc. http://www.garlockbearings.com.

[20] A. Goswami, B. Espiau, A. Keramane. Limit Cycles and their Stability in a Passive Bipedal Gait. In Proc. IEEE Int. Conf. Robotics and Automation, pages 246-251. Minneapolis, Minnesota, April 1996.

[21] P. Gregorio, M. Ahmadi, M. Buehler. Design, Control, and Energetics of an Electrically Actuated Legged Robot. IEEE Transactions on Systems, Man, and Cybernetics - Part B: Cybermetics, Vol. 27, No. 4. Pages 626-634, August 1997.

[22] Guardian Electric Manufacturing Company. http://guardian-electric.com

[23] Helical Products Inc. http://www.heli-cal.com

[24] Knowledge Revolution. Working Model 2D Version 4.0. San Mateo, CA, 1996. http://www.krev.com

[25] Lenze GmbH \& Co KG. http://www.lenze.de 
[26] Lucas Control Systems - Ledex \& Dormeyer products. http://www.ledex.com

[27] MacLean's Magazine, "None of the Mess". MacLean Hunter Publishing, Toronto, Canada: June 7, 1999.

[28] The Mathworks, Inc. The Student Version of Matlab, Version 5. Natick, MA, 1998. http://www.mathworks.com

[29] T. McGeer. Passive Dynamic Walking. In International Journal of Robotics Research. 9(2):62-82, 1990.

[30] T. McGeer. Passive Walking with Knees. In Proc. IEEE Int. Conf. Robotics and Automation, pages 1640-1645, 1990.

[31] G. Mennitto. Compliant Articulated Robot Leg with Antagonistic LADD Actuation. Master's Thesis, McGill University, Montréal, QC, Canada, February 1995.

[32] G. Mennitto and M. Buehler. Experimental Validation of Compliance Models for LADD Transmission Kinematics. In Proc. IEEE Int. Conf. Intelligent Robots and Systems, pages 385-390, 1995.

[33] Midori America Corporation. http://www.midoriamerica.com

[34] S. Mochon and T. McMahon. Ballistic Walking: An Improved Model. In Mathematical Biosciences, 52:241-260, 1980.

[35] E. Oberg, F. D. Jones, H. L. Horton and H. H. Ryffel. Machinery's Handbook. Industrial Press Inc., New York, NY, twenty-fourth edition, 1992.

[36] Parametric Technology Corporation. Pro/Engineer Release 20.0. Waltham, MA, 1998. http://www.ptc.com

[37] Parametric Technology Corporation. Pro/Mechanica Release 20.0. Waltham. MA, 1998. http://www.ptc.com

[38] J. Pratt and G. Pratt. Exploiting Natural Dynamics in the Control of a Planar Bipedal Walking Robot. In Proc. of the Thirty-Sixth Annual Allerton Conf. on Communication, Control and Computing, Monticello, Illinois, September 1998.

[39] M. Raibert. Legged Robots that Balance. Cambridge, MA: MT Press, 1986. 
[40] Rockwell Automation. Clutches and Brakes, Catalog DC6000 Rev. 6/96, 146

Powder Mill Road, Colinsville, CT, USA 06022, phone 1-800-800-6445, http://www.rockwell.com

[41] J. E. Shigley and C. R. Mischke. Mechanical Engineering Design. McGraw-Hill Inc., New York, NY, fifth edition, 1989.

[42] J. Shin, J. Lee. Dynamic Control of Underactuated Manipulators with FreeSwinging Passive Joints in Cartesian Space. In Proc. IEEE Int. Conf. Robotics and Automation, pages 3294-3299, Albuquerque, New Mexico, April 1997.

[43] Thomas Register. http://www.thomasregister.com

[44] K. S. Yamazaki. The Design and Control of SCOUT I, a Simple Quadruped Robot. Master's Thesis, McGill University, Montréal, QC, Canada, February 1999. 


\section{APPENDIX - MECHANICAL DRAWINGS}




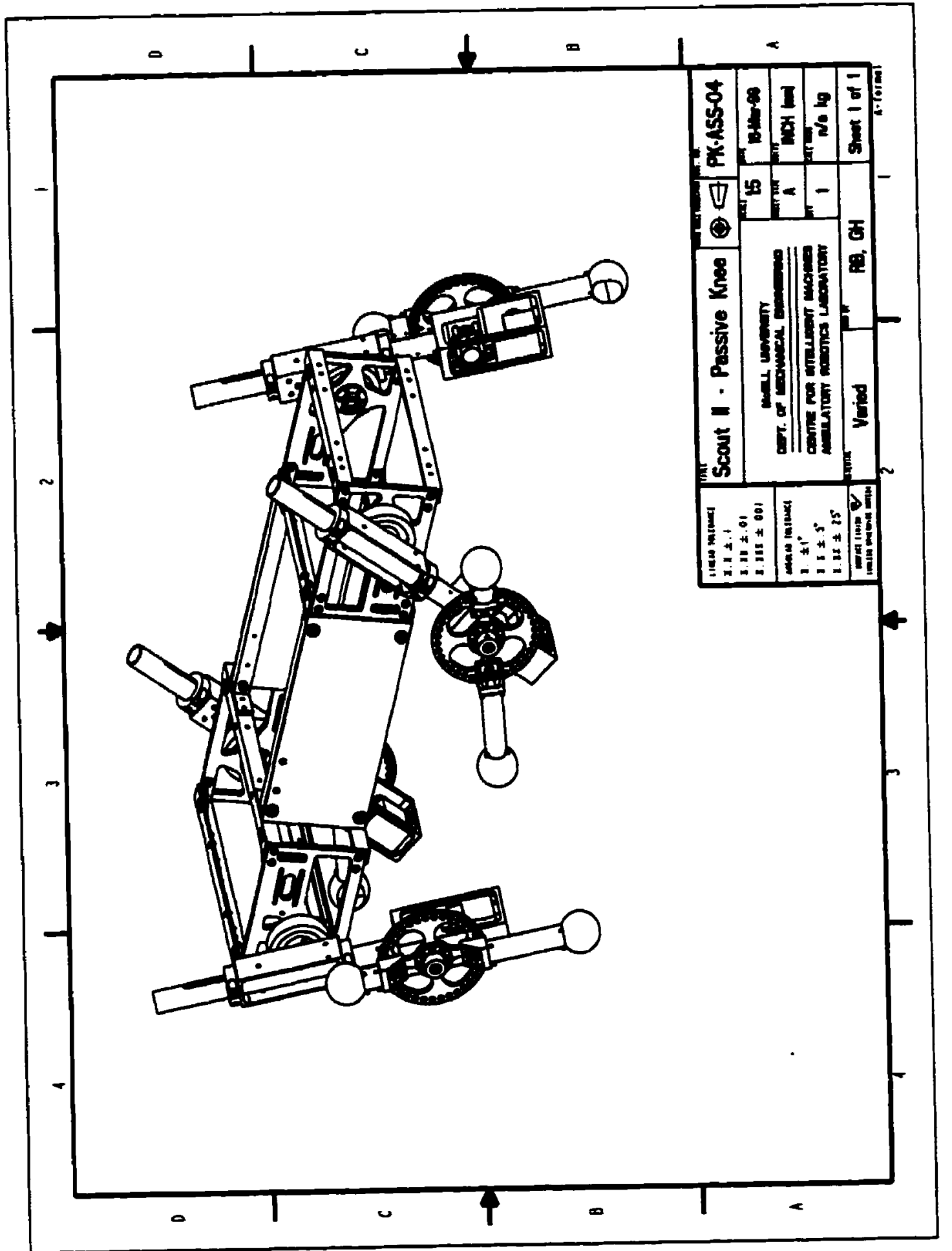




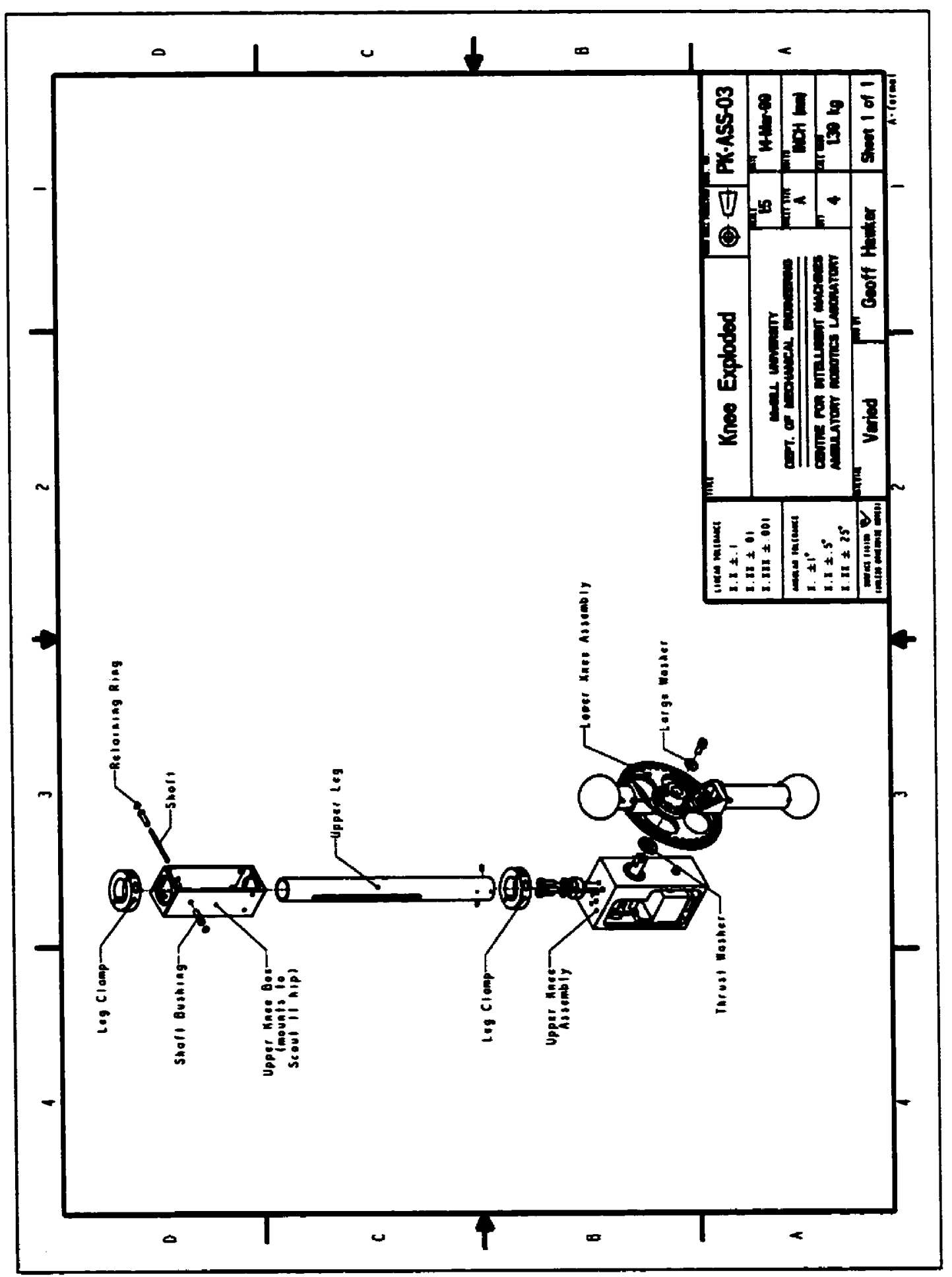




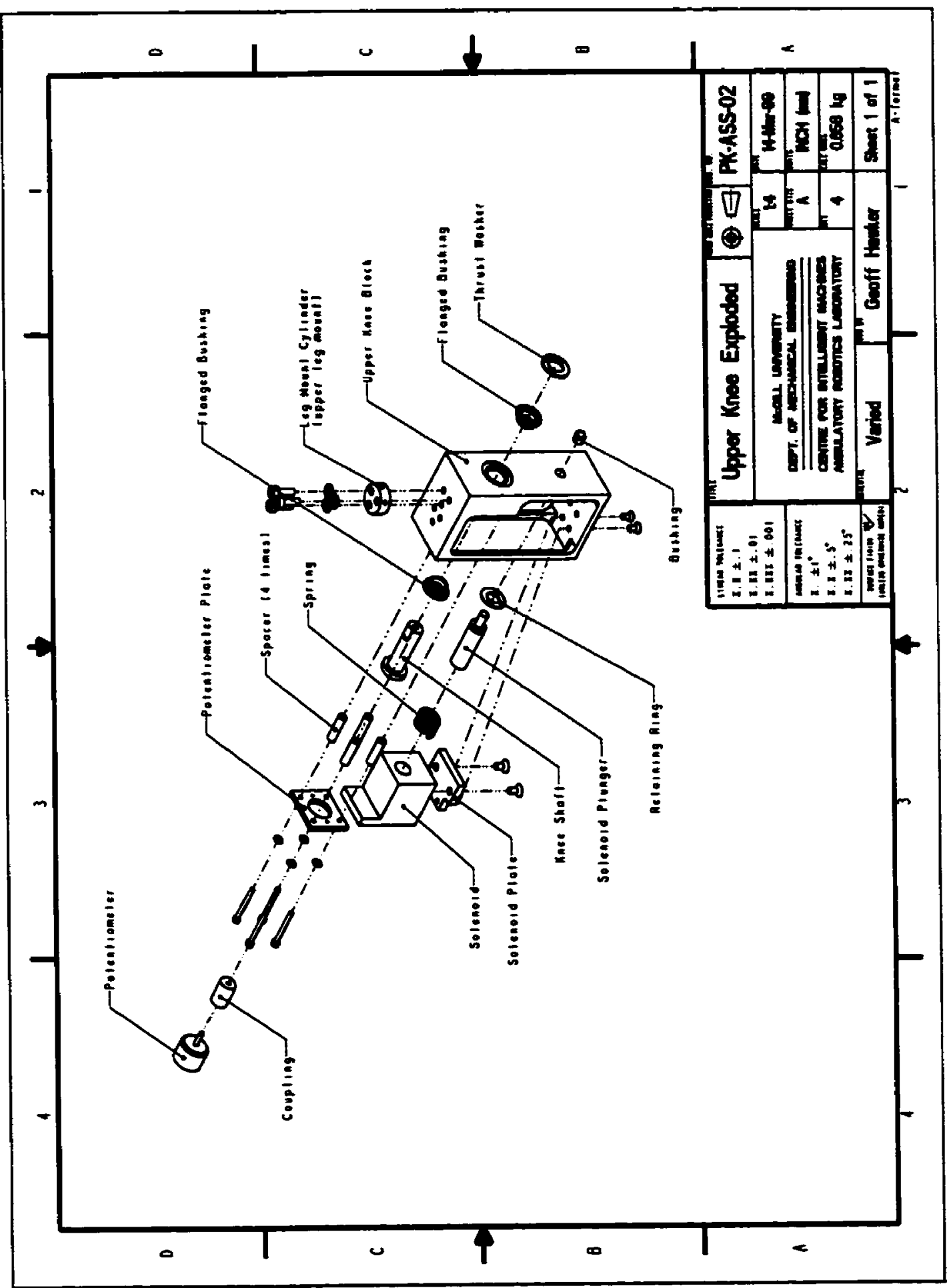




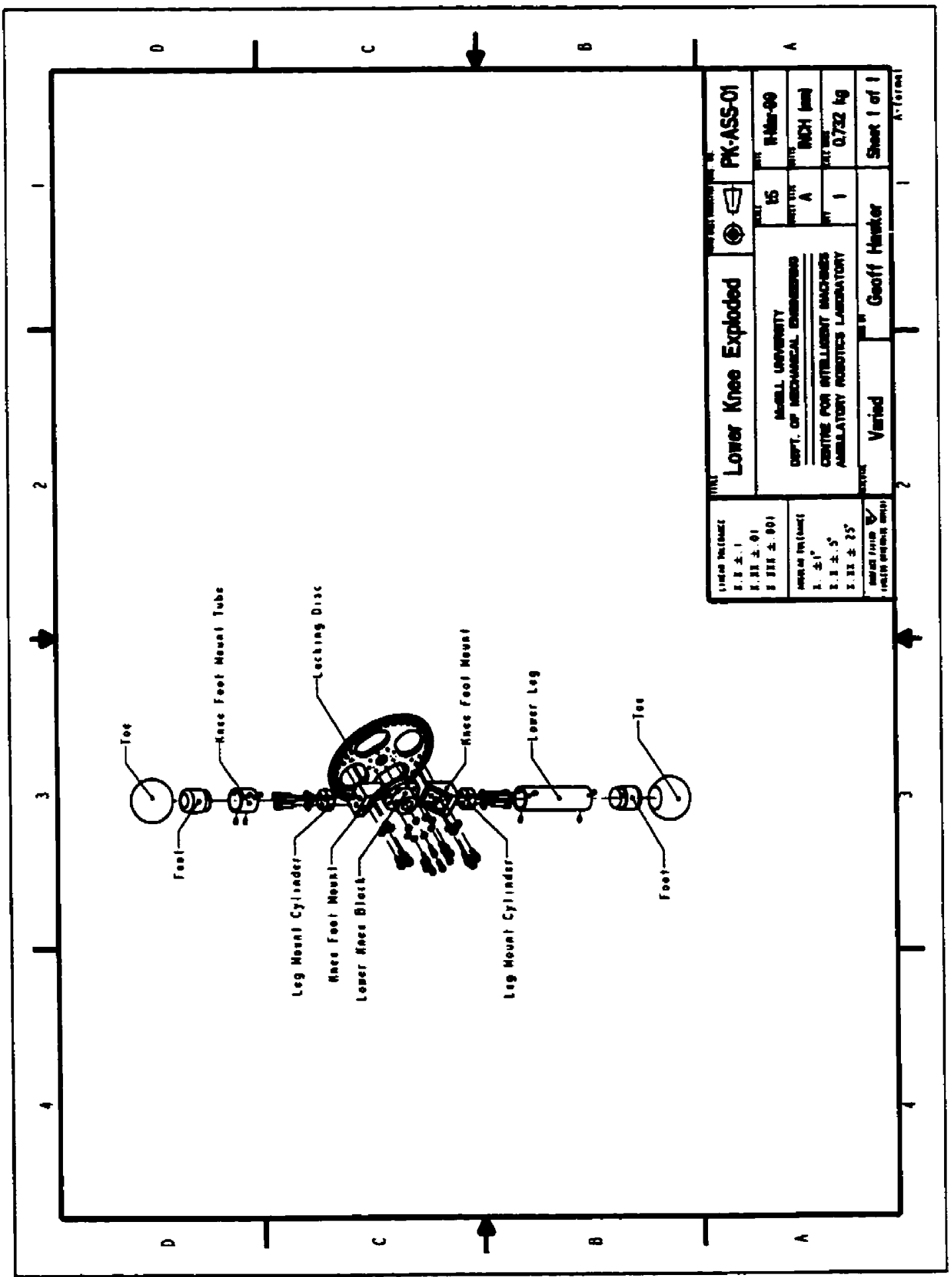




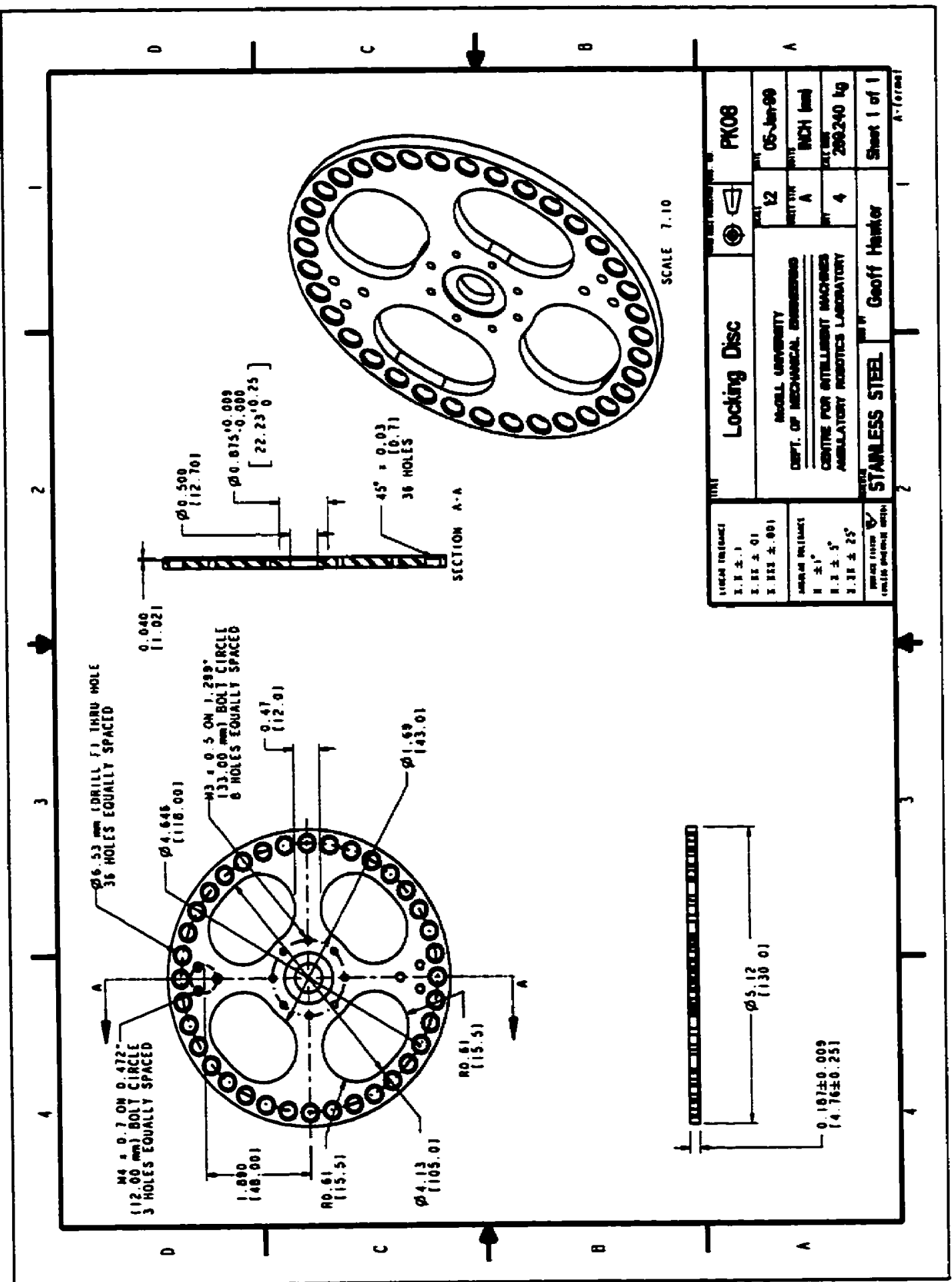




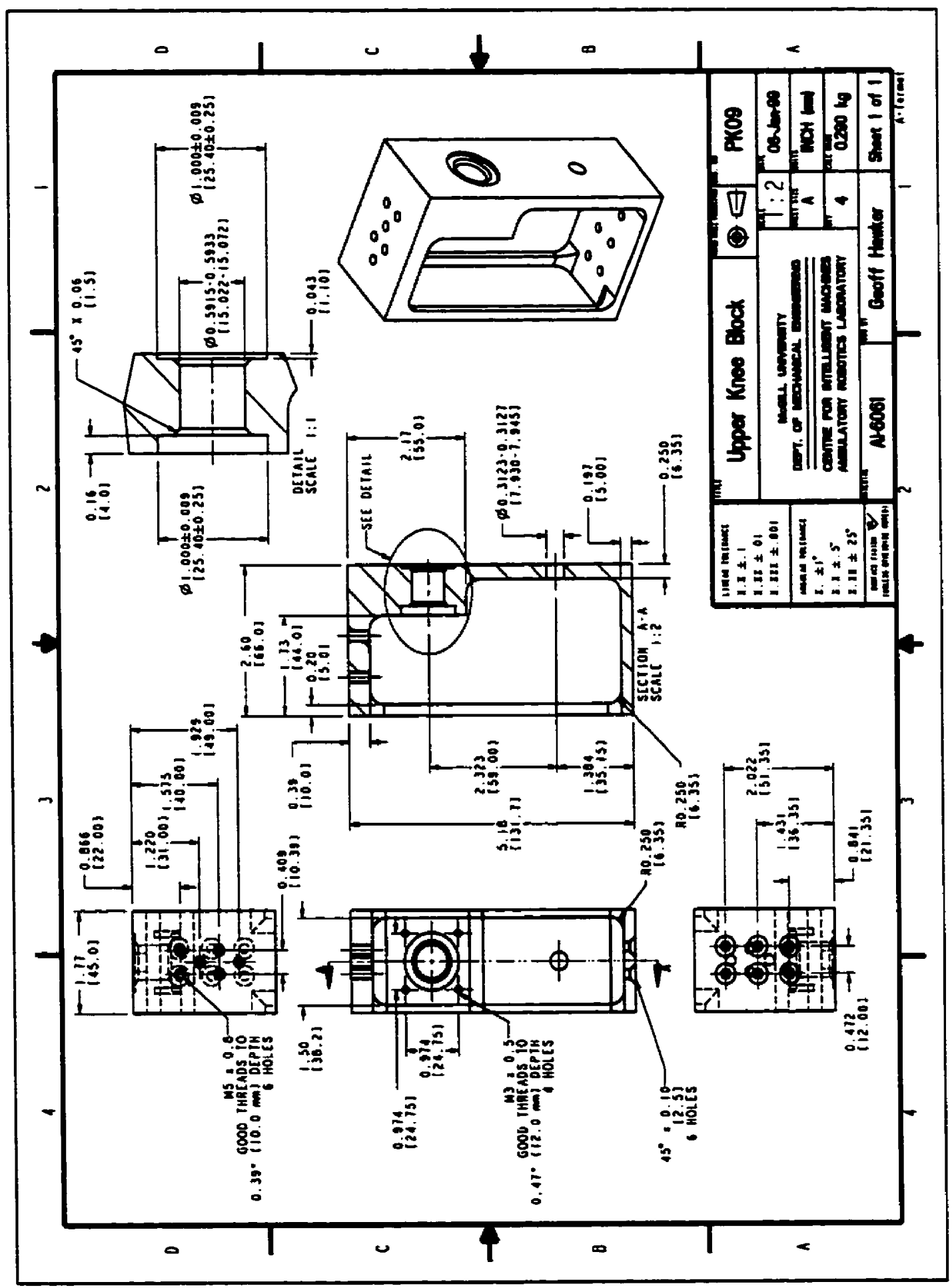




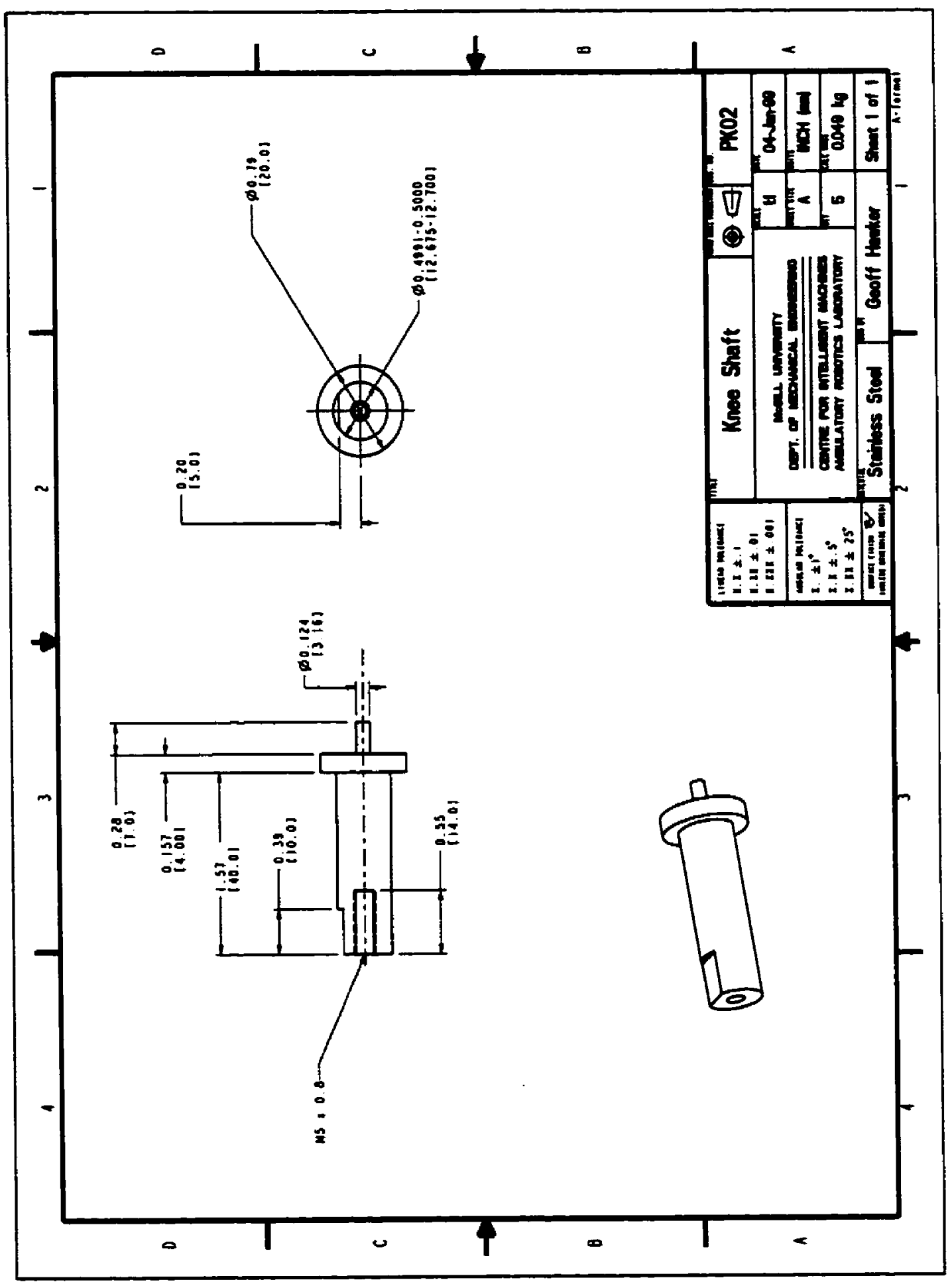




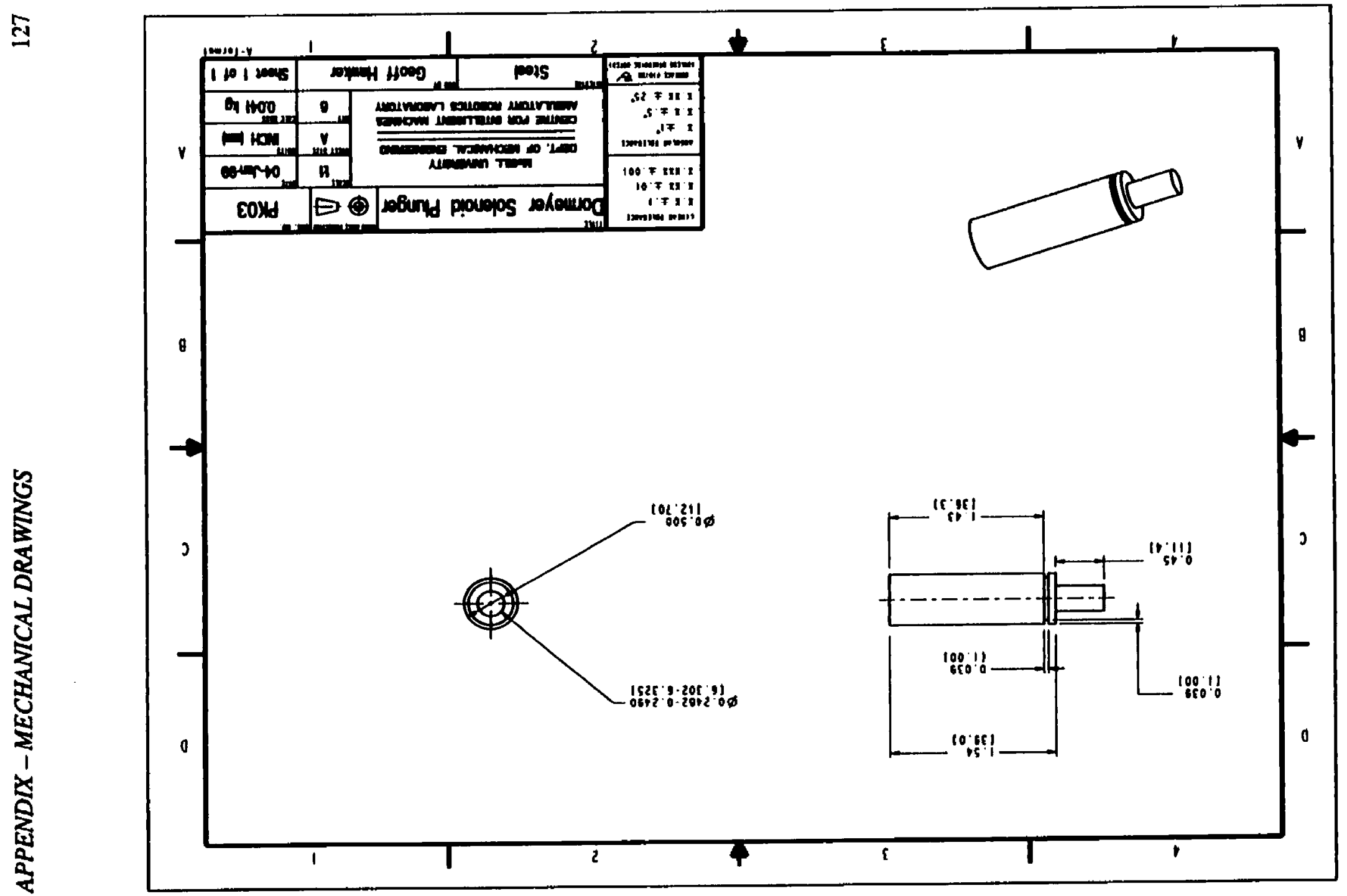

